\begin{abstract}
DIAL, HEATHER KIMBERLY BARTON. Struggling for Voice in a Black and White World: Lumbee Indians' Segregated Educational Experience in North Carolina. (Under the direction of Patricia L. Marshall, Ed.D. and Anna V. Wilson, Ph.D.)

This study investigates the North Carolina Lumbee Indians' segregated educational experience in North Carolina from 1885 to 1970 . This oral history documents the experiences of the Lumbee Indians in the segregated Indian schools and adds their voices to the general discourse about Indian schools in our nation and to the history of education.
\end{abstract}

The sample for this research included six members of the Lumbee community who experienced education in the segregated Indian schools in Hoke and Robeson Counties of southern North Carolina. My oral history research involved interviews with individuals who experienced the role of teachers, students, and administrators. A network selection sampling procedure was used to select participants. The main data sources were the participants' oral educational histories. Limited archival research (e.g., board of education minutes) supports the final analysis. An analysis method for categorizing and classifying data was employed. The analysis method is similar to the constant comparative method of data analysis.

Major findings show that the Lumbee students not only experienced a culturally supportive education, but also experienced a resource poor environment in the segregated Indian schools. Conversely, desegregation provided increased equity in educational resources and educational opportunities for the Lumbee students which unfortunately resulted in a loss of community, identity, and diminished teacher-student connection. 
Findings indicate the participants were aware of the role of segregation in the larger societal context.

Participants emphasized that their teachers in the Indian schools stressed academic success as a key to elevating students out of poverty, however, my research quest led me to question the quality of learning that the Lumbee received. Currently, Lumbee students not only have low scores on major tests of achievement, but also have high dropout rates. Educators in the schools can use this research to critically examine their curriculum, instruction, practices, and policies. 


\title{
STRUGGLING FOR VOICE IN A BLACK AND WHITE WORLD: LUMBEE INDIANS' SEGREGATED EDUCATIONAL EXPERIENCE IN NORTH CAROLINA
}

\author{
by \\ Heather Kimberly Dial \\ A dissertation submitted to the Graduate Faculty of \\ North Carolina State University \\ in partial fulfillment of the requirements for the Degree of \\ Doctor of Philosophy
}

\section{CURRICULUM AND INSTRUCTION}

Raleigh

2005

APPROVED BY:

Dr. Peter A. Hessling

Dr. Ellen S. Vasu

Dr. Patricia L. Marshall

Dr. Anna V. Wilson

Co-Chair of Advisory Committee

Co-Chair of Advisory Committee 


\section{DEDICATION}

"But seek ye first the kingdom of God, and his righteousness; and all these things shall be added unto you."- Matthew 6:33 KJV

I dedicate the undertaking and the completion of this doctoral research and doctoral degree to God.

This work is also dedicated to my mother and father, Mrs. Dolores Barton Dial and Mr. Peter Dial, Jr., who were my first role models, teachers, and my first academic supporters. They believed in me, encouraged me, and most of all loved me. There was never a question of whether I would go to college; they both instilled in me that I would get my education and always reminded me that once I had my education, no one could take it away from me. As an educated woman, I would not have to be dependent upon anyone and I could spell A-B-L-E. I chose to follow in my father's footsteps and become an educator, so I especially want to acknowledge his influence in my life.

I also dedicate this work to my sisters Lana and Amy. Lana, my second mother, supporter, editor, and rock-I love you! Amy, my sister and my friend-I love you! Along with my mother, these women have been an unwavering foundation of support that has enabled me to return to school and work to complete this work and achieve this degree.

This work is also dedicated to my extended Lumbee family: the Dials, Bartons, and Locklears. God has blessed me with many aunts, uncles, and cousins whom I do not wish to leave unacknowledged. I love and appreciate you all.

I dedicate this to my fellow Lumbees and my friends and colleagues-my loved ones. You believed in me, you encouraged me, you supported me, you listened to me, 
you laughed with me and you cried with me. This dedication is to the following individuals: Mandi Baggett, Yonnah Dawn Chavis-Locklear, Jefferson Currie II, Clarice Dial, Dr. Lucy Eaton, Pamela Ruth Taylor Gee, Jerretta Gilchrist, Illeetha Brooks Groom, Alisa Hunt-Lowery, Darlene Jacobs, Bill Jones, Glynis Joseph, Brett Locklear, Gwen Locklear, LaTonya Hammonds Locklear, Sandra Locklear, Rod Lowery, Tamer Lowry, Dr. Malinda Maynor-Lowery, Miranda Gilchrist Pearson, and Dr. Annie Winfield. God has blessed me with many friends, colleagues, and associates so if I did not name you, know that you are appreciated, valued, and most of all loved.

I also dedicate this work to my church family, the members of Dundarrach Baptist Church who believed in me all along and encouraged me to finish so I could return home to my family and to them. A special thank you goes to the Rev. Dalton P. Brooks, PhD, who inspired me to get my doctorate.

I respectfully want to acknowledge the Lumbee participants of my research. It is their voices that I wanted to document and research concerning this time in the educational history of the Lumbee people. Work, worship, and education are a constant theme among us in my Lumbee community. Education is important to the success of our people and that is why I also dedicate this work to the Lumbee people. 


\section{BIOGRAPHY}

Heather Kimberly (Kim) Barton Dial was born on September 27, 1971, to Dolores Barton Dial and Peter Dial, Jr. Kim is a fully enrolled member of the Lumbee Tribe. She makes her home with her parents, nestled in the rural community of Antioch, in Hoke County which borders on Robeson County, in North Carolina. The closest town to Antioch is Red Springs. Most of Kim's extended family lives in Hoke and Robeson counties.

Kim attended J.W. McLauchlin Elementary School, South Hoke Elementary, J.W. Turlington Elementary, Upchurch Junior High School, and graduated from Hoke County High School in 1989. In the fall of 1992 Kim graduated from the University of North Carolina at Pembroke as a Chancellor's Scholar with a BS in Elementary Education. Then, Kim pursued her master's degree and graduated in 1995 with an MAEd in Reading Education and Certification in Educational Administration and Supervision.

Kim taught in the Public Schools of Robeson County for four years before pursuing a doctoral degree in the Curriculum Studies Program of the Department of Curriculum and Instruction at North Carolina State University as a Gates Millennium Scholar.

Her research concerning the segregated Indian schools of the Lumbee was presented at the American Educational Research Association conference in April 2003 and the National Indian Education Association Convention in November 2003. She is currently contributing a chapter from her dissertation research to the book entitled, Transformations in Schooling: Historical and Comparative Perspectives (in press). Kim's research concerns include the segregated American Indian schools of the past, 
Lumbee Indians, culturally relevant teaching/curriculum, preschool education, and reading education.

She is an active member of the Triangle Native American Society. Kim is Research Assistant/Organizer Coordinator with the Nurturing Mathematics Dreamkeepers research project at North Carolina State University. Kim is also an adjunct lecturer with the University of North Carolina at Pembroke. 


\section{ACKNOWLEDGMENTS}

I am overflowing with gratitude to Dr. Patricia L. Marshall and Dr. Anna V. Wilson. These strong and intelligent women have believed in me and my abilities and have served as my role models in academia. All throughout my studies and into my research, they freely offered me advice, support, encouragement, and professional development opportunities. Special thanks to Dr. Wilson who inspired my research and to Dr. Marshall, to whom I will be forever obligated because of the numerous opportunities given to put my skills into practice as an educator and as a researcher.

I am indebted to the assistance, cooperation, and support of my dissertation committee: Dr. Peter A. Hessling, Dr. Patricia L. Marshall, Dr. Ellen S. Vasu, and Dr. Anna V. Wilson. You believed in me, counseled me, and encouraged me! I thank you sincerely for all that you have done on my behalf.

My gratitude is extended is to the following individuals whose knowledge and expertise I have been able to call upon in my research: Dr. Kristin Atkins, Dr. Elise Barrett, Dr. Bryan Brayboy, Dr. Julie M. Burke, Mrs. Agnes Chavis, Mr. Wilson Chavis, Mr. Jefferson Currie, II, Dr. Brenda Dial Deese, Mr. James Dial, Dr. Diane E. Emerson, Ms. Shelia B. Evans, Mrs. Gwen Dial Locklear, Mrs. Patricia Hunt, Dr. Valerie Lambert, Mrs. Helen Locklear, Mr. Proctor Locklear Jr., Dr. Malinda Maynor Lowery, Dr. Waltz Maynor, Dr. Crystal Gafford Muhammad, Dr. Amy S. Overbay, Dr. Linda Oxendine, Dr. Theda Perdue, Dr. Robert Reising, Dr. John L. Sanders, and to the late Rev. Welton Lowry. 
I am most thankful to the transcription expertise of Mrs. Sylvia Dial-Chavis and Mrs. Connie Lowry. Thank you sincerely for all of your work in helping me document the Lumbee voices of my participants!

Recognition and thankfulness is given to my editors whose work has enabled me to complete my research and my work towards my doctoral degree. The first editor I'd like to acknowledge is my sister Lana Dial, whose name should be on the doctoral degree as well for the many papers she has edited for me. I also give thanks for their efforts in shaping my work and research: Mrs. Frances B. Grant, Dr. Gary Weinberg, and to Dr. Annie Winfield.

Thanks to Ms. Elizabeth Brown, the Public Schools of Robeson County Indian Education Resource Center and the Hoke County Public Schools for the use of the images of the Indian schools in this document.

This paper owes much to those Indian educators and students who were generous with their collective knowledge of the segregated Indian schools that are a part of our shared heritage. Without their willingness to share their stories this paper could not have been possible. 


\section{TABLE OF CONTENTS}

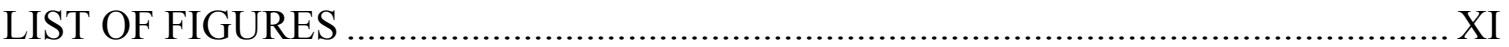

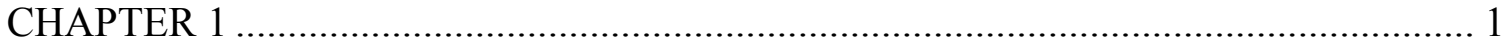

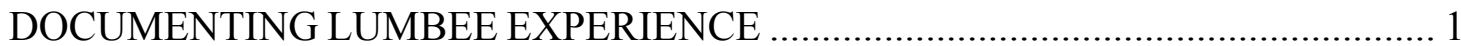

Purpose, Significance, and Goal of Study ........................................................ 2

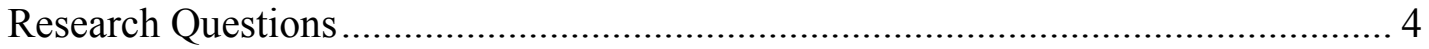

Perspective and Researcher Role ................................................................. 5

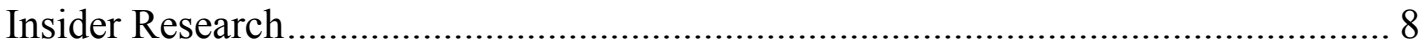

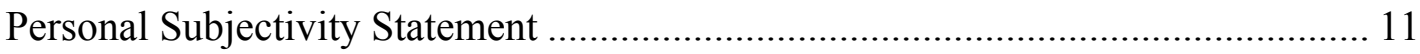

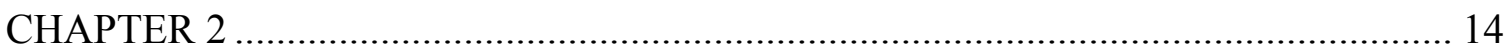

THE LUMBEE AND SEGREGATED EDUCATION ……..................................... 14

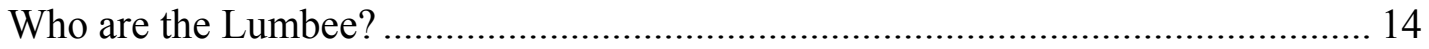

Lumbees Resistance: Reclaiming Identity through Internalized Racism ................ 20

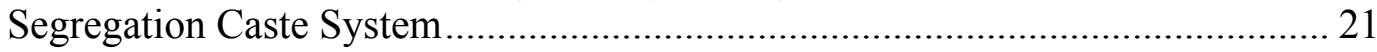

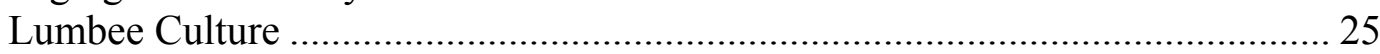

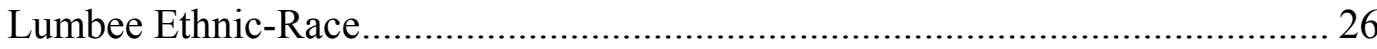

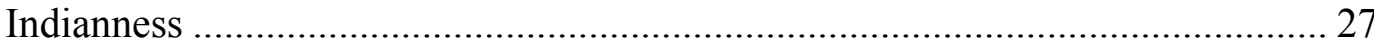

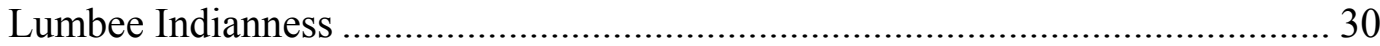

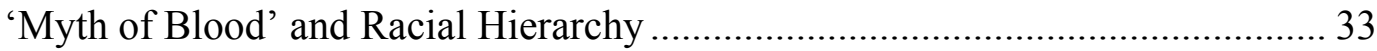

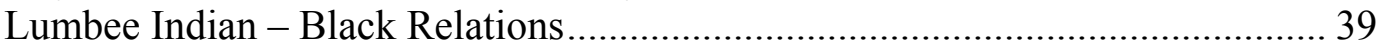

Establishment of Lumbee Schools......................................................................... 41

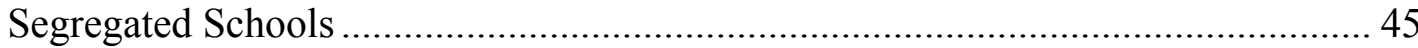

Segregated African American Schools ............................................................... 46

Segregated Native American Schools.................................................................... 50

Segregated Native American Schools in North Carolina ………………………...... 53

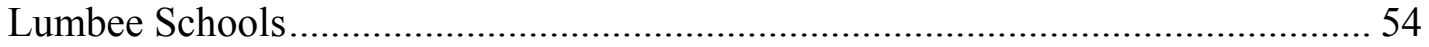

Lumbee Opportunities for Higher Education ................................................... 59

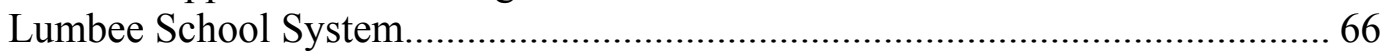

Cherokee, Cohaire, Sappony, Waccamaw Siouan, Haliwa-Saponi Indian Tribes ... 75

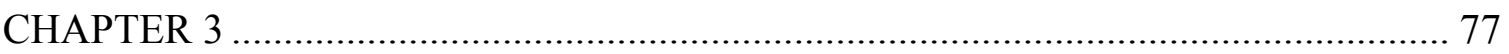

TOOLS TO RESEARCH THE INDIAN SCHOOLS ……………………………...... 77

Data Sources and Data Collection ..................................................................... 77

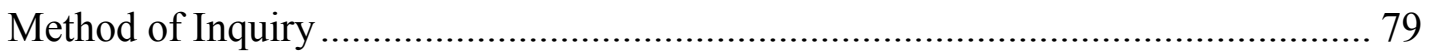

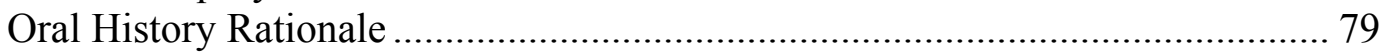

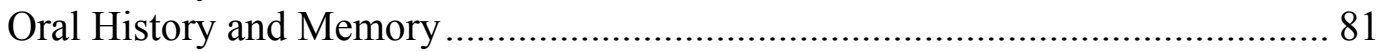

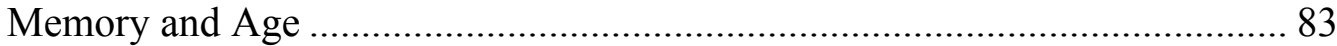

Gender and Culture Impacts Memory ............................................................ 85

Oral History and My Research ..................................................................... 91

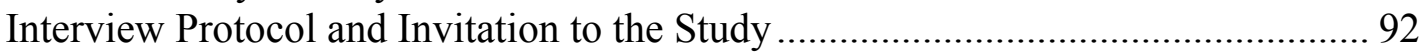

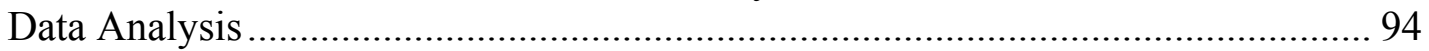

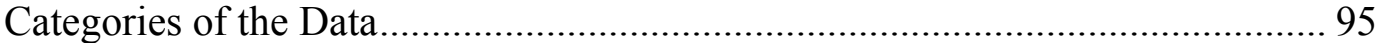

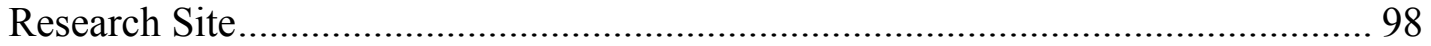

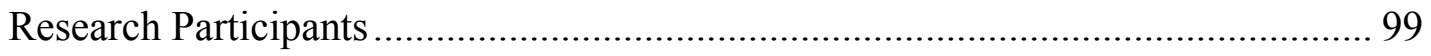




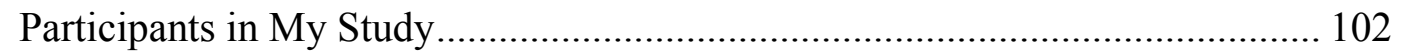

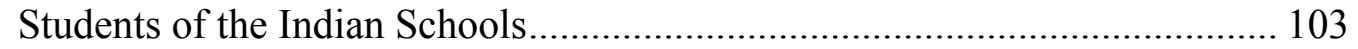

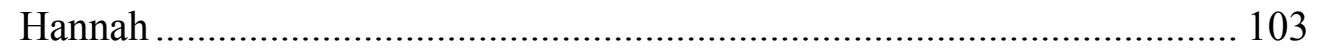

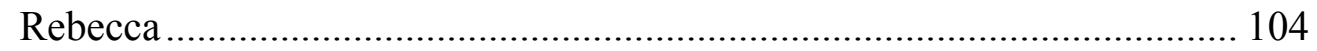

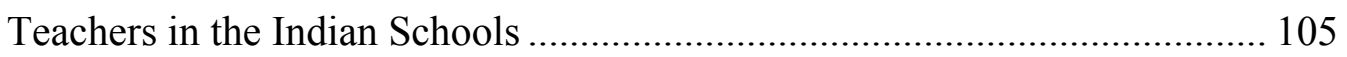

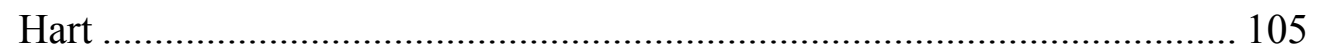

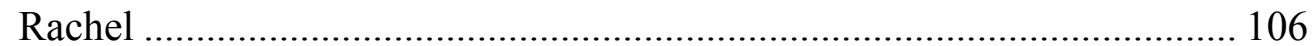

Administrators in the Indian Schools......................................................... 107

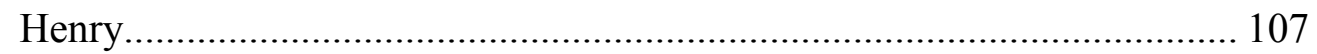

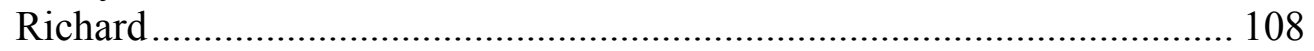

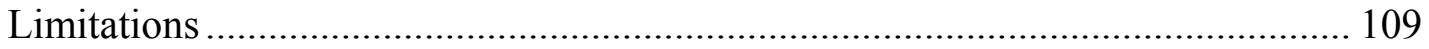

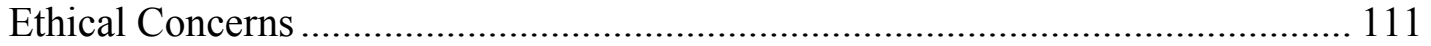

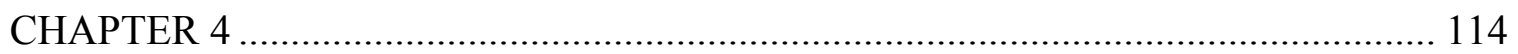

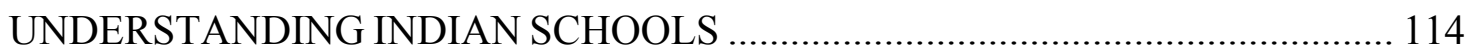

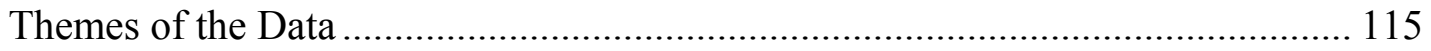

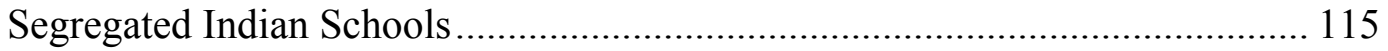

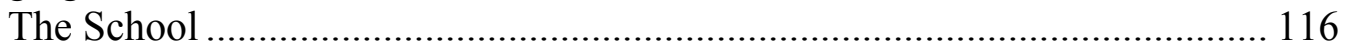

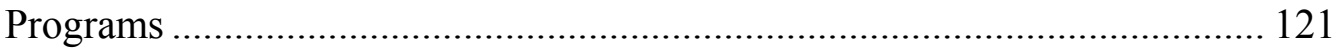

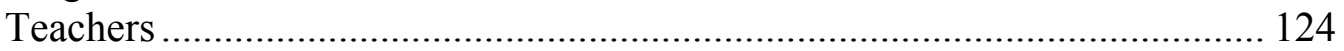

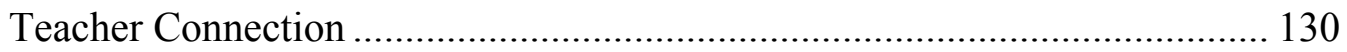

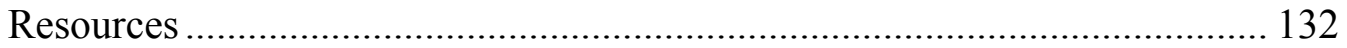

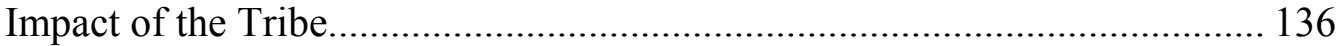

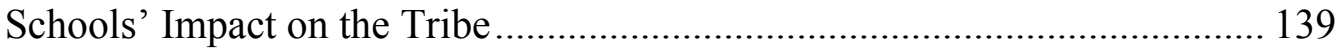

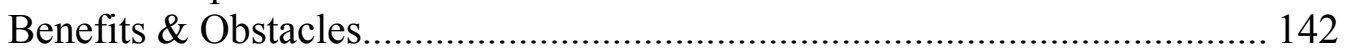

Indian Committees Power......................................................................... 143

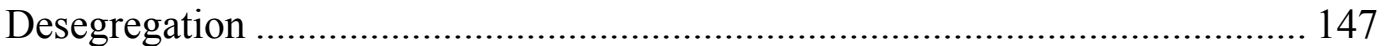

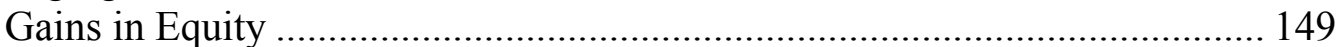

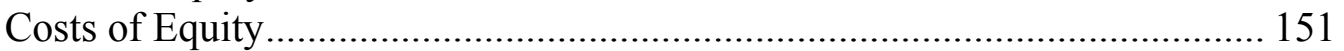

Impact on Lumbee Students...................................................................... 153

Loss of Community for Academics ............................................................ 154

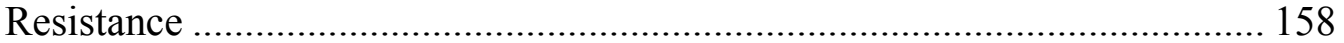

Understanding Segregation \& Discrimination................................................ 162

Understanding Layers of Segregation.......................................................... 163

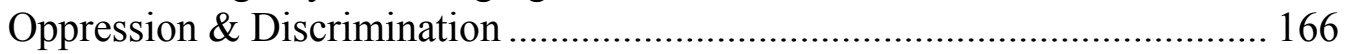

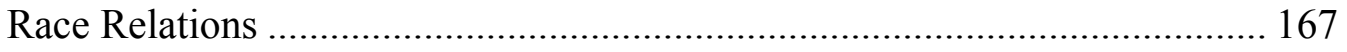

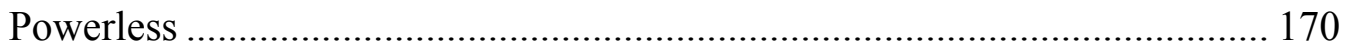

Unanticipated and Inconsistent Research Findings …….................................... 172

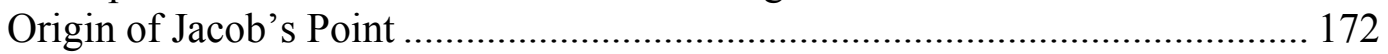

Indian Conflict in Hoke County......................................................................... 173

Class and Disconnection in the Lumbee Community......................................... 175

Teacher Apathy and Educational Mediocrity ………...................................... 178

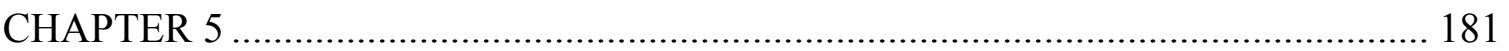

DISCUSSION OF UNDERSTANDINGS FROM THE INDIAN SCHOOLS ............ 181

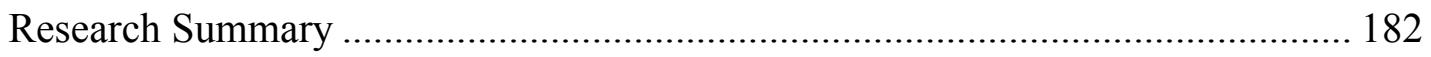

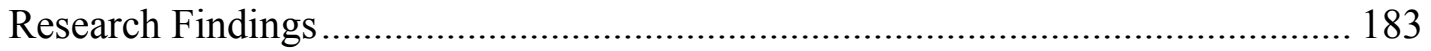


Segregated Indian School .......................................................................... 183

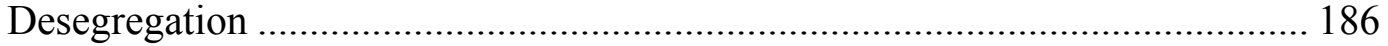

Understanding Segregation \& Discrimination.............................................. 187

Unanticipated and Inconsistent Research Findings ............................................. 188

Research Findings Related to Literature.............................................................. 192

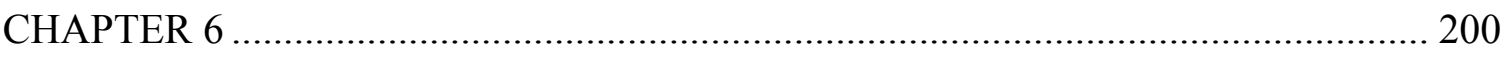

LESSONS LEARNED FROM THE INDIAN SCHOOLS …………......................... 200

Research Recommendations ...................................................................... 202

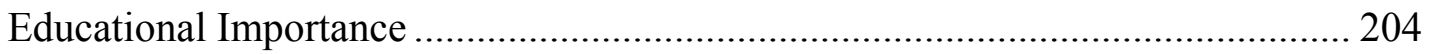

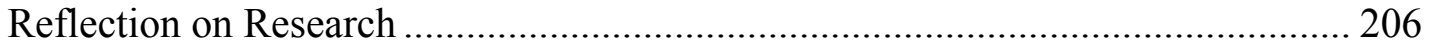

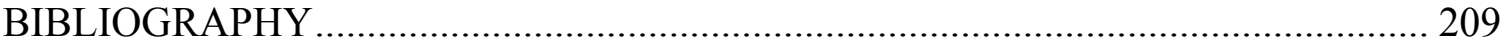

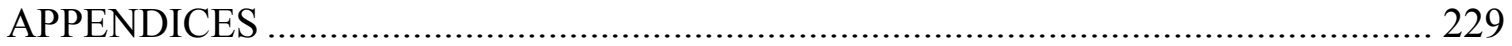

APPENDIX A: FiguRES AND PICTURES OF INDIAN SCHOOLS MENTIONED IN

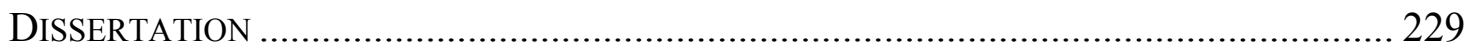

APPENDIX B: INTERVIEW GUIDES FOR PARTICIPANT …........................................... 240

APPENDIX C: LETTER OF INFORMED CONSENT ......................................................... 241

APPENDIX D: EARLIEST FinANCIAL AND STATISTICAL REPORTS OF THE PUBLIC SCHOOLS OF ROBESON COUNTY ……………………………………………... 243

APPENDIX E: LETTERS FROM N.C. NEWBOLD AND A.T. ALLEN CONCERNING THE

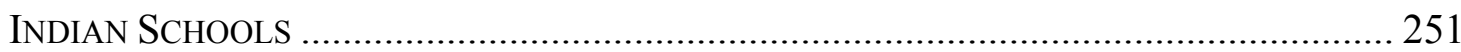

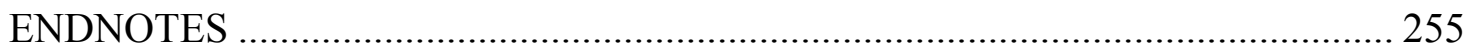




\section{LIST OF FIGURES}

Figure 1. Data Analysis Flow Chart .................................................................... 230

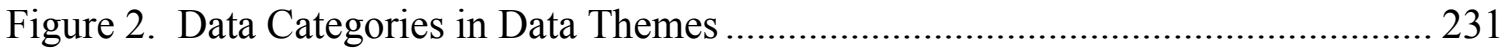

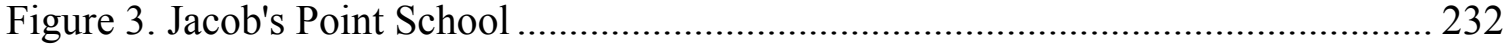

Figure 4. Hawkeye Indian School (South Hoke Elementary School) .......................... 233

Figure 5. Ashpole Center Indian School ....................................................................... 234

Figure 6. Pembroke Elementary Indian School ........................................................... 235

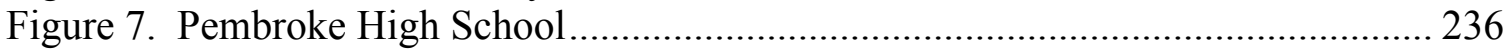

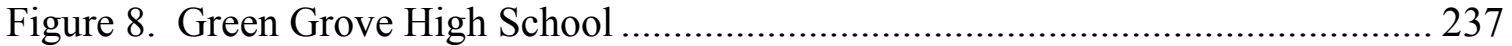

Figure 9. Green Grove High School Home Economics Building ............................... 237

Figure 10. Pembroke Elementary School (contemporary) .......................................... 238

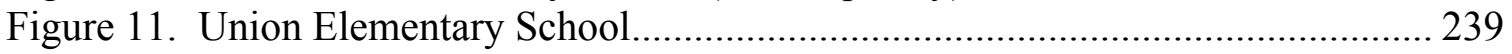




\section{CHAPTER 1}

\section{DOCUMENTING LUMBEE EXPERIENCE}

I went to an Indian- all Indian school up through the seventh grade in my life. And had Indian teachers, all Indian students, you know everybody, it. . .was like community. - Lana Theresa Dial (Lumbee)

Lumbee Indians $^{1}$ are a tribe of non-reservation, state recognized Native Americans in Southeastern North Carolina. The Lumbee Indians' struggle for recognition as Native Americans has been intertwined with their quest for their own schools throughout the past two centuries and historical quantitative research which has been conducted about the segregated Indian schools in Robeson County (Maynor, 1970, p. 54; Thompson, 1973). However, their personal experiences in the segregated Indian schools have never been qualitatively documented (Dial \& Eliades, 1975, p. 23, p. 31, 43, 93-99).

Given the history of marginalized groups in the United States, it is not surprising that Lumbee Indian experiences in the segregated school system are missing from historical studies in education. The history of Native American education documents the experience of other Indians in boarding schools and the experiences of African Americans $^{2}$ in the segregated black schools. The Lumbee Indian segregated experience is absent. In addition, informal conversations with my peers within the Lumbee community have been influential in shaping my interest in this study. A common theme in our conversations was reflecting back to when "we had our own schools and how everything was better." 


\section{Purpose, Significance, and Goal of Study}

This study examines the experiences of Lumbee Indian students in segregated Indian schools in North Carolina from 1885 to 1970 . Lumbee segregated educational experience is missing from both educational history and Native American education literature (Cobb, 2000; Ellis, 1996; Fuchs \& Havinghurst, 1973; Lomawaima, 1994; Lomawaima, 1995; Spring, 2001; Szasz, 1999).

This research documents the Lumbee segregated school experience by collecting and examining oral educational histories. Participants include members of the Lumbee community who experienced education in the segregated Indian schools as students, teachers, or administrators. In 2002, I conducted a pilot study of three members of the Lumbee community. Consequently, I was able to identify several themes that informed my research. Participants agreed that segregated schools were an extension of both community and home for Lumbee people (Dial, 2002). This finding represented an important component left out of quantitative studies. Oral histories reveal that segregated schools were beneficial to tribal identity, academic achievement, and community involvement in the Lumbee's education. Nevertheless, in contrast to these positive influences, my participants' oral educational histories explored not only a number of inequalities experienced in the schools, but also the struggle for equitable educational resources under a system of institutionalized racism (Dial, 2002). Although desegregation, when implemented in Hoke County in 1968 and Robeson County in 1970, provided increased equity in educational resources and opportunities, it also resulted in a loss of community that schools had once provided. The school environment changed from resource poor schools rich in community to resource rich schools with a loss of 
community. A documentation of this transition is vital to record Lumbee educational experience and enhance Lumbee history. This study focuses specifically on Lumbee Indians, nevertheless, the findings offer an increased understanding of the learning environments of other marginalized groups.

From the 1930s through the 1970s, the Lumbee experienced strong community involvement in the segregated Indian schools (Blu, 2001; Chavis, 1986; Dale, 1986; Dial, 1993; Dial \& Eliades, 1975; Massey, 1996; Thompson, 1973). Despite this strong community support, students suffered. Inherent inequalities were perpetuated by a system of segregation wherein Whites were the dominant power socially, economically, and politically. Consequently, Lumbee students experienced societal disenfranchisement and a debilitating lack of resources. This study examines themes that originally emerged from my pilot study concerning the impact of Indian schools on Lumbee tribal identity, academic achievement, and community involvement. The research more fully documents the nuances of the themes identified in the pilot study.

The guiding question behind this research asks: How did Lumbee students selfidentify within segregated settings? Specifically, to what extent were participants aware of segregation within the larger societal context? Findings suggest that there are layers of awareness of segregation. Through the oppression of segregation, the dominant society established the primary layer of segregation: that non-Whites were devalued as second class citizens because of their race and socioeconomic and political status. Lumbee adults had a keen awareness of the segregation and racism directed at them and their children. The participants' responses suggest that parents, teachers, administrators, and the Lumbee community itself attempted to insulate the children from the full racist 
message of segregation. In my study, a student participant expressed that although she knew that everyone in her school — the principal, teachers, staff, and students — were all Indian, she was not aware that this segregated setting existed because she was not wanted in the white school. The student did not understand the reality of segregation, that as an Indian she was considered inferior to Whites and thus was separated from Whites. She accepted this separation of the races because it was all that she knew. Thus, she did not have a reason to question this segregation until a direct encounter with racism forced her to understand the larger meaning of segregation. Her direct experience with racism increased her awareness of the dominant societal message of segregation as racism against non-Whites.

\section{Research Questions}

My research questions explored what the segregated Indian schools meant to participants. Some of the questions that guided this study are:

- What characterized Lumbee Indian schools and what made them distinct?

- What were the effects of the Lumbee schools on students, teachers, and administrators?

- How did the Lumbee schools support or not support Lumbee culture, values, or beliefs?

- How did the Lumbee schools support or not support students' academic achievement? 


\section{Perspective and Researcher Role}

My perspective in this research is from the inside. I am a Native American-a Lumbee conducting research about the experiences of my people, the Lumbee Indians. It is my aim to study and document who we are and what has been our educational experience in North Carolina.

In the fall of 2000, I accompanied my sister Lana to her Indian school reunion that celebrated the classes of students who attended from 1952-1968. At the time, I did not consider the significance of this reunion or the Indian school. My sister attended the only consolidated segregated Indian school in Hoke County-Hawkeye-from 1968 to 1971. Hawkeye School meant something entirely different to me. In fact, Hawkeye became known as South Hoke Elementary. I attended South Hoke Elementary School from the second grade to the fourth grade from 1978 to 1981 . I remember this school positively. I remember being comfortable in South Hoke Elementary School because it was in an Indian community and it was close to my home. Despite the name change, South Hoke Elementary continued to be referred to as Hawkeye by the community. Hawkeye was the name given to the school by Lew Barton (one of the school's Indian teachers) when it was the segregated Indian school (Brayboy \& Barton, 2003). Except for the name and the memory, there were never any physical reminders that it had once been an Indian school. Lana remembered this school because it was composed of the Indian community, and she felt at home there since the teachers, principal, and students were all Indian. Lana did not graduate from Hawkeye School because our parents wanted her to have a better education. So when there was freedom of choice in 19661967 and parents were able to decide which schools their children would attend, our 
parents sent Lana (who was in the eighth grade) to the white school, hence she graduated from the former all- white ${ }^{3}$ high school, Hoke County High. Lana reflected that she was one of the first Indian students to attend Hoke County High School. She was usually the only Indian student in any of her classes during this time of desegregation. Lana explained that as a child she was not fully aware of the implications of segregation. She implied that she was unaware that as an Indian she was often considered a second class citizen and was inferior according to the dominant society. Our parents had insulated Lana from the hatred associated with segregation. Lana did not understand how bad racism was until she graduated from high school and entered college. When I asked Lana about her experience in the segregated Lumbee Indian school, this is what she said:

I felt like I got more attention, and that there weren't assumptions that had already been made to the detriment of me. . .when I was in the Indian school, the teachers knew what I could and could not do. And their expectations were higher of me, let me put it to you like that. Whereas, whenever I changed schools their expectations were lower. And because they were lower, you know, it's like well if she gets it, she gets it, if she don't, she don't. And you know no extra time or anything was spent with me. I didn't. . .get to know my teachers very well. Except for a very select few who-I think, you know. . looking back upon it, could see beyond my skin color, see beyond that I was this little Indian girl (Lana Dial, personal communication, September 19, 2003).

Lana perceived that her teachers in the Lumbee Indian school gave her more attention. The Lumbee teachers had high expectations of her innate abilities. In contrast, her teachers in the desegregated school had lower expectations of her ability. 
When I attended the Hawkeye Class Reunion with my sister, I made several observations. I noted that my memories and experiences in school were totally different. I viewed school from a combination of different perspectives and experiences. I had never experienced an educational setting where the administration, teachers, and students all shared my ethnic and racial background as had these individuals around me in the South Hoke gymnasium. The individuals at the reunion expressed fond memories of their time at Hawkeye School, and this sentiment seemed to be shared by all there with the exception of me. As an outsider, I remember experiencing mixed thoughts and emotions about the Hawkeye School Reunion. I felt left out of the educational experience that the alumni of Hawkeye shared. Within me, I desired to possess such positive memories of an educational experience as they expressed about their school. I felt like an outsider because I did not have this segregated experience. Nevertheless, I appreciated their resilience in maintaining pride in their heritage and history. Desegregation could not erase this history of their Lumbee Indian school. This positive view of the alumni toward their Indian school is important because there was no perception that the segregated educational setting was forced upon the Indian community. The very existence of the reunion and the warm feelings shared there evidenced a sense of loss within the Indian community for the old Hawkeye School. The Indian community in Hoke County placed a monument at South Hoke Elementary in the fall of 2004. The monument honored, posthumously, two of the individuals who were responsible for the establishment of Hawkeye Indian School. The two individuals honored were Mr. Elisha Dial, Sr. and Mr. Rodney Locklear, Sr. 
This high school reunion experience, coupled with my advisor's research of the experience of African American teachers and students of segregated schools, created my desire to examine the history of the Lumbee Indians. I wanted to learn about not only the Lumbee Indian experiences in the segregated school system, but also to learn about the experiences of students and teachers in segregated settings.

\section{Insider Research}

In understanding subjectivity in the context of qualitative research, one must acknowledge that the researcher interprets the phenomena that she is researching through the lens of her historically and culturally created point of view (Creswell \& Miller, 2000; Maxwell, 1996). Thus, it is impossible to ever eliminate the biases, beliefs, and past experiences that comprise a researcher's subjectivity (Patton, 2002). Qualitative research admits this subjectivity of research and seeks to address issues of subjectivity. There are ways that qualitative researchers address the issue of subjectivity and bias, specifically as 'insiders' in their studies. I addressed these issues in my research.

One way I address this potential bias is by grounding my research in the Lumbee Indian experience. As a Lumbee Indian, I share a common culture, background, and perspective with my participants. It is important that I use this foundation on which to base my research relationship with my participants. My participants' interaction with me, their sharing of experiences, is relevant to my research because their participation in the research imbued it with their knowledge, voice, and perspective as Lumbee Indians. Why is sharing experiences vital to my research? I wanted my research to be a space for them to tell their stories. It is significant because some of these stories have never been told. Understanding human experience is the heart of qualitative research. Such 
understanding would not have happened in my research if I had approached my research quantitatively as something that I 'did to them.' As a Lumbee, I used my dual role as researcher and member of the Lumbee community to understand the voice of the Lumbee people.

As a member of the Lumbee community, I have a pre-existing relationship with my research participants. This relationship offered an ease of access into my research setting and an ability to locate research participants for my study. By conducting research within my community, I was able to ensure that my research was not exploitive. My research was respectful and useful not only to my community, but also to the individuals who participated in the study. This research is deeply meaningful to me. I am an active member of the Lumbee Indian community and this is my home. Thus, I was uniquely positioned in my research setting to ensure accuracy of the representation of my participants' voices and experiences.

The depth of my insider status is revealed by my empathy with all the research participants. Patton (2002) suggests that in the researcher's relationship with participants the research should demonstrate empathy for the participants' experiences. I ascribe importance to my participants and their varied experiences. Conducting my study in a research setting with which I am engaged enables a collection of rich data. This engagement in the research setting facilitated interaction between my participants and me. Collins (1990) and Lofland \& Lofland (1995) suggest researchers be engaged with their research setting in order to facilitate understanding of participants' experiences, knowledge, perspective, and their worldview. 
Native American researchers have stressed the importance of having American Indians conduct research in their communities to accurately portray their experiences and to have their voices heard (Brayboy \& Deyhle, 2000; Swisher, 1996). Swisher (1996) contends that research conducted by outsiders is often fraught with stereotypes whereas a Native American researcher's familiarity with the American Indian perspective is more likely to accurately portray American Indians' experiences and voices. Although I am a Lumbee who conducted inside research, I do not have complete knowledge of the Lumbee experience. As with all cultural groups, the Lumbee community varies considerably. It was important for me to examine my individual perspective as a Lumbee Indian conducting research in my community. Consequently, I was able to increase my awareness of personal potential biases that could affect my research. For example, I made an effort to make my familiar knowledge of the Lumbee experience and community "strange" in my research and data collection (Erickson, 1986).

It is from this perspective and understanding that I approach my research. There are experiences, perspectives, and knowledge that members of the Lumbee community possess which I do not possess. I value and wish to learn first-hand historical accounts of the Lumbee experience in the segregated Indian schools. Having never personally experienced segregated education, I do not know what it was like to be surrounded by members of my Lumbee community in this segregated educational setting. Understanding more about the segregated educational experience can affect the development of educational curriculum and school policy that is relevant and successful for Lumbee and other non-white populations. In my research, I became personally engaged in my efforts to empathically understand this time in my participants' lives. It is 
significant to note that such personal empathic involvement delves to the heart of qualitative research—understanding the human experience (Patton, 2002).

Although I am an insider, in terms of sharing cultural, social, and historical background with my participants, in many ways I am still an outsider. I did not grow up in the Robeson county community, and I am now part of an academic community. However, these potential limitations to my role as a researcher within this community neither closed the gate to the access of facts nor did it limit the information the participants were willing to share with me.

\section{Personal Subjectivity Statement}

As a Native American woman conducting research about Native people, my voice as a person of color and as a woman is one that has been suppressed in the past by the dominant society (Collins, 1990; Sarris, 1993; Stanfield II, 1994). My experience as a Native American and a Lumbee Indian form the perspective and standpoint through which I conducted research with the Lumbee population.

My home community is Hoke County. This could have posed a problem for me with members of the Lumbee community who reside in Robeson County. Community and home place are very significant to the Lumbee. If the Lumbee people are not familiar with an individual or that individual's family, or if that individual is not from the 'right community,' individuals may not be forthcoming. Deese (2002) explains that the concept of 'belonging' to the community does not necessarily include other Indians from different communities. Furthermore, there is an intergroup attitude within the Lumbee community against those members of the Lumbee tribe who do not live in Robeson County. Pembroke is viewed as the center of the Lumbee community (Blu, 1996). It 
seems the further an individual lives from Pembroke, the "less Indian" an individual is considered to be. Fortunately, my father has roots in Robeson County, and as a former educator, he is well known in the Indian communities of Hoke and Robeson. Many members of the Lumbee community spoke to me and participated in this research because of their relationship with and knowledge of my father.

There were other potential dangers related to my insider perspective. As a Lumbee Indian conducting research in my community, it was essential that I continuously and critically examine the familiar. I had to be cognizant of the possibility that I may take the familiar for granted. This focus on the familiar required me to probe past personal presumptions in order to obtain facts. Throughout my research my participants assumed that I knew certain facts because I am Lumbee. In fact, I interacted with my participants as a novice and as a student. My research role was to ask my participants to give me in-depth explanations of various situations. As a novice, I was unfamiliar with the potential educational and psychological ramifications which existed in segregated schools.

Thus, adopting this role as a novice and student helped me in addressing my outsider status as a researcher. Indeed as a Lumbee, I shared a cultural and historical background with my participants. Also, I am a member of the Lumbee community. The relationship was unequal. As an academic researcher, I was privileged in this relationship (Anderson, 1993; Lofland \& Lofland, 1995). I was acutely aware of my privilege as a researcher. This influenced the way I interacted with my participants. 
In this chapter, I have discussed the problem of my research study, introduced my research, and outlined my own perspective. In the following chapter, I will provide the history of the Lumbee Indians as a context for my study. I will examine the gaps in the educational history and American Indian educational literature concerning the segregated experiences of the Lumbee. In chapter three, I will discuss my research methodology. 


\section{CHAPTER 2}

\section{THE LUMBEE AND SEGREGATED EDUCATION}

One of the problems that a lot of people make... is that they have a formula, this formula for Indian history... then it raises some questions about who you are, your heritage, and your tribal identity. And the formula is usually based on what we know about Plains Indians, not Indians in the 1800's. I think it is important that things shaped very differently for us and what was happening in the state from the late 1600 s on... But because of the strong kinship system, the shared values, and the shared history, we kept both the tribal identity and the Indian identity.- (Linda Oxendine, in Deese, 2002, p.164-165)

In the above statement describing the Lumbee, Dr. Linda Oxendine stresses the Indian identity of the Lumbee. In this chapter, I will provide a historical context of the Lumbee Indians, their identity, and including segregated schools. Then, I will cite existing literature concerning the historical segregated settings of African American schools and Native American schools to support the importance of my Lumbee research. Finally, I summarize how my research adds to the existing literature and enriches the depiction of Native American education.

\section{Who are the Lumbee?}

Lumbee Indians are a tribe of non-reservation ${ }^{4}$, state recognized Native Americans in Southeastern North Carolina. The Lumbee tribe is the largest tribe east of the Mississippi with partial recognition by the federal government. This concept of partial federal recognition refers to an act by the US Congress in 1956 which acknowledged the Lumbee as Indians in name only. Conversely, the act notes "any services performed by the United States for Indians because of their status as Indians, and none of the statutes of the United States which affect Indians because of their status as Indians shall be applicable to the Lumbee Indians" (An act relating to the Lumbee 
Indians of $\mathrm{NC}, 1956)$. This partial recognition has been a hurdle for the Lumbee in obtaining complete federal recognition through the Bureau of Indian Affairs (BIA).

Federal recognition refers to tribes that have a legal relationship with the United States government, and thus the government recognizes the trust responsibilities to these Indian tribes and acknowledges their eligibility for funding and services through the Bureau of Indian Affairs (Ogunwole, 2002; Prucha, 1985). Although the act recognized the Lumbee, it simultaneously denied them any services; thus, the only way for the Lumbee to become a federally recognized Native American tribe would be through another act of Congress. The Lumbee Recognition Act of 1956, must be taken within the context of the political climate at the time. From 1945 to 1961, the United States was engaged in terminating government relationships with tribes. Additionally, the Lumbee Recognition Act of 1956 is an example of the attempts of the Lumbee to prove their Indian identity to the external non-Lumbee community. Since 1956, the Lumbee have lobbied unsuccessfully for bills to be introduced into the House and Senate in 1974, 1988, 1991, 1993, and 1994. The Lumbee had two bills for recognition, the Lumbee Recognition Act in the House (2003) and Lumbee Acknowledgment Act of 2003 in the Senate, but no action was taken on these bills during the $108^{\text {th }}$ congressional sessions (Lumbee Acknowledgment Act, 2003; Lumbee Recognition Act, 2003). However, Representative Mike McIntyre re-introduced the Lumbee Recognition Act in the House January 4, 2005 (Lumbee Recognition Act, 2005). 
The Lumbee are a unique Indian population as evidenced by their unusual history and cultural origins. The indigenous people now known as the Lumbee tribe historically lived in the area of Southeastern North Carolina. Currently, and throughout history, Lumbee tribal territory covered a large section of Southeastern North Carolina, now known as the counties of Robeson, Hoke, Cumberland, and Scotland. A few hundred Lumbee lived in this area at European contact (Sider, 1976), but the number of Lumbee in the United States, according to the 2000 Census, had increased to 57,868 (Ogunwole, 2002).

Due to their efforts to define their cultural origins to non-Lumbee, the Lumbee have been known by many names. The Lumbee people have been known as Croatan Indians of Robeson County, Indians of Robeson County, and Cherokee Indians of Robeson County (An act to provide for separate schools, 1885; An act to change the name, 1911; An act to restore to the Indians, 1913; An act relating to the Lumbee Indians of NC, 1953;). Drawn from the history of the Lost Colony ${ }^{5}$, the first attempt to trace the origin of the Lumbee resulted in their designation as Croatan Indians of Robeson County. The Lost Colony theory holds that Lumbee Indians are descended from intermarriage between European colonist John White's failed colony and the Hatteras Indians of Roanoke Island (Lawson, 1709; McMillan, 1888). This theory is supported by oral history among the Lumbee who recall that their ancestors were descendants of the Lost Colony and the Hatteras Indians (Barton, 1967; Dial \& Eliades, 1975; McMillan, 1888). 
In 1913, Lumbee designation as the Cherokee Indians of Robeson County ${ }^{6}$ was based on Robeson Senator Angus W. McLean's theory that the Lumbee were descendants of the Cherokees who refused to be moved during Andrew Jackson's infamous removal ${ }^{7}$ of Indians from the East (McLean, Purcell, Singletary, \& Purcell, 1942). Lumbee oral tradition, as well, asserts a claim of their descent from the Cherokee tribe (Dial, 1993; McLean, Purcell, Singletary, \& Purcell, 1942).

Additional theories claim that the Lumbee originated from many of the Siouan tribes of North and South Carolina as the Waccamaw and Cheraw or even Algonquian or Iroquoian Indians (Blu, 2001; Mooney, 1894; Swanton, 1934). Blu (2001) reasons that there may have been remnant groups of Indian tribes ${ }^{8}$ who found safety in the area of Robeson County and thus intermarried, forming a single tribe that may have included non-Indians. The possibility that the Lumbee could originate from other Siouan tribes like the Cheraw, is the source of the Lumbee tribe's present explanation of their origin. The Cheraw theory is that the Lumbee are the remnants of the Cheraw Indian tribe; one group of Cheraw Indians came to Drowning Creek (Lumbee River) in present day Robeson County and found solace and security in the swamps during the troublesome time of initial contact with Europeans (Merrell, 1989).

There are various theories that demonstrate the richness of the Lumbee Indians' origins. In North Carolina, the Lumbee Indians experience a very strange world where the major social, political, and economic forces have been framed monochromatically by segregation in black and white. In the case of the Lumbee Indians, if one is neither white nor recognized as an Indian, then one is relegated to a status of black. This is inconsistent with the identification as Native American. An example of this denial of Lumbee Indian 
identity is evidenced by the plethora of labels North Carolina state government officials have created for the Lumbee, including '“mixt crew,' 'free Negroes,' 'free persons of color,' 'mulattoes,' or 'mixed-blooded people' ” (Dial, 1993).

The Lumbee River fed the swamps and provided the Lumbee people with their name and a place to settle. The geographical area of North Carolina that the Lumbee ancestors called home was characterized by land largely considered to be undesirable by European settlers for a number of reasons. Comprised primarily of swampland, woodland, and sandy soil, the area was difficult to traverse and was unsuitable for farming (Dial \& Eliades, 1975; Maynor, 1995). The Lumbee homeland was part of the Cape Fear Valley area. In 1650, English settlers from Virginia developed a settlement north of the Cape Fear Valley area in the region of the Albemarle Sound. Another English settlement, Charles Town in South Carolina, was established south of the Cape Fear Valley. The Lumbee Indians were between these English settlements. In addition to the undesirability of the land, the Lumbee homeland was furthermore undesirable due to the political instability of this area between the years of 1711 and 1776 before and during the American Revolutionary War (Blu, 2001; Dial \& Eliades, 1975; Perdue, 1985).

From 1663 to 1729, the two colonies of Carolina, north and south were under proprietary government (Bassett, 1894). In 1729, North Carolina became a royal colony separate from South Carolina. During this time period, the area the Lumbee Indians called home bordered North and South Carolina and both North and South Carolina colonies claimed this area (Blu, 2001). Additionally, this area was bordered to the northeast by the Tuscarora Indians who controlled the land between the Roanoke and Neuse Rivers (Perdue, 1985). The Tuscarora Indians initiated attacks on English 
colonists in 1711 out of fear of the encroaching English settlements on the Tuscarora tribal lands (Perdue, 1985). This began the Tuscarora War of 1711-1713. The presence of the powerful Tuscarora and the Tuscarora War itself also helped reinforce the seclusion of the Lumbee Indians in the Cape Fear Valley region which bordered the Tuscarora land. However, these political conflicts and undesirability of the land were aspects that made this area ideal for Lumbee Indians because it provided geographical seclusion. This isolation helped to protect the Lumbee, enabling their unique Indian culture to flourish without much disruption. Early in North Carolina history, only Native Americans considered this place desirable; therefore this area was one of the last areas to be settled by Europeans (Sider, 1993).

When the Tuscarora were defeated by the English colonists in 1713 and the remaining Tuscarora finally abandoned their land in 1803 , this land was opened to English settlers (Perdue, 1985). There was a push to settle this area once belonging to the Tuscarora. The Scottish Highlanders were the first to settle in the Cape Fear Valley region, and their appearance was a challenge to the peaceful isolation of the Lumbee Indians (Dial \& Eliades, 1975).

Over time, the Lumbee Indians incorporated a number of English customs, including language, farming, wearing beards, living in European style homes, owning slaves, and attending religious services (Barton, 1967; Dial \& Eliades, 1975; McMillan, 1888). The Lumbee Indians adopted a form of Christianity associated with Methodist and Baptist sects. Lumbee knowledge of Christianity developed before contact with missionaries due to the Lumbee migration and possible encounters with Whites, Blacks, or other Indians who practiced Christianity in the Protestant or Catholic traditions 
(Maynor, 2002). This is significant because the first permanent European settlers in the area were Presbyterian Scottish Highlanders, and thus, their religious views did not influence the Lumbee who were already practicing Christianity in the Methodist and Baptist traditions (Dial \& Eliades, 1975). Due to their utilization of European customs and lifestyle, Lumbee Indians have no vestige of their original language, but they have their own unique dialect of English which is referred to as Lumbee English. There are variations in the dialects of Lumbee English within the Lumbee community due to generational differences and regional differences (Wolfram, Dannenburg, Knick, \& Oxendine, 2002). During the time of Indian Removal 1814-1858, Lumbee, unlike other Indians, did not live in an Indian tribal manner, but individually owned their land. Due to this difference, Lumbee were not considered Indians, so they posed little threat to the dominant culture (Blu, 2001; Dial, 1993). The Lumbee existed in meager surroundings. The swamp terrain contributed to their isolation and the Lumbee Indians were considered insignificant. In 1835, the political climate in North Carolina began to change with the revisions of the North Carolina Constitution.

\section{Lumbee Resistance: Reclaiming Identity Through Internalized Racism}

Prior to 1835 , the Lumbee community coexisted with the white community in that they voted, and attended school and church with Whites (Fuchs \& Havinghurst, 1973; Maynor, 1995; McPherson, 1915). Specifically, although a few Lumbee children who possessed fair skin and looked white (Pierce, 1987) attended white schools that had been established in the Indian communities, most attended what were called subscription schools created by the Lumbee themselves (McPherson, 1915). Subscription schools are defined as schools where the students paid the educators to attend school. However, in 
1835, in a vote of 64 to 55 the North Carolina Constitutional Convention voted to disenfranchise free non-Whites (North Carolina, 1835; Maynor, 1995). The enactment of what were known as the Free Negro Codes entailed that:

no free Negro, free mulattoe, or free person of mixed blood, descended from Negro ancestors to the fourth generation inclusive (though one ancestor of each generation may have been a white person) shall vote for members of the Senate or House of Commons (North Carolina, 1835, p. 98).

The 1835 North Carolina Constitutional Convention did not refer specifically to the Lumbee, and there was no acknowledgement of them or their identity as Indians at this time. The assumption by the state of North Carolina was that this non-white population would fit within the category of "no free Negro, free mulatto, or free person of mixed blood" (North Carolina, 1835, p. 98). This revision of the Constitution, in effect, disenfranchised the Lumbee Indians, and denied their Indian heritage, and breached their isolation. One of the ways the Lumbee community reacted to this denial of their heritage was to resist this classification with African Americans.

\section{Segregation Caste System}

Cultural hegemony and colonization creates a social hierarchy wherein the dominant culture depends on the domination and oppression of non-dominant populations to reaffirm status and to ensure dominance (Comaroff \& Comaroff, 1997; Marshall, 2002). Such was the case in the south. In North Carolina, and in the South overall, slavery, the Civil War, and Reconstruction were characterized by a black and white caste system of segregation and racial hierarchy. Enacted and enforced by a socio-economic

and political structure wherein Whites were the 'upper caste,' segregation and racial 
hierarchy became deeply entrenched social norms. In this system, Whites considered themselves 'superior' because of their racial, cultural, political, and socio-economic dominance (Franklin, 1995; Wilson, 1997; Woodward, 1974). Within the common hierarchy, Blacks represented the 'lowest caste' and a number of laws regulated intimacy and contact between castes. The laws restricted the freedom of Blacks and reinforced the inequality between the castes (Woodward, 1974). Regulation of the physical and social distance between castes served to preserve the 'purity' of the 'upper caste' from the 'impurity' of the 'lower caste.'

Prior to the Civil War, Blacks were controlled by socio-economic and political structures (Wilson, 1997; Woodward, 1974). After the Civil War, so called Jim Crow laws were enacted to control Blacks (Woodward, 1974). Segregation replaced physical control, and these laws limited their new freedom. Blacks had minimal political power, could not vote, were excluded from public education, and had limited economic opportunities (Wilson, 1997; Woodward, 1974). As a result, they had little to no social respect (outcast status), and thus, because of this status, they continued to be subject to white authority.

The Lumbee represented a unique manifestation of a caste within an otherwise black and white racial hierarchy. Lumbee people struggled to define themselves within this imposed structure. Although they acknowledged they were not white, they knew also that they were not black, so how were they to fit in this caste system? The issue was settled for the Lumbee by the North Carolina Constitutional Convention which reclassified their ethnicity by including them within the category of "no free Negro, free mulatto, or free person of mixed blood" (North Carolina, 1835, p. 98). 
Lumbee Native American identity has never been questioned internally by the tribe since Lumbee Native American identity has always been confirmed by the community. According to Tatum (1997), identity is a complex concept "shaped by individual characteristics, family dynamics, historical factors, and social and political contexts" (p. 18). In this sense, one's identity is a reflection of the world that surrounds that individual. Historical, social, and political factors that shaped the identity of the Lumbee also helped to foster an animosity against Blacks. Willis (1963) depicts the climate of division between Indians and Blacks in the 18th Century which Whites helped foster in the colonial era of the Southeast. Some Indian tribes of the Southeast, specifically the Catawba Indians, already held hostility against Blacks because of competition for trade. But Willis (1963) argued that Whites in the colonial era found themselves in a problematic position because they had two exploited populations-black slaves and Indian tribes - which were challenges to white supremacy.

Whites feared the alliance of Blacks and Indians so they endeavored to insulate these groups from each other (Willis, 1963). First, the interaction between these populations was prevented in the 18th Century by forbidding intermarriage and trading (Willis, 1963). Then, Indian slavery was curtailed to prevent the alliance of Indian slaves and black slaves (Willis, 1963). Whites believed that prohibiting Indian-black interaction would prevent black slaves' flight for freedom into Indian country. To further prevent a black-Indian alliance and to maintain slavery, Indians were employed by Whites to ferret out runaway slaves and Maroons ${ }^{9}$ (Willis, 1963). Additionally, Whites endeavored, as James Glen the governor of South Carolina explained, to "creat [sic] an aversion in them [Indians] to Negroes" (Willis, 1963, p. 165). Willis (1963) explained 
that Whites caused conflict between Indians and Blacks through producing fear, suspicion, and hatred. Although Whites did not record their tactics used to cleave Blacks and Indians, they spread lies about Blacks to the Indians (Willis, 1963). These lies included how Blacks were responsible for the smallpox epidemic that devastated Indian tribes and how Blacks endeavored to ruin trade for the tribes (Willis, 1963). Whites also rewarded black slaves with freedom for fighting Indian tribes (Willis, 1963). This added to the animosity that Blacks had against Indians for their efforts as slave catchers and in fighting black slave insurrections (Willis, 1963). Thus, Whites worked to develop enmity between Blacks and Indians because Blacks viewed Indians as threats to their freedom and Indians viewed Blacks as enemies.

Given this climate of animosity between Indians and Blacks that Whites created in the $18^{\text {th }}$ Century, the Lumbee also faced a dominant white world in the late $19^{\text {th }}$ Century which could not afford to acknowledge another cultural population, such as Native Americans, to challenge their supremacy. While Blacks were being controlled through segregation, Native Americans were subject to the Indian Removal Act that resulted in their relocation from their homelands to the west. The government's failure to recognize the Lumbee as an Indian tribe was an advantage in that it preserved them from Indian Removal. White supremacy had little room for negotiation, and an acknowledged Lumbee presence would certainly challenge the black and white hierarchy. Lumbee challenged this system through their claim to equal status with Whites in voting, attending school, and attending church with Whites prior to 1835 (Fuchs \& Havinghurst, 1973; Maynor, 1995; McPherson, 1915). 


\section{Lumbee Culture}

Lumbee based their equality to Whites on the fact that when Whites encountered the Lumbee Indians they were living in a European manner (McMillan, 1888; McPherson, 1915). Culturally, Lumbee have long identified with Whites. During the colonial period, the Lumbee were not considered Indian because at that time the definition of an Indian was cultural rather than ethnic-racial (Dial \& Eliades, 1975) as it was during the Civil War and Reconstruction. Due to the earlier definition of Indian, the Lumbee no longer lived in a manner that aligned with the white perception of Indian tribal manner. As a result, interactions between the Lumbee Indians and Whites were without much incident and with only two Lumbee concerns: first, to protect their lands from Whites and second, for them to be treated "as equals not as 'inferior savages'" (Dial \& Eliades, 1975, p. 30).

Moreover, because of Indian Removal the assumption by Whites was that all Indians had been eliminated and if there were any remnant Indians they were part of the free mulatto communities interspersed in the South (Berry, 1963; Johnson, 1939; Maynor, 2002). As was the case with other Native American cultures, Lumbee culture was not fixed, but was constantly changing along with European contact variations. The Lumbee, while still maintaining their Indian identity, adopted the English language and customs. However, this adoption was not assimilation, but was accommodation to adapt and survive as a people alongside the European settlers. This contact shaped their Indian culture - it did not eliminate their culture. Historically, the dominant society has been intolerant of the realities of Native Americans like the Lumbee whose experiences challenge the continuity of what is thought to be Native American culture-traditional 
and unchanging (Clifford, 1988). The reality of the Lumbee Indians' culture is unlike the stereotype the dominant society has of Western Indians on a reservation. As such, the Lumbee shatter that stereotype. They are unique.

\section{Lumbee Ethnic-Race}

During the Civil War and Reconstruction period in North Carolina, it was not the Lumbee Indians' cultural differences or similarities with Whites, but their phenotype which changed the status quo for Lumbee-white relations. Southern Whites, during this time, based equality and acceptance on ethnicity and race (Dial \& Eliades, 1975). The Lumbee appeared racially mixed to the Whites who encountered them. This appearance gave rise to the labels including, 'mixt' crew,' 'free Negroes,' 'free persons of color,' 'mulattoes,' or 'mixed-blooded people' (Dial, 1993). The Lumbee suffered from prejudice and racism because they were non-white, and they defied the stereotype of what was considered Indian which had been fixed in the minds of Whites. As with any other population, there are different characteristics that make people individually unique. Lumbee hair textures and colors varied. The Lumbee skin tones ranged from fair to dark (Blu, 2001; Bordewich, 1996; Maynor, 1995). Similarly, eye colors include brown, black, blue, green, and hazel (Blu, 2001; Bordewich, 1996). Many Lumbee had European names due to acculturation and the various family heritages within their community (McMillan, 1888; McPherson, 1915; Sider, 1993). The most important challenge to their identity as Indians was a result of Lumbee intermarriage with members of other Indian communities as well as white and black communities. Although Native Americans are not all alike, the differing phenotypes within the Lumbee community were

a problem for Whites in their classification of white and non-white because of their 
conceptions of blood-purity and impurity. The "one drop rule" was the definition of blackness in the South, meaning that one drop of black blood made a person racially black. So this one drop rule enabled Whites to deny the Lumbee Indian identity because of the Lumbee intermarriage with black communities.

\section{Indianness}

There are three central components of Indianness, or what it means to be Indian. Aspects of identity shared by all tribal Indians are blood and descent, relation to the land, and sense of community (Fogelson, 1998). Other external cultural identity markers including language, participation in cultural activities, dress, physical features, consumption of Indian foods, and a particular lifestyle are flexible and can be lost and regained. In other words, external elements of culture can be invented or reinvented, but the core of Indianness is descent, relationship to the land, and the sense of community.

Most significant in this idea of 'Indianness' is blood line descent. The issue of 'Indianness' in terms of blood and descent has been defined differently by Indians and by the dominant culture. Herring (1994) explains that

identity issues for North American Indians - including questions of mixed blood and full blood - stem from attitudes and ideas fostered by the majority European American culture and government. Before the 'white man's coming,' marriage across tribal and clan lines was common, and the offspring were not marked as mixed blood. Neither was tribal membership based on blood quantum or degree of acculturation (p. 172). 
Native Americans did not define Indianness in terms of blood quantum ${ }^{10}$, but kinship (Fogelson, 1998). This kinship was not limited to individuals who shared a common biological descent, but was extended to include other clans and nations (Fogelson, 1998). Kinship was not limited to biological reproduction of offspring, but allowed for individuals and groups to become part of the Native American people "through naturalization, adoption, marriage, and alliance" (Fogelson, 1998, p. 45). Indianness/identity involved inner qualities, beliefs, and the social action which unified them as a people, cohesiveness beyond mere blood. In contrast, the constructs of the biracial caste system developed by Whites center around identity in matters of race, not culture (Dial \& Eliades, 1975; Fogelson, 1998). Before Indian Removal, Indianness had little to do with race; rather kinship and maintaining kinship were important to Indian identity. Kinship is still important to Lumbee identity, in using one of Fogelson's criteria of Indianness, descent. Descent for the Lumbee entails tribal membership and kinship. The Lumbee tribal membership criteria requires that an individual be able to trace descent from,

persons who were identified as Indian on the source documents. . and their direct descendants. The source documents identified are: 1900 and/or1910 U.S. Special Census of Robeson County, North Carolina; 1900 and or 1910 U.S. Special Indian Census of Bladen County, North Carolina; 1900 and/or 1910 U.S. Special Indian Census Richmond County, North Carolina; 1900 and/or 1910 U.S. Special Indian Census Cumberland County, North Carolina; 1900 and or 1910 U.S. Special Indian Census of Scotland County, North Carolina; Indian County Taxable Records from 1890 to 1910 for Robeson County, North Carolina; 1900 
and/or 1910 U.S. Special Indian Census Marlboro County, South Carolina; Croatan School Attendance List of O.R. Sampson from 1891 to 1896 (Pierce, 1987, p. 233).

Although Lumbee tribal membership specifically refers to blood descent, my research shows that the Lumbee community incorporates other ways of establishing membership-kinship. Fogelson (1998) describes kinship among Indians before European contact as a peoplehood, a network of communities wherein they had "reciprocal rights and duties toward one another and shared a collective sense of community" (p. 52). Lumbee sense of kinship is evidenced by their efforts to 'adopt' others by making them 'Indian too' through marriage, especially if there is intermarriage outside the Indian ethnic group.

However, this sense of adoption and kinship is not always the case with Lumbee intermarriage with Blacks. Pierce explains that intermarriage with Blacks was taboo in the Lumbee community...

While most things could be forgiven, marrying black could not [be forgiven] and young people were kept away from any contacts with Blacks. Individuals who married Blacks were forced to leave the community. There was no similar prohibition against marrying Whites within the Indian community, but it did not occur often, particularly toward the end of the century, because Whites would drive out the couple (Pierce, 1987, p. 149).

Intermarriage with Blacks was taboo, but intermarriage with Whites was acceptable in the Lumbee community. Whites who intermarried with Indians lost their white privilege and their offspring were then subject to the same biases that Indians were subject to 
(Deese, 2002). There was a cost for Whites in their intermarriage with Lumbee Indians. There was a cost for Lumbee who intermarried with Blacks as evidenced in the research of Dr. Jack Campisi,

marriage to a black will result in social ostracism, particularly if the couple chooses to live in the Lumbee community. One elderly woman put the matter quite bluntly. "Always remember the unborn. If you married someone who was unacceptable you would be cut off. Who would you go to for help?" (Pierce, 1987, p. 165).

The cost of intermarriage with Blacks would be severed ties with family members and ostracism from the Lumbee community.

\section{Lumbee Indianness}

Peck (1972) offers one aspect of understanding of Lumbee Indianness: selfsegregation, which explains the reason the Lumbee guarded their interactions with nonLumbee. In his description of the Pembroke Lumbee, the Indian Town Indian, Peck explains that the Indian Town Indian understands that Indians are best left alone with other Indians and doesn't mix with outsiders as Whites, and Blacks-who do not belong (Peck, 1972). He further explained that the Indian Town Indian was vigilant and avoided places where he might be discriminated against and treated as if he was black (Peck, 1972). Also, the Indian Town Indian was wary of engaging in friendly interactions with Blacks lest other members of the Lumbee Indian community misunderstood the interactions as if one was "pulling the whole [Indian] race down" (Peck, 1972, p. 56). So to be Lumbee was to limit interactions with only Lumbee Indians and to guard against interactions with non-Lumbee, especially Blacks. 
However, there is another more complete view of Lumbee Indianness. To be Lumbee is to know that one is Indian in spite of the black/white dichotomy of the South and the lack of federal recognition. Dr. Linda Oxendine explained Lumbee Indianness with regard to white/non-white assumptions of the Lumbee and regarding federal recognition as,

Lumbees are not looking for themselves, rather, they are trying to understand themselves, to see how we fit in with the rest of the Indian world. . .Lumbees know who they are. But they don't know why they are. A lot of people define Indian identity as traditional religion, tribal land, and language. Along with that, there is a tendency to believe that when Indians adapt, they become less Indian. Lumbees are Christians, private landowners, and speak English. But adaptation is the essence of being Indian. Before contact, tribes borrowed from each other. After contact, they borrowed from the Whites. Tribes were always changing. Total adaptation was not the goal, but people did what was necessary to make life good for themselves, or what they had to do to survive (Bordewich, 1996, p. 79). In Dr. Oxendine's explanation, the Lumbee Indians are certain of their Indian identity and understand that their Indianness is not tied to having a reservation. Nor is their Indian identity lost when the Indian language is lost. Some Indian tribes have lost their languages. Many tribes have voiced opposition against the federal recognition of the Lumbee because they do not have a tribal language, a tribal religion, a reservation, a treaty, or have demonstrated lineage from a historic tribe (Bordewich, 1996; McCulloch \& Wilkins, 1995). 
However, the key to Indianness in Dr. Oxendine's statement about Lumbee Indian identity is the survival of the people, the Indian people-that is the essence. That is what matters most to the Lumbee a collective concern for "our people." The Lumbee have a strong social cohesion and have lived as a culturally distinct Indian people. A constant question asked of the Lumbee people is "how do you answer questions by Western Indian tribes and non-Indians that you are not a legitimate tribe?" Those who ask this question are ignorant of the realities of Eastern Indian tribes and how European contact disrupted the culture and lives of Eastern Indians. Specifically with the Lumbee, European contact impacted the external cultural identity markers of the Lumbee (i.e., language, clothing, and lifestyle). External cultural identity markers can be lost and be regained as evidenced in Lumbee English and participation in pan-Indian powwow cultural activities. But there is no culture if the people do not survive. The Lumbee have adapted European customs and language to make them their own in order to survive.

The Lumbee indeed have survived and flourished, and ironically, it is the sheer size of the Lumbee population that is the greatest obstacle to their federal recognition as Indians. Federal officials estimate that to provide services for the Lumbee tribe would cost \$30-100 million a year (McCulloch \& Wilkins, 1995). This is seen as too great a burden for the budget and has led to the continual denial of Lumbee recognition (McCulloch \& Wilkins, 1995). Federally recognized tribes fear that with Lumbee recognition, the limited federal support that is available to tribes would be spread too thin and thus these tribes fear the Lumbee as competitors (Bordewich, 1996; McCulloch \& Wilkins, 1995). 


\section{'Myth of Blood' and Racial Hierarchy}

European definitions, in contrast to Native Americans' definitions of Indianness, defined Indian identity differently. Prior to European contact, it was of little importance for American Indians to define who were Indians because all inhabitants were Indians (Thornton, 1987). American Indians defined themselves with regard to other Indian tribes. In fact, most Indian tribes referred to themselves as the 'real people' and other tribes as non-human (Thornton, 1987). After contact, Europeans defined American Indians as a group irrespective of tribe and it took time for American Indians to view themselves in this manner as a category with regard to Europeans (Thornton, 1987). Fogelson (1998) shows European Americans defined Indian identity based on external characteristics or racial traits such as the physical features of skin color, hair, eye color, and the biological physical nature of the blood.

The European focus on the biological physical nature of the blood in defining racial identity concerns the purity of the blood regarding genetic and racial differences. This concern with blood purity is due to a 'myth of blood, ${ }^{11}$ which suggests blood permanently carries the fluid heredity of a people (Comas, 1958; Fogelson, 1998). This 'myth of blood' predates the knowledge of genetics (Jordan, 1968). In the 'myth of blood,' the blood was the source of human life and generation (Jordan, 1968). Specifically, the blood is believed to carry the distilled essence of a people, and in this manner the blood carried a sense of permanence throughout the generations (Comas, 1958; Fogelson, 1998; Jordan, 1968). So if the blood can be kept pure then the people are pure (Comas, 1958; Fogelson, 1998). There is no biological foundation for the 'myth of blood' because blood has nothing to do with heredity (Comas, 1958). Furthermore, all 
of humanity is of racially mixed origin (Comas, 1958). However unfounded this 'myth of blood' may be, it has fueled the ideas of racial purity and the view of miscegenation as a pollution of blood (Comas, 1958; Fogelson, 1998; Jordan, 1968). Thus, purity of the race provided the impetus for focusing on blood among Whites because they believed that the mixture of the races would pollute the purity of their bloodline.

This understanding of blood purity gives another context for understanding white supremacy and the perception and treatment of non-Whites as inferior. In addition, an understanding of blood purity gives clarity to the classification of Negro and Indian blood. Blood purity caused a measuring of blood, such as "one-sixteenth part of 'Indian blood' or 'black blood'-that is, when one of their sixteen direct ancestors (great-greatgrand-parents) was a Negro or an Indian" (Comas, 1958, p. 18). Further, Comas (1958) reasoned that if an individual possesses an infinitesimal amount of black blood and is considered black, then it would be just as logical to declare anyone who possesses a drop of white blood to be white. Comas (1958) explained that the absurdity of this racial classification of blood is that its focus is not biological. Rather the racial classification of blood was based on a cultural, economic and social classification. The need for classification in the Americas could be traced to the Spanish Inquisition. During the Spanish Inquisition, religion was used to distinguish Christians from non-Christians such as Jews and Muslims (Fredrickson, 2002). The cleanliness of blood was referred to as "limpleza de sangre" (Fredrickson, 2002). Also this classification based on the purity of the blood could also be seen in the response of the Spanish and Portuguese to logically order the European, Native American, African, and racial mixtures of these populations which emerged in the new racial caste systems in the American colonies (Forbes, 1993; 
Jordan, 1968). Specifically, the definitions of mestizo, mulatto, and zambo were given to classify the new racial mixtures (Forbes, 1993; Thornton, 1987). Descendants of Europeans and Indians were referred to as mestizo. The offspring of Europeans and Africans were categorized as mulatto. Progeny of Africans and Indians were identified as zambo.

In 1715, North Carolina passed an anti-miscegenation law prohibiting the intermarriage of Whites and Blacks (Franklin, 1995). Lumbee disenfranchisement, the Jim Crow laws, and laws against intermarriage of Whites with Blacks (which the Lumbee were considered) all served to control the black population and to protect white supremacy. The segregation hierarchy along with definitions of culture, race, ethnicity, and Indianness all serve as a context for understanding the impact of Lumbee Indians' classification as black. Instead of Whites acknowledging a third category that would be a challenge to the bi-racial hierarchy, the categorization of this population as non-white was created to deny their Indian identity (Blu, 2001; Dial \& Eliades, 1975; Maynor, 1995). Thus, this population's identity is assumed and treated as part of the inferior lower caste. Further, the social construct of race positions the black cultural population as the 'pariah race' (Ogbu, 1978); being associated with this cultural population lowers one's status.

The Lumbee resisted this categorization and hierarchy because it relegated them to second class citizenship. It denied their previous identity as equals with Whites developed through their attending common churches, attending common schools, and voting with Whites (Fuchs \& Havinghurst, 1973; Maynor, 1995; McPherson, 1915). Like other Native Americans, the Lumbee reified their Indian identity through 
internalized racism by assertion of Indian heritage and embracing segregation (hooks, 1992; Maynor, 2002). Through their efforts to assert their Indian identity, to self segregate, and through their internalized racism, the Lumbee endeavored to distinguish themselves from Blacks. Some scholars (Berry, 1963; Johnson, 1939) have hinted that this effort to assert Indian identity was a way for the Lumbee to avoid being classified as black. That is, if the Lumbee could not become white, they would settle for being Indian (Berry, 1963; Johnson, 1939). However, research shows that some Lumbee were identified by United States census takers as white, and there is evidence of some Lumbee who left the Indian community, and because of their lighter skin, 'passed' as white (Blu, 2001).

'Passing,' in this context, means the efforts of Lumbee to attempt to use their lighter skin color and other 'phenotypical white racial traits' to perpetrate a white racial identity. Doing so would afford them socio-economic, political, and educational opportunities that being "white" offers to members of the dominant population. For example, Maynor (2002) documented a separate Lumbee community in Georgia that developed from Lumbee Indians seeking economic opportunities away from home. These Lumbee could have passed as Whites, but they maintained their distinctiveness as Indians and kept their kinship ties and re-connected with their home in Robeson County as they created another homeplace in Georgia. The Lumbee have consistently struggled not only to maintain the tribe but also to preserve their community as Indians. 
What if the Lumbee had been categorized as a sub group of Whites? Would the Lumbee have asserted their Indian identity? My conjecture is that based on Lumbee history and my understanding of the Lumbee people, they would not have resisted categorization as white as long as it did not affect their way of life and limit their freedoms as the categorization of black had. The Lumbee did consider themselves as equals to Whites, and their first problem with Whites was protection of their lands from economic competition. Additionally, if the Lumbee had been categorized as a sub group within the white population, this would not have prevented them from being discriminated against. For example, the Irish, Italians, Jews, and Polish are ethnic groups within the white classification, and their being white did not save them from prejudice and subservient treatment from the dominant society (Takaki, 1993). Moreover, these groups were encouraged to deny their ethnicity and become part of mainstream white society, thus denying their identity (Takaki, 1993).

This denial of heritage and ethnicity would run counter to the Lumbee culture, because the Lumbee Indian identity and the distinction as an Indian people or "our people," as the community refers to itself, is important to maintain. Of course, there are exceptions. I am aware of some Lumbee who have passed for white because of their phenotype and have broken ties with the community to become white. Also, I am aware of some Lumbee who have also passed for black and have broken ties with the community to become black. However, the Lumbee community as a whole seeks to maintain, persevere, and continually improve themselves for the success of the tribe and most importantly for their children and their elders. Therein is the goal of the Lumbee tribe, to take care of and work for the best for "our people." 
Of course, the reality for the Lumbee is that they were categorized as black and not white, and they resisted this classification as black. Lumbee distinguished themselves as being "not black" ${ }^{12}$ by asserting their Indianness, directing racism toward Blacks, and accommodating white values (Maynor, 2002). It may be that by buying into this system of cultural hegemony and colonization, the Lumbee attempted to ally themselves with the dominant class by engaging in the oppression of Blacks (An act to amend the laws of 1885 and 1887, 1889; , An act to empower the trustees, 1911) and thereby distancing themselves from Blacks (hooks, 1992; Lovett, 2002). Despite this attempt by the Lumbee to distinguish their Indian identity from Blacks, this distancing was ultimately of benefit to Whites in that it created a cleavage between Indians and Blacks. Creating disharmony among these lower castes was advantageous because of the danger of these populations uniting and working together to challenge white supremacy. Nat Turner's 1831 violent revolt against slavery and Whites represented a radical and bloody resistance that substantiated the fears of Whites. The Lowrie War provides another violent example of resistance to the injustice of the caste system (Evans, 1995; Maynor, 1995). In the years of 1864 to 1872 , the Lowrie War involved a band of Indians, Blacks, and poor Whites led by an Indian, Henry Berry Lowrie, who engaged in violence to combat white tyranny in the South. The Lowrie Band were sort of modern day Robin Hoods who used guerrilla tactics to repay the injustice done to them and to other nonWhites in Robeson County. 
After the Civil War, there were friendly relationships between the Lumbee and their black neighbors and the example of the Lowrie Band of freedom fighters showed social and political unity. However, the Lumbee's internalized racism strained relationships because Blacks viewed the Lumbee as participating in and allying with Whites rather than resisting the system of segregation (hooks, 1992; Lovett, 2002). This discussion of internalized racism is not an attempt to vilify the Lumbee, rather it is to reveal the sickness of a system of racial hierarchy wherein a non-dominant population actively participates in the oppression of another non-dominant population. The Lumbee sought a position on the periphery of 'white supremacy.' Most important in this understanding of the internalized racism among the Lumbee is the position of Whites in exerting power over both Lumbee Indians and Blacks and the benefits of this domination to Whites. In this manner, internalized racism and oppression manifested itself by excluding, delegitmizing, demeaning, distancing, and "othering" another non-white population. Hence, Lumbee internalized racism developed in the face of their own oppression at the hands of the dominant white population (North Carolina, 1835; Dial \& Eliades, 1975).

\section{Lumbee Indian - Black Relations}

I would like to say that no tensions exist in current Lumbee-Black relations, but the reality is that tensions still exist. Again, due to Lumbee internalized racism there are still struggles. These tensions are evidenced by regular school violence between Lumbee and black students at Purnell Swett High School in Robeson County since 2002 (Jenkins, 2005; Locklear \& Elofson, 2004; , "Students", 2002). In response to the violence the North Carolina Human Relations Commission developed a plan in 2002 to address the 
racial issues in Robeson County schools, but the plan was never fully implemented (Jenkins, 2005). However, that violence does not tell the whole story. Due to the social, economic, and political dominance of Whites in Robeson County there have been united efforts on the part of the Lumbee Indian and black communities to work together to improve these conditions (Dial, 1993; Sider, 1993). During the 1960s and the 1970s the Lumbee Indians worked with Blacks on issues of political representation and equal opportunity through voter registration drives, placing candidates of color in office despite single shot voting ${ }^{13}$; and ending double voting ${ }^{14}$ which kept Whites in power at the board of education (Sider, 1993).

Also, combined efforts of the black and Indian communities in the 1980s saw the consolidation of the five school districts in the county in 1988 , the appointment ${ }^{15}$ of the late Dexter Brooks as the first Native American Superior Court Judge in 1988, and the creation of the public defender's office (Dial, 1993). In 1994, Glenn Maynor, a Lumbee was elected Sheriff of Robeson County (Dial, 1993). Today more people of color hold political positions than in the past due to the combined effort of the voting power of the Lumbee and Blacks in Robeson County (Dial, 1993). This voting power is substantial considering the racial make up of the county. According to the 2000 census data: American Indians number 46,459 comprising $37.67 \%$ of the population (the Lumbee tribe is included in the category of Native American as the census statistics for the county did not distinguish for tribal affiliation) (Robeson County, 2000). Blacks number 30,827 comprising $24.99 \%$ of the population; Hispanics number 5,994 comprising $4.86 \%$ of the population; and Whites number 37,999 and comprise $30.81 \%$ of the population (Robeson County, 2000). Asian or other ethnic-racial population number among 2,060 and include 
$1.67 \%$ of the population in Robeson County (Robeson County, 2000). Thus, with a total population in Robeson County of $123,339,67.52 \%$ of the population is non-white (Robeson County, 2000).

Although tensions are still present in Lumbee-Black relations, the context of Lumbee internalized racism helps in understanding this tension in the past as well as the present. Because the Lumbee were drawing a distinction between themselves and the black community, the Lumbee refused to attend school with Blacks when they were denied admission to the white schools by the 1835,1868 , and 1875 revisions of the North Carolina Constitution. Moreover, after the 1835 constitutional revision, the state did not provide for free statewide public schools system until 1840 (Lefler \& Newsome, 1973). North Carolina had provided public schools, but did not provide funding for the schools until 1840 (Lefler \& Newsome, 1973).

\section{Establishment of Lumbee Schools}

After the Civil War, North Carolina again revised the state Constitution, in 1868 and 1875 , to reflect the fact that education would be provided for Blacks, Indians, and Whites. However, the language spoke only of white children and "colored" children being taught in separate schools and did not acknowledge Native cultures in any way:

And the children of the white race and the children of the colored race shall be taught in separate public schools, but there shall be no discrimination made in favor of, or to the prejudice of, either race (North Carolina. Secretary of State. \& Cheney, 1981, p. 883). 
In 1869, the Freedman's Bureau ${ }^{16}$ established schools for Blacks in North Carolina and in 1877, a normal school for Blacks was established in Fayetteville, NC (Bizzell, 1983). The Lumbee refused to attend these schools with Blacks.

During Reconstruction, the Lumbee, aided by the efforts of historian and Legislator Hamilton McMillan, sought not only their own schools, but also recognition of their Indian status (Blu, 2001; Dial, 1993; Dial \& Eliades, 1975). McMillan an historian from Red Springs, was the Robeson County Representative and was well acquainted with the Lumbee Indians (Blu, 2001; Dial, 1993; Dial \& Eliades, 1975). McMillan, took a personal interest in conducting several years of historical research on the origin of constituent Lumbee Indians and sponsored legislation, in 1885, giving the Lumbee state recognition and entitling them to their own separate schools (Blu, 2001; Dial, 1993; Dial \& Eliades, 1975).

The legislation that Representative McMillan brought before the North Carolina State General Assembly had two provisions: 1) to provide for the legal recognition of the Lumbee as an Indian people giving them the name Croatan Indians; and 2) to provide separate schools for them. In 1885, North Carolina passed the first state law regarding Indians which addressed education. This law stated that:

Whereas, the Indians now living in Robeson county claim to be descendants of a friendly tribe who once resided in eastern North Carolina on the Roanoke river, known as the Croatan Indians; therefore,

The General Assembly of North Carolina do enact:

Section 1. That the said Indians and their descendants shall hereafter be designated and known as the Croatan Indians. 
Section 2. That said Indians and their descendants shall have separate schools for their children, schools committees of their own race and color, and shall be allowed to select teachers of their own choice, subject to the same rules and regulations as are applicable to all teachers in the general school law (An act to provide for separate schools, 1885, pp. 92-94).

Although this act refers to the Indians in Robeson County, the Lumbee Indians from Hoke County are included in this legislation because Hoke County was carved out of Robeson County in 1911. Croatan Indians who lived in counties outside of Robeson such as Scotland, Richmond, and Cumberland County also gained schools of their own with this legislation.

The Croatan Indian Recognition Act of 1885 provides evidence of the Lumbee assertion of their Indian identity through their embrace of racial segregation. Beyond a refusal to attend schools with Blacks, the racism of the Lumbee against Blacks is evident in their attitude toward Blacks. Hamilton McMillan, in a communication with O.M. McPherson explained that, "Since their recognition as a separate race, they have made wonderful progress. Their hatred of the Negro is stronger than that entertained by Caucasians" (McPherson, 1915, p. 242). This hatred was another effort to separate and segregate themselves from Blacks. The Supervisor of Indian Schools, Charles F. Pierce, was sent from the United States Department of the Interior to gather information about the Lumbee, and he described the Lumbee as, "[not associating] with the Negro race, looking upon them in about the same way as to [sic] do the Whites of their community" (Pierce, 1987, p. 53). The Lumbee effort to not associate with Blacks and their view of Blacks mirrored the white oppression of Blacks. Such racism and oppression is also seen 
in the efforts of the Lumbee to advocate for legislation in 1889 and 1911 to exclude and keep African American children from attending their schools (An act to amend the laws of 1885 and 1887, 1889; An act to empower the trustees, 1911). This effort to enforce exclusion of black children is another example of Lumbee internalized racism.

In 1921, the North Carolina General Assembly passed legislation which established school committees to control admission to Indian schools, recommended teachers and principals for hiring and firing, and brought in Indian votes for key elections (An act to establish an Indian legislative committee, 1921). One committee established by the Lumbee through this legislation was a 'blood committee,' in existence until desegregation in 1954, which screened students who sought to enroll in the public schools and the normal school (Blu, 2001). The blood committees were created to maintain the racial enrollment of the Indian schools. Blood committees screened out students whose ancestry included black blood. This Act gave the Lumbee the power to control who attended their schools-no African Americans and no individuals of black mixed heritage such as the group of individuals known as the Smilings.

Dial and Eliades (1975) explain that the Smilings were "the product of miscegenation [who]... migrated to Robeson County from the area of Sumter, South Carolina, after World War I" (p. 99). Smilings was the name this population was referred to because the family name Smiling was not a Lumbee family name (Sider, 1993). The predominant family names for the Smilings were Smiling and Epps (Sider, 1993). A school was created for this separate group of Indians when they were denied admission to the Lumbee Indian schools. There were then four separate schools in Robeson County based on the designations, black, white, Indian, and one for the Smilings (Blu, 2001; Dial 
$\&$ Eliades, 1975; Sider, 1993). From the four separate schools, we might conclude that the Lumbee had prejudice against Indian groups which could not clarify their Indian heritage, as the Smilings, and that these groups were not accepted fully into the Indian community. And also, one could argue that the Lumbee appropriated the one drop blood distinction from Whites.

Another example of Lumbee resistance and internalized racism can be seen in their opposition to the desegregation of their Indian schools, a subject discussed later in this chapter. According to Massey (1996) and Thompson (1973), the Lumbee viewed the schools as a way to preserve their distinct cultural traditions which they feared would be lost through desegregation.

This literature review of the Lumbee presence in North Carolina provides the contextual understanding of the Lumbee, their struggle to assert their identity, and their preference for their own schools in the context of the segregated educational system. The next section discusses the segregated schools of African Americans and Native Americans as well as the American Indian schools in North Carolina.

\section{Segregated Schools}

Native American researchers have documented the oral histories of the boarding schools, but the Lumbee experience has been overlooked (Cobb, 2000; Ellis, 1996; Lomawaima, 1994). My research on the Lumbee segregated educational experience adds to the body of historical literature regarding segregated educational experiences (Anderson, 1988; Ashmore, 1954; Bond, 1939; Cecelski, 1994; Emerson, 2003; Hessling, 1993; Walker, 1996; Wilson, 1997; Wilson \& Segall, 2001) and also to research on Indian Education (Cobb, 2000; Ellis, 1996; Fuchs \& Havinghurst, 1973; Lomawaima, 
1994; Lomawaima, 1995; Spring, 2001; Swisher \& Tippeconnic, 1999; Szasz, 1999). This research fills a gap in the examination of state-supported segregated schools, which is currently limited to African American populations. An oral history of the Lumbee Indians' segregated schools adds to the richness of American Indian Education.

\section{Segregated African American Schools}

Research concerning the educational experiences of African Americans (Anderson, 1988; Ashmore, 1954; Bond, 1939; Cecelski, 1994; Emerson, 2003; Hessling, 1993; Walker, 1996; Wilson, 1997; Wilson \& Segall, 2001) in the segregated schools contributes to the illumination of segregation as a particular aspect of educational history. The research of Anderson (1988), Ashmore (1954), and Bond (1939) documents the experiences in segregated African American schools in the early $19^{\text {th }}$ century, but limits its critical examination of segregation after the Civil War until 1935. During this time, segregated black schools were characterized by an inequality of funding and resources resulting in a separate and unequal education when compared to white schools (Harlan, 1968). Although the segregated schools may have been resource-poor, the research of Cecelski (1994), Emerson (2003), Hessling (1993), Walker (1996), Walker (2000), Wilson (1997), Wilson \& Segall (2001) also documents that in the period after 1935 until desegregation, these schools were rich in support. Some segregated schools were rich in educational support from the African American teachers, administrators, and the community as a whole. 
Anderson (1988) documents the inequalities found within African American segregated schools. Reflecting an era where former slaves became involved in creating schools, community members sought to provide their children with the tools to maintain their freedom and to elevate them from poverty and second class citizenship. The struggle to create and sustain these schools occurred in an environment where Blacks lacked the economic and political power to disrupt southern white oppression. Although black schools were well attended and illiteracy declined, white southerners still viewed the schools as unfair drains upon resources and deemed them of little worth (Anderson, 1988; Ashmore, 1954; Bond, 1939). Blacks faced institutional racism in the form of inadequate funding and in the form of the type of education (industrial education vs. classical curriculum) their schools provided (Bond, 1939). These obstacles did not deter Blacks in their efforts to elevate and uplift their community through education, but helped shaped the belief that the education of Blacks was a black responsibility (Anderson, 1988). If non-Blacks would not help, then the black community would help itself by providing financial support and other resources that the schools needed. This resulted in a self-imposed double taxation. Self-help and double taxation were not expected of the white community.

My research explores and documents memories of the Lumbee people that demonstrates self-help and financial involvement in the Lumbee schools. Thompson (1973) estimated that the Lumbee invested over one million dollars in resources to their schools during the period from segregation to desegregation. Participants in my research told how the community hosted fundraisers for resources for the schools. The Board of Education minutes for both the Hoke and Robeson County schools show that white 
administrators asked the Indian community to provide matching funds for school facilities (Dial, 2002; HCBE Minutes; PSRCBE Minutes).

The lack of physical resources that characterized segregated schools led to a depiction of these schools as inferior (Anderson, 1988; Ashmore, 1954; Bond, 1939). Walker (2000) explains that these negative conclusions resulted from white researchers' reliance on archival documents as the only mode of historical inquiry. Negative conclusions were perpetuated by a failure to include oral interviews in their methodology (Walker, 2000). The researchers' lack of contact with and understanding of the black community, contributed to the limitations of prior research (Walker, 2000). However, additional research on black segregated schools documents that the students had positive experiences, which fostered substantial student development. Various researchers document that excellent teaching occurred within those schools (Cecelski, 1994; Emerson, 2003; Hessling, 1993; Walker, 1996; Wilson, 1997; Wilson \& Segall, 2001).

Citing archival data, Walker (1996) described the conditions of segregated schools for African American children in North Carolina. A January 1935 report by the Governor's Commission for the Study of Problems in the Education of Negroes in North Carolina showed that:

in a great many instances the school buildings now in use for the colored children are in a poor state of repair. Generally, many are poorly lighted and heated, and in many instances are too small to give adequate accommodations to the pupils . . . In many of the classrooms, the furniture is antiquated, the blackboards are insufficient in size and badly abused. Very few rural colored schools are equipped with modern single desks. Little or no provision is made for teaching health and 
sanitation. Laboratories for science and the vocational subjects are few and inadequate (Walker, 1996, p. 2).

However, Walker (1996) and Celeski (1994) used oral histories, in addition to archival research. Thus, they reported positive findings in their research describing two segregated African American schools in rural North Carolina.

Specifically, they found that each school's excellence was attributed to the combined efforts of the parents, teachers, administrators and community. Parents and community members valued schools because they built, funded, and advocated for the schools, and made them part of the community (Cecelski, 1994; Walker, 1996). Communities provided needed resources while principals and teachers supported the students' educational achievement. Principals and teachers built relationships with students. They acted like surrogate parents in that they developed student talents with high academic standards and a college preparatory curriculum (Cecelski, 1994; Walker, 1996). These educators believed in the children's ability to learn (Cecelski, 1994; Walker, 1996). In fact, educators strongly believed that education was the only way the African American students and communities could advance. So, although these schools had poor resources, they "experienced no poverty of spirit" (Walker, 1996, p. 201).

My research study explores these themes found in research on segregated African American settings and applies these questions to the Lumbee Indians' segregated educational experience. This dissertation enriches the documentation of the segregated school experience and adds to the understanding of the research in the field of southern education through the added perspective of Native Americans. Research concerning the Lumbee experience (Blu, 2001; Chavis, 1986; Dale, 1986; Dial, 1993; Dial \& Eliades, 
1975; Massey, 1996; Thompson, 1973) gives evidence that the Lumbee schools were also resource poor and struggled to obtain funding.

\section{Segregated Native American Schools}

Researchers have studied the education of Native American tribes whose education was federally supported (Fuchs \& Havinghurst, 1973; Lomawaima, 1995; Spring, 2001; Swisher \& Tippeconnic, 1999; Szasz, 1999). The federal government supported these tribes' education between the late 1800s and the late 1940s. Then the federal government terminated support to the tribes and subsequently contracted with the states for the education of these tribes. Federally supported tribal education was characterized by boarding schools administered by the Bureau of Indian Affairs (BIA). The BIA wanted to hasten Indian cultural transformation through education and to assimilate them into the mainstream (Cobb, 2000; Ellis, 1996; Fuchs \& Havinghurst, 1973; Lomawaima, 1994; Lomawaima, 1995; Spring, 2001; Swisher \& Tippeconnic, 1999; Szasz, 1999). The belief was that once Indians were assimilated, they would be less dependent on the federal government. To hasten assimilation, boarding schools were located away from reservation lands in order to isolate students from their parents, their language, and their culture. Some students were seized and taken to the schools. In other cases, parents were coerced into sending their children to these schools. The schools emphasized forced assimilation, harsh discipline, hard labor, and vocational training in their efforts to 'kill the Indian to save the man ${ }^{17}$ (Bordewich, 1996; Cobb, 2000; Ellis, 1996; Fuchs \& Havinghurst, 1973; Lomawaima, 1994; Lomawaima, 1995; Marshall, 2002; Pratt, 1892; Spring, 2001; Swisher \& Tippeconnic, 1999; Szasz, 1999; Tatum, 1997). Students were exposed to physical, emotional, and even sexual abuse. The 
boarding school movement began in 1879 with the opening of the first off-reservation boarding school, the Carlisle Indian Industrial School, in Carlisle, Pennsylvania. The assimilationist agenda of the boarding schools continued until the 1930's (Bordewich, 1996; Cobb, 2000; Lomawaima, 1995; Spring, 2001; Swisher \& Tippeconnic, 1999; Szasz, 1999; Tatum, 1997). The educational experience of federally recognized tribes is different from the Lumbee educational experience. While boarding school experience is well documented, Lumbee Indian educational experience is missing from American Indian education literature.

In 1936, Walcott Beatty, the Bureau of Indian Affairs Director of Education, endeavored to reshape Indian education into a culturally relevant education for Indian students (Lomawaima, 1995). As a result of his efforts, contemporary BIA boarding schools are more culturally sensitive than the early boarding schools. Despite the improvements of the boarding schools, Kleinfeld (1973 ) argued that public boarding schools are inadequate to the needs of Indian children and should be closed in favor of the establishment of schools in the students' home villages. In fact, reservation boarding schools or day schools were the second kind of educational settings that were offered Native American tribes, and these were well supported because they required little transportation, were cheaper, and they did not take the children away from home (Szasz, 1999). 
Native American students were also educated in public schools. Their education in public schools was due to federal termination ${ }^{18}$ of support to tribes in the late 1940 s (Fuchs \& Havinghurst, 1973). The termination of support and allotment ${ }^{19}$ of Indian lands were additional assimilationist efforts to change Indians. Education of Indian students from these tribes with termination status then became the responsibility of the states (Szasz, 1999). Federal funds for Indian education were allocated to the state schools to compensate them for the education of the Indian students. For example, in Oklahoma at the turn of the $20^{\text {th }}$ century when Oklahoma became a state, the state Constitution defined Blacks as anyone with black blood, and Whites as anyone else, including Native Americans (V. Lambert, personal communication, July 10, 2004). Thus, these Indian students did not attend segregated schools, but attended schools with Whites. Although the states were responsible for the education of the students, the federal government provided funding for these students' education (Szasz, 1999).

Current historical literature does not document the education of tribes whose education was solely state supported as was the case of the Lumbee tribe. My research alleviates this gap in the literature. A major study of American Indian education by Fuchs and Havighurst (1973) has documented that the Lumbee are a unique case because they are a non-reservation tribe and historically had a separate school system within North Carolina's educational system. This documentation is limited and does not explore oral histories of the Lumbee in order to understand their experience in segregated schools. Nevertheless, the experiences of other Native American tribes have been documented (Cobb, 2000; Ellis, 1996; Lomawaima, 1994). Although these oral histories explore the experiences of tribes in Oklahoma whose histories have shaped them and 
their education differently, they do not reflect Lumbee experience. The Lumbee have a unique history which has shaped them as a tribe, and their educational experiences are distinctly different from these other tribes. Researching the Lumbee segregated educational experience contributes knowledge about the education of non-reservation tribes to Native American education research.

\section{Segregated Native American Schools in North Carolina}

My research adds to the existing literature on segregated education and enriches Native American educational research. Lumbee research adds to the description of the segregated educational experience just as the research from the segregated African American schools has established a picture of what this experience was like for those groups. The Lumbee experience allows for exploration of themes found in the research of African American settings. Through using an oral history approach similar to researchers who have conducted research in the African American community (Emerson, 2003; Hessling, 1993; Walker, 1996; Wilson, 1997; Wilson \& Segall, 2001) this research documents the segregated educational experience of the Lumbee who advocated for their separate schools and viewed them as part of their cultural identity.

In North Carolina, segregated Indian schools varied by tribe. These tribes included the Eastern Band of Cherokee, Coharie, Person County, Waccamaw Siouan, Haliwa-Saponi, and the Lumbee, the focus of this study. The education of the Eastern Band of Cherokee Indians in North Carolina was the responsibility of the federal government since they are a federally recognized tribe, but the government initially inconsistently provided for their education (Finger, 1984, 1991). Schools for the Eastern Band of the Cherokee Indians took many forms during the $18^{\text {th }}$ and $19^{\text {th }}$ centuries. For 
example, in the 1800s Quaker missionaries established day schools and a boarding school in Cherokee (Finger, 1984, 1991; Perdue, 1985). The education these schools provided was deculturalizing to the extent that the goal was to remove Cherokee language and culture. In 1930, industrial education was the focus of the new program the federal government offered the Eastern Band of Cherokee along with a new school and federally paid teachers (Finger, 1984, 1991; Perdue, 1985).

\section{Lumbee Schools}

In 1885, the Lumbee received state recognition as Indians. As a result, they received their own schools in Robeson and Hoke Counties. In addition to providing their own schools, this action reaffirmed the racial identity of the Lumbee. The Lumbee went willingly into these schools. They had lived in a separate community from Blacks and Whites and had sought to establish their own segregated schools for 50 years. Advocating for their own schools became an important part of validating the Lumbee identity. The Lumbee schools came to represent more than an affirmation of Indian identity to the Lumbee people. Sider (1993) explained that:

more than being a core feature of Lumbee political organization, the separate elementary and high schools have been crucial to an Indian cultural and social life: schools and churches are the places where Indians become connected to other Indians. They are not simply the center of the community; in fundamental ways they are the community (p. 71).

Sider explained the importance of the segregated Indian schools to the Lumbee as places where they bound together as a tribe for political action and where they bound as a community. Furthermore, their schools enabled the Lumbee to transmit their cultural 
values, traditions, and heritage. The schools and the cultural identity of the Lumbee were intertwined. In this sense, I contend that education is a cultural characteristic of the Lumbee because achieving separate schools for their education not only benefits the people, but also defines the Indian identity of the Lumbee.

The Lumbee Indians struggle for their own schools helped reify their Indian identity in opposition to their previous categorization as Blacks. Indian schools became a place of cultural, social, economic, and political agency for the Lumbee. Lumbee teachers', administrators', parents', and community members' involvement in the schools perpetuated Lumbee ideals, beliefs, history, heritage, and culture. The Indian schools were places central to the social life of the Lumbee community. As my research participants explained, there were only two places that one could go for socializationthe church and school. Educational and teaching opportunities in the Indian schools increased Lumbee economic opportunities. Teaching was considered secure white collar work. The teaching profession was an alternative to farming for the Lumbee. As a result of this education system, teaching represented a new career opportunity wherein the Lumbee had access to education and could, in turn, become educators themselves in the schools. Thus, education and teaching became synonymous for the Lumbee, just as their excellent skills as farmers had also defined them. Dial (1993) suggested that Lumbee Indians were the most educated of all Native American tribes because of the impact of UNC-Pembroke the former Indian Normal School and the Lumbee segregated Indian schools. 
The schools also provided political agency for the Lumbee because it was through their attainment of their separate schools they became acknowledged as Indians, and through the schools they were able to exert some power (Sider, 1993). Agency was demonstrated by control over who was admitted to their schools and who taught in their schools (Sider, 1993). Furthermore, the Indian schools developed Lumbee leaders who would advocate for the Lumbee socially, politically, and economically (Sider, 1993). Finally, the Indian schools were also tied to Lumbee identity because one of the contemporary criteria of tribal membership is proof of descent from individuals who attended the segregated Indian schools (Pierce, 1987).

Although the 1885 Act to provide for separate schools for Croatan Indians in Robeson County provided separate schools for the Lumbee Indians in Robeson County, the Lumbee remained at a disadvantage. The 1885 Act provided funds to pay teachers to teach in the schools and instructed the treasurer to distribute the school funds evenly, so the Lumbee Indians received their proportional share of the school funds. However, the law did not provide funding for the building of separate schools or for the education of Indian teachers to teach in the schools. Representative McMillan (1888) raised this concern to the legislature on behalf of the Lumbee, resulting in the establishment of an Indian Normal $\mathrm{School}^{20}$ for the training of teachers. This legislation provided $\$ 500$ to pay school instructors, but did not provide for building construction; hence, the Lumbee had to build the school on their own. In 1887, Lumbee school trustees donated $\$ 1000$ worth of materials and labor to build the Croatan Normal School (Dial, 1993). Although initially inadequately funded, the legislature added $\$ 1,000$ to the Croatan Normal 
School's funding in 1889 and the school continued to operate (An act to amend the laws of 1885 and 1887, 1889; Dial, 1993).

In 1890, two years after an unsuccessful request for federal funding, W.L. Moore, an activist for the Lumbee, contacted the Office of Indian Affairs in Washington, D.C. to ask for funding for the education of the Lumbee. Commissioner of Indian Affairs T. J. Morgan responded to Moore based on the information that Hamilton McMillan had provided to him about the Lumbee:

It appears from his statement that this band is recognized by the State of North Carolina, has been admitted to citizenship, and the state has undertaken the work of their education.

While I regret exceedingly that the provisions made by the State of North Carolina seem to be entirely inadequate, I find it quite impractical to render any assistance at this time. The Government is responsible for the education of something like 36,000 Indian children and has provisions for less than half this number. So long as the immediate wards of the Government are so insufficiently provided for, I do not see how I can consistently render any assistance to the Croatans or any other civilized tribes (Pierce, 1987, p. 40).

Morgan's statement reveals the prejudice of the federal government in dealing only with federally recognized tribes. In 1890, T. J. Morgan, one of the highest ranking government officials overseeing the welfare of the Native Americans, proclaimed the education of Indians was insufficiently provided for, yet he was refusing to give funding (Pierce, 1987). The Lumbee (Croatan) tribe was denied financial assistance because they were considered a civilized tribe, and the purpose of federal education for American 
Indian tribes was to 'civilize' them. Although the Lumbee have lost many elements of their culture through encounters with Europeans, intermarriage, and tribal heritage, this process was never planned.

Charles F. Pierce in 1912 echoed the words of T. J. Morgan in denying federal assistance to the Lumbee based on the United States Indian school policy decisions, At the present time, it is the avowed policy of the government to require the states having an Indian population to assume the burden and responsibility for their education, so far as possible. North Carolina, like the state of New York, has a well organized plan for the education of the Indians within her borders, and there does not appear to be any justification for any interference or aid on the part of the government in either case, especially in a prosperous community like Robeson County, North Carolina (Pierce, 1987, p. 54).

The Lumbee sought federal funding again for an Indian School that offered advanced courses for them beyond the Indian Normal School. The other state schools were not open to the Lumbee in 1900, 1912, and then in 1933 (Blu, 2001; McPherson, 1915). In 1933, the federal government insisted that they had no treaties with the Lumbee to provide for their education and were not obligated to provide school facilities (Blu, 2001). Lumbee people had limited means of making a living—as farmers, clergy, or educators in the segregated Indian schools. Separate schools gave the Lumbee access to secure jobs that paid regularly and did not hinder them from continuing to farm or to preach. This enabled the development of a Lumbee middle class of educators (Fuchs \& Havinghurst, 1973). 


\section{Lumbee Opportunities for Higher Education}

The Indian Normal School was once the only institution in North Carolina for the Lumbee to attend. Indian teachers who taught in Indian schools in Robeson County barely had a high school education because there were no high schools the Lumbee could attend (Thompson, 1973). Teachers in North Carolina were certified to teach in North Carolina up until 1917 by successfully passing an examination administered by the county superintendents (The State Educational Commission, 1927). Thereafter teaching certification could be issued according to 1) educational training, 2) state examination, and 3) out-of-state certification (The State Educational Commission, 1927). The certification levels for teachers in North Carolina at the time of the Indian Normal School were high school, grammar grade, primary, elementary, and nonstandard grade (The State Educational Commission, 1927). High school, grammar grade, and primary grade certifications included Class A, B, and C certificates with Class A signifying the highest certificate. Elementary certification included Class A, B, and Provisional Elementary Certification. Certificates of nonstandard grade included classes of one-year temporary and Provisional A and B Certification. The temporary and provisional certification was contingent upon the teachers' continual professional credits earned during summer school teacher training at approved higher educational institutions in North Carolina (The State Educational Commission, 1927). In Robeson County by 1938 twenty-four Indian teachers were college graduates with Class A Teaching Certificates (Thompson, 1973). There were eighty-three Indian teachers who had completed only three years of college and had Class B teaching certification (Thompson, 1973). Eleven Indian teachers had less educational training and held temporary and non-standard certification, but were 
working on their certification credits through summer school (Thompson, 1973). No Indian teachers in Robeson County by 1950 held non-standard teaching certification (Thompson, 1973). Thompson (1973) found that by 1970 Lumbee teachers in Robeson County possessed Class A teaching certifications with the exception of 12 Indian teachers who had Class B Certificates. These teachers held Class B certification because they had not received an adequate score of 950 or better on the National Teacher Examination (Thompson, 1973).

The Indian Normal School enabled Lumbee to become teachers. In 1928, the first class of Lumbee teachers graduated from the Indian Normal School (Thompson, 1973). The elementary classes ended and only the high school and normal school remained operational (Powell, 1970). A full college curriculum was developed in the 1930's, and the first college degrees were conferred in 1940, transforming the normal school into Pembroke State College for Indians (Powell, 1970). This distinction made the college the first state supported college for Indians in the United States (Dial, 1993). Only Lumbee Indians were allowed to attend the college until 1945 when it was open to any American Indians (Dial, 1993). Whites were admitted to the University of North Carolina at Pembroke in 1949, and in 1954 the college was open to individuals of any race or ethnicity (Dial, 1993). The exclusionary nature of the University of North Carolina at Pembroke is in contrast to historically black colleges and universities whose charters were not exclusionary, although the schools were founded for African American students. On June 23, 2005 the University of North Carolina at Pembroke was designated as North Carolina's historical American Indian university (An act designating the UNC-P, 2005). 
Until 1942 the college only offered teaching degrees for the Lumbee; then nonteaching baccalaureate degrees were added to the college in 1942 (History of UNCP, 2005). Thus, if any Lumbee wished to pursue an educational degree other than teaching before 1942 or wished to pursue graduate school they had to leave the area and seek other colleges that would admit them. And even after 1942, if any Lumbee Indians wanted a graduate degree they still had to leave the area for colleges that would admit them. In North Carolina, the state provided institutions of higher education for white and black populations, and these institutions by law were not open to the Lumbee Indians (McPherson, 1915). The Lumbee wanted other career opportunities and to learn different trades. In order to learn trades, some Lumbee Indians attended the Carlisle Indian Industrial School. This is significant because only members of federally recognized tribes attended school there, and the acceptance of the Lumbee in this school was recognition that they were Indian (McPherson, 1915; Pierce, 1987). Although Indian boarding schools offered different career opportunities than teaching, it was not sufficient for the Lumbee who wished to pursue higher educational degrees.

In North Carolina, six public institutions of higher learning were established for non-Whites. Five of these universities were for African American students and they are Elizabeth City State University, Fayetteville State University, North Carolina Agricultural and Technical State University, North Carolina Central University, and Winston-Salem State University (as they are now named). The University of North Carolina at Pembroke was the only institution for Indian students. Remaining public institutions of higher education in North Carolina were for Whites, and non-Whites were not allowed admission into these schools. There was no one law that segregated the 
institutions of higher education in North Carolina, as was provided in the 1875 revision of the North Carolina Constitution to provide for separate schools for white and colored children. Instead, as the North Carolina legislators established/acquired/developed each institution of higher education, the language used within the legislation that established the college also defined who could attend the schools (J.L. Sanders, personal communication, July 15, 2005). In light of the Supreme Court cases of Plessy v. Ferguson $^{21}$ (1896) and Cummings v. Richmond County Board of Education ${ }^{22}$ (1899) which affirmed segregation, North Carolina could prescribe separate but equal with regard to education and legislate who could attend which institution. The University of North Carolina at Greensboro began as a school for white females (Powell, 1970). Some of these institutions began as normal schools, as the University of North Carolina at Pembroke was established as a teacher training school for Lumbee Indians. Others began as private schools and became public institutions of higher education, as with North Carolina Central University which began as a private religious institution for black students and became a public institution for black students in 1923 (Powell, 1970).

Other institutions were affected by federal legislation, as was North Carolina Agricultural and Technical State University (NC A\&T) and North Carolina State University (NCSU). Specifically, NC A\&T began as the public agricultural and mechanical school for black students (Powell, 1970). North Carolina Agricultural and Technical State University was established and funded in 1891 in response to the Second Morrill Act (Powell, 1970). NC A\&T was known then as the Agricultural and Mechanical College for the Colored Race (Powell, 1970). The Second Morrill Act 1890 gave equitable funding to establish and maintain land grant institutions for teaching 
agricultural and mechanical arts for white and colored students. Additionally, the 1862 Morrill Act funded North Carolina State University established in 1887 and opened in 1889 as the North Carolina College of Agriculture and Mechanic Arts (Powell, 1970). The Second Morrill Act stated, complete endowment and maintenance of colleges for the benefit of agriculture and mechanic arts now established or which may be hereafter established. . (1) Provided, (2) That no money shall be paid out under this act to any State or Territory for the support and maintenance of a college where a distinction of race or color is made in the admission of students, but the establishment and maintenance of such colleges separately for white and colored students shall be held to be a compliance with the provisions of this act if the funds received in such State or Territory be equitably divided as hereinafter set forth: Provided, That in any State in which there has been one college established in pursuance of the act of July second, eighteen hundred and sixty-two, and also in which an educational institution of like character has been established, or may be hereafter established, and is now aided by such State from its own revenue, for the education of colored students in agriculture and the mechanic arts, however named or styled, or whether or not it has received money heretofore under the act to which this act is an amendment, the legislature of such State may propose and report to the Secretary of Education (3) a just and equitable division of the fund to be received under this act between one college for white students and one institution for colored students established as aforesaid which shall be divided into two parts and paid accordingly, and thereupon such institution for colored 
students shall be entitled to the benefits of this act and subject to its provisions, as much as it would have been if it had been included under the act of eighteen hundred and sixty-two, and the fulfillment of the foregoing provisions shall be taken as a compliance with the provision in reference to separate colleges for white and colored students (An act to apply a portion of the proceeds, 1890, p. 417).

Thus, under the Second Morrill Act of 1890, states were able to receive federal funding only if race or color was not a part of the admission requirements, or else the states had to establish separate but equal institutions for black students. This act is another example of segregation and higher education that influence higher educational institutions in North Carolina.

Explicit legislation was not always a factor in the segregation of higher institutions. In the case of the University of North Carolina at Chapel Hill, it was the university trustee policy to exclude black students, and although there was not a statute excluding black students, the policy had the same effect as law (J.L. Sanders, personal communication, July 11, 2005; Sanders, 1993). This policy changed in 1951 when the first black students were admitted to the University of North Carolina at Chapel Hill (Snider, 1992). In 1957, the language of racial exclusion was removed from the legislation for all the public universities of North Carolina (J.L. Sanders, personal communication, July 15, 2005). For example, "The primary purpose of Pembroke State College shall be the undergraduate education of the Lumbee Indians and other persons who may be admitted under uniform regulations of the Board of Trustees (An act repealing articles 2 through 9, 1957, pp. 1091-1092).” 
Before 1951, the Lumbee as taxpaying citizens of North Carolina could not attend these public universities because they were neither white or black. These institutions only recognized white or black racial categories, and most Lumbee were reluctant to 'pass' as black and preferred not to attend institutions for black students. Some Lumbee successfully gained admission and attended white colleges in North Carolina such as Duke University, Wake Forest University, University of North Carolina at Chapel Hill, University of North Carolina at Greensboro, and Western Carolina University in their pursuit of graduate degrees (Blu, 2001; J. W. Currie, personal communication, July 1, 2005; L. Oxendine, personal communication, July 5, 2005). It is possible that the Lumbee who attended these white colleges "passed" for white and did not acknowledge they were Lumbee because they would not have been admitted to these colleges. Other Lumbee, like many African Americans, however, were denied admission to white colleges in North Carolina and thus had to pursue their graduate education at universities outside of North Carolina at institutions such as the University of Georgia, the University of Michigan, Ohio State University, University of South Carolina, and George Peabody College (Blu, 2001; Harris, 1958; W.M., personal communication, October 11, 2001; W.L. personal communication, October 21, 2001; Richard, personal communication, November $10 \&$ 15, 2004; J. W. Currie, personal communication, July 1, 2005). One of my Lumbee research participants explained that at the University of Georgia he was documented on school admission records as white because they didn't have a category for American Indians (Richard, personal communication, November $10 \& 15,2004$ ). He never denied his Lumbee Indian heritage in gaining admission to the school, but the school classified him as white so he could attend there. 


\section{Lumbee School System}

Although the Lumbee had limited higher educational opportunities, the Lumbee Indians had separate primary and secondary schools in both Robeson and Hoke counties where they were part of a tri-partite (white, black, Lumbee) school system in each county, respectively. This tri-partite system was a result of the 1875 revision of the North Carolina Constitution to provide separate schools for white and non-white children. The North Carolina Constitution was further amended in 1923 to include reference to the Lumbee or as they were referred to as Croatan Indians at the time,

The children of the white race and the children of the colored race shall be taught in separate public schools, but there shall be no discrimination in favor of or to the prejudice of either race. All white children shall be taught in the public schools provided for the white race, and all colored children shall be taught in the public schools provided for the colored race; but no child with negro blood, or what is generally known as Croatan Indian blood, in his veins, shall attend a school for the white race, and no such child shall be considered a white child. The descendants of the Croatan Indians, now living in Robeson, Sampson, and Richmond counties, shall have separate schools for their children (An act to amend the consolidated statutes, 1923, p. 311). 
The Lumbee schools in Robeson and Hoke County were both under boards of education that were white controlled. Furthermore, these Indian schools and the Indian Normal School were under the state supervision of the Division of Negro Education. This supervision and categorization under the Division of Negro Education was an affront to the Lumbee, and they pressured to have the Indian school records kept separate (Sider, 1993). The act was not approved to keep the entire records separate at the state level, but only at the county level,

The County Superintendent in and for Robeson County shall keep in his office a record of schools for the Cherokee Indians of Robeson County, which said record shall disclose the operation of such schools, separate and apart from the record of the operation of schools for the other races (An act to amend section five thousand, 1931, p. 181).

In 1931, the Lumbee were referred to as Cherokee Indians of Robeson County.

The Indian school system in Robeson County was the last of the three systems to be developed (white, black, and Indian) (Massey, 1996). Of the three systems in Robeson County, Indian teachers were paid the lowest salaries and had the fewest number (Massey, 1996). The school buildings were smaller and the construction did not compare to the quality of the white schools. There were fewer textbooks available to the students in the Indian schools compared to white students. Even given the inequities between the white and Indian schools, research shows that the black schools' condition was worse in comparison to the conditions of the white and Indian schools in Robeson County. 
Hancock (1935) conducted a study of the three school systems in Robeson County. His findings showed that the black schools suffered the most from inequities. There were 32 school buildings for Indians and five were of brick construction compared to 3 brick structures of the 55 black school buildings (Hancock, 1935). Hancock (1935) considered the buildings of the black schools old and poorly constructed compared to Indian and white schools. Most of the black schools in comparison were one room schools with light and heat provisions. In evaluating the teaching resources and equipment, Hancock (1935) found that both Indian and black schools were poorly equipped compared to the better equipped white schools. All of the Indian and black schools and most of the white schools suffered from overcrowding (Hancock, 1935). The county attempted to address the overcrowding by manufacturing crude desks for the black and Indian schools, but Hancock (1935) did not find any of these crude or second rate desks in the white schools.

In his research, Hancock (1935) found that the school buses that transported the Indian and black students were old, in need of repair, and were unreliable, resulting in students' inability to get to school on time-thus missing instruction. There were fewer numbers of black students who were bused and had access to buses in comparison to their Indian and white counterparts (Hancock, 1935). In the available faculty in the Robeson County schools there were fewer Indian teachers: there were 181 white teachers, 94 Indian teachers, and 162 black teachers (Hancock, 1935). 
The black schools in Robeson County had lower enrollments and monetary value than Indian schools as shown by the Robeson County Board of Education Annual Statistical Report for the years 1951-1952. According to the report, black schools were valued at $\$ 738,040$ with an enrollment of 3,319 students thus the per pupil expenditure was \$222.37 (PSRCBE Minutes; Thompson, 1973). Indian schools were valued at $\$ 2,090,360$ with an enrollment of 7,910 thus $\$ 264.27$ per pupil expenditure (PSRCBE Minutes; Thompson, 1973). The inequalities of resources to the Indian and black school systems with the same white school board leadership is comparable to the inequalities expressed by research on the segregated African American schools and was the impetus for the Brown v. Board ${ }^{23}$ (1954) case.

In the late $19^{\text {th }}$ Century, the responsibility for funding schools in North Carolina and in Robeson County was the responsibility of the county with some assistance from the state (Lefler \& Newsome, 1973). The North Carolina legislature had passed the Public Law of 1869, which provided for a free public school system for students aged six to twenty-one for a four-month school term (Lefler \& Newsome, 1973). This system was to be paid for by the counties, enforced by the indictment of the county commissioners if they did not provide public schools for a four-month term (Lefler \& Newsome, 1973). The financial support for the schools would come from county poll taxes and property taxes with supplemental funding from the state. The State Board of Education was responsible for managing the school funds with the state superintendent apportioning to counties their share of the school funds (North Carolina Department, n.d.). Lefler and Newsome (1973) argued that North Carolina's educational law would have established an excellent state school system if it would have been enforced and if the tax revenue had 
been sufficient. Poor political leadership in educational improvement, a climate of indifference to public schools, and a tax-hating voting population were to blame for the educational deterioration in North Carolina where there should have been growth.

The climate of indifference to public schools was reinforced by southern planters' efforts to block universal public schooling because of their fear of the loss of their black and poor white laborers upon which their agrarian way of life depended (Anderson, 1988). They feared that educational opportunities would make the black and poor white labors unfit to be exploited as cheap farm labor. Middle and lower class Whites depended on the southern planters so they did not go against the wishes of the southern planters in striving for universal public education (Anderson, 1988). Upper class Whites sent their children to private schools; they were less inclined to spend their tax dollars in educating the masses. However, Blacks pursued universal public school education. Freedmen viewed the pursuit of education as an expression of freedom and believed it was a basic right (Anderson, 1988). Thus, the universal public school system in the South is a result of the efforts of African Americans' pursuit of education. With this climate concerning education, southern planters sought to control the education of Blacks in order to control them. One of the ways that they controlled the education of Blacks was through the shortening of school terms. Southern planters depended heavily on child labor. Thus, black schools had shorter school terms in the years when the crops were abundant (Anderson, 1988). North Carolina relied heavily upon agriculture and southern planters were economically and politically powerful. Thus, the influence of southern planters impacted the educational progress of public schools in North Carolina. 
State Supreme Court decisions also contributed to the decline of education in North Carolina. The court forbade counties to collect any taxes for the schools beyond the combined county and state property taxes of 66 and 2/3 cents per 100 dollars of property value and the poll tax of $\$ 2.00$ (Lefler \& Newsome, 1973). Thus, without the means to gain additional revenue, it was difficult for counties to maintain a four-month public school system (Lefler \& Newsome, 1973). However, in 1907 the decision was reversed by the state Supreme Court. They gave county commissioners the right to levy taxes beyond the $662 / 3$ cents on $\$ 100$ valuation of property, if necessary, to maintain the schools for the required four-month school term (Lefler \& Newsome, 1973). Also, in 1913 the General Assembly levied a state property tax of $5 \notin$ on $\$ 100$ property value which enabled the state to lengthen the school year to a six month term (Lefler \& Newsome, 1973). The General Assembly also improved the compulsory school law requiring children aged 8-12 to attend school for four months out of the year (Lefler \& Newsome, 1973). In 1918 the school term was extended state-wide to a six-month term, but not until 1931 did the state take responsibility for funding the six-month term (Lefler \& Newsome, 1973). Then, in 1933, a 3 percent general sales tax enabled the state to further financial support to the public schools and extend the school term to eight-months (Lefler \& Newsome, 1973).

Although there were improvements in education and the schools for North Carolina in general, there were still inequities. Specifically, black school buildings and resources were still unequal in comparison to the white schools and the resources provided for them. In state and county records, the Indian schools were included in the records of the black schools. Hancock (1935), Thompson (1973), and Massey (1996) 
showed the inequities present in the Indian schools in comparison to the white schools. What is telling about the system of inequities in North Carolina is that the leadership of the white, black, and Indian schools were by law under the State Board of Education and were under the supervision of the state superintendent. In 1903, the General Assembly required that all schools receiving state funds were to submit reports to the county and state superintendent (North Carolina Department, n.d.). County boards of education were to submit reports of "amount of funds available from local sources, student enrollment, and average daily attendance figures" (North Carolina Department, n.d.). The state superintendent then submitted the figures from these reports to the State Board of Education, and this informed their apportionment of funds to the school districts (North Carolina Department, n.d.).

The Public Schools of Robeson County Board of Education minutes included reports which detailed sources of funds such as the following: (1) county property taxes; (2) the state public school fund; (3) general state and county poll tax; fines, forfeitures, and penalties; (4) the Rosenwald Fund; (5) miscellaneous state funds; (6) local taxes; (7) private donations; (8) the sale of school resources and property; (9) bank interest; (10) and borrowed money. Robeson County's earliest financial and statistical report of July 1, 1921 to June 30, 1922 to the State Superintendent is seen in (see Appendix D). In the financial and statistical report, the category for Indian schools was created by typing in the information since the document only provided for white and black schools. Also noted in the financial report are the expenses of the Indian Normal School. In the general statistics of the report, the average days in school term for all the Indian schools was 119 days which were a few shorter than the average 121 days for all the black schools. On 
the other hand, all the white schools averaged 137 days in the school term. The difference in the school terms could be due to the impact of agricultural needs for child labor to harvest crops. Additionally, the difference in the school terms could be attributed to the inequitable funding of these schools which is impacted by the cost of maintaining the schools and the teachers' salaries.

In 1921, the black and Indian schools were under the leadership of the Division of Negro Education - a newly created division by the State Board of Education (North Carolina Department, n.d.). The Division of Negro Education was supported by additional out of state grants such as the General Education Board Fund ${ }^{24}$ and the Rosenwald Fund $^{25}$ (North Carolina Department, n.d.). From 1906 to 1928 the General Education Board, the Rosenwald Fund, the Jeanes Fund ${ }^{26}$, and the Slater Fund ${ }^{27}$ greatly impacted the black schools by providing additional funding in the amount of $\$ 1,877,000$ to promote the education of the black population (Lefler \& Newsome, 1973). Although the Public Schools of Robeson County Board of Education minutes do not detail the expenditures of these funds to the Indian schools and the black schools specifically, the funds were a nominal additional support. Further letters and documents from the Division of Negro Education demonstrate their appropriation of funds to Indian schools. Such documents are the letters from the Director of the Division of Negro Education N.C. Newbold and the State Superintendent A.T. Allen concerning the appropriation of $\$ 30.000$ in 1923 for the building of Indian schools in Robeson County (see Appendix E) (Newbold \& Allen, 1923). 
By 1970, all Indian schools in North Carolina had ceased to operate except for those in Robeson County which were among the last schools in the nation to be formally desegregated (Massey, 1996). The Lumbee vehemently opposed desegregation in Robeson County through protests and sit-ins at the former Indian schools. One reason the Lumbee fought segregation had to do with internalized racism which Massey (1996) describes as Native American racism targeted against Blacks.

Ironically, although the Lumbee were discriminating against Blacks. The Lumbee fight to retain segregated schools was their way of combating racism against themselves, and an effort to protect their identity. The late Dexter Brooks, one of the first Lumbee appointed to serve as a superior court judge in Robeson County, explained in an interview that the schools protected the Lumbee:

Indians avoided the worst aspects of racism during the $\mathrm{Jim}_{\mathrm{Crow}^{28}}$ era by literally creating their own communities ... many communities were self-contained ... when I was a kid you could go weeks without coming in contact with a nonIndian . . . back then it was an advantage because you avoided all the racism (Massey, 1996, p. 100).

Schools enabled the Lumbee to preserve their distinct cultural traditions, which they feared would be lost through desegregation (Massey, 1996; Thompson, 1973). 


\section{Cherokee, Coharie, Sappony, Waccamaw Siouan, Haliwa-Saponi Indian Tribes}

In 1885, North Carolina had two recognized tribes of Native Americans: (1) the federally recognized Eastern Band of Cherokee and (2) the state recognized Lumbee Indians. The Lumbee Indians' successful struggle for state recognition as an Indian tribe set the precedent for other unrecognized Indian tribes in North Carolina to validate their Indian identity and to secure their own schools (Lerch, 1992). Many unrecognized Indian tribes such as the Sappony, the Cohaire, and the Waccamaw-Sioux endeavored to designate themselves as Croatan Indians in order to fund their Indian schools (Lerch, 1992; Massey, 1996). The Sappony Indians, historically known as Person County Indians, successfully petitioned for state recognition as Indians in 1913; and they successfully advocated for a school of their own from the Person County Board, the High Plains Indian School (Massey, 1996). Later, the Coharie Indians followed suit by gaining recognition and securing their own Indian schools in New Bethel and East Carolina (Jackson, 2004). The Waccamaw-Sioux had a more difficult struggle for recognition and separate Indian schools, and did not gain Hickory Hill School until 1933 (Lerch, 1992; Massey, 1996). Haliwa-Saponi Indians did not receive state recognition and have their own separate school until 1957 (Massey, 1996). The Haliwa Public School was closed in 1970 because of desegregation (Massey, 1996), the school reopened in 2000 as the Haliwa-Saponi Tribal School (American Indian Education, 2005). The Cherokee, Cohaire, Sappony, Waccamaw Siouan, and Haliwa-Saponi are not the only Indian tribes in North Carolina, but they are the Indian tribes that had separate Indian schools prior to desegregation. Other Indian tribes in North Carolina include the Meherrin, who were 
recognized by the state as an Indian tribe in 1986, and the Occaneechi Band of Saponi Nation who were the last Indian tribe to gain state tribal recognition in 2002.

An oral history of the Lumbee adds to the American Indian education literature by documenting the educational experiences of a state supported tribe who advocated for their own separate schools. The oral history documents the complex social, cultural, and historical reasons the Lumbee wanted separate schools, including gaining and maintaining their identity as Indians. Lumbee oral history gives another example of a tribe using education to sustain their culture as Cobb (2000) documented in her oral history of the Bloomfield Academy. Furthermore, my research will enhance American Indian educational history in North Carolina by going beyond the history and establishment of schools in Robeson County for Lumbee Indians (Blu, 2001; Dale, 1986; Dial, 1993; Dial \& Eliades, 1975; Massey, 1996; Thompson, 1973) to examining the Lumbee Indians' personal experiences in these schools.

This review of literature has provided a historical context for understanding the Lumbee Indians and their schools. Research of the segregated experiences of African Americans and Native Americans were examined. This examination demonstrated the gaps in the literature that are addressed through oral history research on the Lumbee Indian educational experience. The next chapter is a discussion of the methodology of my research. 


\section{CHAPTER 3}

\section{TOOLS TO RESEARCH THE INDIAN SCHOOLS}

They [the Lumbee] are classed as good citizens, are quite industrious, law abiding, and, to repeat an expression used by the county superintendent of schools, 'Are crazy on the subject of education' (Pierce, 1987, p. 53).

\section{Data Sources and Data Collection}

My research uses Lumbee oral history as the main source of data to examine their personal experiences in the segregated Indian schools. I document Lumbee educational experiences as either students, teachers, or administrators in Indian schools as well as their desegregation experiences. This in-depth exploration is beyond the anecdotal evidence Chavis (1986) briefly mentioned in his quantitative survey of the recollections of Lumbee participants' perceptions of their teacher-student relationships. Qualitative research is necessary because such research reveals more about the experiences of the Lumbee in the segregated schools and helps in understanding how they were supported in these settings. This information yields a context for examining what prevalent situations exist in integrated settings. In-depth interviewing was the primary data-gathering methods for my oral educational history (Marshall \& Rossman, 1999). I used my interview guide (See Appendix B) to facilitate conversation with my participants to learn more about their significant experiences in the segregated Indian schools in Robeson or Hoke Counties. 
In addition, I reviewed archival data to supplement the data gathered from my participants' oral educational histories (Marshall \& Rossman, 1999). The primary documents used in this study were (1) North Carolina legislation, (2) Board of Education minutes, (3) newspaper articles, (4) dissertations about Lumbee Indians and their schools, and (5) letters related to the segregated schools. I conducted research for primary and secondary archival data from (1) the North Carolina State Archives in Raleigh, (2) the North Carolina Collection in the Wilson Library at the University of North Carolina at Chapel Hill, (3) the Lumbee Collection at the University of North Carolina at Pembroke, (4) the Public Schools of Robeson County Board of Education (5) the Public Schools of Robeson County Indian Education Resource Center, (6) the Hoke County Board of Education, and (7) the Hoke County Public Library.

Secondary archival data sources that I used were (1) contemporary records concerning the Indian schools from newspaper articles from the News Journal, (2) the Robesonian, and (3) the Fayetteville Observer, (4) pictures of the Indian schools obtained from a compilation CD from the Public Schools of Robeson County Indian Education Resource Center and (4) the Hoke County Public Schools website. In addition I included my own photographs. These archival sources were used to enhance my study, because the majority of my data was gleaned from the oral educational histories of my participants. 


\section{Method of Inquiry}

Oral history is the method of inquiry most appropriate for my research. Oral history allowed me to gain evidence about the segregated Indian schools in Hoke and Robeson County from the memories and the personal narratives of individuals who experienced the details of history first hand (Ritchie, 2003; Thompson, 2000).

\section{Oral History Rationale}

The reliability of historical data gleaned from oral history interviews is sometimes questioned. Some concerns about reliability are the subjectivity of the participants and the substance of the oral evidence to reconstruct the reality of the past. As with other sources of data, whether documentary, experimental, or statistical, there are issues of bias and subjectivity in oral history. Oral history involves the participants in understanding their past. Scholars recognize the reality that bias cannot be eliminated, but bias may be addressed to minimize its effects. The reality of the past cannot be reconstructed and known in oral history in the same manner in which quantitative research purports to describe and explain the known world/reality through objective experimentation or statistical means. On the other hand, oral history is a valid methodological choice for my research because it yields unique data from the past, conveys individual and collective memories of the past, and conveys the living humanity of the past (Thompson, 2000). Through the oral histories that my participants shared this enabled access to their individual memories of education in the Indian schools. The rich memories of my participants about their experiences in the Indian schools are what has been missing in the research on the Lumbee Indian schools. Previous research has documented the establishment and history of the Indian schools. My use of oral history to delve into the 
memories of those individuals who experienced education in the Indian schools places a humanizing lens in viewing historical facts of these schools. The richness of my respondents' oral histories in describing the Indian schools is in contrast with the detached researcher's documentation of the history of the Indian schools. In addition, oral history data may enhance and supplement evidence gained from other sources (Thompson, 2000).

The oral evidence from participants also gives subjective and reflective perspectives about the history experienced. Researchers who have explored the segregation experience have successfully used oral history to delve into the subjective and reflective experience of individuals who have experienced this time in history. Wilson (1997) utilized oral history in her research to get the memories of her participants' unique experiences as black and white cross-over teachers who were part of the Austin Texas Independent School Districts' desegregation solution. Their oral histories yielded subjective and reflective experiences about their experience during segregation and desegregation. Their experiences also describe how they remembered that time and gave such a vivid experience of what it was like for them in a way that the facts alone could not capture. Walker (1996) used oral history to delve into her participants' memories about CCTS to find what they valued about this segregated school. She wanted their subjective and reflective views on the school. Hessling (1993) also used oral history to research his participants' subjective and reflective views of their segregated schools as "good schools." These researchers have successfully employed oral history to document the subjective and reflective perspectives of their participants. The data they found not only went beyond mere facts, but also gave a richer description 
of what it was like for their participants who experienced segregated education at that time. In a like manner, I use oral history to document my participants' experience of education in the Indian schools beyond the facts of the history of the Lumbee Indian schools that have been documented. My participants' subjective and reflective perspectives are the experience of the Indian schools and how they remember those Indian schools, which I wish to research and document.

Additionally, oral history allows a researcher to interact with their participants in the process of learning about the past because their participants are living sources, allowing for an interaction that no other source provides (Thompson, 2000).

\section{Oral History and Memory}

In oral history, several factors may affect memory, such as mental distortion; gender; age; culture; social collective memory; and past preservation or distortion of memory (Schwartz, 1996). Memory is limited. The past cannot be perfectly reconstructed because memories fade over time. Moreover, the mind is not a passive computer which perceives and then objectively files information and experiences. The process in which the mind creates memories is an active process made from numerous tiny associations (Thelen, 1989). Memories are created and stored systematically as evidenced by the memories' capacity to reconstruct other memories (Halbwachs, 1992). As events and experiences intersect within perception, this process affects the recall and contexts of how those memories are stored in the mind (Schwartz, 1999). Lowenthal (1985) argued that narratives are how all those, "contingent and discontinuous facts of the past become intelligible only when woven together as stories" (p. 218). In this manner, the mind archives and coherently orders memory through narratives. 
However, factual accuracy is not the goal of the narrative framework the mind uses to order memories (Gardner, 2003). Inevitably, some data reside in the narratives while some data are left out of the narratives individuals tell. Oral history involves probing the memory in order to locate data that may be left out of the narratives. Gardner suggests that in the editing of the stories of which the mind creates the narrative, some parts of memory may go unexplored and untold in the narrative due to the pattern of the mind in remembering, reinterpreting, and retelling. Other parts of the memory may go unexplored because it is unpleasant to remember and may be blotted out. Thus, a researcher may take the narrative as a place to start and then ask their participants questions to probe specifically into their memory about more detailed information about the past. In this way, oral historians are engaged in listening to the narratives of their participants as well as probing their participants' narratives through questioning. Both the participant and the interviewer are engaged in historical understanding in an effort to connect with the past in order to explain and interpret it (Gardner, 2003). Most important in understanding the effect of the cognitive distortion on memory is that the mind does not reproduce the past in recollections. The mind reflects, orders, and processes experiences through the narrative framework. In my research, I employed this exercise of probing more deeply to get to my participants' experience in the Indian schools. In fact, most of my participants would preface their statements by stating, "I haven't thought about this in years." 
Memories may have narrative frameworks in their construction, but there is a subjective and social context to their creation. Bodnar (1989) explained that some scholars have argued that oral histories contain previously told stories that are a part of public discourse; thus, these stories are shaped by individual, community, and hegemonic perspectives. Specifically, he asserted that certain historical and social agents have exerted more power in shaping these stories (memories). Thus, oral history reveals more than facts. Oral history reveals the conceptual frameworks that participants use in remembering past events. This is important for me to be aware of in my research because of the collective memory in the Lumbee community of "how everything was better when we had our own schools." I understood that this could impact my participants' memories of their experience in the Indian schools. In Hessling's (1993) research he noted his participants' fond remembrance of their schools despite the unpleasant experiences they conveyed in their memories. Thus, it is important for the researcher to be aware of how the participants' organized their memories of that experience.

\section{Memory and Age}

Other factors that impact memory are age, gender, and culture. While research has shown that from age 11 through adulthood, short-term memory begins to decline, this reduction in short-term memory does not affect the memory's storage capacity (Thompson, 2000). According to Thompson (2000) after age 30 short-term memory slowly declines, but this decline of memory is not a concern to oral historians because there is no difference in memory when interviewing younger adults or older adults who are healthy. Thompson (2000) cites the research of Butler in describing the final significant development of memory, the life reflection stage. In this stage, as people 
grow older they are engaged in reviewing their past and they have a strong desire to remember the past whether they are asked about their memories or not (Ritchie, 2003; Thompson, 2000). The elderly in this stage have such a willingness to remember they reveal many aspects of their life they have never told before, and they tend to reveal these memories regardless of their audience (Ritchie, 2003; Thompson, 2000).

Given the nature of my research with individuals who are elders of the Lumbee community, my participants' capacity to recall and the accuracy of their memories of the Indian schools could be questioned. However, research supports interviewing the elderly for their oral histories. Ritchie (2003) explained that interviewing the elderly creates a mutual benefit wherein the oral historians gain valuable data. The elderly receive positive gains in self-esteem through sharing their memories with individuals who are eager to listen. In interviewing the elderly, the interviewer does need to be aware that recalling names and places may be difficult (Ritchie, 2003). Thus, interviewers must address this problem in the research and their preparation of questions that will support their participant's recollections. These strategies can be applied to interviewing people in general and include conducting excellent preparatory research and having well constructed questions. In my research, I did gain valuable data from my participants. They were grateful that I was interested in and valued their memories of the Indian schools. Frequently some of my participants did not remember some vital components of their segregated educational experience. Consequently, I used probing questions to get at more specific details. 


\section{Gender and Culture Impacts Memory}

Gender and culture both affect memory, and most oral historians have marginalized the voices of women and people of color (Gluck \& Patai, 1991). Many women and people of color have responded through engaging in oral history to record experiences and perspectives which are generally missing from history. My research is an effort to record Lumbee Indian experiences and perspectives about segregation, which are missing from educational and Indian history. Culture is reflected in the community and the social environment of people, and culture shapes memory. The social context will be discussed in further detail later; the gender impact will be explained next.

Gender and culture are aspects of identity, and both shape individual memories. The dominant culture privileges males. Consequently, the memories of females and males reveal how this privilege is internalized through individual recollection (Thompson, 2000). Differences in memory regarding gender are evidenced in the way memories are recalled and the context of the memories.

Females tend to have more detailed memories than males. The memories of females have a social, emotional, and relational context (Fivush \& Buckner, 2003). Also, females tend to easily talk about their memories (Thompson, 2000). Researchers have found that the memories of females are focused on their relationships with others as their family, their memories are more emotionally focused than males. Females downplay personal accomplishments in order to emphasize the accomplishments of their family members (Fivush \& Buckner, 2003; Sangster, 1997; Thompson, 2000). As a result of the focus on relationships with others in lieu of a focus on self, when females remember they avoid using a first person singular view point, and often refer to others as "we" or "me 
and my friends" (Sangster, 1997; Thompson, 2000). Female focus on family is so embedded in their memories that their family's development serves as benchmarks for their memories (Sangster, 1997).

Conversely, male memories are characterized by a focus on their work, their goals, and their self-directed actions (Thompson, 2000). Male memories contain fewer references to others, refer less to emotion, and tend to use the first person singular point of view (Fivush \& Haden, 2003; Thompson, 2000).

Fivush \& Haden do warn that most research done on the impact of gender and memory has been done with the dominant population. Sangster does note that French women were the subjects of some of the research findings on the differences in women's memory. Thompson, however does not elaborate as to the cultural population that is the source of his findings on the differences in gender and memory. Nevertheless, we are unaware of whether this difference in gender and memory is a common finding among men and women of the dominant population or the non-dominant population.

Studies have shown that there are variations in memory across culture ${ }^{29}$. Leichtman et al. (2003) warn that cultural differences in autobiographical memory cannot be equated with gender differences because patterns of gender and cultural differences are inconsistent. However, despite culture differences, women in general tend to clearly recall and greatly value personal event memories more than men (Leichtman, Wang, \& Pillemer, 2003). 
In my research with the Lumbee Indian population, I had three female respondents and three male respondents. I did not note a remarkable difference in the use of the first-person point of view among my participants. However, I did note that more of my female respondents spoke in more detail about their emotions related to their memories than did my male respondents. All of my informants spoke in great detail about relationships specifically about their family, the community, and the school. Female and male respondents with the exception of one female respondent spoke freely about their accomplishments.

Gluck \& Patai (1991), Honig (1997) and Sangster (1997) have argued that oral history is a feminist methodology because through oral history women's voices are placed at the center of historical research and gender is seen as another form of analysis. Feminist researchers insist that although the magnification of the marginalized voices of women is accomplished through their oral narratives, these are memories and are not factual truths, but are the recollections of their past (Gluck \& Patai, 1991; Honig, 1997; Sangster, 1997). However, an oral historian understands that these recollections of the past might be factual, but the focus is on the complexities of remembering and their participants' perceptions. The impact of gender in understanding how and why women construct their memories, as they do, is part of the social context of memory. This social context of memory is another aspect of memory that was important for my increased awareness and understanding of my participants' experiences in the Indian schools. 
In understanding the social context of memory, there is a consideration of the impact of the collective community. The collective community impacts the social context of memory at an individual level and at the level of the individual's membership within the larger community. At the individual level, the social context of memories are shaped by what individuals are told about their pasts by their elders' and parents' recollections as well as the effect of the shared memories that their communities hold (Schwartz, 1996). Such significant others as elders, parents, or spouses shape memories of the past through their recalling of people and events that may have been forgotten (Zerubavel, 1996). One example of the impact of the social environment upon memory can be seen in parents telling their children how they were born. Another example would be a spouse's correction of their partner's memory through reminding them of a place or event they had forgotten. This social context is, in essence, a filter of memories and affects the facts that are recalled from memory (Zerubavel, 1996). In my research, two participants were aided in the recall of their experiences by the correction of a spouse or a child. This assistance helped to stimulate my participants' memories.

Although the memories that are distinctly personal have been discussed at the individual level, at the community level are memories that are exclusively shared with others. These memories are shared within the collective community memory and may not be found outside the community. Thus, these collective memories form the social environment that affects memory (Zerubavel, 1996). The social environment shapes memory of the past referred to as social or collective memory. Social or collective memory is not objective and transcends personal subjectivity because it has been experienced by others (Zerubavel, 1996). As a result, collective memories not only 
influence, but determine individuals' memories and serve as expressions of collective identity (Thompson, 2000). Thelen (1989) explained that, "memory, private and individual as much as collective and cultural, is constructed, not reproduced. . .this construction is not made in isolation but in conversations with others that occur in the contexts of community, broader politics, and social dynamics" (, p. 1119).

In Thelen's (1989) explanation of collective memory, he expanded upon the collective memory research claims of Halbwachs (1980) that individuals may look to others to check their recollections for accuracy. Thelen asserted that in these collective constructions of memory the input of others is involved in the selection of which recollections to remember and in the interpretation of experiences and events. Through this social construction of memory, people develop a collective identity through their efforts in "identifying, exploring, and agreeing on memories" (Thelen, 1989, p. 1122).

Collective memory can be problematic due to the dependence on others in constructing memories. The social context of memory here illustrates a need to please the individuals with whom the memories have been discussed. Conversely, there is another competing need to verify with others the accuracy of their recollections (Thelen, 1989). Understanding the social context of memory is important in conducting oral history to prevent the dismissal of a participant's recollection that is not factually accurate. The oral historian's concern then is directed toward exploring why the participant constructed this recollection in that particular manner, at that particular time, as well as the social impact in the construction of that memory (Thelen, 1989). 
The social impact of memory construction raises the concern of the reliability of oral history. Again, memory is not objective, and the past cannot be reconstructed. Although it is possible to reconstruct past events with oral evidence, this is not the focus of oral history (Thompson, 2000). Oral history is more than the events and actions of the past, but is concerned with how these events and actions are remembered in the memories and imaginations of those who experienced the phenomena (Thompson, 2000). Those memories are equally as important as what actually happened. However, the oral historian can address the reliability of the oral evidence of his participants in several ways. The oral historian can consider the internal consistency in the data from participants (Thompson, 2000). In addition to oral evidence, other data sources can be utilized for corroboration (Thompson, 2000). Most importantly, the oral historian accepts that the evidence is imbued with subjectivity and does not view subjectivity as a distortion of data. In fact, as Portelli (1991) argued, discrepancy between fact and memory ultimately enhances the value of the oral sources as historical documents. It is not caused by faulty recollections. . .but actively and creatively generated by memory and imagination in an effort to make sense of crucial events and of history in general (, p. 26).

Oral evidence yields invaluable data that, "tell us not just what people did, but what they wanted to do, what they believed they were doing, and what they now think they did" (Portelli, 1991, p. 50). Thus, in my oral history research again it is not only the factual events of the Indian schools history that are important, but also it is those subjective aspects of their historical experience that are important as Portelli described. To use Portelli's phrasing, I wish my research to describe my participants' reflections on their 
experiences in the Indian schools as to what they wanted to do in the Indian schools, what they believed they were doing in the Indian schools, and how think they did in the Indian schools. Therefore, oral history is an appropriate methodology for me to inquire about my participants' educational experience in the segregated Indian schools not only for the factual information about their past experiences, but also their subjective memories of what that experience was like for them as collective Lumbee Indians.

\section{Oral History and My Research}

Participants in my research helped reconstruct what their educational experiences were like from their multiple perspectives. I chose six individuals who represented the points of view that were missing from the historical documentations of the segregated schools: two students, two teachers, and two administrators, one of each from each county (Hoke and Robeson), respectively.

The personal experiences of my participants, as conveyed through their oral educational histories, also enhances what is known in the history of education and has the potential to challenge or affirm assumptions held about Native American education and the education of students in North Carolina. Furthermore, through using oral history I am preserving the vanishing experiences of Lumbee administrators. Lumbee administrators as elder members of the Lumbee community, were few in numbers or availability to participate in my research. Their participation in my study was essential because of their valuable experience in the segregated Indian schools as former students, teachers, and as administrators. Oral history is qualitative research and quantitative concerns of the representativeness of a small sample of two administrators are not the focus of this study. As a oral history qualitative study the focus is not on the generalizability of the findings 
of my study with such a small sample to a larger population. The focus in oral history is not representativeness or reliability, but it is validity in selecting those individuals who are knowledgeable because of their proximity to the phenomena of study as participants and direct witnesses (Thompson, 2000). Thompson (2000) used the argument of Herbert Blumer to illustrate the importance of validity: "a half dozen individuals with such knowledge constitute a far better 'representative sample' than a thousand individuals who may be involved in the action that is being formed but who are not knowledgeable about that formation" (p. 151).

\section{Interview Protocol and Invitation to the Study}

Through my contacts in the Lumbee community, I chose the six participants who represented former teachers, students, and administrators in the Indian schools. I contacted each of my participants by phone informing them of my research and asked for their participation in my study. Upon their acceptance of my invitation, I then coordinated a meeting time with each of my participants. In the introductory meetings, conducted at either their homes or places they chose. I thanked them for their willingness to work with me, and I further informed them about the study and gained their consent to use their interview data in my research. My participants signed forms of consent (see Appendix C). Thereafter, I began the interviewing process.

In the interviewing process, I viewed myself as a student learning from my participants, and my goal was to learn as much as I could from my participants. Toward that end, I was well prepared with background information and with well-developed open-ended questions (Ritchie, 2003; Sommer \& Quinlan, 2002; Thompson, 2000). My interview guide helped me delve into my participants' educational experiences (see 
Appendix B). Preparing questions ahead of time and recording the interviews allowed me to focus on my participants' stories. The guide was created so it was flexible and did not constrain participant responses. Some individuals needed no prompting to tell their stories and many expressed self-admonishments of "I'm just rambling here," when their stories were heavy with rich information concerning the Lumbee experience beyond the questions. I facilitated my participants' telling their stories with prompts or cues when appropriate. My questions were clear, direct questions that asked who, what, when, where, and how. I avoided leading questions because I wanted my participants to understand what I asked them, so they could tell their stories without my views shaping their stories.

The interviewing process involved two in-depth interview sessions that lasted approximately 90 to 120 minutes to avoid fatiguing my participants. Ritchie (2003) recommended more than one interview to develop a relationship with participants, so they become comfortable with sharing their experiences. In the first interview session was an introduction to get to know my participant and to ask some of my research questions. The second interview session was a follow-up to ask the remaining research questions and any clarification questions that arose from the previous interview. I had a follow-up visit with my participants wherein my participants had the opportunity to review transcripts of the previous interviews to verify the information I recorded from their oral educational histories. Interviews were audiotaped and notes were taken during the interviews. I transcribed verbatim all the interviews. Fortunately, I had the additional help of two professional transcribers. These professional transcribers were cousins of mine. They signed a confidentiality agreement. When listening to the oral histories for 
transcription purposes, this confidentiality agreement (with my two cousins) would protect my participants' confidentitiality. The agreement forms were submitted to the North Carolina State University Institutional Review Board Administrator, Ms. Debra Paxton.

In the transcription process the authentic Lumbee dialect, known as "Lumbee English," was included to reveal the nuances of the Lumbee culture in documenting my participants' experience (Marshall \& Rossman, 1999). My interviewees' use of Lumbee English could be viewed as an example of how comfortable they felt during the interview in sharing their experiences. Although, the Lumbee have lost their language, their use of "Lumbee English" is unique to them. My respondents' use of Lumbee English should not be judged as "bad English” (Wolfram, Dannenburg, Knick, \& Oxendine, 2002).

\section{Data Analysis}

Data gathered during my research through interviews and archival research were analyzed through strategies of managing the data, reading and making memos from the data, describing and classifying the data, and interpreting the data.

I organized my data through a method of file folders to manage the physical collected data and computer files for the wordprocessed and electronic data. In the reading and memo making process of my data analysis, I became immersed in my data. Additionally, in the process I wrote notes as an initial way of sorting and coding my data. Then, I began describing and classifying the data wherein I described my participants' educational setting and provided a context for understanding my participants' experiences. I used the computer software program ATLAS.ti (Muhr, 1998) as a tool to assist my data analysis. ATLAS.ti was developed by Scientific Software Development to 
assist with the qualitative analysis of visual, textual, and aural data (Muhr, 1998). I used this program to help with coding, classifying, and developing categories within my data. ATLAS.ti software allowed me to assign each of my participants' transcripts into the program to ease my line by line coding through the in-vivo coding feature so I could use the direct quotes from my participants' transcripts create my initial codes. There were 315 quotes that revealed the segregated Indian school experience from the transcripts. Then, I was able to use the codes feature of the ATLAS.ti software to create category headings so I could sort relevant repeating ideas related to my research questions that I found within the 315 quotes. I sorted the repeating ideas into these categories based on similarities. There were initially 31 categories of repeating ideas. The ATLAS.ti software features enabled me to code my data and develop my categories through the codes and invivo coding features. I conducted, by hand, a further analysis of the categories of repeating ideas and found that the categories had common topics or themes which allowed me to organize these categories of repeating ideas within the data.

\section{Categories of the Data}

All qualitative oral histories produce voluminous amounts of data and require a clear process of classification. Initially, interview transcripts were coded based on their relevance to my research questions. For example, this following quotation is representative of the repeating idea "advantages of the Indian school":

Hawkeye [Indian School] was the beginning of the bonding of the Indian school and Indian students. It is sad it broke up when it did, [the students] . . . were just beginning to come together. Hawkeye was becoming a very aggressive school, 
the students that were coming out of there could get a college education, and they were beginning to use this. With integration, it broke us down again (Hart, 2004). This repeating idea "advantage of the Indian school" also was the category header to organize those aspects of the data that expanded upon the advantages of the Indian school. This excerpt from Hart's oral history was categorized as under "advantages of the Indian school" because of the unique information revealed about the bonding that occurred within the Indian school setting. The category "advantages of the Indian school" was itself a unique subclassification within the overall theme of "segregated Indian school" because the category "advantages of the Indian school" told more about the common theme of "segregated Indian school."

My Lumbee respondents' oral histories yield a rich depiction of their experiences in the segregated Indian schools and the subsequent experience of desegregation. Thirtyone primary categories emerged from the data (Figure 2) that served to sort the data, all of which served as baskets that explained and defined some aspect of their experience. In examining the data further, three of these categories emerged as common themes for describing Lumbee experience in the Indian schools. As stated these themes are segregated Indian schools, desegregation, and the Lumbee understanding of segregation and discrimination as shown in Figure 2. These themes are similar to the themes found in my pilot study: the segregated school experience, inequality, and desegregation. In Figure 2, the themes are presented as a Venn Diagram in which the theme segregated Indian school is interconnected with the theme desegregation by the theme of understanding segregation and discrimination. The overlapping themes show the interconnected experiences of these realities the participants recalled in their oral 
histories. The further classifications of the data, the subcategories, had the common theme of "segregated Indian school" which developed this theme. Thus, the subcategories under the theme of "segregated Indian school" illustrate what the Indian schools were like and what happened in those schools as well as the impact of these schools upon the Lumbee people. These subcategories of the theme "segregated Indian school" were not classified by looking for what fit into the theme "segregated Indian school" but what the categories revealed about the segregated Indian school in general. Thus, categories were not being imposed upon the data, but rather the data shaped and formed the categories through the analysis process. This process is a manageable way of handling and analyzing the bulk of data through the solidification of the categories of the data (Glaser, 1994; Lincoln \& Guba, 1985).

After the coding and classification of the data, I began interpreting the data in order to comprehend the possible ramifications of this research data. There were many quotes from my participants' transcripts that I could have presented in my written report as examples of the categories of the data and the themes of the data. However, I selected those quotes that best represented the categories and which uniquely revealed my participants' memories of experience in the Indian schools. Three themes that emerged which organized and described my informants' experience in the Indian schools:

(1) segregation, (2) desegregation, and (3) the tribal experience of discrimination that was part of the reality of segregation and desegregation. These themes provided a framework for me to summarize the data which described what my informants' stories told me about segregation, desegregation, and their awareness of the reality of discrimination. In Chapter 4, I will present the results from my data analysis in a written 
report. I will in Chapter 5, summarize the categories and the connections between the categories that my data yielded.

\section{Research Site}

My research site included Robeson and Hoke counties. Robeson County is home to the largest population of Lumbee Indians within this southeastern community in North Carolina. Additionally, the Robeson County public school system was the first school system North Carolina provided for state recognized Indian tribes, and the Lumbee were the first tribe to be granted state recognition.

Hoke County is included in the study because of the large population of Lumbee Indians residing in the county and because a separate school system for American Indians also existed in this county. The Hoke County segregated Indian school system differs greatly from the Indian school system in Robeson because many of the educators in the Hoke County schools were Lumbee Indians from Robeson County who taught in Hoke, but lived in Robeson County. Some members of the Hoke County Lumbee Indian community perceived that the teachers were not a part of the Hoke County Indian community. Possibly Hoke County Lumbee Indians viewed Lumbee Indian teachers from other communities as being less invested in their students. They may have viewed that a shared community would have created stronger attachments between the teachers and their students. Research has shown that black teachers who lived in the same communities as their black students had stronger attachments and investments in their students (Foster, 1994; Ladson-Billings, 1994; Walker, 1996). Another difference between the two counties is that the Lumbee Indians in Hoke County suffered the loss of their only consolidated and operating Indian school, Hawkeye, when the schools were 
desegregated. Hoke County integrated in 1968 before Robeson County. All the other Indian schools in North Carolina had ceased to operate by 1970 while the schools in Robeson County were still segregated until late 1970 (Massey, 1996). Hawkeye Indian School was built to replace the Antioch Indian and Macedonia Indian Schools. Hawkeye ceased to operate in 1968 when Hoke County integrated all of its three segregated school systems including both Hoke County High School (white school) and Upchurch School (the black school). Hawkeye Indian School became an elementary school and was renamed South Hoke (MacDonald, 1953 ; MacDonald, 1991).

Additionally, although Hoke County has a large population of Lumbee, they are not the majority population in the schools as were the Lumbee in Robeson County. The Robeson County School System has 10,340 Native American pupils compared to Hoke County with 942 Native American pupils (2004). Although the 2004 North Carolina public schools statistical profile does not designate a tribal affiliation, Lumbee Indians have historically and continually been the major Native American tribe residing in the areas of Hoke and Robeson Counties. Moreover, these areas are part of the Lumbee tribe's ancestral territory.

\section{Research Participants}

My research participants included the members of the Lumbee community who experienced education in segregated Indian schools in Hoke or Robeson Counties. Other ethnic/racial populations were excluded from this research. Specifically, I interviewed individuals who were students, teachers, or administrators in the segregated Indian schools in Hoke or Robeson Counties. These individuals were selected to be interviewed because of their unique knowledge about their experiences within the Indian schools. In 
deciding the sample size of my study the literature suggests that oral history researchers should not set a number of individuals to interview because imposing a number can affect the quality of the interviews and the processing of the interviews (Ritchie, 2003). Specifically within qualitative research, the focus is on small samples and in some circumstances, a sample of one (Patton, 2002). The participants are selected purposefully because of the richness of information that they provide in understanding the phenomena of study in depth (Maxwell, 1996; Patton, 2002). In qualitative research the focus is not on the sample size because the sample size depends on the nature and purpose of the qualitative inquiry (Patton, 2002). Thus, concerns that should guide the researcher in the decision of sample size for a qualitative study are: what the researcher wants to know and why the researcher wants to know it, what will be useful, how will the researcher use the findings, and what can be done with the available resources and with a fixed time frame (Patton, 2002). Ritchie (2003) also suggests that a researcher should not set the number of interview hours and sessions because interviewees may vary with the wealth of knowledge they may give. Some interviewees may have more to tell than others and thus may require more time to interview than others who have less to say.

In consideration of these suggestions, a small sample of six individuals is appropriate for my study. Three individuals (a student, a teacher, and an administrator) represented the Hoke County segregated Indian school experience in my sample. Conducting these interview sessions with my three participants allowed me to investigate the segregated oral educational experiences of the student, teacher, and administrator for my study. Through my contacts, I located several teachers who taught at Hawkeye Indian School. One declined to participate, however, others were pleased to participate in 
the study. It was difficult to find individuals who had been teachers or were principals in the segregated Indian schools of Hoke County compared to the segregated Indian schools of Robeson County. All of the teachers and principals of the Antioch and Macedonia schools have passed away.

Robeson County had a greater Lumbee population; thus, there were more segregated Indian schools and more individuals who were administrators and teachers in these schools. I found more former administrators from the Indian schools in Robeson County than the one administrator I found from the Indian schools in Hoke County. However, I had to limit my selection of study participants to three to make this study possible within my limited time frame and budget.

My network sampling method (LeCompte \& Preissle, 1993) of selecting participants was similar to the method Deese (2002) described as the 'Indian Grapevine.' Through network sampling, I was able to speak with members of the Lumbee community about my research topic. They, in turn, suggested and contacted individuals who had rich segregated Indian school experiences as students, teachers, and administrators. The individuals who participated in my study were open to cooperate with me because of my membership within the Indian community. They realized the value of this research because they genuinely wanted to share their life experiences about their education in the segregated Indian schools.

Due to my closeness to the community being studied, my interpretation of my participants' interviews could have been biased toward finding what I wanted to find in my data. To lessen this possibility, I employed member checking (Lincoln \& Guba, 1985) to address these biases. Member checking occurs when the participants review 
their oral educational history transcripts and a draft of the report. This qualitative research technique not only provides additional aspects of documentation, but also allows participants to check for accuracy in the recording of their experiences. In short, member checking was a way of increasing the trustworthiness of my study (Creswell \& Miller, 2000; Lincoln \& Guba, 1985; Patton, 2002). Additionally, I kept a personal journal to document what I did and what I encountered in my research, as well as my ideas, thoughts, and my personal reflections in the research field (Denzin \& Lincoln, 1998; LeCompte \& Preissle, 1993).

\section{Participants in My Study}

Six individuals participated in my study by sharing their oral educational histories. Their oral educational histories yielded a wealth of data considering that very little documentary evidence exists describing the Indian school experience. Each interviewee contributed information that depicted the Indian schools as he or she remembered through their distinct perspective as students, teachers, or administrators. The pictures their words painted illustrated a separate world of the Indian community and the schools in juxtaposition to that of the dominant society which they knew existed, but through which their segregation served to protect them. The students in my study are the Hoke County Student coded as (Hannah) and the Robeson County Student coded as (Rebecca). Teachers in my study are the Hoke County Teacher coded as (Hart) and the Robeson County Teacher coded as (Rachel). The administrators in my study are the Hoke County Administrator coded as (Henry) and the Robeson County Administrator coded as (Richard). 


\section{Students of the Indian Schools}

\section{Hannah}

Hannah was the eldest member in my study, 91, and she informed me immediately when I came to interview her that there was a lot she didn't remember, but she would be happy to share what she knew. She is unique also among my participants as the only individual whose entire educational experience was in the segregated Indian schools in Hoke County, specifically Jacob's Point School. Jacob's Point was the school Hannah remembered, one of the remaining two former segregated Indian school buildings that exist in Hoke County. Hannah's story included rich data concerning the segregation experience from the standpoint of a student. Furthermore, Hannah's father was one of the Indian leaders in Hoke County who advocated for and helped the development of Indian schools in Hoke County, so this connection enhanced her perspective of the Indian schools.

Despite Hannah's age she was in good health, spirited, and had a pleasant demeanor so she was delightful to interview. Hannah, wearing a house dress, was a petite five feet with a pale honey complexion with soft white and iron-mixed grey hair in a loose bun. I interviewed Hannah in her home. During the interview, Hannah's daughter was present and she served to help stimulate her mother's memory through comments and reminding her of certain recollections that Hannah had told her in the past. Hannah's daughter contributed to help shape and to jog her mother's memory as Schwartz (1999) and Zerubavel (1996) describe as the social context of memories. She was known in the community as such a strong woman and yet she spoke nothing about her achievements but about the efforts of others. Hannah's work, however, and 
especially that of her father of whom she spoke chiefly is well known in the Hoke County community.

\section{Rebecca}

I conducted Rebecca's interview in her home. Rebecca is a 75 year old educator and leader in the Indian community whose perspective as a student was through her educational experience attending the Indian schools in Robeson County of Pembroke Elementary and Ashpole Center. She was dressed casually, and she had an ever present smile and engaging manner during the interview. Rebecca had a toasted honey complexion framed by soft white curly locks and was about 5 foot five inches in stature. Her interview yielded a wealth of experiences as a student and as a teacher in the Indian schools in Robeson County. She experienced education entirely through the segregated Indian schools from primary, secondary, and into college.

Rebecca taught over 30 years in the Public Schools of Robeson County and expressed that she still hasn't stopped teaching as she was heavily involved in volunteering with the schools. In addition to her teaching, Rebecca became active in advocating for teachers and for students as a leader of many educational and teacher organizations. She is still an advocate for the schools and expressed how she wants to help teachers meet the challenges posed by the diverse cultural needs of all students. Rebecca is not only an educational leader, but also a community leader as well. She is known throughout the county, state, and nation for her work in improving Indian education, reaching Indian students, and advocating for the Lumbee. The spectrum of responses Rebecca gave demonstrated the depth and critical examination of her experience in a segregated setting as well as how she valued working and learning with 
diverse populations. Rebecca exhibited regrets over missed opportunities because of unequal opportunities. The success and the life that Rebecca lives reveals that she has taken all the adversities and made opportunities for herself.

\section{Teachers in the Indian Schools}

\section{Hart}

The interview with Hart was conducted at his home. Hart is 72 years old and is a retired educator who experienced education from primary, secondary, and into college in the Indian schools in Robeson County. He is about 5 foot 9 inches in height with a walnut tanned appearance with salt and pepper gray hair worn in a close crew cut. Hart wore his overalls. He made time for my interview between his various projects. His varied experience as an educator with the Coharie Indians in Sampson County in their Indian schools and his experience as a teacher in the Hawkeye Indian School made him an invaluable resource.

Hart lived in Hoke County and taught at Hawkeye Indian School in Hoke County. Most Indian teachers that taught in Hoke County did not live there. They commuted from Robeson County. He taught over 30 years in the Indian schools and in Hoke County. Hart was one of the few Indian teachers that taught at the high school in Hoke County. He was a vocal advocate for Indian students and a motivator for all of his students. Meanwhile, Hart was also a church and community leader as well. Hart has left a lasting legacy in the schools, but he is just beginning with his current efforts in representing Hoke County and the Indian community in his political and economic leadership roles. He was pleasant to interview and his rich experiences and knowledge proved him an advantageous living resource. 
I found his critical reflection on the state of Indian students and their educational opportunities to be the most poignant of all my participants. He recalled his educational experiences and although he spoke of them as challenges to his goals, his achievements spoke for themselves, and it was as if he used each obstacle as a stepping stone toward his personal and career growth. Hart spoke fondly of the students he taught, the Indian children at his church, his children, and grandchildren interchangeably in his concern for their taking advantage of their educational opportunities. He spoke of all of his efforts to direct and guide these young people that are in his care. He still functions as an educator by advocating for the educational achievement of his Indian students.

\section{Rachel}

I interviewed Rachel at a religious center where she does volunteer work. She is a 70 year-old retired teacher with a toasted almond complexion and framed by thick dark brown locks. She was wearing business casual as she had paused in her busy schedule for my interview. Rachel also had an educational experience in the segregated Indian schools in Robeson County from the primary and secondary grades into college. Her interview yielded valuable information about her experience as an educator in Robeson County at the Fairmont Indian School and later as a teacher during desegregation in the Fairmont white school. Rachel taught over 30 years in the Indian school and the Public Schools of Robeson County. In addition to being an educator, Rachel was part of the educational leadership on the school board. She strove to get more Indian parental and community involvement to improve the educational success of Indian students in Fairmont. The resistance that she encountered from her own people saddened her but did not defeat her efforts. She continued to be an advocate for the students there until she 
directed her focus on her church community. She is now an essential leader for women in the Indian Baptist Association. This leadership role is significant considering the conservative resistance of the Southern Baptist Association to the efforts of women in leadership positions. Rachel was a cheerful individual to interview and disclosed a great deal of information beyond my questions. I was grateful for the opportunity to interview her.

\section{Administrators in the Indian Schools}

\section{Henry}

I interviewed Henry in his home. His wife was present throughout the interview sessions. His wife helped to stimulate his recollections as I asked him questions throughout the interview. Although Henry was only 77, he explained that before his illnesses his memory was much better. He stood about 5 foot 8 inches tall with a pecan tanned appearance and steel and snowy grey mixed wavy hair. Henry was a precious resource for me to find as he is the only living administrator who experienced education in the Hoke County Indian schools, specifically Hawkeye Indian School. He was a teacher, a basketball coach, a bus driver, and an assistant principal at Hawkeye Indian School. His varied 35 years experience in the Indian schools and Hoke County made him a valuable resource to interview. Henry also experienced education from the primary and secondary grades into college in the segregated Indian schools in Robeson County. Unlike Hannah and Hart, Henry did not live in Hoke County, but only taught and was the assistant principal at Hawkeye Indian School while continuing to live in Robeson County. Henry became most animated and energetic in his telling of Hawkeye Indian basketball, the tournaments and speaking of the Hawkeye reunions. He gave me a litany 
of all the students he taught and how he had kept up with them and their accomplishments. Although his focus is now on developing his church and his leadership role there, he has not forgotten his students.

I found during my time with Henry that we were related. His knowledge of my family tree emphasized such a 'Lumbee' moment. Family is very important and finding out 'who your people are' is important in locating a Lumbee in the context of family and community so one understands an individual better and that the individual can be known, in this manner Lumbee Indians determine whether the individual belongs to 'our people.' Henry knew my father very well. I treasured his stories about my father and my family. I enjoyed his warm demeanor, and he was so easy to talk and to listen and learn from.

\section{Richard}

I had the opportunity to interview Richard in his home. He shared a wealth of information with me about the Lumbee Indians. Richard's comments yielded the most data for my research. Richard is 75 years old and possesses an acute mind. He is a stately 6 feet in height with steely grey wavy hair and a pecan honeyed appearance. Richard's cheery and spirited interview belied any illness. He had been very sick. He was still dealing with health problems. He gained his primary and secondary education through the Indian schools in Robeson County. He obtained his college degree from the University of Georgia. Richard worked as an educator and administrator in the Robeson County school system during segregation in the Indian schools and during desegregation.

He taught at Deep Branch Elementary and was the principal of Pembroke Elementary School. His involvement in the Indian schools and the Public Schools of Robeson County as an administrator and teacher stretches over 30 years. 
Richard had very thoughtful reflections on the impact of the Lumbee culture, the Indian schools, and the role of education in the success of the Lumbee people. He spoke directly concerning the abilities of the teachers to take their limited resources and create extraordinary experiences for their children because of their exceptional abilities as teachers. Richard believes the teacher is the most important aspect in that classroom that affects the success of the students. He stressed how important it was for the teachers to know their students' culture, background, and experiences in order to better communicate with and teach them. These were not empty words. Richard's actions in the school system were living legacies to his value of education as the key to success. He also has not stopped in his continued efforts to improve the educational system in Robeson County. He is involved as a volunteer and community leader in efforts to improve the schools. I thoroughly enjoyed my time with Richard and there were times when I lingered longer than I had promised to gain more of his wisdom and his memories.

\section{Limitations}

A limitation of this study is my translation of this unique Lumbee segregated educational experience through my research. Qualitative research studies must be viewed in context; thus, the results are limited and are not generalizable to another population. The results may be transferable to another study that has a similar context as this study. Stake's (1978) idea of naturalistic generalization is derived from tacit knowledge of understanding the similarities and the natural covariations of research case studies in and out of context. Specifically, the case studies provide vicarious experiences for the readers of the research. 
Donmoyer (1990) provided a further explanation of generalizability which draws upon Stake's naturalistic generalization and Piaget's schema theory. In Donmoyer's understanding of generalizability, researchers use narrative in describing the study's case and this allows the readers of the research enough information, so they can vicariously experience the case being studied (Donmoyer, 1990). One of the benefits of this vicarious experience for the readers is the expansion of the range of interpretations of the research that are available to the readers (Donmoyer, 1990). Thus, the uniqueness of the case study is an asset not a liability. Another benefit of vicarious experience is the perception of the research case through the eyes of the researcher which enables the readers of the research to view the case in a manner which they otherwise may not have conceived (Donmoyer, 1990).

In my research, I provide rich description to allow the readers to have a vicarious experience of what participants actually experienced during this time of segregation and desegregation as members of the Lumbee tribe in North Carolina. In addition, this description provides them a unique case study that they would have otherwise never known. Furthermore, they are viewing this research through the eyes of a Lumbee Indian conducting research in my community. This also expands the perception of the readers of my research. 


\section{Ethical Concerns}

Individuals that I invited to participate in my research were asked to complete informed consent documents (See Appendix C). The informed consent form introduced me to my participants, explained the purpose of my study and why they should participate in my study. Additionally, the letter of informed consent conveyed to them my effort to protect their oral educational history memoirs. The letter also communicated to them that their participation was voluntary; they could leave the study or refuse to participate in the study at any point without penalty and repercussion.

The oral educational histories of participants were audiorecorded with their permission. With the permission of the participants, written notes were taken during these interviews. I communicated to my participants that they had the right to not answer any question I asked during the interview. They could, and some of my participants did, ask me to turn the audio recorder off during the intervew. They could have stopped the interview at any time.

Throughout the data collection and data analysis process, my participants' names were held anonymously and they were given pseudonyms of their own choice and the identifying information about their location was also given a pseudonym and was vaguely described in my written reports. The data from these interviews were held in confidence by me, my doctoral advisory committee, and two professional transcribers who signed statements of confidentiality. 
The interview digital recordings were stored and secured on compact discs within a locked cabinet at my residence. Interview digital recordings were given to my participants on compact discs for their own use. Most of my participants chose to donate their interview recordings to the Lumbee River Fund, a historical documentation project and collection housed at the University of North Carolina at Pembroke SampsonLivermore Library to preserve information, data, and archival objects about the Lumbee experience. Letters of informed consent, participants' control over the interview, protecting my participants' identities, and their ownership of the oral memoirs all helped to communicate to my participants that I sought to protect the trust they had shown in sharing their experiences and that I was not trying to exploit them.

\section{“Getting it Right”}

Qualitative research seeks to understand a social world that is in constant construction and thus, the quantitative focus on validity to verify the quality of research as if the known world can be tested and measured is inappropriate for my research (Wolcott, 1990). To verify the quality of my research I endeavored to "get it right" by talking less, listening more, and asking for feedback from my participants (Wolcott, 1990). This method allowed me to document the voices of my participants and accurately write the stories of their experience. My argument in conducting this research is that their stories are missing, so I needed to hear their stories in order to document them. Furthermore, I needed to seek their feedback to make sure that what I have documented accurately depicts their reconstructions of their experiences of this time in history. I believe such feedback also informed my participants that I valued their expertise in the 
telling of their stories, which reinforced their authority. The story is theirs, told in their voice and I wanted to represent them accurately.

This chapter provided the research methodology used in my study. I explained my data sources, data collection, my method of inquiry - oral history, interview protocol, and data analysis. Then I discussed my rationale in selecting my research site, research participants, and I introduced my research participants. Finally, I addressed the limitations and ethical concerns of my study. In chapter four, I will present the categories of the data and the connections among the categories that my study yielded. 


\section{CHAPTER 4}

\section{UNDERSTANDING INDIAN SCHOOLS}

Being in the . . . all Indian school growing up we all had the same morals, same values, same standards and we were like one big family. We were an extended family, because all of us, the majority of us, were related. The parents knew each other, we visited each other, you went to church together. It was like we was all the same family we just lived in different houses. We were taught to respect our elders we were taught [the respect] the teachers. [The teachers] just in their personalities, their dress code, portrayed respect. . . . It wasn't a kinda anything goes atmosphere environment, being in that school was like being at the church almost there's certain things you didn't do. (Lumbee Student Participant, pilot study)

This study explored the Lumbee Indians' segregated Indian school experience, and the findings from the study are presented. The chapter is organized by three themes that emerged from the data: (1) segregation, (2) desegregation, and (3) the tribal experience of discrimination that was part of the reality of segregation and desegregation. These themes provide a framework for understanding the Indian schools which my informants' stories told me about segregation, desegregation, and their awareness of the reality of discrimination. I will discuss the three different themes. These themes were demonstrated by the data collected and were unveiled and documented in the related Lumbee experience in both segregated and desegregated settings. The segregated Indian schools, desegregation, and understanding segregation and discrimination themes explain and interconnect the 31 different baskets of experience that my categories classified.

The quotes from my respondents capture the authentic Lumbee dialect, known as Lumbee English. I viewed my interviewees' use of "Lumbee English” instead of using the formal standard English as an example of how comfortable they felt during the interview in sharing their experiences. I respectfully request the readers of my research to try to understand that the grammar of the quotes from my informants are indicative of 
"Lumbee English" and should not be judged as incorrect grammar (Wolfram, Dannenburg, Knick, \& Oxendine, 2002). This research is to document the authentic voice of my participants and this includes affirmation of their dialect.

\section{Themes of the Data}

\section{Segregated Indian Schools}

Participants were asked to describe the segregated Indian schools, the school building, the grounds, their resources, and the materials for instruction. These questions permitted me to visualize the schools, their buildings, their resources, and the curriculum. In asking about the distinctiveness of the school and the effect of the school upon my participants' experience, I wanted to explore the relevance of the schools. I wanted to probe the impact of these schools on the participants as students, teachers, and administrators. I wanted these descriptions in order to not only understand the educational experience of my respondents in the schools, but also the effect these schools had on them.

Then, I asked about how the family, the Lumbee community, and other nonLumbee factors affected their experience in the Indian schools. I wanted to probe in order to obtain the degree of parental and Lumbee community involvement and the effect of various elements outside of the Lumbee community that may have shaped their experience in the Indian schools. In asking about their perception of their Lumbee culture, values, and beliefs, I sought to use their responses as a foundation for deeper examination. This foundation provided insight into the participants' understanding of the Indian schools' cultural support or lack there of. I then asked how the Indian schools were supportive of their academic achievement. The purpose of this inquiry was to 
obtain what kinds of educational practices occurred or did not occur to foster educational development.

The data yielded findings about the school, programs, teachers, teachers' connection with students, and the resources available to Indian schools. Participants revealed a great deal about the effect of the tribe on schools, and the schools' impact on the Lumbee. Finally, participants articulated advantages and disadvantages of the Indian school experience.

\section{The School}

During the early twentieth century, there were two separate Lumbee communities in Hoke County who had developed schools: (1) the Antioch Indian community and (2) the Macedonia Indian community. The two Indian schools in Hoke County, Jacob's Point (Figure 3) and Macedonia Indian School were inherited from Robeson County. Both schools preceded the creation of Hoke County, because Hoke County was carved out of Robeson County. The Macedonia Indian School was developed by the Macedonia Indian community. In 1933 the Macedonia Indian School burned and the Indian students in this community were bused to schools in Robeson County for a few years (MacDonald, 1991).

Jacob's Point was in the Antioch Indian community. Hannah informed us that Jacob's Point started with the leadership of her father who wanted his children to have a better education. Hannah explained that her father went directly to the superintendent of schools and requested the use of Jacob's Point building by the Indians of Hoke County. The superintendent agreed to establish a school if Hannah's father could get 20 parents involved. 
he wanted a school so[the]Superintendent [of schools in] Raeford told him if he'd get 20 parents that [he] would let their children come to school then he could use that building and it was in good shape, the windows was bad and so that's where school started.

Hannah described her father's tireless efforts to reach out to the Indian community to get the involvement in a school, "when he'd work every day and hook up the mule at night and go around through the community trying to get enough students to get a school started" (Hannah, 2004). Although the Hoke County Board of Education Minutes do not mention Hannah's father specifically, they do mention that, "Several Croatans from Antioch Township came before the Board to petition for a school. Their petition was considered favorable though no definite action was taken towards the establishment of a school" (HCBE Minutes, April 6, 1914).

Hannah's father was successful and Jacob's Point Indian School was purchased for $\$ 150$ on August 19, 1914; the school was established in 1914 (HCBE Minutes). Hannah's father's efforts in establishing Jacob's Point provide a poignant example of community impact and involvement in the schools. Over the next two decades, the enrollment in Jacob's Point School increased. Consequently, Jacob's Point became too small and could not house the students, then the school was closed. Hannah described years of overcrowding inside the building. Over the years, this overcrowding eventually became intolerable. 
Subsequent to the closing of Jacob's Point, students in the Antioch Indian School began attending Antioch Indian School, built in 1935-36 (MacDonald, 1991). The structure was built across from Mt. Elim Baptist Church. Mt. Elim Baptist Church was a prominent church in the Lumbee community in Hoke County; this church was also founded by Hannah's father. However, when the board built the Antioch Indian School, they intended that the Macedonia Indian community attend this school as well. However, there were issues between the two Lumbee communities that affected the development of a consolidated school for both Antioch and Macedonia Indian students. There was animosity between the two communities because the Macedonia Indian community questioned the Indianness of the Antioch Indian community. The Antioch Indian community was accused of having black blood and, as a result, the Macedonia Indian community refused to attend the same school with the Indians from the Antioch community (D.B. Dial, personal communication, February 28, 2005). As a result of this animosity the two communities were reluctant to unite and consolidate in order to benefit from more resources for their children.

When the Lumbee community in Hoke County asked for more resources for their Indian schools, the response was that the Indian communities had to unite and consolidate their schools. As evidenced by Hannah's father's experience with starting Jacob's Point, there was little fervor to start schools for the Lumbee. Hannah further explained that her father wanted his children to go to school, but there was resistance from the Macedonia Indian community to the establishment of the schools by the Antioch Indians. When I asked Hannah about the resistance of the Macedonia Indian community to the Antioch Indian School she couldn't explain, "but some of the people from [Hoke] County, I could 
call names but I won't and I don't know what the problem was but they didn't want we children to go to school" (Hannah, 2004). She explained that she wouldn't name anyone, which seemed that she knew who these individuals were from the Macedonia Indian community who did not want the Antioch Indian community to have the new school nor did they want the students to attend the school. However, she said there were Indians that didn't want the Antioch Indian children to go to school. Further inquiry of members of the Hoke County Indian community explained why_-black blood. Even Henry, who was an assistant principal, was unaware of the source of animosity that existed between the two different communities. The two different schools of Antioch Indian School and Macedonia Indian School were, competing against one another...There was still some friction between the students, Macedonia and the other church [Mt. Elim], they naturally wanted to uphold their traditions from each community (Henry, 2004).

Henry understood the friction between these communities. He interpreted the friction as (1) competition and (2) upholding Indian traditions. But, he didn't understand the machinations of internalized racism between these communities. Hannah agreed that students from these communities were resistant and did not want to go to the new school, known as Hoke County Consolidated Indian School and later named Hawkeye. Built in 1952, Hawkeye Indian School was renamed in 1968. The new name for Hawkeye Indian School was South Hoke Elementary School (Figure 4). The board built the school with the input of the Indians of the Antioch and Macedonia communities; the school was built in a location that both communities agreed upon. The location is an equal distance away from the heart of both the communities. Despite the initial resistance, Henry assessed 
that the consolidation was good for Hoke County. The development of the schools at this site not only provided unity for the Lumbee Indian communities, but also provided better educational opportunities and facilities for their children. The fellowship and camaraderie that the Hawkeye alumni have conceal any past animosity. Indians from both Macedonia and Antioch Indian communities meet every five years to fondly remember and celebrate their time at Hawkeye Indian School.

The pooling of resources, in order to support schools, was a common occurrence in both Hoke and Robeson County. Such consolidation was necessary in order to offer the students better facilities and more opportunities. The Hoke and Robeson County boards of education refused to fund small schools with low student enrollment. As Rebecca describes, in her explanation of the differences in the two schools she attended, school attendance varied for the Lumbee. School attendance was based on the economic realities of the students and their parents' value of education. Rebecca attended Pembroke Elementary (Figure 6) and Ashpole Center (Figure 5). She believed that the differences between the two schools were due to the larger student enrollment and attendance of Pembroke Elementary School; and there was better local support for Pembroke Elementary School. As Rebecca tells us,

Pembroke Elementary was an old brick building; therefore, it was a better building. You had people [in Pembroke] who were more concerned about school than at Ashpole. Ashpole was a small 4-room wooden building. Pembroke was a larger school at that time because more people in this area went to school... Back then the parents kind of sponsored the school, not the state. So that was [why] Pembroke [was] better equipped [than] Ashpole (Rebecca, 2004). 
Rebecca explained that due to parental involvement and support of Pembroke Elementary it was a better built school compared to Ashpole Center. She explained that the parents supported the school more than the state. Hannah's and Rebecca's narratives illustrate the degree to which Lumbee advocated for their own schools with boards of education and within the communities themselves.

\section{Programs}

The richest and most influential aspects of the Indian schools were the programs and activities they offered to both students and community. Richard explained that the Christmas, Halloween, May Day, and school closing programs were opportunities for children's self-esteem and development as well as a chance to develop closer ties with the community. School closings were end of the year celebrations when the entire community would come to the school (Dial \& Eliades, 1975). At the school closings, the entire community would share a meal comparable to a picnic, and there would also be school performances. Hannah described the school closing as,

They would take a covered dish, brought in a box, [and have] all day activities, and a program on stage ... [they would have] lunch and they would have a sports activity. This was to celebrate the end of school ... This was for parents, students, and teachers. That way it showed the pride in school, and coming together (Hannah, 2004).

The programs were of resounding importance because the community was invited to the school. Richard explained that the May Day program in particular would be an all day event with a May flower dance. Although it took time away from the classroom and time might have been better spent studying, Richard explained that, 
you just couldn't do that. Because the community expected that. They expected that and you had to do it, not necessarily it was the best for the school, but that .. . that's what the community expected and you had to do it that way (Richard, 2004).

Moreover, the community wanted the same programs that other schools had such as May Day programs. The May Day program showed school and community pride. If Prospect had a program then Pembroke would do the same thing. Richard tells us that if the school didn't participate then "your school wouldn't be counted as a good school" (Richard, 2004). Richard enjoyed these programs and saw them as providing opportunities for the community to really come out and support the school. However, these school programs were not only a focus of competition for the Indian communities, but also the school programs were a source of community and school pride. Richard explained that the school programs were extremely important to the community because the programs provided a much needed social opportunity for the Lumbee community. Within the Lumbee community, the church and the school represented the two institutions in which the community was invested, the church and the school were also the only social outlets the community had.

We have seen that within the segregated Indian schools, programs and activities provided a social outlet for the Lumbee community. It was basketball though that profoundly expressed the communities' passion. The Indian athletic conference represented an important and exciting community event. For the Lumbee, supporting their schools in basketball was a social event as well as a source of pride for the schools 
and the community. Henry explained the importance of the Hawkeye Indian School's inclusion in the conference and the community,

We excelled in sports and everything. It really helped out. It put the school on the map. . We really cherished it. We could see the progress the school made, we could compete with Prospect, us being a baby school, and Prospect school so much larger, but Hawkeye rated high with the other schools (Henry, 2004).

Henry explained how Hawkeye Indian School's ability to play sports was another opportunity for the school to excel and compete with other well established Indian schools like Prospect. Brayboy and Barton (2003) document the excellence of Hawkeye's athletic prowess in basketball. Coach Hartman Brewington helped to place Hawkeye as the 1965-1966 basketball tournament runner-up, Hawkeye lost 53-23 to Pembroke High School, in the newly reorganized Tri-County Indian High School Athletic Conference (Brayboy \& Barton, 2003). The reorganized Tri-County Indian High School Athletic Conference in 1966 included Hawkeye Indian School (Hoke County), Les Maxwell School (Cumberland County), and the Robeson County Indian schools which replaced the Eastern Carolina School (Sampson County) in the conference when the school was closed in 1965 (Brayboy \& Barton, 2003).

In addition to being the assistant principal of Hawkeye Indian School, Henry was also a basketball coach, bus driver, managed the books for lunchroom, and taught classes as well. Henry explained that it was not uncommon for the administrators and teachers to serve in many different capacities in the schools. Due to the lack of resources, he explained, certain duties had to be accomplished. Consequently, these roles were part of the job of teaching and being an administrator. Henry explained that driving school 
buses, working with the athletic programs in varying capacities, and taking on administrative secretarial work were some of his additional roles as a teacher and as an administrator. Henry is an example of the exceptional and versatile qualities of the educators in the Indian schools. These same qualities of the teachers will be discussed next.

\section{Teachers}

In addition to the importance of the community/school connection that the Indian school programs provided, the teacher/student connection was fundamental in segregated Indian schools. Indian teachers had many demands placed on them. Teachers were responsible for a host of other duties in addition to teaching multiple classes.

Hannah explained that at Jacob's Point School she felt her teacher cared for her, but as Hannah explained both of the teachers had eight grades to teach at one time. Sometimes teachers would keep students after school to make sure that the lesson was covered. Although Henry was an assistant principal, he also had teaching duties and would sometimes have responsible students cover class when he had to leave for a few minutes to attend to other duties. In addition to their dynamic flexibility, the Indian teacher's dedication is evident in their stress on academic achievement and school success as well as their devotion to helping elevate their students out of poverty.

All participants' stories emphasized that teachers in segregated Indian schools stressed academic achievement as a way out of economic oppression. Rebecca, Rachel, Hart, and Richard all shared narratives describing how the Lumbee generally worked as tenant farmers, working the land and earning profits for the white landowners. Farming was the major occupation for the Lumbee before the late 1960s (Dial, 1993; Dial \& 
Eliades, 1975; Fuchs \& Havinghurst, 1973; Sider, 1993). Most Lumbee were involved in tenant farming (Fuchs \& Havinghurst, 1973). Rebecca, Rachel, and Hart expressed how the white landowners did not value education and viewed education and schooling as making their workers unfit for work. Hart and Rebecca explained that this unfortunately put Lumbee parents in opposition to education, because Lumbee parents needed the immediate help of their children in working the land. Thus, as a result, some Lumbee parents couldn't see the benefits of sacrificing the extra help of their children so their children could go to school. An example of putting agriculture before education was seen in the Robeson County Board of Education minutes. An Indian committee asked that the Union Chapel School be permitted to open later because of harvesting,

Committee- headed by Martin Luther Lowry, made request that, owing to crop condition, Union Chapel School be premitted [sic] to open not later than October $18^{\text {th }}$. This request was granted by the Board (PSRCBE Minutes September 6, 1937).

Rebecca, Rachel, Richard, and Hart explained that although the parents couldn't see education as an investment in their children's future, their teachers could see the value of education. The teachers provided an example of the benefits of education. It is in this manner that teachers played a vital role in the lives of Indian students. As Hart explained, students "did not have any role models, except our schoolteachers. Basically, the children looked up to the schoolteachers and that was about as high as you could go" (Hart, 2004). Teachers were clearly influential role models to the students. Teachers revealed what students could achieve through education and teaching. The teachers 
envisioned for the students, another career alternative to farming-the teaching profession.

In addition to being role models and teaching students how to improve themselves, Lumbee teachers attempted to accommodate their students' learning in a number of ways. Richard reflected on the ways Indian teachers were able to meet their students' educational needs,

we had some teachers that was better adapted at teaching a child that was, ... I won't say a slow learner, but he was ... not on grade level. And I would try as an administrator try to make sure those children were placed with this type teacher that they would have a good relationship. And believe it or not it made a big difference ... some of our Indian teachers ... they had the gift to do more (Richard, 2004).

Richard understood that some of his Indian teachers had special education and specific accommodations skills. He rationalized that it was advantageous to use his skilled teachers by matching the students with these gifted teachers. Enlisting the support of the parents and the PTA, Richard supported the academic achievement of the students, "those that was academic gifted, so to speak, we provide extra incentives for them. We would try to provide field trips so they could get out of the community and see some of the other things that was going on" (Richard, 2004). 
In contrast to Richard's description of dedicated teachers, Rebecca believed that the teachers in Indian schools lacked skills. Some teachers lacked the ability to be effective teachers because of their education at the Indian teacher preparation school which required a less rigorous A and B certification instead of a four year college degree. Rebecca felt a teacher with a four year college degree had better skills and believed this reality substantially affected Indian schools. Rebecca, a teacher herself who experienced education at this post secondary school, does not criticize the quality of the teachers, but rather the limits of their education. Here are her observations:

The teachers in elementary they only had a B degree, two years of college degree. When I was in 4th grade I had my first teacher that had a four year degree. In even the $6^{\text {th }}$ and 7 th grade my teacher only had a B degree. There was an A degree and a B degree. Probably you read something where Pembroke changed from a two year gradually went to a four-year [college]. And at one time, it was [a] high school and then [it was] a two-year [college] then went to [a] four-year [college] (Rebecca, 2004).

At that time, the school was confined to specific areas of teacher preparation. Resources were limited in terms of the courses and degrees offered. Four-year degrees were not offered until 1940 when Pembroke State College for Indians finally became a four-year institution. Rebecca stated that teaching was all that the school offered when she attended school there, and she wanted to teach math, but she could not. The college instructor, who would have taught the math courses that Rebecca needed to become a math educator, had been called for duty during World War II. Rebecca was a sophomore 
at the time. One of Rebecca's instructors talked her into changing her major to elementary education,

To me at that time Pembroke State was designed basically for Indians and all you had was teaching. There was nothing else. We did not have the teachers we needed or the materials. I mean like science and those kinds of things. I remember in my sophomore year I wanted to go into math but during that time our teacher was in the World War II, and there was no one else so I had to change my major, and my teacher talked me into going into Elementary Education, he said I had lots of patience. But I would have loved to be a math teacher. It was not feasible at this time (Rebecca, 2004).

Richard also talked about the limitations of the educational opportunities that were available to the Lumbee Indians, specifically in terms of the pursuit of a graduate degree. Pembroke State University was the college for Indians in North Carolina, and Richard as a Lumbee Indian could not attend graduate school in North Carolina before integration because he was neither white nor black. He explained that he went to the University of Georgia for his master's degree in 1951. He had an avenue into the university through his white army friend, who invited him to go to school with him to pursue a graduate degree at the University of Georgia,

then I went to the University of Georgia for a masters . . but when I came out [of the army] there was a friend of mine-I was in the Army with . . . [who] lived in Hampton, Georgia and so he invited me and I come down there. He was going to college and of course that's before they had integrated we're talking about [before] 1954 [Brown vs. the Board of Education of Topeka was decided in 1954]. And I 
went down there and of course I knew ... I wasn't really supposed to go . . . but at that time they didn't say anything about it and I just sorta mingled in. He was there and he invited me, I was his friend, and . . we didn't have . . . problems, but that's before, of course, they integrated. But my experience in Georgia was . . . I had to go with the White element. See there were no other Indians in the whole school and of course I was counted a Caucasian, because there were no Blacks in school (Richard, 2004).

Richard was able to pursue his graduate degree at the University of Georgia. He explained that because of the university's designation of him as white, he was able to attend the University of Georgia. Richard also explained that other Hispanic students were also considered by the university as white.

Understanding the educational limitations that Indian teachers faced regarding their own educational opportunities and professional development enables us to better appreciate the outstanding abilities of the Indian teachers in reaching their students. An example of this connection to students is illustrated by Rachel's reflection on her role as a teacher in the Indian school,

In the Indian schools, we were required to visit the home of every child, and we had to do this in the fall. You got to go to the home and see how the child lived. We found that [if] our background were the same, [then] you felt a connection, a closeness. You did not think about a class, but as a part of your family (Rachel, 2004). 
At the core of the connection between Indian teachers and their students was a shared common knowledge, communication, values, traditions, attitudes, and norms which allowed the teacher and student to have an intimate understanding of where each was 'coming from' (Irvine, 1990; Marshall, 2002). This understanding of a shared cultural worldview allowed students and teachers to engage in the knowledge creation process with harmony (Irvine, 1990).

\section{Teacher Connection}

The connection between teacher and students was clearly an asset for the Indian schools because as Richard explained, in the Indian school,

the people that was in the school, primarily was the people that you went to church with. And also our backgrounds were similar. We, you know, our experiences was the same. We have the same kind of experiences (Richard, 2004).

Indian schools were deeply connected with the community; there was a cultural understanding present in the Indian schools. This connection with students was so important that Richard explained that he preferred Indian teachers over and above white teachers to teach his Indian students. His analysis was based on his experience in the Indian schools. He stated that:

I didn't mind telling people I'd rather have an Indian teacher, than a white teacher. . . . Because of that, I felt like the Indian teacher, I'm talking about the majority, the Indian teacher was more loyal to the Indian student. . . . And they had a better feeling for where they came from (Richard, 2004). 
Richard explained that the Indian teachers were able to put the best needs of the Indian students first because they better understood where the Indians students came from because of their shared culture and background. Hart agreed with Richard's stress on a shared community bond. He didn't feel this was present in the Indian schools in Hoke County. The Indian teachers in the Hoke County schools never became a part of the community because they lived in Robeson County and taught only at Hawkeye. Hart understood the importance of creating a bond with the community. When he began to teach in Hoke County he explained that, "I did not hesitate when I came here to teach, to build here" (Hart, 2004). He explained that being a part of the community was a vital part of the teacher/student connection and enabled them to get the support of parents in participating in the school success of the students.

The teachers were respected and were held in high esteem in the Indian community: "an Indian teacher people kind of thought of him as next to a preacher" (Richard, 2004). The teachers were also given the respect and regard of parents. Teachers had the right to discipline students in the place of the parents at school. This section has described the teacher and the teacher's relationship to students in the Indian schools. The next section will examine the resources available to students and teachers in segregated Indian schools. 


\section{Resources}

Participants' narratives revealed many inconsistencies and conflicting perspectives concerning the resources available in the Indian schools. One example is the overlapping routes of the buses for the Indian, white, and black schools. As Richard explained, "you know we had, we had three [buses] white, black, and Indian, and a lot of times you had three buses coming down the same road all the time" (Richard, 2004). Richard described how he had to explain to an outside federal authority about the differing bus routes of the schools when he questioned the overlapping routes of the school buses. He then described that although the different buses picked up children who lived on the same road, those buses were separate. The school buses took the children to separate schools as well. This situation of segregated school buses and overlapping routes ended with desegregation. Robeson County was an impoverished segregated school system with limited financial resources. It seemed ludicrous to Richard to send three separate school buses into the same neighborhood to take children to their separate schools. Clearly resources could have been better utilized.

There was a discrepancy between Hart, the teacher, and Henry, the administrator, in their recollections of the availability of resources in Hoke County. The Hoke County Board of Education minutes provides another perspective concerning the availability of resources. Hoke County Board of Education minutes document many requests from the Indian community concerning needs at the Indian schools in Hoke County. The Robeson County Minutes demonstrated similar needs for the Indian schools; however, the Hoke County and Robeson County Boards of Education often listened to the request and either denied the request or refused to take action. The Boards of Education often demanded 
that the Indian communities donate resources of their own toward the request. For example, the Hoke County Board of Education minutes document that the Lumbee community had been requested to raise funds for the purchase of a school—with the county matching the funds. The combined monies were to be used to purchase Jacob's Point School. The minutes read:

Several Croatans from Antioch Township came before the Board to petition for a school. Their petition was considered favorably though no definite action was taken towards the establishment of a school.

Dan Newton and James Locklear were appointed to raise funds for the purchase of the Jacob's Point School House. The County to pay one half the cost of same (HCBE Minutes April 6, 1914).

A similar example is found in the Robeson County Board of Education Minutes where the Lumbee community was to pay half the cost of chairs for Green Grove Indian school,

Ordered that three hundred opera chairs be purchased for the Green Grove Indian school at a cost of $\$ 425.00$. The community to pay one-half of cost when chairs are delivered.

Ordered that $\$ 212.50$ be placed in the May budget for opera chairs for the Green Grove district (PSRCBE Minutes March 2, 1931).

There is no evidence that the same condition of matching funds applied to the white schools. 
Henry did not recall having any problems with resources and did not remember having to beg for equal supplies. He noted that desegregation did improve conditions. Henry felt that since Hawkeye was only one small Indian school that Hoke County had to provide for, the school did not present a particular burden on the county. Robeson County, in contrast, had to take care of numerous Indian schools. Henry felt that Hawkeye Indian School was equal to and just as proficient as the Indian schools in Robeson County. The only difference he saw in the Indian schools in Robeson County and Hawkeye was there were more Indian students in Robeson County to be served. Hart agreed with Henry that desegregation improved conditions in Hoke County. Hart stated that the lack of resources made him a better teacher. He learned how to compensate and how to improvise. However, Hart argued that the Hoke County Indian schools did, "not get the materials that the white schools got and we had to teach ... [teachers] ... would learn to improvise materials. This made us better teachers, being able to improvise" (Hart, 2004).

Furthermore, Richard described a similar lack of resources in the Robeson County Indian schools. Richard stated that the teachers back then had to spend their own money to buy supplies for their classroom. Richard explains, this situation did not pertain to additional needs the teachers had, the teachers purchased supplies because those basic resources were not available to them,

the money just wasn't available, and we didn't get the supplies. Now part of ... that was the way schools operated. Then the other part was that being Indian, and having no control at the board of education . . . we probably didn't get our fair share of the resources that was coming in to the schools (Richard, 2004). 
Indian schools didn't get their fair share. There was little that could be done because the Indians had no agency to represent them in their quest for equitable resources. However, Richard also expressed that Pembroke Elementary school thrived because of the monetary parental support of their school. Pembroke had a growing middle class and an active parent base. Parents insisted that their children have the best. In their efforts to support the school band, parents raised money to purchase musical instruments for those students who could not afford a musical instrument. Also, they raised money for students who could not afford to go on school field trips; the money raised was put in a reserve fund.

The plentiful resources at Pembroke enabled community schools like Pembroke Elementary and Pembroke High School (Figure 7), to have more courses and opportunities than were available at other schools like Green Grove (Figure 8). Rebecca explained that Green Grove was such a small high school that it could not provide courses and resources that she deemed necessary to prepare her for college. Rebecca decided,

If I had to go to Green Grove in 11th grade I would drop out. So I had to board away from home and [I] stayed with cousins [so I could] . . a attend Pembroke. They built a new school [in Pembroke] in 1939. Green Grove only had that fourroom building, and we had a little old building with Home Economics in it. We did not have the opportunity here [at Green Grove]. I felt I would have a better opportunity at Pembroke. I transferred to Pembroke High School. I had told my parents I would drop out [if I had to go to Green Grove]. They sacrificed and let me come to Pembroke (Rebecca, 2004). 
Pembroke High School was newly built in 1939, and Rebecca felt that this school would prepare her for college, so her parents enabled her to board in Pembroke and attend the high school there. This section has not only examined the resources and opportunities available in the Indian schools, but also explained what these schools did to prepare their Indian students. In the next section, we will probe the interconnections between the Lumbee culture and the perpetuation and sensitivity to the Lumbee culture in their schools.

\section{Impact of the Tribe}

The voices of the respondents, so far, have told how important and significant the Indian schools were to the Lumbee. Richard explained that he had opportunities to visit other Indian tribes in the west and compare their education with that of the Lumbee. He was able to understand more of the western Indian tribes' educational experiences because of an earlier research opportunity that he had with western Indian tribes. Through Richard's experience, he surmised that the Indian tribes in the west were lagging in educational achievements when compared to the Lumbee,

They don't have the education. Now I think the thing that has helped us here is the education. That is the only thing that has helped pull us up to where we are right now (Richard, 2004).

Segregated Indian schools and the educational opportunities they offered benefited the Lumbee on the whole as a people. In a further comparison, Richard explained that the Indian schools were also superior to the Bureau of Indian Affairs (BIA) schools of western tribes because the BIA schools were boarding schools; the children he saw in the 
BIA schools were unhappy. BIA schools had few, if any, Indian teachers. The Lumbee Indian schools were completely staffed by Indian teachers and administrators, Most of those schools are boarding schools . . the one thing that I noticed right away is the children were very unhappy, because . . . every school I went into I didn't see a professional Indian teacher, they all were either white or black. And it's primarily that way today. You have very few Indian ... working ... in the tribal and the BIA schools. Now you have social workers, ... but the Indian [teachers], you have very few of them (Richard, 2004).

According to Richard, Lumbee have had Indian schools with qualified Indian teachers for years and that it was the Lumbee system of education that enabled the Lumbee to be educationally advanced compared to other tribes.

Another impact of the Lumbee tribe was evidenced in the informants' stories of leaving the Lumbee community in order to pursue educational and career opportunities. Their stories revealed a moving urgency to return to the Indian community in Robeson County and Hoke County. When away from their Lumbee home, they communicated an effort to seek out other Indian communities. Kinship is an integral part of Lumbee culture and the Lumbee seek to be a part of an Indian community (Blu, 1996; Deese, 2002). This concept of community and kinship was evident in the respondents' narratives of the closeness they felt in segregated Indian schools. This sense of community and closeness respondents' experienced in the segregated Indian schools was not evident in their stories of their desegregated school experience. 
Segregated Indian schools reinforced community values in many ways. Participants expressed their pride in their Lumbee culture and the degree to which their heritage and customs were taught to them by their parents and the community. Lumbee Indians' religion, connection with God, and their churches formed the core of their culture, and participants expressed this connection through the schools. Henry explained how religion was expressed in the Indian schools in Hoke County with devotions and gospel songs,

But now we could have devotions in the classrooms ... and on Friday evenings we could have songs, services, and the children could sing songs. They were ... gospel songs or regular songs, but a lot of the times they were gospel oriented (Henry, 2004).

Rebecca described the religious program, society, in the Indian schools in Robeson County which was comparable to public speaking,

We had society in the afternoon. You would have programs with devotions and sing songs ... It was still like church, [society was about] trying to get [students] . .. adjusted to standing up talking, but [located in the] school (Rebecca, 2004).

Rachel explained the reason for devotions in the Indian school was that the church provided a foundation for the school. The establishment of Indian schools coincided with the establishment of Indian churches. She explained that,

Well, the churches back then were the foundation of the school. A lot of the little schools used to be churches. Our schools started from the churches, like New Bethel, is one [example]. So I guess that had a big influence, because devotion was taught in school just as in church (Rachel, 2004). 
This section explored the impact of the Lumbee tribe on the Indian schools. The next section describes the Indian school's role within the Lumbee tribe.

\section{Schools' Impact on the Tribe}

Teachers were vital in influencing the Lumbee tribe, because the community held them in high esteem, and thus, the teachers positively impacted the Lumbee community. Richard gave several explanations of how teachers positively impacted the Lumbee community,

Indian teachers had a high sense of value and two they ... we ... thought of [an] Indian teacher as being next to an Indian preacher. They had a lot of prestige and most of them, they was ... leaders in their communities (Richard, 2004).

Richard explained that teachers were the leaders in the community and they were shaping the future of the community not only in the classroom, but also outside the classroom. As a result of the school's efforts to improve the community, the parents supported both the teachers and the school. As this quote from Richard shows, there was an interconnection between the Lumbee community and the school,

Well, the Lumbee community was sorta like an extension of the school community, all was one in the same. So being in a predominant Indian community ... that reinforced our school, ... just like the church (Richard, 2004).

The community, the school, and the church were interconnected; consequently, they supported each other. 
One unique way Henry explained that the Indian community in Hoke County supported their school was the Victory Garden ${ }^{30}$ that the parents planted and harvested to ensure the students would have a good lunch,

We had it on campus, we would get vegetables from the garden, parents in the community took care of it, I think it was an outgrowth of our PTA ... We called it a Victory Garden ... f for children to eat in the cafeteria. I think that is how they did this ... I think the volunteers harvested in the afternoons for the next day's lunch (Henry, 2004).

Another way the Indian schools impacted the parents and community was through the combined efforts to advocate for more resources for the schools, as the Indian committee did for Hawkeye. The Hoke County Board of Education meeting minutes documented the Hoke County Indian community's efforts to provide for the education of their children. The minutes revealed a story of how the Indian community had been engaged in an historical struggle for education for their children. The struggles were witnessed by (1) their attempts at organizing their voices, (2) their failures in obtaining resources, and (3) finally their successes in securing schools for the Indian children in Hoke County.

Also, the community supported the schools through various fundraisers. Participants spoke of box suppers, candy sales, and other concessions to raise money for resources, supplies, and necessary equipment the schools needed. Box suppers were also social events for the community. Girls from the community would prepare boxed suppers, and the boys and men from the community would bid on the boxes for the pleasure of sharing the dinner with the young woman who prepared the meal. Hannah 
explains, "The box supper, they would fix a box, and the girls would carry the box and take bids and whoever got the highest bid would eat with that girl" (Hannah, 2004).

Although there was support from the parents and the community for the schools, the teachers and administrators experienced resistance in trying to improve the community by influencing them to elevate themselves through education. All of my participants' explained how difficult it was to get Indian students to come to school due to their parents' need for them to help with farming; the economic need was simply too great for some families. They could not see that sacrificing additional help on the farm and allowing their children to go to school would benefit them and their children later. Richard recalled that when he started teaching, Indian students did not come to school on a regular basis and there was a high drop out rate because they had to stay home and help their parents on the farm. Richard said that he tried to talk to the parents about the importance of education, but many parents did not value education as his father had:

a lot of the parents being uneducated, they didn't really realize or didn't see how important education was. So they didn't really push the child you know to attend school. And its true you know that they had to stay home to work, the work was the first thing (Richard, 2004).

However, Richard informed us that some students stayed home even though they didn't have work obligations. He said it was a constant struggle to keep the students in school. This resistance to education that the parents and students exhibited was one of the disadvantages of the Indian school. The benefits and the disadvantages of the Indian school experience will be discussed in the next section. 


\section{Benefits \& Obstacles}

The final findings explore the benefits and the disadvantages of the Indian school experience. Benefits of the Indian school were the sense of community and family the participants felt in the school settings. Rebecca explained that teaching was easier for her in the Indian schools because of this unity of the school, community, and the home,

I had the cooperation of parents, I had the cooperation of the community, and therefore the cooperation of the school. It was when I first started teaching [we] called [our school environment] family group — the teachers we were all close and if something happened to one of us, [it happened to] all of us. So see that was all Indians, [the Indian school] but now I don't see that closeness (Rebecca, 2004).

Rebecca described this sense of community which was present within the relationships of the teachers in the school, their relationships with their students, their connections to the parents and the communities. She further explained that this community closeness enabled the teachers to teach Indian students ways of understanding segregation and how to resist being treated as inferior. Rebecca explained that the teachers taught them pride in themselves as Lumbee Indians. Most of my respondents and some informants from my pilot study lamented the loss of the opportunity in contemporary desegregated schools for the teachers to teach the Lumbee students pride in their heritage,

They taught us things you could not teach in the integrated school now, I feel that they [were] proud of who we were. Mr. O was one teacher and in Rowland there was a movie theatre [with segregated] sections for white, black, and Indian. And he would mock how the Indians would have to go upstairs and sit, [in the segregated section] and [he would] say that we [Lumbee Indians] should not even 
go there because you are better than that, you are not second class (Rebecca, 2004).

Rebecca explained that teachers could not convey such messages of Lumbee self-pride and self-improvement in contemporary desegregated classrooms. She believed the other cultural populations present in contemporary desegregated classrooms would feel marginalized by a lesson directed specifically to Indian students.

\section{Indian Committees Power}

One disadvantage of being in the Indian schools was illustrated through the harmful effects of the Indian committees. Indian committees seemed, from my participants' narratives, to be more harmful than beneficial to the Indian schools. Although these committees were supposed to empower the Lumbee as a source of Indians' input into a political system (education), the Indian committees often misused this power. This misuse of power was evident not only in my informants' narratives, but also in the board of education minutes. Rachel explained that she was fired because one Indian committee member held a grudge against Rachel's husband. This committee member sought retribution by firing Rachel. My respondents' narratives all showed that the teachers feared the Indian school committees. Rachel explained,

Teachers would always be frightened when they would meet in the spring because the board would meet during this time to fire and hire in the early spring, and you could be fired over grudges and it would be right away. This was a dreadful time for teachers. Whether you were a good teacher or not, but sometime they would fire over incompetence (Rachel, 2004). 
Although the committees would fire teachers because of incompetence, there was an additional misuse of power which was truly damaging. Misuse of power was evident in examples of nepotism from the Robeson County Board of Education Minutes,

A delegation of 13 people appeared from the Green Grove School. The delegation made the following ... observations:

2. That the present school committee at the Green Grove School, together with many of the teachers, were operating the Green Grove School as a family affair: that the principal is a son-in-law of the board chairman, that the principal's wife, who is a teacher at Green Grove, is the daughter of the board chairman, etc. (PSRCBE Minutes April 5, 1954)

The Indian community of Green Grove saw conflicts of interest and a misuse of power with their Indian school committee. The Indian community asked the Board of Education to address this issue. Because the Board of Education could appoint and/or could remove individuals previously selected to serve on the Indian school committee.

The Indian committee may have misused its power as communicated in my findings. The Indian committee did exercise its power by maintaining the racial enrollment of the Indian schools. The Indian committee had the power to exclude African Americans and individuals with black mixed heritages from attending the Indian schools. 
My interviewees did not speak about the Indian school committees' efforts to screen students; the Hoke County and Robeson County Board of Education Minutes document the Indian school committees' actions in screening students from the Indian schools. One example from the Hoke County Board of Education Minutes follows the attempts of Troy and Maggie Locklear's to resist the Indian committees' barring their children from attending the Macedonia Indian School. This was first brought before the board in January 2, 1933 as a request for a hearing. Then later, on January 9, 1933 at the hearing, the board decided,

After hearing evidence on the part of the petitioner and on the part of the School Committeemen of said Indian School, it was decided that ther [sic] following judgement should be rendered:

In re: Adnel Locklear and Isabel Locklear and Annie Locklear, minor children of Troy Locklear and his wife, Maggie Locklear.

This matter coming on to be heard before the County Board of Education of Hoke County, N.C., upon petition of Troy Locklear herein filed, all parties being present before the Board, and being heard, the Board sustained the action of the school committeemen in barring said children from the Macedonia Indian school, until said Troy Locklear and his wife Maggie Locklear should produce sufficient evidence to show that said children have no negro blood in their veins to the fourth generation.

Notice of appeal was given by the counsil [sic], representing Troy Locklear (HCBE Minutes January 9, 1933). 
The story of Troy Locklear's efforts to enroll his students at Macedonia Indian School ended abruptly at a Hoke County Board of Education meeting. Subsequently, there was no further mention of Troy Locklear in the board of education minutes. There is no additional information to discover whether he could prove the Indianness of his children through verification of blood as the board requested. This abrupt end of the story could be contributed to the fact that the Macedonia Indian School burned in 1933.

Robeson County Board of Education Minutes also documented the Indian school committees' attempts to bar students not only from attending Indian schools, but also from riding the Indian school buses. An initial example from the minutes, documents the board of education requesting justification from the Indian community as to why the children of Robert Brewington were not allowed to attend the Indian schools,

Ordered that notice be given to the committee of district \#1, Indian, Burnt Swamp township, to be present the first Monday in December and show cause why the children of Robert Brewington are not entitle [sic] to attend the Indian schools of Robeson County (PSRCBE Minutes November 6, 1922).

Another example, however, shows the limitations of the Indian committee's power, the Indian Committee, "ordered the the [sic] children of J. W. Hunt be allowed to attend the Rennert indian [sic] school until further order of the Board" (PSRCBE Minutes March 5, 1923). In this instance, the board allowed children to enter the Rennert Indian school that the Indian committee had tried to screen out. The Indian committees may have had the power to control who taught in their schools and who attended the schools, but the board of education held the power 
to appoint individuals to the Indian committee. Thus, the board of education had the ultimate power concerning the decisions the Indian committee made.

This section explored what the segregated Indian schools were like for my participants as students, teachers, and administrators. The next theme, desegregation, describes the Lumbee experience during desegregation.

\section{Desegregation}

The theme of desegregation developed from my respondents' descriptions of their transition from their Indian schools into desegregated schools. My interview questions delved into my participants' experiences in order to understand how desegregation affected them as students, teachers, and administrators. I wanted to envision what my participants experienced in the transition from segregated to desegregated schools. Some of my participants didn't have a direct desegregation school experience. Hannah, for example, did not pursue a career outside the home as a teacher after her education in the segregated Indian schools. She worked as a homemaker, mother, and community leader. However, in my questions I also wanted to know how desegregation affected my informants' families and their Indian communities. Their responses also revealed the social, economic, and political ways that desegregation affected their lives.

In order to visualize the educational setting and understand the desegregated school experience, I asked about the school, the resources, and the materials for instruction. The answers to these questions enabled me to make comparisons of the desegregated and the segregated Indian schools. I then asked how the contemporary schools supported or failed to support my participants' academic achievement and their Lumbee culture. These probing questions were formulated in order to understand how 
desegregation not only influenced education for the Lumbee, but also affected Lumbee identity and culture.

The questions provided a foundation for comparison between the segregated and desegregated educational settings. Several findings concerning the desegregation experience and the contrasts with the segregated Indian school emerged from the data. The findings included (1) gains from desegregation and (2) the costs of desegregation. Other findings included the impact of desegregation on Lumbee students and their Lumbee identity. One of the poignant findings of the desegregation experience explained the loss of community in the Indian schools in exchange for educational opportunities. The final finding of the resistance scenario describes how the Lumbee community of Robeson County made a diligent effort to resist desegregation.

Desegregation is a theme that continues the story of the Lumbee transition from their Indian schools into desegregated settings. In 1968, Indian schools in Hoke County were desegregated. The Indian schools in Robeson County were desegregated in 1970. The respondents' expressed stories of thankfulness to the efforts of the black community and to Dr. Martin Luther King, Jr. for the strides in justice and equality that the Lumbee benefited from with the Civil Rights Movement. Henry explained how the Lumbee gained as much as Blacks through desegregation, but the Lumbee did not fight for desegregation because they didn't have a strong leader,

we gained as much as the Blacks if not more. A lot of our people felt that just because we were Indians, we did not have to same rights to public office. We had been deprived of use of public restrooms, and even [the right to visit] . . the doctor's office. We deserved the same privileges that they [Whites] did. I think 
we were not as strong fighting for it [civil rights]. We never really did not fight for it, as the Blacks, we never really seem to have a strong leader as Martin Luther King. That did not say that we did not want to be recognized, but they [Blacks] were in the forefront fighting for this and getting equal rights for everybody (Henry, 2004).

According to Henry, if the Lumbee had somehow produced a leader to galvanize them, this would have made a significant difference in the Lumbee fight for equity. The benefits of equity to the Lumbee will be presented next.

\section{Gains in Equity}

Desegregation meant gains for the Indian school community in the equity of resources and services available to the schools and the level of voice in the system. Henry describes the Hawkeye Indian School as able to receive more benefits because of the Indian community's greater involvement in the school system. They now had the opportunity to be involved in the schools at the board level in planning with Indian representatives on the board of education. This inclusion on the board of education permitted the Indians to discern whether they were receiving the same funding as other schools. Although Henry insisted that Hawkeye never suffered for resources, he did explain that with desegregation more resources did come to the school. Henry explained that the school received more resources because of the increased student enrollment the school and consequently the school also needed more resources,

We did not have that many students before desegregation, but after the desegregation we had more. ... We lost our high school students, but we now 
had elementary students. We had more supplies because the classes were larger after desegregation. We needed more supplies (Henry, 2004).

In contrast, Hart, the teacher, recalled the resources of Hawkeye differently from Henry, the assistant principal. Hart explained that, "When we integrated everyone got the same thing for materials, black, white, and Indians. But before this the white got more than the black or the Indian. The Indian got as least as possible" (Hart, 2004). In addition to equitable resources, Hart explained that there were more teachers for the students. As for the improvement in the teacher-student connection, Hart described that before desegregation more teachers taught in Hoke County, but they lived in Robeson County. After desegregation more teachers lived and taught in Hoke County, so there were community ties that were vital to understanding the students.

In addition to equal resources, Richard described that the schools began receiving equitable services from the school system with desegregation even though there were no major changes at the school system level,

they did a better job on keeping the building up ... they contributed that to having a better budget. ... I think too that attitude had something to do with it you know. They were more willing to come in and do some more things than they was before (Richard, 2004).

Richard perceived that the increased services and a willingness to work with the former Indian schools showed that there was an effort to ignore the needs of the Indian schools during segregation. The next findings show that the gains in equity were balanced by the costs to the Indian schools and the Lumbee community. 


\section{Costs of Equity}

There were tremendous costs of desegregation for the Lumbee. Richard explained that one of the costs of desegregation was the loss of Lumbee control of their schools. This loss of control affected the Lumbee Indians more than it affected the

Whites. Richard described the reality that with desegregation many school systems of color lost control over their schools; Whites retained control of their school system.

Another deprivation described by Hart were the students that he was not able to teach because of tracking. This loss, however, was balanced by increased opportunities for students to choose other courses and classes,

your better children, let's say students, were put in the better classes: English, math, chemistry. They didn't take your vocational classes. This is one effect. That was also a good thing, because our better students they did not have take the vocational course. But they could take other vocational courses, at Hawkeye ... you automatically took agriculture (Hart, 2004).

Hart described how the better students were tracked into courses, rather than the vocational classes which he taught. Hart was one of the few Indian teachers at Hoke High when I was a student there. And as he described, I did not elect to take vocational courses; I chose college preparatory courses.

Rachel and Hart experienced desegregation in former white schools. Their experiences illustrate what happened in the transition from the Indian schools. Henry went to the former black schools in Hoke County and only expressed a difference in the behavior of the students compared to Hawkeye Indian schools. He explained that he worked well as a teacher with the teachers and staff in the former black schools of 
Turlington and Scurlock, and it was a smooth transition. Henry explained that it seemed that the black students wanted to have more control over the schools In contrast, he did not notice this trend in the Indian students that he knew when he functioned in the role of an administrator in the Indian school. While Rebecca and Richard remained in the Indian schools, their experiences showed that desegregation did not affect the Indian schools as sharply as my other respondents reported.

Rachel explained that she volunteered to go to the former white school in Fairmont. She left Ashpole Center because her daughter was going to school there at Fairmont, and she wanted to be there to watch out for her daughter. She also felt that those students needed a good teacher just as her Indian students needed a good teacher. However, she did experience some differences in the white school from her teachers and the administrator,

I knew I was a good teacher and but I kind of intimidated them...I found out that I was ahead of them. I sort of intimidated them, but I did not mean to. But this was how I taught with my learning centers, lesson plans, and these teachers would look at me as though I was trying to show them up (Rachel, 2004).

Rachel did experience loneliness as well in the school and missed the Indian community of teachers to support her. She explained that the other teachers were cordial, but that sense of community and belonging was missing. The desegregation experience was a change that benefited my informants and it came with some costs. Desegregation's impact on students is explored in the next section. 


\section{Impact on Lumbee Students}

Lumbee identity was one aspect that suffered as a result of desegregation in Hoke County according to my Hoke County participants. Hart explained that,

[In] the Indian school, the children had an identity, and they were proud. Integration came [and] they lost this, because they were looked down upon by the white and black race because they were a minority. It has had an affect on them . . . The bad thing [is that] the students lost the relationship they had with the teachers. They became a number, not an individual ... We were turning out good students at Hawkeye (Hart, 2004).

The Indian schools seemed to isolate the Indian students from discrimination and prejudice. In desegregated schools the Indians lost this shield as well as the advocates who cared for them. Hart explained that the students were served better in the smaller school. In the larger desegregated school, they were not only viewed as inferior, but they were reduced to a number. Hart's explanation that the Indian students were reduced to numbers is in reference to the lack of individual attention the Indian students received in the desegregated schools. My Hoke County participants expressed a stronger desegregation experience than my Robeson County participants. My Robeson County participants could sympathize with losses of voice, identity, and agency that my Hoke participants described. There were Indian communities in Robeson County where Indians were the minorities in the schools as in Lumberton, North Carolina. This was in contrast to other areas in Robeson County where Indians remained the majority as in Pembroke. Desegregation had very little affect on the Pembroke Schools' identity as 'Indian' schools. The Indian majority population in the schools reduced the impact of 
desegregation for these schools. I will present the rationale for the diminished impact of desegregation further in my discussion of resistance.

\section{Loss of Community for Academics}

The informants' narratives described the educational advantages of desegregation for the Lumbee in more resources, courses, and educational opportunities. However, such educational gains came at a cost to the Lumbee students' identity and the loss of community that the students had in the Indian schools. Rachel explained this loss of community as a loss in connection with the parents

At the integrated schools, the backgrounds changed and you did not know them [the students] or their parents. This was deleted. You did not get connected with the child and the parent. I thought this was important to get to know these children (Rachel, 2004).

This loss of connection with the parents led to a loss of closeness and community that was present in the schools. Teachers explained how important this connection was because of the investment of the teachers in the students' success. Desegregation inhibited this connection because the teachers and students were put in schools outside their community. Not being a part of the community severed the teacher's connection with students because teachers knew very little about their students from their contact with them in the classroom. Richard explained that,

In order to instruct a child, you need to know something about his background ... you really need to know where he came from. What kind of home environment he is living in (Richard, 2004). 
Hart further elaborated that when there is a connection with the community, the teachers are able to work with parents for the success of the students. He explained that this changed with desegregation,

students knew the teachers and teachers knew the parents. And they [teachers] could call on the parents for help. However after integration of schools, the teachers did not know the student or parents. And they [teachers] did not care if you pass[ed], fine. If [you did] not [pass], that was fine (Hart, 2004).

Hart explained that with desegregation teachers didn't have a connection with the students. Consequently, the teacher's concern for their students' success and their willingness to be advocates for the students was missing. He further explained that as a result the Indian students were failing in the desegregated schools,

We just did not [have] among the Indian students, ... at the high school, enough role models. The teachers did not take as much interest in the Indian students, not as they did white or black races - especially the white. This is why our Indian students are dropping out. Our better students, some drop out. I do know the attendance would be better if we had kept our [Indian] identity and kept our Indian schools as we had in the 1950 and 1960 (Hart, 2004).

Hart perceived that Lumbee student school failure and eventual drop out was due (1) to the lack of Indian teachers as role models and (2) to the lack of teacher investment in the Lumbee Indian students. He felt that if the Hoke County Indian Community had maintained their Indian identity through their Indian school it would have made a positive impact on the Lumbee students' attendance. 
Rachel tried to be an advocate for the Indian students in the desegregated school. As a member of the Robeson Board of Education, Rachel unsuccessfully tried to get more parents involved with the schools where Indians were in a minority. She felt that teachers as well as parents could become role models and advocates for the Indian students. She described her efforts in Fairmont,

I kept pushing our students in filling out applications and awards. Those two years we had two Indians who were valedictorians. Every teacher was working with their own race and I worked hard to do this for these [Indian] students ... I think integration hurt students in this area (Rachel, 2004).

Rachel also tried to get parental involvement from the Indian community. Parent apathy existed in Fairmont, and Rachel was unable to get parents involved in the schools. She wanted the parents to be advocates and role models for the Indian students. Richard also perceived apathy from the parents in an Indian community which he attributed to the Indian parents' lack of agency in a white dominated setting,

Because ... where you have a school [with a] small minority of Indiansstudents, like Lumberton High school for instance. The parents just don't feel, they don't feel welcome. . . It's hard to have an impact where you ... have a minority of students you know, because the majority always rules so to speak. And ... so many times our parents, rather than to fight that, they just quit (Richard, 2004).

Richard further explained that the Indian parents didn't have to intervene in the Indian schools to advocate for their children. Since the Indian teachers were the role models and they could entrust that their children were in the best capable hands. As a result when the 
situation changed, and the Indians were no longer the majority in the schools, parents didn't know how to intervene or perhaps parents didn't believe it would be worth the trouble.

Respondents shared examples of how the desegregated schools tried to involve Indian leadership and tried to address the needs of Indian students. Henry explained that an Indian was hired as principal of Hoke High, the former white high school, and this had a positive impact on the Indian community. Robeson County findings showed the contemporary desegregated schools attempted to address the cultural and academic needs of Indian students through the federal Indian education programs provided by Title VII, ${ }^{31}$ enacted in the 1970's. Title VII involves programs and services to address the cultural and academic needs of the students. Richard explained that the Title VII Indian education programs helped by funding an Indian Youth Counselor, who was an advocate for the Indian students in the schools and served as a liaison to the Indian parents and the school

they're there to talk and hopefully solve [problems] and give support to the Indian students. That's their primary concern, and also they meet with the parents of the Indian children. That's, . . one of the positive things (Richard, 2004).

Other efforts they described included additions to the curriculum to integrate Native American material during the month of November in North Carolina because of its designation as Indian heritage month. Native American student organizations also formed to help students develop a voice and presence in their schools. Even with these accommodations, there was still a high school drop out rate among Indian students. 
Richard contributed the high drop out rate to some Indian parents' low value of education and the lack of students' agency in school,

Our Indian students, of course, we have a high ratio of drop outs. And that's not good. Part of that is the change in our living style and the value that we put on education. We have some of the parents that don't put a high value on it. And also some of the children get turned off the way the schools are operated. [The students $]$. . . they don't have a voice in it [school] . . . and they just drop out (Richard, 2004).

Richard reasoned that students needed a connection and involvement in the school as well as parents who had a high value and concern for education. These findings described the costs of desegregation in the loss of Lumbee students' identity and school success. The next category of resistance describes the unique finding in Robeson County regarding the resistance to desegregation.

\section{Resistance}

Resistance to desegregation was unique to Robeson County. This resistance to desegregation resulted from Lumbee attempts, in Robeson County, to keep their Indian schools. Resistance to desegregation meant that some schools in Robeson County could still be considered "Indian" schools because Native Americans were the major cultural population of those schools. The segregated nature of these schools was due to residential patterns in the Indian community and was reflected in the school population. Resistance was not present in Hoke County, even in the major Indian community in the area of South Hoke, the former Indian school Hawkeye. Hoke County expressed regrets about the loss of the school and the sense of community, but there was never an 
organized movement to resist desegregation. There were sentiments in the Hoke County Indian community that it was better in the segregated schools.

Richard, an administrator for Robeson County, gave some background explaining the uniqueness of Robeson County regarding segregation and its influence on the Lumbee,

Pembroke wasn't as segregated, you see, we've always had here in Pembrokeyou had a majority of Indians. We had places like a drugstore places we could go in, and eating places. Whereas you know in some of the other places, Lumberton and around, well you couldn't do that. You wasn't allowed to do it (Richard, 2004).

Richard explained that as a result of this Indian majority in Pembroke, the Lumbee community was isolated from the harshness of segregation in the form of open discrimination they experienced when they ventured outside Pembroke. Isolation of the Indian community coupled with their majority Indian presence served to reduce the impact of desegregation on the community as Rachel explained,

You know I really don't think it had that much effect on the family, as you know our churches are not integrated. I did not think desegregation had a large affect on the family because it was just an order to send your child to an integrated school. I believe the schools made a pretty good effort to make things go smoothly (Rachel, 2004).

Students were affected by desegregation significantly more than the family or the community, according to Robeson County participants. However, the community did react to desegregation as Richard described, 
Now I don't know any Indian that would wanted to integrate. Now you had the black-you know they had meetings wanting to integrate the schools. But we never had any Indians [desiring desegregation]. The Indians were satisfied with the school. The only thing we wanted was our share of resources ... And I had people at school, ... really I would have a problem at the beginning of the year, because they didn't want a white teacher or a black teacher to teach their child (Richard, 2004).

The Lumbee community in Robeson County resisted desegregation and did not want their schools integrated. Richard explained that as a principal during this time he experienced the reaction that the Lumbee community did not want Whites or Blacks teaching their Indian children. But desegregation came and according to Richard it didn't change things for him in Pembroke or at Pembroke Elementary where he taught and was an administrator (see Figure 10 for a picture of the contemporary Pembroke Elementary), you must remember I was in a predominantly Native American school, and ... because of our community, our student population didn't change a whole lot. Now the one change that we did have was ... we integrated the teachers. And where at one time I had 100 percent Native American teachers, after integration, we had something like $30-40 \%$ Indian and maybe $10 \%$ black and the rest white. And two, the majority of those teachers, the new teachers that came in, lived in a different community from ours (Richard, 2004).

For Richard, the significant change was the addition of white and black teachers from outside the Indian community in the school. A perusal of the classrooms revealed that the school still remained predominantly Indian. 
Because of the Lumbee closeness and kinship there is a pattern of generations living in close proximity to each other (Blu, 1996; Dial, 2001). As a result of these residential patterns, entire communities are comprised of Indian families. Consequently, the majority Indian population of the communities is also reflected in the schools. These residential patterns helped reduce the impact of desegregation on the former Indian schools. Pembroke Elementary School is an example of a former Indian school which retained its Indian school identity because of the Lumbee majority school population of the school which is located in an Indian community. Richard explained the living patterns of the Lumbee and how this impacts the schools,

And the Indian community, if you notice even today, they tend to congregate in one community, the majority of them ... I'll tell you about Union-Hopewell. Well now, that school even today, it's probably $90 \%$ Indian. Pembroke Elementary School is $90-95 \%$ all-Indian today and that's because of the community. Indian has a tendency to - they love to stay in close proximity to each other. You know that's just ... that's a part of our culture (Richard, 2004).

Richard commented on this impact of desegregation for schools with a Lumbee majority in contrast to schools with a Lumbee minority commenting that in, "other areas where you have a small number of Indians, you don't have ... that support system that you have in the predominantly Indian school” (Richard, 2004). 
Richard believed that Lumbee students' succeed because of their majority status and their community control over the Indian schools. He even illustrated the positive impact the Lumbee community in Pembroke had on the students and the school, we did have one advantage at Pembroke that you didn't have at all the schools. A lot of our Indian teachers and professional people lived in Pembroke, so they were more supportive from a financial standpoint (Richard, 2004).

Lumbee parents of children who attended Pembroke Elementary School would financially support the school, whether the school needed equipment or other resources. All Richard had to do was justify the need to the parents, and it was funded. He even explained how the school had computers before any other schools had computers for students. Richard explained that the parents insisted they have the best for their children, so they raised about $\$ 24,000$ to purchase computers for the schools. These findings discussed the resistance of the Lumbee in Robeson County to desegregation as well as the impact of desegregation on students and the next section explores the theme "understanding segregation and discrimination".

\section{Understanding Segregation \& Discrimination}

My respondents' understanding of the Lumbee perspective of segregation and discrimination unites their experiences in the segregated Indian schools and the desegregated schools. Although I did not directly ask any questions to shape this theme, the theme emerged from the data in my participants' understanding and awareness of segregation. This understanding of the realities of segregation was evident in the respondents' narratives. The Lumbee chose to self-segregate to create a culture of safety 
in response to living in a segregated society. They were classified as black and this selfsegregation was a response for the Lumbee community to affirm their Indian identity. Their acceptance and reaction to question this reality of segregation was found in their stories.

Several understandings concerning segregation and desegregation were revealed. An awareness of oppression and discrimination helped the Lumbee understand the system of segregation. The circumstances of experiencing oppression and discrimination caused them to question segregation. Lumbee interactions or refusal to interact with Whites and Blacks during and after segregation were examined. The powerlessness Lumbee experienced by their lack of economic political agency during segregation is uncovered as well. Although there was a resistance to desegregation, the Lumbee were empowered by desegregation.

\section{Understanding Layers of Segregation}

Pembroke helped to shelter the Lumbee from the discrimination and the full impact of segregation that they would have experienced outside their isolated Indian majority community. Richard explained that the Lumbee Indians self-segregated and therefore had little contact with non-Indians during segregation in Pembroke,

And it was isolated, now we was isolated from the white ... a lot of our Indian had ... no contact. 'Cause you remember all, at the time of integration, all the parents had went to all-Indian schools. And they lived in an all-Indian community, they attended all-Indian church, and all our social activities was allIndian (Richard, 2004). 
Richard explained that the change for the Indian community came during desegregation when they had to interact and communicate with a white or black teacher. Most of my informants explained that Pembroke protected them from the full intent of segregation until they experienced discrimination first hand outside of the Indian community of Pembroke,

We knew that if you went to the landlord's house you had to go to the back door to ask for something - the Blacks and the Indians [understood this]. And this made you feel second-class by having to do this. But in [the] Pembroke area, the business were owned by the Indians and it was a different setting when I was up here (Rebecca, 2004).

Rebecca explained that, as a child, her all-Indian experience didn't prepare her for the reality of a desegregated society. Nevertheless, she understood segregation because of the inferior treatment she received as a child by the landowner. This made her feel second-class. Rebecca knew that the Indians in Pembroke didn't feel inferior because of their economic power they experienced by owning their own businesses. She explained further that,

As a child you felt second-class anyway, and you were put in a class and it did not bother me. Or [to] go to the back door at the landlord's house it did not bother me, because I did not know any better. If you do not have the knowledge you accepted this (Rebecca, 2004).

Rebecca didn't have the knowledge to know that she could question this inferior treatment that she was given until her teachers taught her differently, 
like I told you my 7th grade teacher, how he taught me to be who I was and to not degrade myself. We had the movie theaters, there was one section for the white, [and] one section for the black. And he taught us to be proud of our[selves] and not even go into that theater, because they were classifying us as half citizens. And it was like, ... you're better than that (Rebecca, 2004).

Rebecca explained that her teachers in the Indian schools taught her how to question this treatment and how to feel proud of herself as an Indian. Her teachers stressed that she should not be treated as an inferior individual.

Participants explained that they were aware of the system of segregation and racism wherein Whites felt superior to Indians and as Rachel explained,

Even today you know that a black or Indian has to be twice as qualified. We still have this problem and it was more open back then. They were white and you [were] Indian and second-class. Today it is not as open, but it is there (Rachel, 2004).

As Rachel explained during segregation the system of racism and discrimination was more overt, while today racism and discrimination is more covert. She asserted that people of color are still at a disadvantage because there are still obstacles for them to overcome. Thus, the Lumbee have to be better equipped to challenge these obstacles, and even then that does not ensure success. These findings describe Lumbee understanding of the system of segregation. The next category further explores the Lumbee experience with oppression and discrimination. 


\section{Oppression \& Discrimination}

The realities of oppression and discrimination that the Lumbee experienced living in a segregated society were quite apparent in their stories. All of my participants expressed brushes with discrimination and vehemently expressed the oppression of being Indian in a white-dominated segregated society. Rebecca explained one vivid example, from her childhood, when she had to walk to school while the white children rode a school bus,

The Indian children would throw would dirt at the [white] bus and sometimes the white bus would stop. And white and Indian children would fight. They would call one another names. But I never fought, the big boys would do most of the fighting, and they felt like they were discriminated against and they only got to go to school once in a while (Rebecca, 2004).

Rebecca understood the reality of the inequity of resources and opportunities. These inequities and biased opportunities caused the Indian students to react with the only power they had available at that time - their frustration. She explained that the Indian students' limitations to transportation prevented them from attending school on a regular basis since they had to walk to school. Rebecca explained that students who lived within five miles of the schools had to walk while students who lived farther could ride the bus - if the transportation was reliable. Hancock (1935) documented the inadequate transportation in Robeson County, especially for Indian and black students. 
Another example of discrimination was the reality of separate county and city school systems that were present in Robeson County. As Rebecca explained, the Indian students could not go to the city schools, only the county schools. Even if their parents stayed in town and paid city taxes, ... because it was segregation. Therefore the city school [system] had a black and white school, but the county had three schools [system] white, black, and Indian (Rebecca, 2004).

Additionally, the separate county and city systems in Robeson, enabled Whites to have a double vote, so they continued to maintain control over the administration of the schools until this was ended in the late 1970s (Sider, 1976; Thompson, 1973).

\section{Race Relations}

Respondents described the interactions and relations between the racial populations during and after segregation in their narratives. Rebecca explained that before desegregation her segregated reality and the interactions that she had with Whites and Blacks helped to prepare her for a desegregated society,

You knew you had to work together, but that was as far as it went. But you did not go to church together, or school together or socialized together. I was kind of fortunate, because some of them [other Lumbee] it was not that way. It happened that we had a white family and a black family, but mostly there was no interaction between the races. We were on a small farm. The Whites might be the landlord and never have any dealings with you (Rebecca, 2004).

This reality of dealing with another black family who was in a similar situation of being tenant farmers on the white landowner's farm showed Rebecca similarities between her family and the black family. She explained that viewing the similarities of her family, 
the black family, and the white landowner's family helped her to perceive that they were all human beings. Rebecca's family and the black family were both trying to earn a living, under the 'kind,' but still oppressive power of the white landowner.

This understanding of dealing well with other races was where my participants differed. Robeson County participants expressed the most difficulties with race relations, specifically with Blacks. Rebecca and Richard both expressed the Lumbee community's problems with black teachers. When Rebecca was teaching at Union Elementary (Figure 11) during desegregation a volatile situation occurred where two black teachers were to start teaching and the parents were staging a boycott. The Indian parents were not going to let the children go in the black teachers' classroom. The parents would walk down the halls and ask the teachers what grade was the class and push the student into that classroom ... They [the parents] were determined that no black teacher was going to teach their children (Rebecca, 2004).

Rebecca explained that the entire school met after school and remained with the black teachers to wait out the parents, so they would not harm those teachers. She explained that the next morning the teachers did not return. The community resisted the presence of black teachers. This is an example of Lumbee internalized racism toward Blacks. Richard explained that black teachers did not want to teach in the Indian schools even though, as a principal, he had tried to recruit black teachers for his school during desegregation. The hesitancy of black teachers to teach in Lumbee schools is understandable considering the community boycott of black teachers as Rebecca described. 
Richard explained that because the Lumbee self-segregated themselves from Blacks it was difficult for them to learn to deal with other non-Indians,

It was very difficult for some of the black teachers, in particular, to come to our school, because in the past we just had very few black people in our community. . .. in the community around Pembroke we had very few black people, so the [Indian] people wasn't accustomed to dealing with people of different races. Now that was by choice, our people's ... they segregated themselves (Richard, 2004).

Richard reflected that the Lumbee had few interactions with Blacks by choice, the Lumbee chose to self-segregate. Also, there were very few Blacks who resided in the Indian community. Richard reasoned that the black teachers did not want to work in Indian schools because of the schools' preference for Indian teachers. He described that many Lumbee teachers preferred to work in Indian schools, and they preferred their children to go to Indian schools. It seems that black teachers' awareness of Lumbee internalized racism and the Lumbee preference to self-segregate from Blacks could have also reduced the desire of black teachers to teach in the Indian schools.

Hoke County participants did not express difficulties teaching white or black students nor describe problems working with white or black teachers. In fact, Henry explained, "We learned a lot from the Blacks and they in turn learned from us" (Henry, 2004). He even further commented on the present tension between the Indian and black students at Purnell Swett High school in contrast to his experience in the desegregated school,

The Blacks came in to work with us, they seem to work with us well, I don't remember us having any white teachers that consolidated with us, we would have 
a little bit of problem with the black, but nothing out of hand. Nothing like they are having at Purnell Swett (Henry, 2004).

Only one participant shared a relevant memory regarding Indian-white relations. Richard expressed how his relationship with his friend from the army enabled him to attend and graduate from the University of Georgia with his master's degree in 1951 before the college had been desegregated. The fact that the university had no category for Indians and that they didn't allow Blacks enabled Richard to benefit from being classified as white. Such a move was savvy for Richard, but it also demonstrated how people of color didn't have power in a segregated society; rather, the economic and political power was held by Whites. These data will be examined in the final category entitled "powerless."

\section{Powerless}

The final findings in the theme of understanding segregation and discrimination describes the lack of power that the Lumbee experienced in improving their political and economic conditions because of segregation. Richard explained the lack of political agency the Lumbee had in affecting change over their schools:

Yes, for a long time you see, we as administrator[s], we had a white superintendent and ... most of our board members were white. . . if you don't have anybody in ... authority it makes it real bad for you even today. ... We didn't have nobody in our central office, no Indians, and those when they did get some in there, they had limited authority in what they could do (Richard, 2004).

Richard further elaborated that the school system was situated, so the Lumbee couldn't change anything. He explained, that even if the Lumbee tried to change things, they 
could be replaced by the board with someone who wouldn't question the board. A few Indians held positions at the board level, such as the Indian school committees and the Indian truancy officer; these board positions could not do anything to affect the school policy.

The Lumbee also lacked economic agency because they were tenant farmers working the lands of rich white landowners. This relationship combined with their lack of education in keeping records hurt them,

when [the Indian farmers] they got ready to settle up with the cotton crops and what little bit of tobacco [raised], they would be in debt with the merchants where they bought their stuff from. And lose their land to these merchants over these taxes. My great grandfather on the Cummings side, lost all but 10 acres of land. If he had to give up 40 acres to save 10 acres, he was in debt pretty good (Henry, 2004).

As the Lumbee became more educated they kept better records, and this helped prevent such debt situations from occurring (Sider, 1993). However, for the Lumbee to gain an education would be detrimental to those who had taken advantage of them. The landlords did not want to encourage the Lumbee children to become educated. The landlords wanted them to assist their parents in working the farm. As Rebecca explained, a lot of landlords did not want children to go to school. Therefore a lot of them [children] had to stay home and work, I was lucky to have parents that wanted and saw $[$ to $] \ldots$ their children ... go[ing] to school. . . . Even though a lot of landlords would not allow children to go to school, but our landlord was one that allowed us to go to school, as long as we got the work done (Rebecca, 2004). 
Rebecca explained that her parents worked hard to compensate for the loss of her efforts on the farm in getting much needed work done, but they wanted her to get an education to improve her condition. My respondents' narratives emphasized that the Indian teachers stressed education to their students because they were aware of the economic reality of their students. The teachers encouraged the students to get their education to elevate themselves in order to break this cycle of poverty. The Indian teachers stressed education as the key to success.

\section{Unanticipated and Inconsistent Research Findings}

I encountered unexpected findings in my research. These findings are of the 1) origin of Jacob's Point School in Hoke County, 2) inter-group conflict in the Indian community in Hoke County, and 3) class and disconnection in the Lumbee community. Inconsistent research findings related to teacher apathy and educational mediocrity which did not support findings from my pilot study. Another unanticipated finding was the lack of Indian identity as a theme in the research which will be discussed further in chapter 5 .

\section{Origin of Jacob’s Point}

The archival research has shown that Jacob's Point was an Indian school inherited by Hoke County when Hoke County was carved out of Robeson County in 1911. A deed for the school dated February 27, 1894, shows that Jacob's Point was part of Robeson County Public School district \# 20. The Jacob's Point building was sold to the Indians in Hoke for $\$ 150.00$ in 1914 for a school. However, Hannah mentioned that it was, "a school they said that it was started ... it was a slavery building" (Hannah, 2004). No mention was made of the Jacob's Point building being a slavery building, although the

board of education minutes for April $6^{\text {th }} 1914$ refer to moving the "colored school 
[Jacob's Point] to a more central point" (HCBE Minutes). It is unclear if the board members were referring to the school being a 'colored' school or if the board members were referring to the status of the school as being an Indian school due to the classification of Indians with Blacks as 'colored'. Jacob's Point school is near my parents' home in Hoke County. The present owner of the deed to the school and the land of Jacob's Point, Ms. Elizabeth Brown, is my parents' neighbor. I asked about the history and Ms. Brown's daughter explained that she had heard mention of the school being used to teach former slaves. She did not have any evidence or documents to support this former slave house theory. This theory was based on what she had heard. This information about the possibility of the school's origin certainly was a surprise.

\section{Indian Conflict in Hoke County}

A further surprise was that the Indian community in Hoke County tried to prevent the Indian students from attending the newly established Antioch Indian School. Hannah explained that someone was always trying to destroy and/or vandalize the building. She described one incident of school vandalism concerning the destruction of a gas light her father had specially ordered for the school,

my dad ordered a gas light ... it was so beautiful, went there one Monday morning and ... somebody had come in and broke it all to pieces. ... We had a lot of problems with [vandalism] ... I never heard my daddy say nothing about calling the law or going to the law ... he had so much patience. ... We just went along, after awhile, ... some of them died and some of them moved out and left the school alone (Hannah, 2004). 
Hannah described her father as a patient man with these acts of vandalism because he persevered and did not call the authorities. She explained that he did act when individuals made threats to the children to prevent them from going to the school, they made threats about going out and throwing us out it the window. And my brother they talked to him, and you know he was young and he told my dad. And ... I'll never forget that $\mathrm{Pa}$ went into the house and got his shotgun and laid it in his buggy with his mule and left. And we never heard him ... and all I know is they didn't bother us no more (Hannah, 2004).

Hannah explained that, for the moment, her father had taken care of the situation concerning the harassment of the Antioch Indian students. However, she explained that in order to cause the cessation of the harassment issue, he did have to call authorities. Then the harassment stopped.

Another unexpected finding was that the source of animosity between the two Indian communities of Antioch Indian School and Macedonia Indian School was accusations of black blood. Indians in Macedonia accused the Indians of Antioch of possessing black blood (D.B. Dial, personal communication, February 28, 2005). This is another example of Lumbee internalized racism directed within the Lumbee Indian community. It seems that in Hoke County, the Macedonia Indians considered the Antioch Indians as inferior to them. The Macedonia Indians resisted association with the Antioch Indians. The Macedonia Indians feared being considered 'black by association.' Thus, the Indian community of Macedonia refused to attend the Antioch Indian School, and they wanted their own school built. The Macedonia Indian community believed that the board owed them their own school because their students had to be bused to the 
Robeson County schools when their school burned in 1933. However, the board of education, instead of building two separate Indian schools in the separate communities, built the Antioch Indian School in 1935-36 in the Antioch community (HCBE Minutes; MacDonald, 1991). Considering the animosity that the Macedonia community had against the Antioch community, which Hannah, Henry, and D.B. Dial explained, it could be perceived that the Macedonia Indian community resented the Antioch Indian community's new school. As a result of this resentment members of the Macedonia community may have vandalized the building and harassed the Indian children of the Antioch Indian School. Hannah explained that she was too young; she never really understood why they did this, but could only tell me what she remembered. My data revealed puzzling information concerning the Indian schools of Hoke County. It was disheartening to hear about the effects of inter-group conflicts. Animosities between the two communities seem well buried in the past. This shocking evidence of strife was unearthed in my research. Currently, the two communities exist peacefully with no apparent conflicts.

\section{Class and Disconnection in the Lumbee Community}

Both Rebecca and Rachel shared data concerning the feeling of disconnectedness from the Lumbee that they experienced concerning the Lumbee communities in Rowland and Fairmont. This was a surprising piece of data for me to discover because this was the same disconnectedness that I experienced as a Lumbee in Hoke County. I heard other

Lumbee Indians from Scotland and Cumberland County express similar feelings of disconnection from the Lumbee community (in personal conversations). Rebecca explained that the Indian community in Rowland felt disconnected from other Lumbee 
Indians in Pembroke. She explained that the Rowland community had the smallest high school in Robeson County; the community was comprised of Indians who were of lower economic status compared to other higher economic status Indian communities like Pembroke,

I think the Rowland school, they still feel left out and less important than the other children in the county ... The Rowland area feels like they do not get anything. Because of the large concentration of the Indians in Pembroke, the LRDA ${ }^{32}$ is right here in Pembroke and Prospect. And they [the Rowland Indian community] do not feel as part of the tribe. They are kind of left behind (Rebecca, 2004).

Rebecca felt that the source of the disconnection of the Rowland Indian community with the other Indian communities in Pembroke and Prospect was not mainly economic differences resulting from one community having more resources than another. She believed the difference in the economic resources the schools had was due to the parents' aggressiveness in advocating for their children.

However, Richard viewed community economic differences as the source of the disconnection in the Indian communities. This was evident in Richard's comparison of Hawkeye Indian School, the Indian communities of Rowland and Fairmont to Pembroke's Indian schools,

I noticed one thing in particular about Hawkeye at that time, the Indians they was more deprived [in Hoke County] than the Indians here [in Pembroke]. I mean it was very obvious that we had more advantage here. And I think one thing, because you see our Pembroke, the town with the school, there we had more advantages you know so far as education. And at that time ... a lot of the Indians 
that lived in Rowland and Fairmont ... would come up here to go to high school ... because their high schools just was not up to par (Richard, 2004).

Richard referred to the time of segregation that existed prior to 1968 in reference to the Lumbee community in Hoke County which attended Hawkeye Indian School. He explained that the Hoke County Indian community had less economic resources than Pembroke. It is true that the Lumbee community in Hoke County did not develop a substantial Indian middle-class comparable to the middle-class of educators and other white-collar professionals of Pembroke (Peck, 1972). Peck (1972) addressed this economic difference in class in his research about the Lumbee Indians. He identified the Pembroke Indian as the, Indian Town Indian, who is middle class and is secure and proud of his Indian heritage. The Indian Town Indian knows that this Indian town, Pembroke, is his place and he belongs (Peck, 1972). Peck, however, does not address disconnection within the Lumbee community itself. This sense of disconnectedness with the Indian Town Indian or Pembroke Indian, that my informants shared in their narratives is what I have personally felt. I attribute the source of my personal disconnection to my background and upbringing in Hoke County. I perceived that this, Indian Town Indian from Pembroke, was the ideal Lumbee and that the closer proximity and ties that a Lumbee had to Pembroke, the 'center' of Lumbee culture, the more "Indian" one was. Thus, I felt that there was an understanding that if one were not a Lumbee Indian from Pembroke or Robeson County that person's Indianness was questioned. I did experience a disconnection with the Lumbee community by not being reared in either Pembroke or Robeson County. These findings about Jacob's Point and the disconnection of the Rowland community were all surprises that I did not expect to find in my research data. 


\section{Teacher Apathy and Educational Mediocrity}

Teacher apathy and educational mediocrity were findings in my pilot study which were not supported in my research study. The teacher informant, in my pilot study, recalled the Indian schools as places where mediocrity and teacher apathy could flourish. He explained that the white-controlled school system cared little for progress in the Indian schools. There was a conscious intent to forget that the Indian schools existed. Because of such a lack of concern for the running of the schools, he explained that the teachers were autonomous. The teachers, he stated, could teach or not teach as they desired due to the lack of supervision. He also described that as a result of his inferior education in the Indian schools, he struggled when pursuing his graduate degree in another educational setting. Thus, there was an impression from my teacher informant in my pilot study that the education he experienced in the Indian schools was inferior. This finding of teacher apathy and educational mediocrity was not supported by my research.

Hart was the only participant who discussed a kind of apathy that he felt from his teachers. He spoke specifically about one teacher who felt had no concern about the education of the students and didn't motivate them.

Mr. A. was one teacher who could have cared less about the students in high school, as I recall he had no concern. Ms. M. she was tough, Mr. C. was tough, our teachers were concerned back then but they did not motivate. I tried to motivate my students. I told them of the schools in the North compared to our schools in the South. About the black and especially the white schools got more materials. And the parents motivated them and we did not at that time. [The schools] They were more advanced than ours (Hart, 2004). 
Hart also was the only participant to speak negatively about the quality of education he received in the Indian schools. The difference he perceived between his Indian school experience and other school experiences helped motivate him to become a better teacher when teaching his own students.

I realized that our school was below the educational level that other schools were doing. It caused me to look at myself and come home, go to college and become a teacher and do the best I could. I think my high school experience, . . . having been raised rural, ... not having [the] opportunity to go to school, ... not having a good role model, and having the one good role model - it made me a better teacher. It made me a better teacher, because I could understand students who had problems [and] ... were unable to attend school or did not want to attend school. I encouraged them to be better and attend school and they would not limit themselves to what they could do (Hart, 2004).

Hart could relate to his students because he shared their background. Hart had experienced the same obstacles that his students faced. Consequently, he could encourage his students, provide guidance and help them define their present goals and future opportunities.

He also explained that his education in the Indian schools made it difficult for him to pursue other educational opportunities,

I went to Pembroke my first two years of college it was easy, but when I went to NC State I paid for it, it was like going from [a] dark room into a light room. I had to hustle to get good grades at NC State, at Pembroke I [was] sort of floating around. Since then, Pembroke has become a much better school than it was when 
I was there in 1957. In 1958, I transferred to NC State and finished at State (Hart, 2004).

Hart went to Pembroke in 1957 and then transferred to North Carolina State University. He was among the first Lumbee to go to school at North Carolina State University. Hart explained that he struggled there because of his limited education and his lack of role models in the Indian school. However, he felt these challenges made him a better teacher. He had an empathy and was really perceptive when he encountered students who had the same problems he had.

In chapter 4, I presented the categories of the data and the connections between the categories that my study yielded. The next chapter will provide a summary of my research and a discussion of the themes of my research findings. 


\section{CHAPTER 5}

\section{DISCUSSION OF UNDERSTANDINGS FROM THE INDIAN SCHOOLS}

The Lumbee have always, of necessity, exhibited a great degree of selfsufficiency; it is the characteristic, more than any other, that has allowed them to maintain their identity as a people, and it is this trait that enables them to continue their struggle, for despite past setbacks, the Lumbee remain determined to achieve full recognition and equal rights - as Indians and as Americans. They refuse to accept other's narrow definitions of "Indianness." They know that the way a person looks or behaves does not make him or her a Lumbee. Instead, they know that their Indianness lies in what they share - a love of their Robeson County home, a special history and heritage, and perhaps most important, a certain way of viewing the world born from their unique past (Dial, 1993, p. 23).

This chapter discusses the interviewees understandings of the Indian schools as

gleaned from their narratives. The discussion is prefaced by a summarization and the major findings of the study. Then the discussion begins with the three central themes that emerged from my respondents' stories of the Indian school experience. Unanticipated results from the critical examination of my data will be discussed. The discussion will link the themes of the study's findings to the review of literature. Also, the discussion will probe the facts and critically examine the data. Such an interpretation of the results of the study within the existing literature is to examine the relevance of the study in contributing knowledge of the Lumbee Indian schools to historical educational research and American Indian educational research. 


\section{Research Summary}

The Lumbee Indians of North Carolina were the recipients of a unique segregated educational experience. In general, the Lumbee experience in the segregated Indian schools has been left out of the historical discourse of segregated education and Native American education. My research assesses this gap by examining the impact of Indian schools on Lumbee tribal identity, academic achievement, and community involvement. In addition, I examined the contextual impact of the shift to desegregation on Lumbee school experience.

My oral history research involved six members of the Lumbee community who experienced education in the segregated Indian schools in Hoke and Robeson Counties of southern North Carolina. My oral history research involved interviews with teachers, students, or administrators. Participants were selected based on recommendations from members of the community as good individuals to interview. The main data sources were the participants' oral educational histories and were supported by limited archival research such as board of education minutes. An analysis method for categorizing and classifying data was employed. The analysis method is similar to the constant comparative method of data analysis.

Major findings in the data show that the Lumbee ${ }^{33}$ students not only experienced a culturally supportive education, but also experienced a resource poor environment in the segregated Indian schools. Conversely, desegregation provided increased equity in educational resources and educational opportunities for the Lumbee students, but resulted in a loss of community, identity, and diminished the teacher-student connection. 
Findings indicate the awareness of the participants regarding the role of segregation in the larger societal context.

\section{Research Findings}

The study yielded several significant findings about the Lumbee experience in the segregated Indian schools in Hoke and Robeson Counties. Three major themes of that emerged from my results: (1) segregation, (2) desegregation, and (3) the tribal experience of discrimination that was part of the reality of segregation and desegregation. These themes provide a framework for understanding the Indian schools through my informants' stories about segregation, desegregation, and their awareness of the reality of discrimination. Segregated Indian schools created a lasting and profound influence on the lives of participants, as did the shift to desegregation and the resulting exposure to racism and discrimination with the broader society.

\section{Segregated Indian School}

The segregated Indian school theme included findings about the development of (1) Indian schools, (2) programs, (3) teachers, (4) teachers' connection with students, and (5) the resources of the Indian schools. Findings also illuminated not only the reciprocal impact of the Lumbee tribe on schools, and the schools' impact on the Lumbee. In addition, my research uncovered the benefits and disadvantages of the Indian school experience for my participants.

The research showed how Jacob's Point and Hawkeye Indian schools were established in Hoke County through the leadership of the community. Also, resistance occurred in the Indian communities of Antioch and Macedonia in response to the consolidation to form Hawkeye Indian School from smaller community based schools. 
In addition to advocation and moral support, Lumbee schools were supported financially by the Lumbee community. This support was demonstrated by the efforts of the communities to support the schools either in labor and/or material goods. Available resources of the communities and their investment in the schools were evident in the disparities in the physical structures of the schools. Indian school structures varied from poorly constructed buildings to fine structures depending on the resources available to the community. School programs within the Indian schools (e.g., May Day programs and sports such as basketball) were particular sources of pride for the school and the Indian community. Furthermore, the school acted as a focal point and was the place for many social events for the community.

Lumbee teachers, within the segregated Indian school, described dynamic teachers who managed to teach and also perform other required educational and/or administrative duties. The teachers were not only role models for the students, but also were role models for the entire community. They were invested in the students and connected with students, parents, and the community for the academic and future success of their students. Lumbee teachers stressed education as a way of elevating their students out of poverty and as a way of resisting discrimination.

Recollections about Hoke County Indian schools produced conflicting perspectives of available resources. Despite strong evidence from a number of sources showing a serious lack of resources, former administrators remember having adequate resources. The data showed that Indian schools in Robeson County also suffered from inequitable resources. My exploratory examinations revealed a vast difference in the resources and educational opportunities available in the different Indian schools. 
Research showed that the Native Americans depended heavily on the support of the Indian community.

A clear symbiotic relationship between the Lumbee community and their schools emerged from the data. Lumbee culture was inherent in the religious aspect of the school programs and curriculum. Moreover, the Lumbee tribe invested in the success of the schools because the schools were an integral part of the community. As such, there was an interconnection between the Lumbee community and the schools in establishing, advocating and financially supporting the schools.

Eventually, my findings indicated that the segregated Indian schools provided a distinct advantage for the Lumbee Indians. Ultimately, my data indicated that the segregated Indian school represented the community and the family. The community and the family formed the essence of the Native American schools. This enabled the teachers to have a closer relationship with their students and the parents and promoted their school success. Disadvantages of the Indian schools included the power of the Indian committees. Indian school committees were highly political, allowing a platform for certain figures in the Indian community to misuse their power instead of helping the schools. Board of education minutes revealed nepotism in the hiring decisions of the Indian school committees. It could be interpreted that such a misuse of power evidenced in the nepotism of hiring decisions would occur considering that teaching was a viable white collar profession for the Lumbee. The teaching profession was readily available to the Lumbee and there were only limited opportunities to teach in the segregated Indian schools. Thus, severe competition existed for these teaching positions. Consequently, 
family and friends of the Indian committees would have a distinct advantage in gaining these coveted positions.

\section{Desegregation}

This theme also illuminated the advantages and disadvantages of separation from the mainstream white population. On the one hand, findings in the theme of desegregation include a gratefulness of the Lumbee to the black community. Another discovery revealed the Lumbee resistance to desegregation.

Although the Lumbee had historically worked to disassociate themselves from Blacks, the Lumbee community benefited from the efforts of the black community and Dr. Martin Luther King, Jr. in strides for justice and equality. This equality was seen in the advantages equity of resources and opportunities made available for the Lumbee. Specifically, desegregation (1) allowed the Lumbee input into the educational system, (2) increased materials and resources for the schools, and (3) expanded the curriculum for Lumbee students.

However, gains in equity came at the expense of the Indians' loss of control over their schools. Also, the sense of community was missing in the desegregated schools. Desegregated schools lacked the cultural connection provided by Indian teachers who served as role models and advocates for the Indian students. This loss of Indian teachers who affirmed Indian identity resulted in a loss of Indian identity for Indian students in Hoke County. 
The loss of the Indian community control over their schools was not resisted by the Indian community. The Lumbee Indian schools in Robeson County were the last Indian schools in North Carolina to desegregate. In fact, the residential patterns of some of the Lumbee, as in the large concentration of Lumbee in Pembroke, contributed to schools that would still be characterized as Indian schools because of their majority Indian population. The present Lumbee-black student violence in Robeson County (Jenkins, 2005) could be seen as examples of resistance to desegregation as well as examples of Lumbee internalized racism against Blacks.

\section{Understanding Segregation \& Discrimination}

My research indicated that the Lumbee had a deep awareness of segregation and the resulting discrimination and oppression they experienced. The fact that the Lumbee lived in isolation served to help shelter them within their communities. However, once they left the safety of these communities, they experienced the full impact of discrimination. Due to their unique position and a complex relationship with the dominant racist white society, the Lumbee themselves perpetuated discrimination in their interactions with black teachers in their schools. Discrimination can also be seen in

present tensions between Indian and black students at Purnell Swett High School and Pembroke Middle School (Jenkins, 2005; Locklear \& Elofson, 2004).

Finally the data show the Lumbee lacked economic and political power to affect their reality of existing poverty and inequity. However, the Lumbee teachers stressed education as a means for the Lumbee to elevate themselves from the shackles of poverty and inequity. The Lumbee viewed education as the Lumbee key to success. 


\section{Unanticipated and Inconsistent Research Findings}

Data analysis revealed unanticipated conclusions concerning the (1) origin of Jacob's Point School in Hoke County, (2) inter-group conflict in the Indian community in Hoke County, (3) class and disconnection in the Lumbee community, (4) inconsistent research findings related to teacher apathy and educational mediocrity, and (5) lack of Indian identity as a theme in the research.

Jacob's Point was remembered and understood to be a former slavery building. Hannah remembered that Jacob's Point was a former slavery building. Ms. Elizabeth Brown, the owner of the building and property where the dilapidated Jacob's Point School stands, understands that the building was once a school for former slaves. Although no other data corroborates this understanding of the history of the building, further research could illuminate the origin of the building. Furthermore, what is significant is that the building is one of the remaining standing segregated Indian schools in Hoke County. The school could be designated as an historic site, and consequently, funds could be allocated for restoration. However, the state of its deterioration prevents its removal to another site for restoration.

The discovery of inter-group conflict in the Indian community in Hoke County, the accusation of black blood, was surprising considering that this conflict between the communities does not exist anymore. The literature supports that the Lumbee participated in the oppression of Blacks in efforts to reify their Indian identity. This oppression of Blacks occurred in order to draw distinctions between Indians and Blacks. It was important for the Lumbee to draw these racial distinctions between themselves and Blacks since the dominant white society classified and treated the Lumbee as if they were 
black. However, in this example in the Hoke County Indian community, Lumbee were discriminating against Lumbee and justifying this through the accusation of black blood. The accusation by the Macedonia Indian community was just that, an unfounded condemnation. This disparagement served to other the Antioch Indian community and created a cleavage in the Hoke County Indian community that served to undermine efforts to benefit the Hoke Lumbee community. The common experience of desegregation and the loss of the Indian school helped to unite the Macedonia and Antioch Indian communities. This is evidenced by the Hawkeye Indian School reunions wherein these two communities came together to celebrate and remember their Indian school, Hawkeye.

The finding of class and community disconnection in the Lumbee community was an experience that I understood personally. I had heard these facts communicated descriptively in conversations with Lumbees who lived in other communities outside of Pembroke and those who lived in counties outside of Robeson. I did not expect to hear a discussion of the differences in the economic class of the Lumbee with specific comparison to the Lumbee middle class community of Pembroke. Further investigation of this difference of class and disconnection within the Lumbee could possibly help in understanding the internal conflict within the Lumbee community which serves as an obstacle to tribal unity. 
The research finding from Hart's interview concerning teacher apathy and educational mediocrity was not shared by my other participants. Research data did not uncover supportive examples to corroborate either teacher apathy or educational mediocrity. Although this finding of teacher apathy and educational mediocrity was a major finding in my pilot study, the current data did not support it. Hart expressed that as a student in the Indian schools he perceived that some of his teachers did not care about student success. He also stated how ill-prepared he felt about entering other institutions of higher education because of the quality of education he experienced in the Indian schools. His statements were parallel to findings unearthed in my pilot study. Hart's statements contradict this study's findings of the Indian teachers' (1) investment in their students, (2) strong connection, and (3) teachings to elevate their students out of poverty. Although no other participants shared the same experiences, it could be that further research with other Lumbee participants could reveal similar findings about teacher apathy and educational mediocrity. This finding could serve as another lens in viewing the segregated Indian schools of the Lumbee.

As mentioned earlier, I was aware that the Lumbee community perception of how "when we had our own schools everything was better" would impact their memories of their educational experiences. I understood that this collective memory could impact my participants' memories of their experience in the Indian schools. Hessling (1993) also noted an inconsistency in his participants' fond remembrance of their schools despite the unpleasant experiences they conveyed in their memories. It could be possible that such negative experiences in the Indian schools as Hart expressed and those found in my pilot study could help to provide a more descriptive picture of the Indian schools. There is a 
tendency to forget and edit out unpleasant experiences. Perhaps my participants' forgot to include many negative experiences in their narratives. It is reasonable to believe that these memories were inconsistent with the fond memory of the Indian schools asdistinguished schools. Although the focus of this study was to skillfully document the Lumbee experience in the Indian schools, another study could probe deeper. Another exploratory examination could delve into (1) kinds of education and teaching that occurred in the Indian schools and (2) quality of educational experiences in the Indian schools.

The research findings did not yield identity as a theme. The literature review supported how education was important to the Lumbee identity, but identity was not a theme in my findings. The research demonstrated that the schools affirmed Indian identity. Specifically, in the case of the desegregation of the Indian school in Hoke County, Hawkeye, the findings demonstrated a loss of Indian identity which the school represented in the community. However, the data did not support a significant theme of identity. In examining my data identity did not emerge a category which linked and explained more about the data as the themes of segregation, desegregation, and the awareness of the reality of discrimination did. One of my research questions did attempt to uncover identity within the context of the Indian schools. The research question asked of my respondents was "how did the Lumbee schools support or not support Lumbee culture, values, or beliefs?" It is possible that by increasing the number of research questions examining the extent of the Indian schools to support or not support Lumbee identity in terms of culture, values, and beliefs with additional participants could have yielded a stronger theme of identity. Additionally, in my research I could have examined 
my participants' state of ethnic identity development and this could also have illuminated identity in my study.

The themes of segregation, desegregation, and the awareness of the reality of discrimination were strongly supported in the data. These themes illustrated the reality of a segregated society where the segregated schools and the segregated Indian communities created a shelter from discrimination and oppression. Identity is demonstrated as a subcategory of the theme of segregated Indian schools wherein the schools affirmed Indian identity. It is possible that these themes of a segregated reality overshadowed identity's emergence as a theme. Or, it could be that this lack of identity as a theme is because the Indian schools and the Lumbee community reaffirmed Indian identity.

As the literature explained, the Lumbee did not need to assert and affirm their Indian identity until they experienced a reality that disaffirmed their Indian identity, as the legislation which classified them as black. The desegregation experience of the Hoke County participants did illuminate the issue of identity because the loss of the Indian school challenged Indian identity in that community. It is possible that, with further research of other Indian tribes in North Carolina whose loss of their Indian schools to desegregation, that identity would prove to be a stronger theme.

\section{Research Findings Related to Literature}

My findings about the experiences of Lumbee Indian students in segregated Indian schools in North Carolina adds to, confirms, and extends the research of African American segregated educational settings. Also, my research findings add to the body of Native American educational research. 
One of the findings, from my research concerning the white landlords' efforts to prevent Lumbee children from attending school, was consistent with findings in the literature. Southern planters discouraged the education of the children of former slaves as well as the children of poor Whites. The southern planters discouraged the education of these children in order to exploit these populations for cheap farm labor (Anderson, 1988).

Findings document that the Lumbee community and parents advocated for the development and resources for their schools, and this finding is similar to Walker's (1996) and Celeski's (1994) research concerning the black communities advocation for their schools. The fact that Indian communities such as the Lumbee advocated for the establishment of separate Indian schools is also consistent with the research of Massey (1996) concerning other southeastern Indian tribes' avocation for their schools.

The Lumbee educational system suffered from inequities similar to those of African American segregated schools (Anderson, 1988; Ashmore, 1954; Bond, 1939). Although Indian schools of the Lumbee suffered from inequity of resources, the schools were rich with the investment of the Lumbee community and parental support for the schools' programs, academics, and sports. Findings demonstrate that the Indian school was the focal point and a social outlet for the community. This information is consistent with findings in the segregated black schools (Walker, 1996). School programs such as May Day programs were both sources of pride for the Indian community and the black community. The black community, as well, needed socially appropriate opportunities to develop pride in their community. Additionally, school programs reflected the values of the community, specifically religious values. My participants mentioned the school 
program, chapel, in which the students had a religious devotion and sang gospel songs, but enabled the students to have public speaking experience. Walker (1996) documented a chapel program present at CCTS similar to that of the Lumbee schools in the inclusion of a religious devotion and with the purpose of a practical public speaking experience.

The community and parents also financially supported the schools. This involvement by the community in support of the schools is consistent with research of the educational support black teachers, administrators, and the community gave their schools (Cecelski, 1994; Emerson, 2003; Hessling, 1993; Walker, 1996; Wilson, 1997; Wilson \& Segall, 2001). Research findings of the Lumbee community's personal and financial support of their schools support previous research concerning the Lumbee experience (Blu, 2001; Chavis, 1986; Dale, 1986; Dial, 1993; Dial \& Eliades, 1975; Massey, 1996; Thompson, 1973).

The Lumbee isolation within their Indian community and their Indian schools served to shield them from the discrimination of segregation. This isolation, within the shelter of the community, is consistent with the findings of segregation and isolation in Indian and black communities as evident in the research of (Cecelski, 1994; Deese, 2002; Massey, 1996; Peck, 1972; Walker, 1996; Wilson, 1997; Wilson \& Segall, 2001). These researchers found that community isolation and segregated schools helped to preserve the Indian and black communities from the worst of segregation. Within the isolated Indian communities and Indian schools, the Lumbee were not directly subject to overt discrimination. When the Lumbee were outside of the Indian community they encountered racism and discrimination. This was similar to experiences of Black Americans in their black communities and segregated black schools during segregation. 
My findings concerning Lumbee teachers' close connection to the students and their investment in their education is consistent with the research of Foster (1994) and Walker (1996) who described black teachers' connection with the black community and their students as expressions of kinship. This kinship of black teachers with their students translated into school environments characterized as a family. In a similar manner, the Indian schools were considered extensions of the community and the family. This is consistent with the research of Cecelski, 1994; Emerson, 2003; Hessling, 1993; and Walker, 1996 and their studies of segregated black schools. This sense of kinship and community extended also to the teachers' investment in the community and sharing a similar background to the students. The majority of Lumbee teachers taught in their own communities, and this pattern is consistent with the CCTS teachers who also lived in the same community as their students in Walker's (1996) research.

The respondents in my research revealed an awareness of the way schools acted as extensions of the community in their interest in elevating the students, similar to the findings that Cecelski (1994) and Walker (1996) documented in their research. In speaking to their students about improving themselves as Indian people and building their self-esteem in being Indian, my participants explained that they couldn't have a personal relationship with their Indian students in the desegregated schools as they were able to in the Indian schools. In the Indian schools, the Indian teachers communicated with Indian students about ways to resist segregation. Indian teachers also stressed education as the key to success and urged Indian students to improve themselves as Indian people. These findings of the Indian teachers' efforts to elevate students in the Indian schools mirror previous research concerning black teachers who also stressed education as a means of 
elevating their students (Foster, 1994; Walker, 1996; Wilson, 1997; Wilson \& Segall, 2001). My respondents communicated that the Indian schools supported Lumbee students and affirmed Native American identity, and this finding is similar to the finding of Indian cultural affirmation in Chavis' (1986) research.

My informants described how desegregation affected the Indian school in terms of loss of Indian identity, community, and connection with students. Specifically, in communities without a majority Indian population, the loss of the Indian schools were evidenced by a diminished Indian identity. Hoke County was an example where the Indian school was the focal point of the Indian community, and its loss to desegregation greatly affected the Indian community. Participants described the loss of the sense of community which was present in the Indian schools but was sorely missing in the desegregated schools. This loss of community was compounded by the severed connection of the teacher from the students. All participants communicated how in the Indian schools there was a connection and investment in the students, but this was missing in the desegregated schools. The teachers were from outside the Indian community; they were not invested in the Indian community or culture and this connection was vital for Indian students. Specifically, in Hoke County there were few Indian teachers to serve as role models for the students. Similar findings are echoed in the research of Wilson \& Segall (2001) and Emerson (2003) concerning the loss by Black Americans of community and control over their schools with the closing of black schools because of desegregation. 
Lumbee resistance to desegregation was somewhat consistent with Celeski's (1994) research of Hyde County's similar resistance to desegregation. The Lumbee valued their schools and fought hard not to lose them in a similar way to the African American community documented in Celeski's research. The African American community in Hyde County responded to the desegregation plan which excluded their input and required the closing of their schools, O.A. Peay and Davis, by organizing a school boycott in 1968 (Cecelski, 1994). They refused to send their children to school under the desegregation plan unless a new plan was developed that included their traditionally black schools or allowed the schools to remain open (Cecelski, 1994). The school boycott lasted more than a year and members of the black community were subject to many acts of violence to deter them from their goal of preserving their schools and their civil rights, but they did succeed in 1969 (Cecelski, 1994). The black citizens in Hyde County were able to retain their community schools. They were able to retain control and input into the schools and the crafting of educational policy (Cecelski, 1994).

These two communities differed somewhat in their purpose of their objectives to maintain their schools. The schools, O. A. Peay and Davis, were key in preserving the heritage of the black community in Hyde County. This is consistent with the Lumbee's struggle to keep their schools which was viewed as a vital means to maintaining their Indian identity. The black schools, O. A. Peay and Davis, affirmed the black students and the community. The Indian schools also affirmed the Lumbee students and the Lumbee community. Both the black schools and the Indian schools provided their communities with white collar middle class jobs in the field of education that otherwise would not have existed. 
These two communities differ in that the Lumbee were classified as black and refused to attend black schools and the Lumbee advocated for their own schools. In resisting desegregated schools, the Lumbee fought to retain the cultural distinctiveness that their schools affirmed while this resistance was also viewed as an expression of the Lumbee internalized racism toward Blacks. Internalized racism was also evident in the Lumbee's resistance to the presence of black teachers in the Indian schools and their screening process to keep out anyone with "black blood" from being admitted into the Indian schools. Maintaining segregated schools in order to maintain Indian identity and culture is consistent with the research of Deese (2002), whose southeastern Indian participants believed that their Indian culture was better preserved during segregation. Massey (1996) also found segregated schools were instrumental in cultural preservation within Indian communities.

Findings showed that the Indian committees' screening process contributed to maintaining the Indian schools by controlling who was eligible to attend the schools- no individuals with black blood. The power of the Lumbee Indian committees was evidenced also in the teachers' fear of being arbitrarily fired, and through examples of nepotism where it seems the Indian committee did not put the Indian schools' best interests first. These findings of the Indian committees' misuse of power contradict Massey's (1996) findings of the Indians' high value of the Indian school committees. 
The Lumbee educational experience in their Indian schools was unlike that in the Indian schools provided for other Native Americans (Cobb, 2000; Ellis, 1996; Fuchs \& Havinghurst, 1973; Lomawaima, 1994; Lomawaima, 1995; Spring, 2001; Szasz, 1999). Lumbee Indians advocated and supported their schools. The Lumbee were not forced into schools with the purpose of assimilating them and removing their culture as was the experience of education for other Native American tribes in the boarding schools. The Indian schools of the Lumbee were extensions of their community, and the Indian schools affirmed Lumbee students and Lumbee culture. Lumbee Indian teachers taught in the Indian schools. Lumbee were administrators in the Indian schools in contrast to the Indian boarding schools in which white missionaries and teachers taught. These research findings of the Lumbee Indian schools add to Native American educational history because similar segregated educational settings for other Native Americans have not been documented. One could compare the segregated Lumbee Indian schools of the past to present Indian tribal schools as documented by the research of McCarty \& Bia (2002) and Pewewardy (1998) wherein the tribal schools are culturally affirming and are characterized by the community involvement.

In Chapter 5, I summarized my research and discussed the interpretations of my research findings and the relationship of my findings to the literature. The final chapter provides conclusions and implications of my research concerning the segregated Indian school experiences of the Lumbee. 


\section{CHAPTER 6}

\section{LESSONS LEARNED FROM THE INDIAN SCHOOLS}

We didn't have school on our mind. Getting an education, nobody [was] talking about getting an education. And I come back and think about how in this world did I, how did I get where I did get. I actually made it to college after I come back from the army ... I can't hardly believe it. But, I was always determined . . . that I wanted to get someplace . . . I wanted to be somebody-to have something.-Peter Dial, Jr. (Lumbee)

The lessons learned from the Indian schools, or conclusions, are presented in this final chapter based on the interpretations of findings from my respondents' narratives of their experience in the Indian schools. In light of the lessons learned from the Indian schools, this chapter will present an evaluation of the study and suggest research recommendations for future studies. The lessons learned also include a discussion of the educational importance of this study to research and practice. This chapter concludes with a personal lesson learned from the study of the Indian schools.

That the Lumbee Indian schools provided culturally affirming environments despite a lack of educational resources informs us that these schools have much in common with the segregated black schools. Lumbee teachers and Lumbee schools created environments that were extensions of the community and connected with the students in similar ways to teachers and schools in black segregated educational settings. However, Lumbee are unique in that they advocated for these segregated settings to reify their Indian identity. African Americans did not advocate for separate schools. In fact, the Lumbee Indians fought hard against desegregation in order to maintain their separate Indian schools during desegregation. Although African Americans regretted the loss of their schools and the control over their schools during desegregation, there was no feeling of wanting to remain separate such as that exhibited by the Lumbee. 
The Lumbee viewed segregation as a way to preserve their culture and distinctiveness and felt that desegregation would unweave their hard fought unity and identity. Most significant was the internalized racism of the Lumbee to distance themselves from Blacks. This was evident in their resistance to desegregation and their protest of black teachers in their Indian schools. Internalized racism can be seen in current racial tensions between Lumbee students and black students in Purnell Swett High School and Pembroke Middle School. However, such racial tensions do not tell the entire story. Each participant remarked that the Lumbee benefited from the Civil Rights Movement and that they were thankful for the efforts of the black community and to Dr. Martin Luther King, Jr. for Civil Rights. Additionally, when the black and Indian communities worked together in Robeson County, they made great economic and political progress for their communities. Although racism has to be unlearned and addressed, the Lumbee and the Black American communities share a rich foundation from which to begin this process as evidenced by their past and contemporary relationships. The Indian and black communities have much to gain by working together, especially in terms of economic and political endeavors in Robeson County.

Participants emphasized that their teachers in the Indian schools stressed academic success as a key to elevating students out of poverty. These findings led me to question the quality of learning that the Lumbee received, especially in the context of the present realities of Lumbee students' low scores on major tests of achievement and the high dropout rates. The findings showed that the Indian schools suffered from poor Lumbee student enrollment due to economic conditions requiring them to work on farms and their parents' devaluation of the importance of education. In my research, I only 
interviewed six individuals, but these findings caused me to question if these reasons could possibly be connected to the current problem of Lumbee students' poor school achievement. Also, the research participants spoke of the teacher-student connection and the investment of the Indian teacher in the success of the Indian students. The Indian schools affirmed the Lumbee students and their culture. Would the same cultural affirmation be apparent in the education Indian students received in contemporary schools with a majority Indian population and Indian teachers and administrators? Perhaps reasons for the low retention rate of Indian students in postsecondary institutions where Indians are the minority could be attributed to the quality of education and cultural support they received in the institutions where they are a majority. Perhaps it is due to such lack of Indian cultural support and community. The lack of Indian community and Indian identity found in current postsecondary institutions seems clearly to be a factor contributing to the school failure of Indian students as evidenced in research on the success of American Indians in tribal colleges (Ah Nee-Benham \& Stein, 2003).

\section{Research Recommendations}

The focus of this qualitative oral history has been to document the Lumbee experience in segregated Indian schools. Lumbee Indians experienced an educational system that, while it was resource poor, was culturally affirming and rich in community

experience. Although desegregation resulted in more educational opportunities and equitable resources, this gain was overshadowed by a loss of identity, community, and connection for the Lumbee. 
More oral history research could yield richer data, specifically through the narratives of former students, teachers, and administrators in the segregated Indian schools of the Lumbee from other counties such as Scotland County and Cumberland County. Also, the oral histories of other Indian tribes in North Carolina who experienced segregated education in their own Indian schools could contribute to developing a clearer understanding of what the segregated educational experience was like for Native Americans in North Carolina. Specifically researching the educational experiences of the Cohaire, Haliwa-Saponi, and Waccamaw-Sioux Indians would yield unique data because many of the teachers of the schools of these Indian tribes were Lumbee Indians who were not members of the Cohaire, Haliwa-Saponi, or Waccamaw-Sioux tribes Indian communities. In fact these Lumbee educators were seeking positions teaching outside the Lumbee schools until they were able to secure positions closer home in their Lumbee communities. The oral educational histories of the Lumbee and other Native American tribes in North Carolina concerning desegregation could yield further information about the impact of this experience on them.

Furthermore, oral histories of Lumbee Indians and other Native American Indian tribes in North Carolina concerning their experiences in contemporary primary, secondary, and postsecondary schools could yield information about how their educational needs are being met or are not being met. Such research would potentially yield an enormous body of information to inform teaching practices with Indian students. Additionally, such research contributes to North Carolina educational history while also contributing to American educational history. 


\section{Educational Importance}

The findings of my research suggest that, although desegregated schools offer more educational opportunities and equitable resources for Lumbee students, the sense of identity, community, and connection that the students felt in the Indian schools were missing in the desegregated school. This sense of community and connection with the Lumbee students has yet to be created in the contemporary desegregated schools. One of my participants spoke of a desire in the Lumbee community concerning a need for culturally supportive tribal schools, and Deese (2002) found a similar sentiment in her research. Deese's (2002) participants stressed the importance of Indian educators to teach Indian youth and help them to maintain their Indian identity and culture. My participants all stressed how Indian students continue to fail in the schools and schools are not meeting their needs.

There is support for this belief. Results of the "End of Grade" (EOG) and "End of Course" (EOC)" tests for the years 1999-2003, show that Native American students are consistently the lowest performers on these tests despite their improvement in the areas of math and reading on EOG tests and on the ten EOC tests (Our voice, 2004; , Remaining and becoming, 2003; , United for success). Additionally, Native American students in North Carolina have the highest dropout rates of all ethnic populations in North Carolina. Indian males have the highest dropout rate of all students despite the lowering of this rate between the years of 2000-01 and 2001-02 (Our voice, 2004; , Remaining and becoming, 2003). 
Locally, in North Carolina, and nationally as well, European American (white) students consistently perform better on measures of academic success: National Assessment of Educational Progress (NAEP); Iowa Tests of Basic Skills (ITBS); Scholastic Assessment Test (SAT); Advanced Placement (AP) Examinations; EOG, and EOC (Minority achievement, 2001). Thus, there is an achievement gap between white students and students from some other ethnic populations in North Carolina (Minority achievement, 2001). This gap is consistent with national evidence that African American students entering school are academically behind their white counterparts with this achievement gap increasing throughout elementary and high school years (Barnes, 2004).

Although the intent of my research is to raise consciousness and add to the discourse of the history of education, the educational importance of my research illuminates the experience of the Lumbee Indians in North Carolina, who they are and their educational experiences. Educators in the schools can use this information to critically examine their curriculum, instruction, practices, and policies to determine if they are best serving this population of their students, the Lumbee Indians. Could the schools become places that are culturally affirming to Lumbee students? Are the teachers willing to develop ties with the Lumbee community? Culturally relevant teaching is the kind of affirming education from which all students can benefit. Culturally relevant teaching involves the teacher's role as a cultural mediator who understands and values the students' culture; recognizes students' needs; and makes curricular and pedagogical accommodations in the efforts to meet her students' multicultural educational needs for their educational success in a diverse society (Ladson-Billings, 1995). Elements of culturally relevant teaching are characterized by students'(1) academic development, (2) 
cultural competence, and (3) the sociopolitical conscious development (Ladson-Billings, 1995). True cultural synchronization occurs for students when students' culture is congruent with the culture of the school wherein the teacher and the student share a cultural worldview and mutual understanding (Irvine, 1990). School failure and conflicts in schools stem from misunderstandings because of a lack of cultural congruence (Irvine, 1990). The recommendation of my study is for educators to transform both curriculum and teaching practices to be more culturally relevant and affirming to students. An understanding of multicultural education, studying diverse populations, and culturally relevant pedagogy are recommended practices for educators to begin addressing the needs of their students, like the Lumbee Indians.

Additionally, I recommend that teachers of Lumbee students engage in multicultural educational social justice and anti-racist efforts to deal with Lumbee antipathy toward Blacks. Education is needed to help unlearn the racism which keeps these communities from building coalitions and realizing the interdependence of their communities.

\section{Reflections on Research}

Personally, I have become more aware of my heritage and culture not only as a Lumbee Indian, but also as an educator. I knew of segregation in a detached manner because I had always been thankful for the strides the black community made for equality. Through their efforts many doors were opened for other oppressed people of color, like the Lumbee. This research helped me experience this reality vicariously through the experiences of my participants' telling their stories. However, I had trouble identifying with my participants because I had never experienced an educational 
environment comprised of individuals who shared my culture. Nor had I ever equated segregation with a positive experience of solidarity and community. But I learned from my participants how valuable and affirming such an educational environment could be when one's culture is shared and one's educators identify with the individual. Thus, these educators support the individual student's efforts because they personally knew that student. I also learned through my research how self-segregation not only connected the Lumbee community, but also served to isolate them. The preservation aspects are admirable, but I saw also how segregation crippled their access to equitable resources and equal opportunities. Self-segregation inhibited development of relationships with other racial-ethnic populations. This realization helped reinforce my understanding that culturally affirming environments do not mean and should not be a return to segregated settings for the Lumbee.

Some have proposed the idea of tribal schools in the Lumbee community (Deese, 2002). This sentiment of the Lumbee creation of a tribal school was echoed in one of my interviewees' narrative, “Now they've been talk, I don't [know] if it will ever materialize or not about trying to form a tribal Indian tribal school you know with our tribal government here in Pembroke" (Richard, 2004). I argue that the positives that were inherent in the segregated educational settings of community and connection with the students are aspects that ought to develop in contemporary settings without a return to segregation. 
In reflecting on my interactions with my research participants, I learned a great deal from their wisdom about the past as well as their reflections on the present. Most significantly, I learned from my participants that they were not hoarding their knowledge, expertise, and wisdom; instead they were using their abilities to influence change in their families, communities, and in the schools through their volunteer efforts. Each of my participants, although retired, was heavily engaged in contributing to their families and volunteering with their churches, communities, and the schools. Their many pursuits made reaching them for interviews difficult. Their active involvement is a model for me in sharing my abilities to improve my world continuously and selflessly. I appreciated and cherished their time with me and their readiness to share their memories of this time. Although they may have commented that they were rambling at times, I reassured them that what they were giving me in the interviews was valuable, for they gave me information that was beyond the scope of my questions. It is with the pearls of their experience and wisdom and the pleasure of getting to know them that I am thankful I had the opportunity to preserve this history for them and to contribute to the Lumbee history. All of my participants have chosen to donate their oral histories to the Lumbee River Fund. This fact reassures me that their stories will not be lost. My research has shown me that a great deal can be learned from the past and that it is important to listen to those who know that past and can teach about that past before they are no longer able to teach or are taken away from us. 


\section{BIBLIOGRAPHY}

An act designating the University of North Carolina at Pembroke as North Carolina's historically American Indian university, North Carolina General Assembly, 20052006 Sess.(2005).

An act relating to the Lumbee Indians of North Carolina, North Carolina Session Laws $\S$ Chapter 874 (1953).

An act relating to the Lumbee Indians of North Carolina, 84 Cong., 2nd Sess., Public Law 570 Cong. Rec.(1956).

An act repealing articles 2 through 9 of chapter 116 of the general statues and substituting a new article 2 in lieu thereof, State of North Carolina Session Laws and Resolutions § Chapter 1142 (1957).

An act to amend section five thousand four hundred and forty-five of the consolidated statutes so as to provide keeping separate records for the public schools for the Cherokee Indians of Robeson County, State of North Carolina Public Laws and Resolutions § Chapter 141 (1931).

An act to amend the consolidated statutes and to codify the laws relating to public schools, State of North Carolina Public Laws and Resolutions § Chapter 136 (1923).

An act to amend the laws of 1885 and 1887 so as to provide additional educational facilities for the Croatan Indians; citizens of Robeson County, North Carolina, Laws of North Carolina $\S$ Chapter 60 (1889).

An act to apply a portion of the proceeds of the public lands to the more complete endowment and support of the colleges for the benefit of agriculture and the 
mechanic arts established under the provisions of an act of Congress approved July second, eighteen hundred and sixty-two, U.S.C. $§ 322$ et. seq. (1890).

An act to change the name of the Indians in Robeson County and to provide for said Indians separate apartments in the state hospital., Public Laws of North Carolina $\S$ Chapter 215 (1911).

An act to empower the trustees of the Indian Normal School of Robeson County to transfer title to property of said school by deed to State Board of Education, and to provide for the appointment of trustees for said school., Public Laws of North Carolina § Chapter 168 (1911).

An act to establish an Indian legislative committee for the Indian Schools of Robeson County, Public Laws of North Carolina § Chapter 146 (1921).

An act to provide for separate schools for Croatan Indians in Robeson County, Laws of North Carolina § Chapter 51 (1885).

An act to restore to the Indians residing in Robeson and adjoining counties their rightful and ancient name, Public Laws of North Carolina § Chapter 123 (1913).

Ah Nee-Benham, M. K. P., \& Stein, W. J. (2003). The renaissance of American Indian higher education : capturing the dream. Mahwah, N.J.: Lawrence Erlbaum.

Anderson, J. D. (1988). The education of Blacks in the South, 1860-1935. Chapel Hill: The University of North Carolina Press.

Anderson, M. L. (1993). Studying across difference: Race, class, and gender in qualitative research. In J. H. Stanfield \& R. M. Dennis (Eds.), Race and ethnicity in research methods (pp. 39-52). New York: Sage. 
Ashmore, H. S. (1954). The Negro and the schools. Chapel Hill: The University of North Carolina Press.

Barnes, J. E. (2004, March 22-29). Fifty years after Brown: Unequal education. U.S. News and World Report, 136, 64-75.

Barton, L. (1967). The most ironic story in American history: An authoritative documented history of the Lumbee Indians of North Carolina. Charlotte: Associated Printing Corporation.

Bassett, J. S. (1894). The constitutional beginnings of North Carolina (1663-1729). Baltimore,: The Johns Hopkins Press.

Berry, B. (1963). Almost white. New York: MacMillan.

Bizzell, O. (1983). The heritage of Sampson County, North Carolina. Winston-Salem: Hunter Publishing Company.

Blu, K. I. (1996). 'Where do you stay at?' Home place and community among the Lumbee. In S. Feld \& K. H. Basso (Eds.), Senses of place (pp. 197-227). New Mexico: School of American Research Press.

Blu, K. I. (2001). The Lumbee problem: the making of an American Indian people. Lincoln: University of Nebraska Press.

Bodnar, J. (1989). Power and memory in oral history: Workers and managers at Studebaker. The Journal of American History, 75(4), 1201-1221.

Bond, H. M. (1939). Negro education in Alabama: A study in cotton and steel. Washington: The Associated Publishers.

Bordewich, F. M. (1996). Killing the white man's Indian. New York: Anchor Books. 
Brayboy, B. M., \& Deyhle, D. (2000). Insider-outsider: Researchers in American Indian communities. Theory into Practice, 39(3), 163-169.

Brayboy, T., \& Barton, B. (2003). Playing before an overflow crowd: The story of Indian basketball in Robeson, North Carolina, and adjoining counties. Chapel Hill, NC: Chapel Hill Press.

Brown v. Board of Education of Topeka, Kansas, 347 U.S. 483 (1954).

Bureau of Indian Affairs answers to frequently asked questions. (2004). (Vol. 2004): Bureau of Indian Affairs, BIA, DOI, Interior.

Cecelski, D. (1994). Along freedom road: Hyde County, North Carolina, and the fate of black schools in the South. Chapel Hill: The University of North Carolina Press.

Chavis, B. (1986). The teacher-student relationships as perceived by Lumbee Indians (aware, accept, share, choose). Unpublished doctoral dissertation, University of Arizona, Tucson, Arizona.

Clifford, J. (1988). The predicament of culture : twentieth-century ethnography, literature, and art. Cambridge, Mass.: Harvard University Press.

Cobb, A. J. (2000). Listening to our grandmothers' stories: The Bloomfield Academy for Chickasaw females, 1852-1949. Lincoln: University of Nebraska.

Collins, P. H. (1990). Toward an Afrocentric feminist epistemology. In Black feminist thought: Knowledge, consciousness, and the politics of empowerment (pp. 201220). New York: Routledge.

Comaroff, J., \& Comaroff, J. L. (1997). Of revelation and revolution, Vol. 2: The dialectics of modernity on a South African frontier. Chicago: The University of Chicago Press. 
Comas, J. (1958). Racial myths. Paris: UNESCO.

Creswell, J. W., \& Miller, D. L. (2000). Determining validity in qualitative inquiry. Theory into Practice, 39(3), 124-130.

Cummings v. Richmond County Board of Education, 175 U.S. 528 (1899).

Dale, E. D. (1986, December 19). The Lumbee Indians of Robeson County, North Carolina, and their schools. Paper presented at the National Conference of Christians and Jews, Pembroke, NC.

Deese, B. D. (2002). Ordinary people: Untucking oral teachings, traditions, and stories of southeastern Indians. Unpublished doctoral dissertation, North Carolina State University, Raleigh, North Carolina.

Deloria, V. (1985). American Indian policy in the twentieth century (1st ed.). Norman: University of Oklahoma Press.

Denzin, N. K., \& Lincoln, Y. S. (Eds.). (1998). Collecting and interpreting qualitative materials. Thousand Oaks: Sage.

Dial, A. L. (1993). The Lumbee. New York: Chelsea House Publishers.

Dial, A. L., \& Eliades, D. K. (1975). The only land I know: A history of the Lumbee Indians. San Francisco: The Indian Historian Press.

Dial, H. (2001). Lumbee Indians. Graduate presentation, Chapel Hill, NC.

Dial, H. K. (2002). Struggling for voice in a black and white world: Lumbee Indians in North Carolina (Pilot Study).Unpublished manuscript, Raleigh, North Carolina. Donmoyer, R. (1990). Generalizability and the single-case study. In E. P. Eisner, A. (Ed.), Qualitative inquiry in education: The continuing debate (pp. 175-200). New York: Teachers College Press. 
Ellis, C. (1996). To change them forever: Indian education at the Rainy Mountain Boarding School, 1893-1920. Norman: University of Nebraska Press.

Emerson, D. E. (2003). Education to subordinate-education to liberate: an historical study of the dual role of education for African Americans, 1865-1968. Unpublished doctoral dissertation, North Carolina State University, Raleigh, North Carolina.

Erickson, F. (1986). Qualitative methods in research on teaching. In M. Wittrock (Ed.), Handbook of research on teaching (Third ed., pp. 277-302). New York: Collier MacMillan.

Evans, W. M. (1995). To die game : the story of the Lowry band, Indian guerrillas of Reconstruction (1st ed.). Syracuse, NY: Syracuse University Press.

Facts on the American Indian/ Alaska Native Population. (2003). (Vol. 2003): US Census Bureau.

Finger, J. R. (1984). The Eastern Band of Cherokees, 1819-1900. Knoxville: University of Tennessee Press.

Finger, J. R. (1991). Cherokee Americans : the eastern band of Cherokees in the twentieth century. Lincoln: University of Nebraska Press.

Fivush, R., \& Buckner, J. P. (2003). Creating gender and identity through autobiographical narratives. In R. Fivush \& C. A. Haden (Eds.), Autobiographical memory and the construction of a narrative self : developmental and cultural perspectives (pp. 149-167). Mahwah, N.J.: Lawrence Erlbaum Associates. 
Fivush, R., \& Haden, C. A. (Eds.). (2003). Autobiographical memory and the construction of a narrative self : developmental and cultural perspectives. Mahwah, N.J.: Lawrence Erlbaum Associates.

Fogelson, R. D. (1998). Perspectives on Native American identity. In R. Thornton (Ed.), Studying Native America: Problems and prospects (pp. 40-59). Madison: The University of Wisconsin Press.

Forbes, J. D. (1993). Africans and Native Americans : the language of race and the evolution of Red-Black peoples (2nd ed.). Urbana: University of Illinois Press.

Foster, M. 1. (1994). Educating for competence in community and culture: Exploring the views of exemplary African American teachers. In M. J. Shujaa (Ed.), Too much schooling, too little education: A paradox of black life in white societies (pp. 221244). Trenton, NJ: Africa World Press.

Franklin, J. H. (1995). The free Negro in North Carolina,1790-1860. Chapel Hill: University of North Carolina Press.

Fredrickson, G. M. (2002). Racism: A short history. Princeton: Princeton University.

Fuchs, E., \& Havinghurst, R. J. (1973). To live on this Earth: American Indian education. Garden City, NJ: Anchor Books.

Gardner, P. (2003). Oral history in education: Teacher's memory and teacher's history. History of Education, 32(2), 175-188.

Glaser, B. G. (1994). The constant comparative method of qualitative analysis. In B. G. Glaser (Ed.), More grounded theory methodology: A reader (pp. 95-115). Mill Valley, CA: Sociology Press. 
Gluck, S. B., \& Patai, D. (1991). Women's words : the feminist practice of oral history. New York: Routledge.

Halbwachs, M. (1980). The collective memory (1st ed.). New York: Harper \& Row.

Halbwachs, M. (1992). "The localization of memories" and "the collective memory of the family." In L. A. Coser (Ed.), Maurice Halbwachs on collective memory (pp. 5283). Chicago: University of Chicago Press.

Hancock, E. D. (1935). A sociological study of the triracial community in Robeson County, North Carolina. Unpublished master's thesis, University of North Carolina at Chapel Hill, Chapel Hill.

Harlan, L. R. (1968). Separate and unequal : public school campaigns and racism in the southern seaboard states, 1901-1915. New York: Atheneum.

Harris, N. H. (1958). Desegregation in North Carolina institutions of higher learning. The Journal of Negro Education, 27(3), 295-299.

Herring, R. D. (1994). Native American Indian identity: A people of many peoples In E. P. Salett \& D. R. Koslow (Eds.), Race, ethnicity, and self: Identity in multicultural perspective (pp. 170-197). Washington, DC: National MultiCultural Institute.

Hessling, P. A. (1993). To be "The best school in town": An historical study of two Southern elementary schools. Unpublished doctoral dissertation, University of North Carolina at Chapel Hill, Chapel Hill, North Carolina.

A History of the Victory Garden. (2005). Retrieved March 30, 2005, from http://www.victoryseeds.com/TheVictoryGarden/index.html 
History of UNCP. (2005). (Vol. 2005): The University of North Carolina at Pembroke (UNCP).

Hoke County Board of Education (HCBE) Minutes. Raeford, North Carolina.

Honig, E. (1997). Getting to the source: Striking lives: Oral history and the politics of memory. Journal of Women's History, 9(1), 139-157.

Honors 2003. (2003-2004). [CD]: Public Schools of Robeson County Indian Education. hooks, b. (1992). Revolutionary "renegades". In Black looks : race and representation (pp. 179-194). Boston, MA: South End Press.

Irvine, J. J. (1990). Black students and school failure. New York: Praeger.

Jackson, V. L. (2004, March 19 2004). Asserting identity: Coharie Indians and the East Carolina Indian School. Paper presented at the New Directions in American Indian research: A gathering of emerging scholars, Chapel Hill, NC.

Jenkins, V. (2005, September 27). Mother files race complaint. The Fayetteville Observer, pp. 1B, 6B.

Johnson, G. B. (1939). Personality in a white-Indian-Negro community. American Sociological Review, 4(4), 516-523.

Jordan, W. D. (1968). White over black: American attitudes toward the Negro, 15501812. Chapel Hill: Published for the Institute of Early American History and Culture at Williamsburg, Va., by the University of North Carolina Press.

Kleinfeld, J. S. (1973 ). A long way from home; effects of public high schools on village children away from home. Fairbanks, AK: Fairbanks Center for Northern Educational Research, University of Alaska. 
Ladson-Billings, G. (1994). The dreamkeepers: Successful teachers of African American children. San Francisco: Jossey-Bass.

Ladson-Billings, G. (1995). Toward a theory of culturally relevant pedagogy. American Educational Research Journal, 32(3), 465-491.

Lawson, J. (1709). A new voyage to Carolina; Containing the exact description and natural history of that country: Together with the present state thereof. And a journal of a thousand miles, travel'd thro' several nations of Indians. Giving a particular account of their customs, manners, \& c. Retrieved March 6, 2004, from http://docsouth.unc.edu/nc/lawson/menu.html

LeCompte, M. D., \& Preissle, J. (1993). Ethnography and qualitative design in educational research. San Diego: Academic Press.

Lee, H. N., \& Ward, M. (2004). North Carolina public schools statistical profile 2004. Retrieved February 19, 2005, from http://www.ncpublicschools.org/fbs/stats/statprofile04.pdf

Lefler, H. T., \& Newsome, A. R. (1973). North Carolina : the history of a Southern State (3rd ed.). Chapel Hill,: University of North Carolina Press.

Leichtman, M. D., Wang, Q., \& Pillemer, D. B. (2003). Cultural variations in interdependence and autobiographical memory: Lessons from Korea, China, India, and the United States. In R. Fivush \& C. A. Haden (Eds.), Autobiographical memory and the construction of a narrative self : developmental and cultural perspectives (pp. 73-97). Mahwah, N.J.: Lawrence Erlbaum Associates. 
Lerch, P. B. (1992). State-recognized Indians of North Carolina, including a history of the Waccamaw-Sioux. In J. A. Paredes (Ed.), Indians of the southeastern United States in the late 20th century (pp. 44-71). Tuscaloosa: University of Alabama Press.

Lincoln, Y. S., \& Guba, E. G. (1985). Naturalistic inquiry. Beverly Hills: Sage Publications.

Locklear, M., \& Elofson, M. (2004, October 7, 2004). Swett studies ways to stem the violence. Robesonian.

Lofland, J., \& Lofland, L. H. (1995). Analyzing social settings: A guide to qualitative observation and analysis. Belmont, CA: Wadsworth.

Lomawaima, K. T. (1994). They called it prairie light: the story of Chilocco Indian School Lincoln: University of Nebraska Press.

Lomawaima, K. T. (1995). Educating Native Americans. In J. A. Banks \& C. A. M. Banks (Eds.), Handbook of research on multicultural education (pp. 331-347). New York: Macmillan.

Lovett, L. L. (2002). "African and Cherokee by choice": Race and resistance under legalized segregation. In J. F. Brooks (Ed.), Confounding the color line (pp. 192222). Lincoln, NE: University of Nebraska Press.

Lowenthal, D. (1985). The past is a foreign country. Cambridge Cambridgeshire ; New York: Cambridge University Press.

LRDA Company Profile. (2005). (Vol. 2005): Lumbee Regional Development Association (LRDA).

Lumbee Acknowledgment Act of 2003, 108th Cong., 1st Sess.(2003). 
Lumbee Recognition Act of 2003, , 108th Cong., 1st Sess.(2003).

Lumbee Recognition Act of 2005, 109th Cong., 1st Sess.(2005).

MacDonald, K. A. (1953 September 3). Brief history of Hoke County Schools. . The News-Journal, pp. 1, 3, 8-9.

MacDonald, M. L. (1991). The history of Hoke County High School.Unpublished manuscript.

Marshall, C., \& Rossman, G. B. (1999). Designing qualitative research. Thousand Oaks, CA: Sage Publications.

Marshall, P. L. (2002). Cultural diversity in our schools. Belmont, CA: Wadsworth/Thomson Learning.

Massey, T. R. T. (1996). School desegregation: Its significance for Native Americans of Eastern North Carolina. Unpublished master's thesis, University of North Carolina at Wilmington, Wilmington, North Carolina.

Maxwell, J. (1996). Qualitative research design: An interactive approach. Thousand Oaks, CA: Sage Publications.

Maynor, M. M. (1995). Violence and the racial boundary: Fact and fiction in the swamps of Robeson County, 1831-1871. Unpublished honors thesis, Harvard University, Cambridge, Massachusetts.

Maynor, M. M. (2002). Making Christianity sing: The origins and experience of Lumbee Indian and African American church music. In J. F. Brooks (Ed.), Confounding the color line (pp. 321-345). Lincoln, NE: University of Nebraska Press. 
Maynor, M. M. (2002). People and place: Croatan Indians in Jim Crow Georgia. Unpublished master's thesis, University of North Carolina at Chapel Hill, Chapel Hill, North Carolina.

Maynor, W. (1970). Academic performance and school integration: A multi-ethnic analysis. Unpublished doctoral dissertation, Duke University, Durham, North Carolina.

McCarty, T. L., \& Bia, F. (2002). A place to be Navajo : Rough Rock and the struggle for self-determination in indigenous schooling. Mahwah, N.J.: Lawrence Erlbaum Associates.

McCulloch, A. M., \& Wilkins, D. E. (1995). 'Constructing' nations within states: The quest for federal recognition by the Catawba and Lumbee Tribes. American Indian Quarterly, 19(3), 361-388.

McLean, A. W., Purcell, J. E., Singletary, A. G., \& Purcell, J. E. (1942). Lumber River Scots and their descendants; the McLeans, the Torreys, the Purcells, the McIntyres, the Gilchrists. Richmond,: The William Byrd Press Inc.

McMillan, H. (1888). Sir Walter Raleigh's Lost Colony. Raleigh, NC: Edwards and Broughton Company.

McPherson, O. M. (1915). Indians of North Carolina: A report on the condition and tribal rights of the Indians of Robeson and adjoining counties of North Carolina. Retrieved. from.

Merrell, J. H. (1989). The Indians' new world : Catawbas and their neighbors from European contact through the era of removal. Chapel Hill: Published for the 
Institute of Early American History and Culture, Williamsburg, Va., by the University of North Carolina Press.

Minority achievement report: Trends in subgroup performance. (2001). (Vol. 2004):

Public Schools of North Carolina, State Board of Education, Department of Public Instruction, Division of Accountability Services.

Mooney, J. (1894). The Siouan tribes of the East. Washington, DC: Government Printing Office.

Muhr, T. (1998). ATLAS.ti (Version WIN 4.2 (Build 061)). Berlin, Germany: Scientific Software Development.

Newbold, N. C., \& Allen, A. T. (1923). Division of Negro Education. Raleigh, NC: Department of Public Instruction Office of Superintendent North Carolina. (1835). Constitutional Convention. pp. 106-107. City: Printed by J. Gales \& Son Printers to the Convention.

North Carolina State Archives.

North Carolina Department of Public Instruction Agency History. (n.d.). Retrieved August 27, 2005, from http://www.ah.dcr.state.nc.us/records/schedules/dpi.htm\#hist

North Carolina Indians: American Indian Education. (2005). Retrieved October 20, 2005, from http://www.newsobserver.com/nie/curriculum/social studies/nc indians/story/136 $\underline{8873 p-7377987 \text { c.html }}$

North Carolina. Secretary of State., \& Cheney, J. L. (1981). North Carolina government, 1585-1979 : a narrative and statistical history (An updated of North Carolina 
Government, 1585-1974. ed.). Raleigh, N.C.: North Carolina Dept. of the Secretary of State.

Ogbu, J. U. (1978). Minority education and caste : the American system in cross-cultural perspective. New York: Academic Press.

Ogunwole, S. U. (2002). American Indian and Alaska Native population: 2000 Census 2000 brief Retrieved March 4, 2004, from http://www.census.gov/prod/2002pubs/c2kbr01-15.pdf

Our voice, your voice, one voice: Nurturing American Indian families for school success. (2004). (Vol. 2004): State Advisory Council on Indian Education.

Patton, M. Q. (2002). Qualitative research and evaluation methods (3rd ed.). Thousand Oaks, CA: Sage Publications.

Peck, J. G. (1972). Urban station-migration of the Lumbee Indians. Unpublished Thesis (Ph. D.), University of North Carolina at Chapel Hill, 1972.

Perdue, T. (1985). Native Carolinians: The Indians of North Carolina. Raleigh, NC: North Carolina Division of Archives and History.

Pewewardy, C. D. (1998). Culturally responsive teaching for American Indian learners. Paper presented at the Kansas Institute on effective teaching practices for Indian education, Lawrence, KS.

Pierce, J. T. (1987). The Lumbee petition. Pembroke, NC: Lumbee River Legal Services. Plessy v. Ferguson, 163 U.S. 537 (1896).

Portelli, A. (1991). The death of Luigi Trastulli, and other stories : form and meaning in oral history. Albany, N.Y.: State University of New York Press. 
Powell, W. S. (1970). Higher education in North Carolina. Raleigh: State Department of Archives and History.

Pratt, R. H. (1892). The advantages of mingling Indians with Whites. In F. P. Prucha (Ed.), Americanizing the American Indians (pp. 260-271). Cambridge, Mass.,: Harvard University Press.

Prucha, F. P. (1973). Americanizing the American Indians. Cambridge, Mass.,: Harvard University Press.

Prucha, F. P. (1985). The Indians in American society. Berkeley, CA: University of California Press.

Public Schools of Robeson County Board of Education (PSRCBE) Minutes. Lumberton, N C.

Remaining and becoming: 2003 Report to the State Board of Education (2003). (Vol. 2004): State Advisory Council on Indian Education.

The State Educational Commission. (1927). Report of the state educational commission on the public school system of North Carolina. City: The State Educational Commission.

Ritchie, D. (2003). Doing oral history: A practical guide (2nd ed.). New York: Oxford University.

Robeson County population by race 1980-2000. (2000). (Vol. 2004): CensusScope

Sanders, J. L. (1993). The University of North Carolina: The legislative evolution of public higher education. Popular Government, 59(2), 20-29. 
Sangster, J. (1997). Telling our stories: Feminist debates and the use of oral history. In R. Perks \& A. Thomson (Eds.), The oral history reader (pp. xiii, 479 p.). New York: Routledge.

Sarris, G. (1993). Hearing the old ones talk: Reading narrated American Indian lives in Elizabeth Colson's Autobiographies of Three Pomo Women. In A. Krupat (Ed.), New voices in Native American literary criticism (pp. 419-452). Washington, DC: Smithsonian Institution Press.

Schwartz, B. (1996). Introduction: The expanding past. Qualitative Sociology, 19(3), 275-282.

Schwartz, B. (1999). Memory and the practices of commitment. In B. Glassner \& R. Hertz (Eds.), Qualitative sociology as everyday life (pp. 135-146). Thousand Oaks, CA: Sage.

Sider, G. M. (1976). Lumbee Indian cultural nationalism and ethnogenesis. Dialectical Anthropology, 1, 161-172.

Sider, G. M. (1993). Lumbee Indian histories: Race, ethnicity, and Indian identity in the southern United States. New York: Cambridge University Press.

Snider, W. D. (1992). Light on the hill : a history of the University of North Carolina at Chapel Hill. Chapel Hill: University of North Carolina Press.

Sokolow, G. A. (2000). Native Americans and the law : A dictionary. Santa Barbara, Calif:: ABC-CLIO.

Sommer, B. W., \& Quinlan, M. K. (2002). The oral history manual. Walnut Creek, CA: AltaMira. 
South Hoke Elementary School. (2004). Retrieved June 2, 2004, from http://www.hcs.k12.nc.us/shes/Default.htm

Spring, J. H. (2001). Deculturalization and the struggle for equality: A brief history of the education of dominated cultures in the United States. New York: McGrawHill.

Stake, R. E. (1978). The case-study method in social inquiry. Educational Researcher, 7, $5-8$.

Stanfield II, J. H. (1994). Ethnic modeling in qualitative research. In N. K. Denzin \& Y. S. Lincoln (Eds.), Handbook of qualitative research (pp. 175-188). Thousand Oaks, CA: Sage.

Students: School has racial unrest. (2002, November 2). News and Observer, p. B4.

Swanton, J. R. (1934). Probable Identity of the 'Croatan' Indians. In U.S. Senate Reports, Siouan Indians of Lumber River (Report no. 204, 73rd Congress, 2nd session ed., pp. 3-6). Washington, DC: Government Printing Office.

Swisher, K. G. (1996). Why Indian people should be the ones to write about Indian education. American Indian Quarterly, 20, 83-90.

Swisher, K. G., \& Tippeconnic, I., J. W. (Eds.). (1999). Next steps: Research and practice to advance Indian education. Charleston, West Virginia: Appalachia Educational Laboratory.

Szasz, M. C. (1999). Education and the American Indian: The road to self-determination since 1928. Albuquerque, NM: University of New Mexico Press.

Takaki, R. (1993). A different mirror: A history of multicultural America. Boston: Little Brown Publishers. 
Tatum, B. D. (1997). "Why are all the black kids sitting together in the cafeteria?" And other conversations about race. New York: Basic Books.

Thelen, D. (1989). Memory and American history. The Journal of American History, 75(4), 1117-1129.

Thompson, P. (2000). The voice of the past: Oral history (3rd ed.). New York: Oxford University Press.

Thompson, V. R. (1973). A history of the education of the Lumbee Indians of Robeson County, North Carolina from 1885 to 1970. Unpublished doctoral dissertation, University of Miami, Miami, Florida.

Thornton, R. (1987). American Indian holocaust and survival : a population history since 1492 (1st ed.). Norman: University of Oklahoma Press.

Thuesen, S. C. (2003). Classes of citizenship : the culture and politics of black public education in North Carolina, 1919-1960.

Title VII — Indian, Native Hawaiian, and Alaska Native Education. (2005). (Vol. 2005): United States Department of Education.

United for success 2002 report to the State Board of Education. (2002). Retrieved January 4, 2003, from http://www.ncpublicschools.org/schoolimprovement/closingthegap/reports/indian ed/downloads/indianed01.pdf

Walker, V. S. (1996). Their highest potential: An African American school community in the segregated South. Chapel Hill, NC: The University of North Carolina Press. 
Walker, V. S. (2000). Valued segregated schools for African American children in the South, 1935-1969: A review of common themes and characteristics. Review of Educational Research, 70(3), 253-285.

Willis, W. S. (1963). Divide and rule: Red, white, and black in the Southeast. The Journal of Negro History, 48(3), 157-176.

Wilson, A. V. (1997). Forgotten voices: Remembered experiences of cross-over teachers during desegregation in Austin, Texas, 1964-1971. Unpublished doctoral dissertation, University of Texas at Austin, Austin, Texas.

Wilson, A. V., \& Segall, W. E. (2001). Oh, do I remember!: Experiences of teachers during the desegregation of Austin's schools, 1964-1971. New York: SUNY Press.

Wolcott, H. F. (1990). On seeking- and rejecting- validity in qualitative research. In E. W. Eisner \& A. Peshkin (Eds.), Qualitative inquiry in education: The continuing debate (pp. 121-152). New York: Teachers College Press.

Wolfram, W., Dannenburg, C., Knick, S., \& Oxendine, L. (2002). Fine in the world: Lumbee language in time and place. Raleigh, NC: North Carolina State University Humanities Extension/ Publications.

Woodward, C. V. (1974). The strange career of Jim Crow (3d rev. ed.). New York,: Oxford University Press.

Yellow Bird, M. (1999). What we want to be called. American Indian Quarterly, 23(2), $1-21$.

Zerubavel, E. (1996). Social memories: Steps to a sociology of the past. Qualitative Sociology, 19(3), 275-282. 


\section{APPENDICES}

APPENDIX A: Figures and Pictures of Indian Schools Mentioned in Dissertation 


\section{Data Analysis Flow Chart}

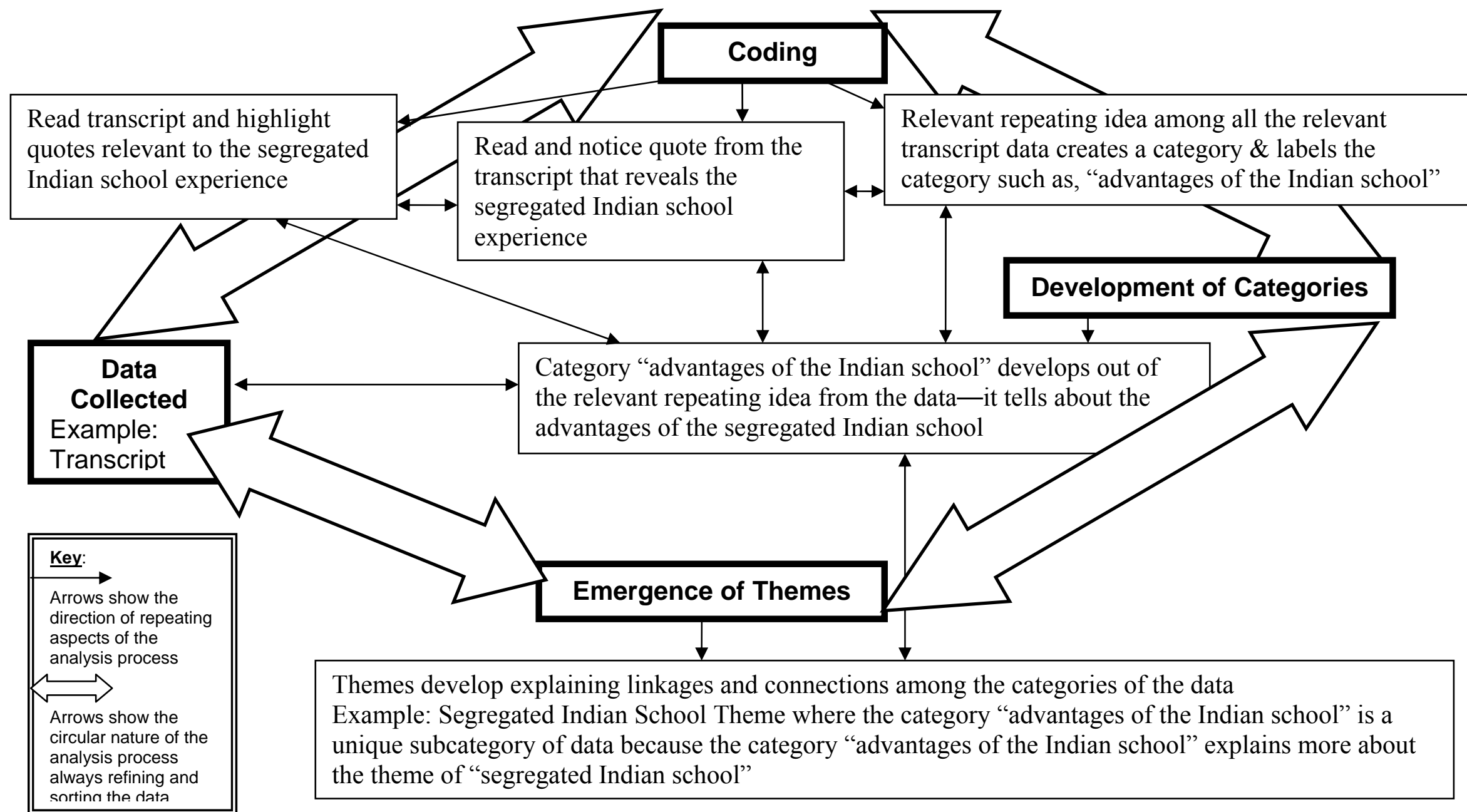

*Note 31 categories (Figure 2.) emerged from the data in this same manner as described with this one category of "advantages of the Indian school" and this is continual process

Figure 1. Data Analysis Flow Chart 


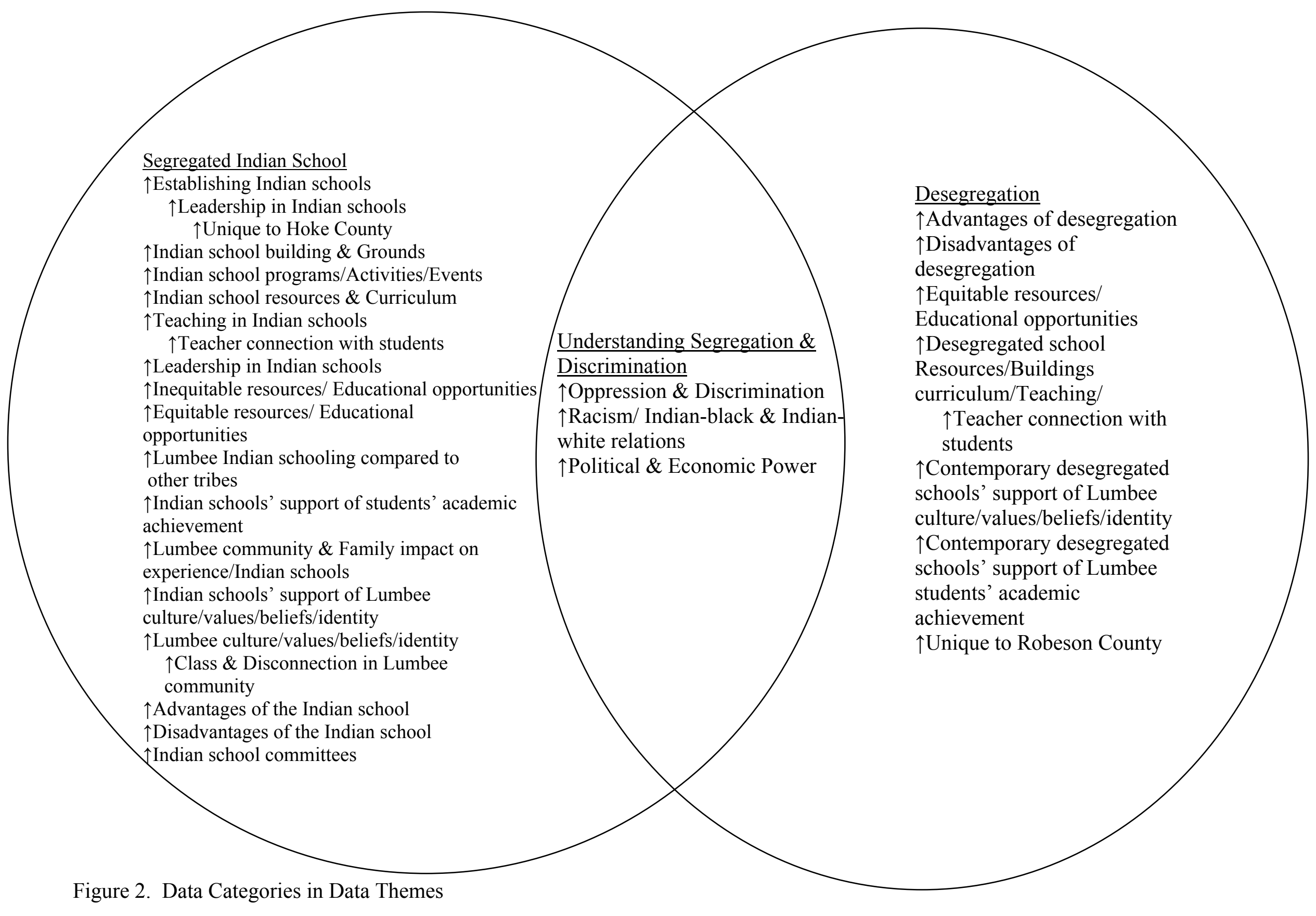




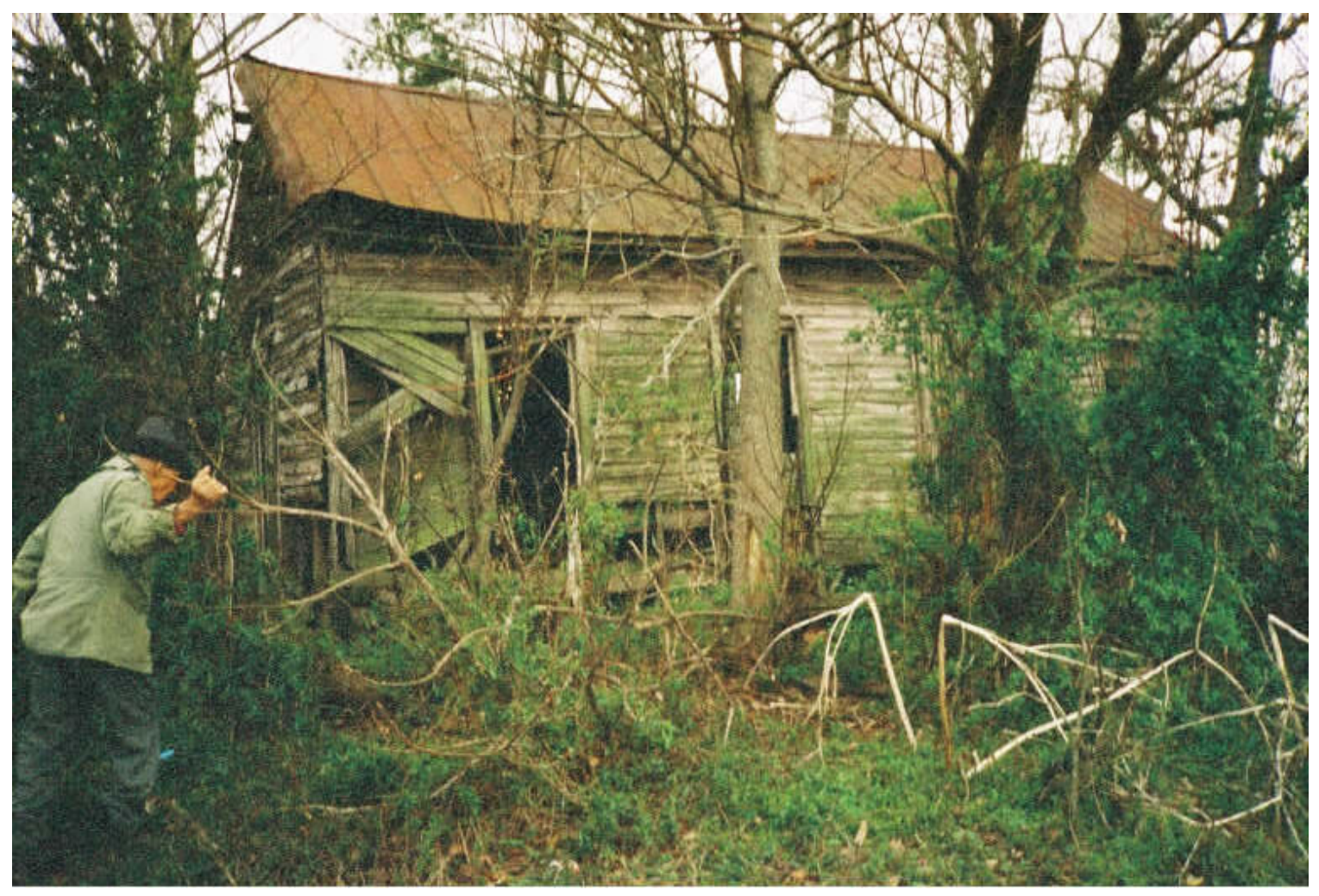

Figure 3. Jacob's Point School ${ }^{1}$

\footnotetext{
${ }^{1}$ Photo taken by Heather Kimberly Dial. Gentleman in photo is the father of Heather Kimberly Dial who also taught and was a principal in the Indian schools.
} 


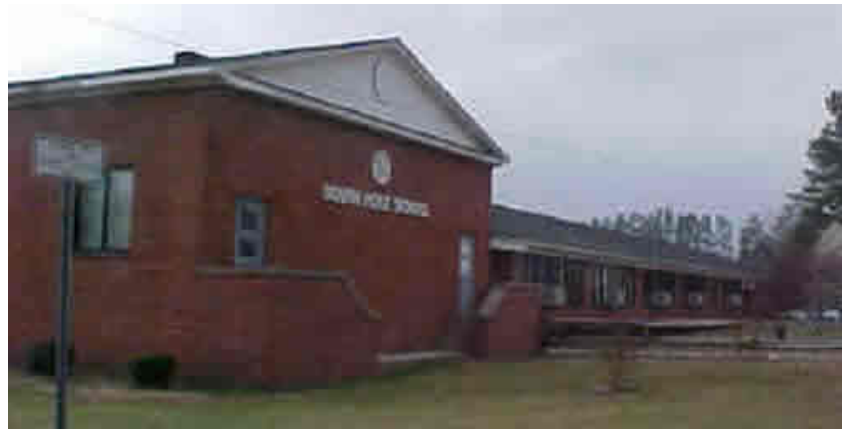

Figure 4. Hawkeye Indian School (South Hoke Elementary School) ${ }^{2}$

${ }^{2}$ Photo Courtesy of Hoke County Schools (South Hoke, 2004) 


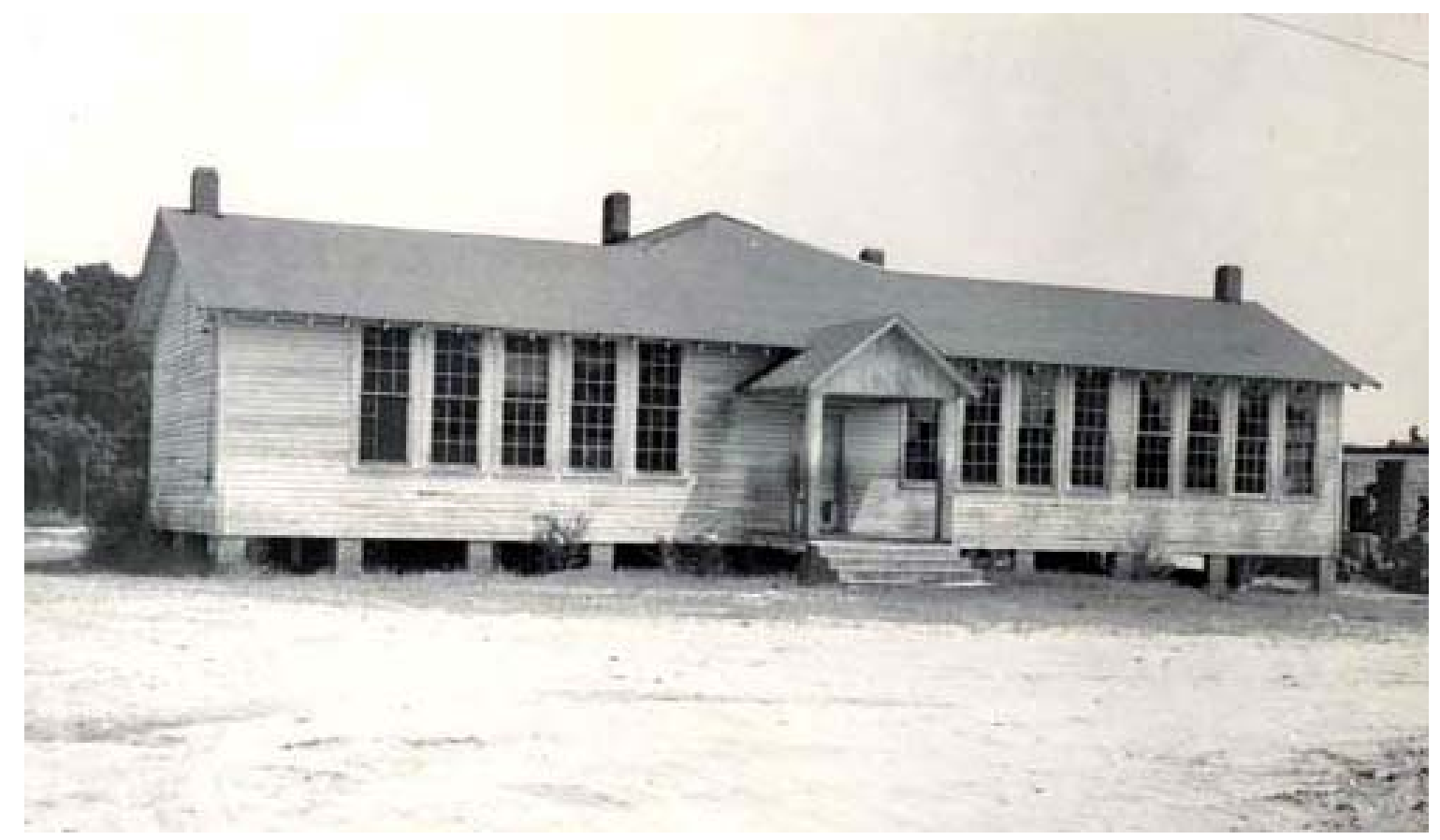

Figure 5. Ashpole Center Indian School ${ }^{3}$

${ }^{3}$ Photo Courtesy of the Public Schools of Robeson County Indian Education (Honors 2003, 2003-2004) 


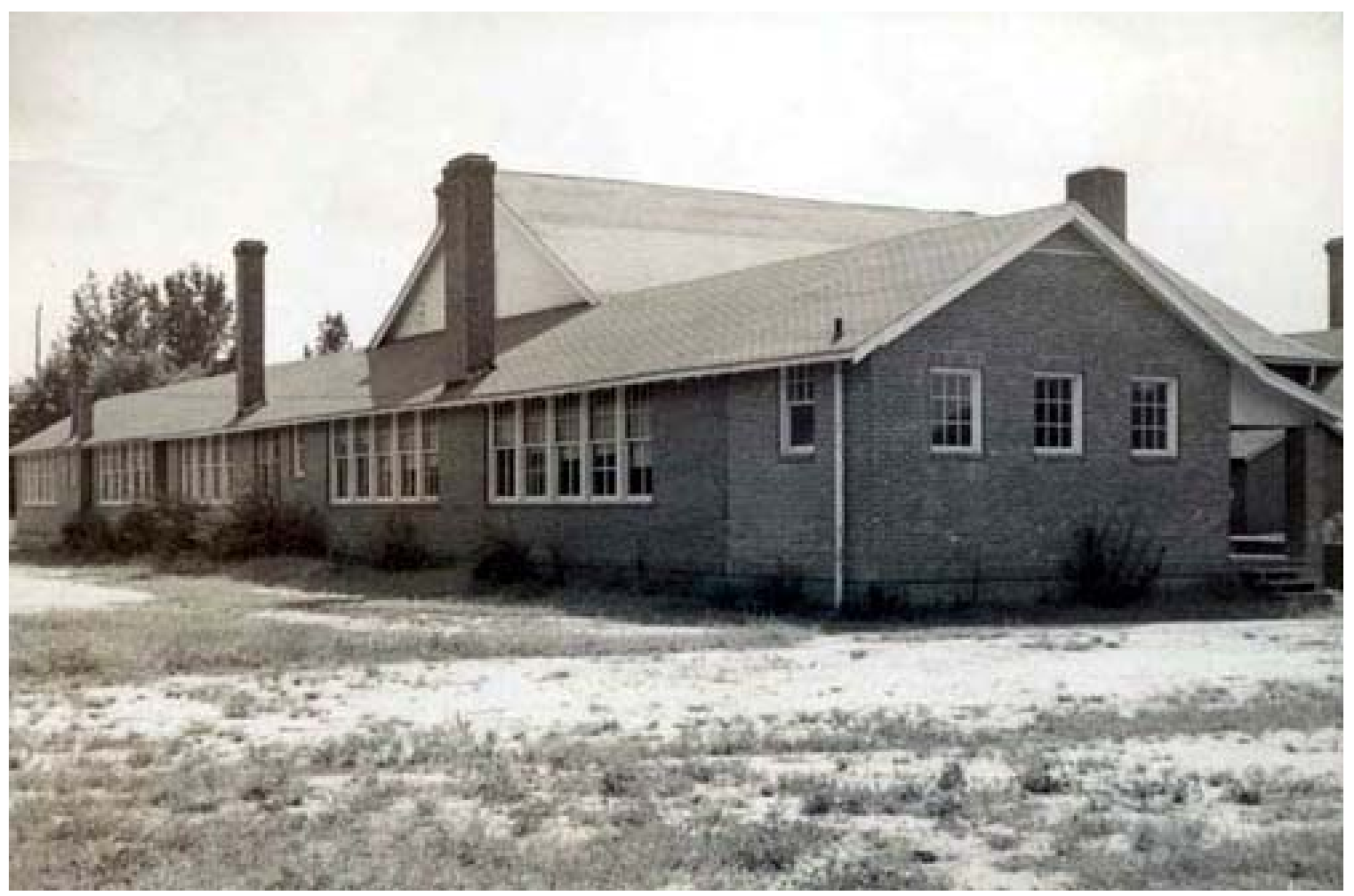

Figure 6. Pembroke Elementary Indian School ${ }^{4}$

\footnotetext{
${ }^{4}$ Photo Courtesy of the Public Schools of Robeson County Indian Education (Honors 2003, 2003-2004)
} 


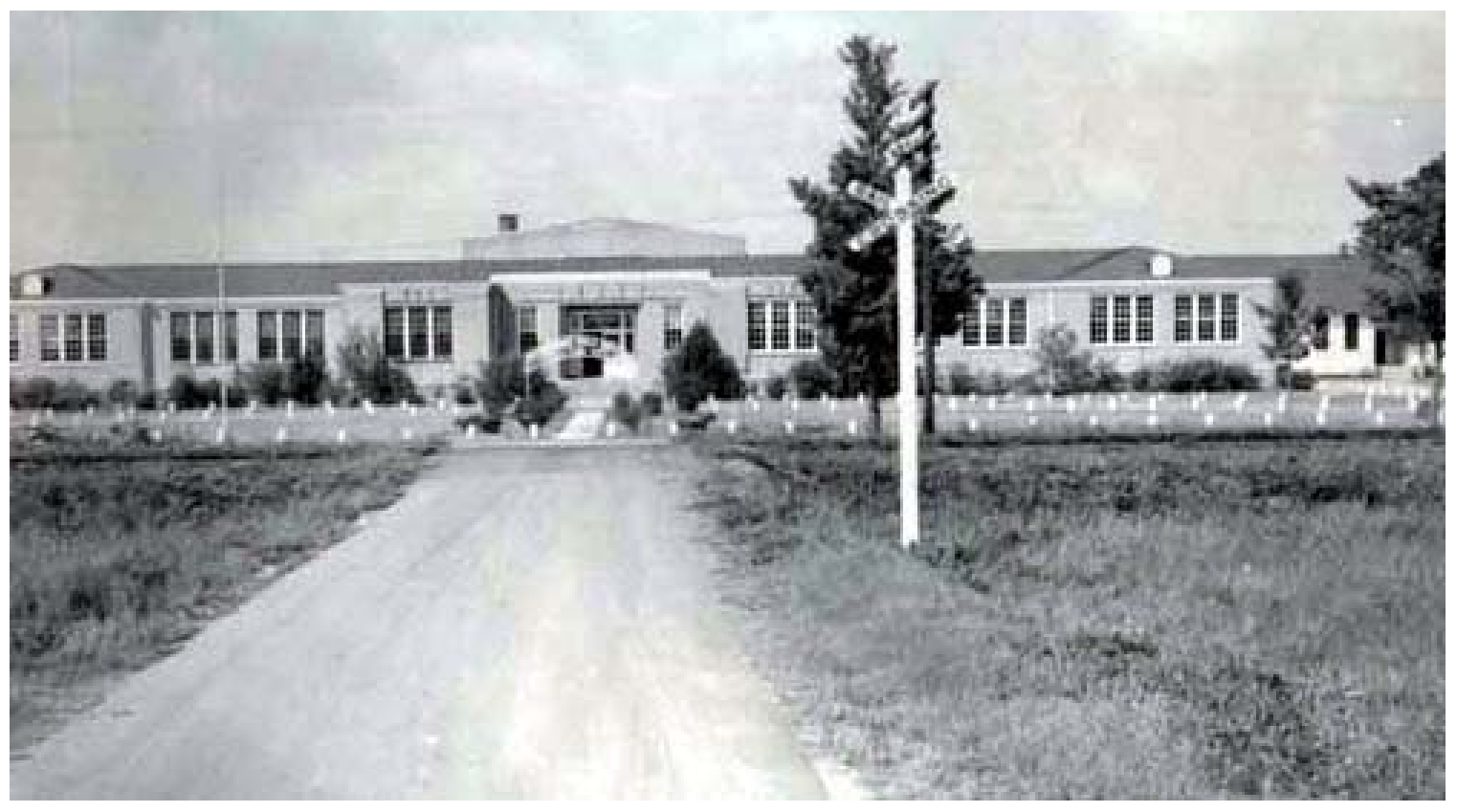

Figure 7. Pembroke High School ${ }^{5}$

${ }^{5}$ Photo Courtesy of the Public Schools of Robeson County Indian Education (Honors 2003, 2003-2004) 


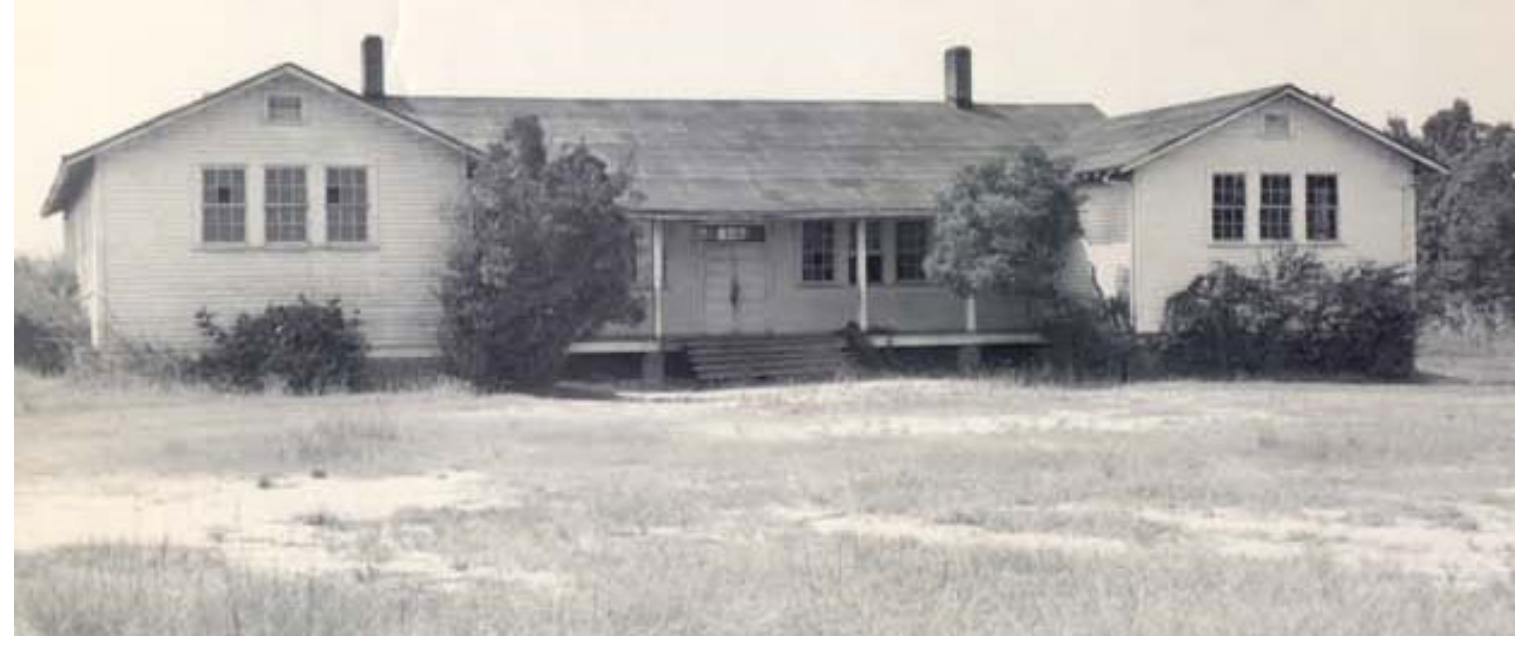

Figure 8. Green Grove High School ${ }^{6}$

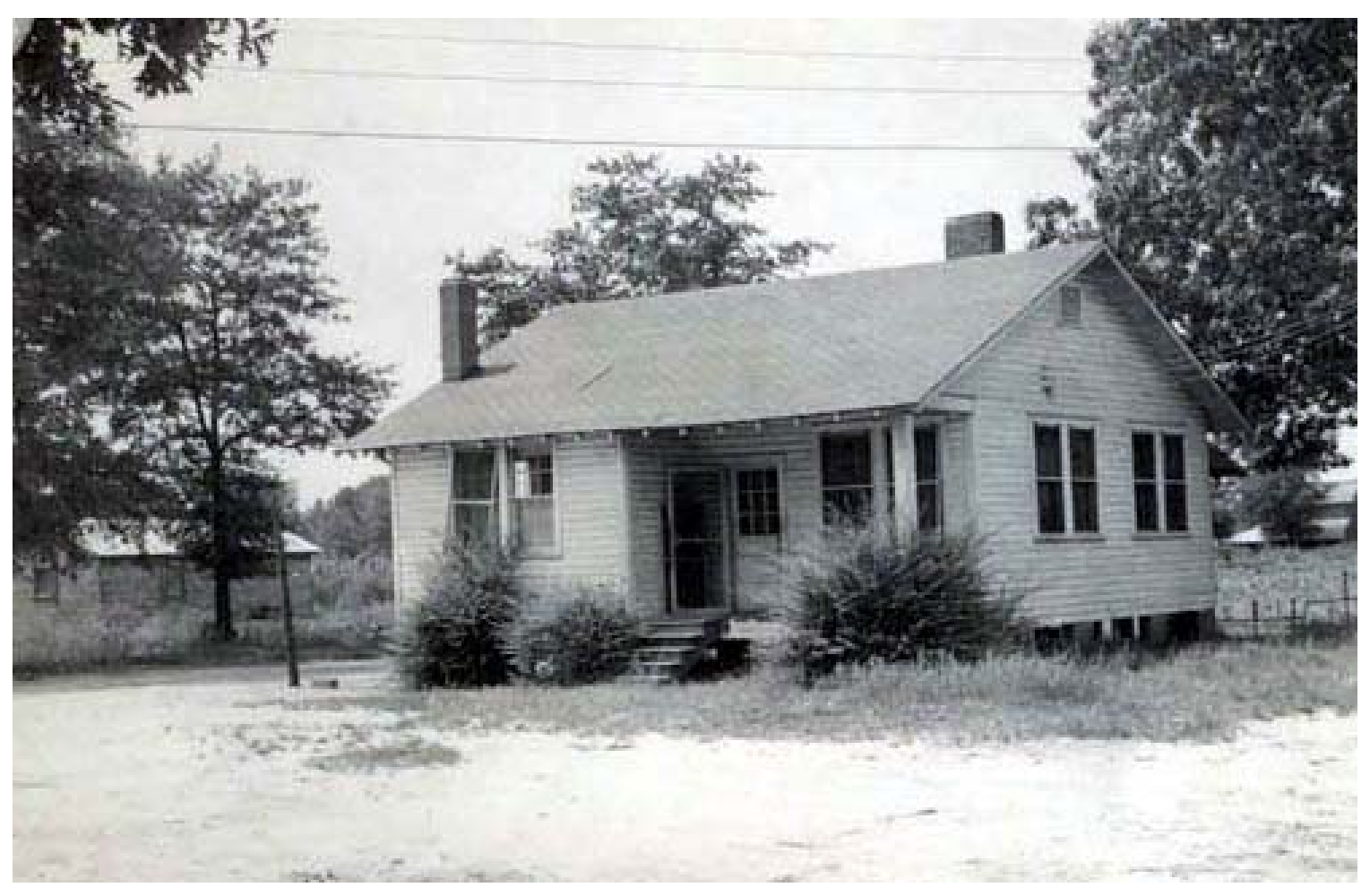

Figure 9. Green Grove High School Home Economics Building ${ }^{7}$

${ }^{6}$ Photo Courtesy of the Public Schools of Robeson County Indian Education (Honors 2003, 2003-2004)

${ }^{7}$ Photo Courtesy of the Public Schools of Robeson County Indian Education (Honors 2003, 2003-2004) 


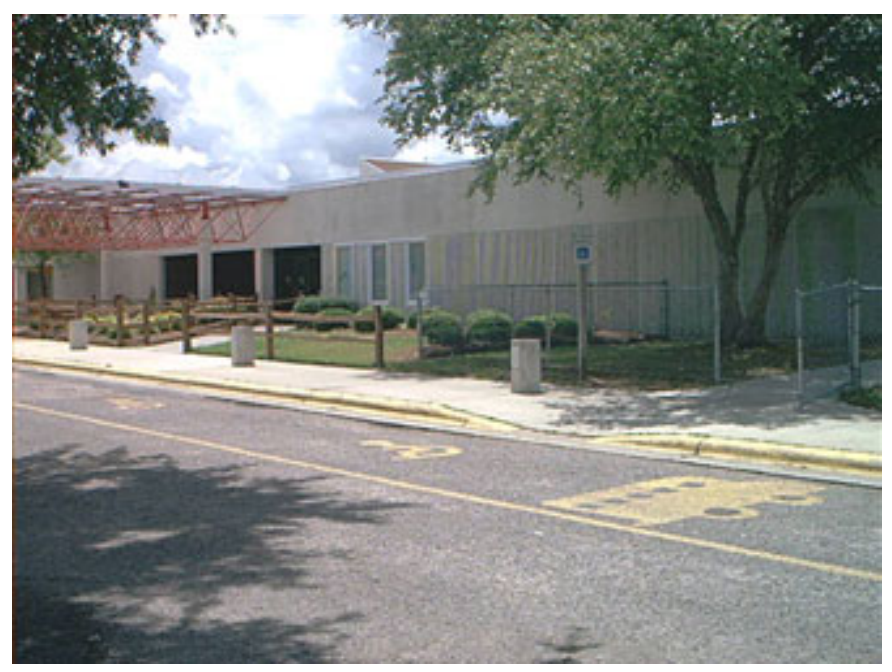

Figure 10. Pembroke Elementary School (contemporary) ${ }^{8}$

${ }^{8}$ Photo Courtesy of the Public Schools of Robeson County Indian Education (Honors 2003, 2003-2004) 


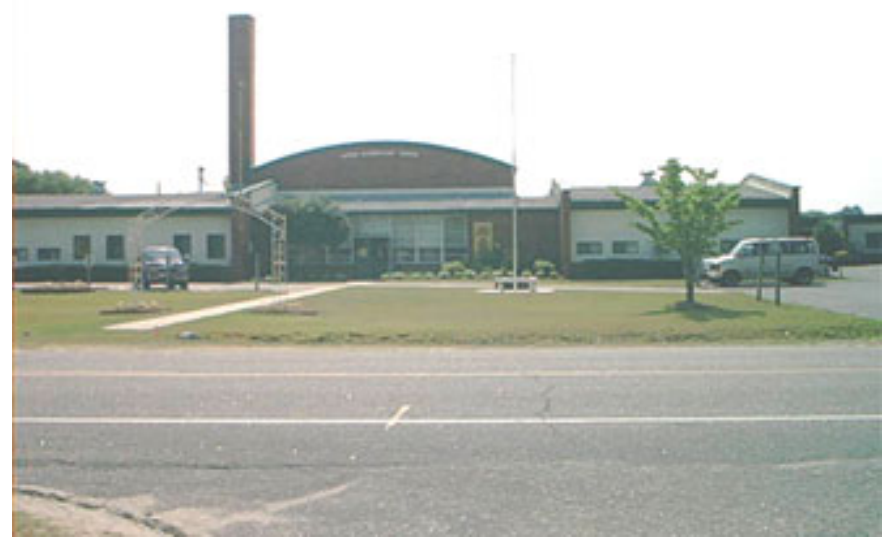

Figure 11. Union Elementary School ${ }^{9}$

${ }^{9}$ Photo Courtesy of the Public Schools of Robeson County Indian Education (Honors 2003, 2003-2004) 


\section{APPENDIX B: Interview Guides for Participant}

I am interested in getting information from you about this time in history when you were in the Indian schools of the past as a student, a teacher, and as an administrator. I want you to think back to that time when you were in the Indian schools. I would like to better understand that experience, what was being in those schools like at that time. I want you to explain things to me so I can understand the world from your point of view and know what that experience was like for you, to walk in your shoes and feel things as you felt them at that time in your life because I didn't have that experience. In this interview, I am asking you to be my teacher and help me understand.

This interview will help to document the experiences of the Lumbee Indians in the Indian schools of the past and add their voices to the general discourse about Indian schools in our nation and to the history of education. The Lumbee experiences have never been documented. Historical research has been conducted about Indian schools, but never have their personal experiences been researched.

In this interview I will ask you to answer questions to learn more about your experience in the Indian schools. I will audio tape the interview, as well as take notes. The interviews will then be written down verbatim from the audiotape and analyzed. You may decline to participate in this interview and you may decline to answer any questions that you do not wish. You also have the right to ask me to turn off the tape recorder at anytime that you are uncomfortable or to stop the interview at anytime that you wish this is completely voluntary and I am thankful for your help. If you decide to withdraw from the interview before I have completed the interview, the audiotape will be returned to you or destroyed as you wish. When the interview and my research has been completed I will give you the audio tape of your interview.

\section{Basic Documentation:}

1. Participant's affiliation in study (indicate whether student, teacher, or administrator in Hoke or Robeson County Indian Schools)

2. Age

3. Race/ Tribal Affiliation

4. Class

5. School Attended

6. Years Attended

7. In what county did you attend school?

8. Where did you grow up?

9. Document where, the date \& time that you conducted the interview.

\section{Interview Questions:}

1. Describe the Indian school. What was it about these schools that marked them as distinct?

2. What was the affect of the Indian schools on you? (As a student in the school. As a teacher in the school. As an administrator in the school. As it applies to each participant's experience.)

3. Did the family, Lumbee community, and other non-Lumbee factors affect your school experience? (As a student in the school. As a teacher in the school. As an administrator in the school. As it applies to each participant's experience.)

4. How did desegregation affect you? (As a student in the school. As a teacher in the school. As an administrator in the school. As it applies to each participant's experience.)

5. How did desegregation affect the family and the Lumbee community?

6. Describe your culture, values, or beliefs as a Lumbee Indian. Were the Indian schools supportive of your culture, values, or beliefs? How?

7. Are the schools today supportive of your culture, values, or beliefs? How?

8. Were the Indian schools supportive of students' academic achievement? How?

9. Are the schools today supportive of Indian students' academic achievement? How?

10. Describe the resources of the Indian school. What were the materials like that were provided for instruction in the Indian school? What were the school building, grounds, and supplies for the Indian school like? How were the materials, school building, grounds, and supplies of the Indian school provided and maintained?

11. Describe the resources of the desegregated school. What were the materials like that were provided for instruction in the desegregated school? What were the school building, grounds, and supplies for the desegregated school like? How were the materials, school building, grounds, and supplies of the desegregated school provided and maintained? 


\section{APPENDIX C: Letter of Informed Consent}

North Carolina State University

Letter of Informed Consent for the Study:

Struggling for Voice in a Black and White World: Lumbee Indians Educational Experience in North Carolina

Month Day, 2004

Dear Members and Friends of the Lumbee Community,

The purpose of this letter is to introduce myself to you and to request your help with a research project I am conducting.

My name is Heather Kimberly (Kim) Dial and I am a graduate student in the doctoral program in curriculum and instruction at North Carolina State University. I am a member of the Lumbee tribe, from the Antioch Community in Hoke County. My parents are Mr. Peter Dial, Jr. and Mrs. Dolores Barton Dial.

My mother's family is from the Harpers Ferry Community in Robeson County. Her parents are the late Mrs. Lizzie Locklear Barton and the late Mr. Wardell Barton. My father's family is from the Red Banks Community in Robeson County. He is the son of the late Mr. Peter Dial, Sr. and Mrs. Sarah Dial. His brothers are Rev. James (Jimmy Dial), Mr. Bethel (Benford) Dial of Robeson County and Mr. Joel Dial of the Antioch Community, Hoke County.

I am in the process of conducting research for my doctoral study on the experience of the Lumbee Indians in the Indian schools of the past in Hoke and Robeson County and I would like to invite you participate in this research study. The purpose of this study is to document the experiences of the Lumbee Indians in these Indian schools in Hoke and Robeson County and to add their voices to the general discourse about Indian schools in our state, nation and to the history of education. The Lumbee personal experiences in these schools have never been documented or recorded in any way. Research has been conducted about the establishment of the Indian schools in Robeson County, however, the Lumbee Indian's personal experiences in the schools in Hoke and Robeson County have never been studied, researched or reported.

This study will involve your participation in an interview in which I will ask you to answer questions to learn more about your experience in the Indian schools. I will audio tape the interview, as well as take notes. The interview will last from one to one hour and a half. The interviews will then be written down verbatim from the audiotape and analyzed.

Your participation in this study is risk-free and is voluntary; you may decline to participate without penalty. If you decide to participate, you may withdraw from the study at any time without penalty. If you withdraw from the study before I have completed the interview, the audiotape will be returned to you or destroyed. Your participation is valued and I am thankful for your help if you decide to participate.

If you choose to participate, I will insure your confidentiality and I will protect your identity by giving you a pseudonym as well as giving your location a pseudonym. Descriptions about you and your location will also be written in a manner to protect your anonymity. 
The audiotape of your interview will be secured in a locked cabinet in my residence and the audiotape will be either destroyed or given to you at the end of the study as you decide. The data from the interviews will only be seen by my doctoral advisory committee. The information from the interviews will only be discussed generally and protecting your anonymity.

The benefits of this study will prove immensely important to our history as a people. Through the Lumbee people sharing their experiences this information can be used to inform and educate teachers, professors, and administrators in the public schools and the institutions of higher learning about the education experience for the Lumbee people during this time in history. These experiences have the potential to greatly affect future teaching practices by giving educators a greater and improved awareness about the Lumbee history and culture, of which education is a vital part. This study could also encourage critical reflection among educators in schools within the Lumbee community as to whether the schools are meeting the educational and developmental needs of the Lumbee students.

If you have questions at any time about the study or the procedures, you may contact me,

Heather Kimberly Dial, at 4216 Loch Harbour Lane, Raleigh, NC 27606, (919) 233-7478, or hkdial@yahoo.com. If you feel you have not been treated according to the descriptions in this form, or your rights as a participant in this research have been violated during the course of this project, you may contact Dr. Matthew Zingraff, Chair of the NCSU IRB for the Use of Human Subjects in Research Committee, Box 7514, NCSU Campus (919/513-1834) or Mr. Matthew Ronning, Assistant Vice Chancellor, Research Administration, Box 7514, NCSU Campus $(919 / 513-2148)$

\section{Participation}

\section{CONSENT}

I have read and understand the above information. I have received a copy of this form. I agree to participate in this study.

Subject's signature Date

Investigator's signature Date

Your assistance with this project is greatly valued and please accept my whole hearted appreciations in advance.

Heather Kimberly Dial (Kim)

4216 Loch Harbour Lane

Raleigh, NC 27606

919.233.7478

hkdial@yahoo.com 
APPENDIX D: Earliest Financial and Statistical Reports of the Public Schools of Robeson County

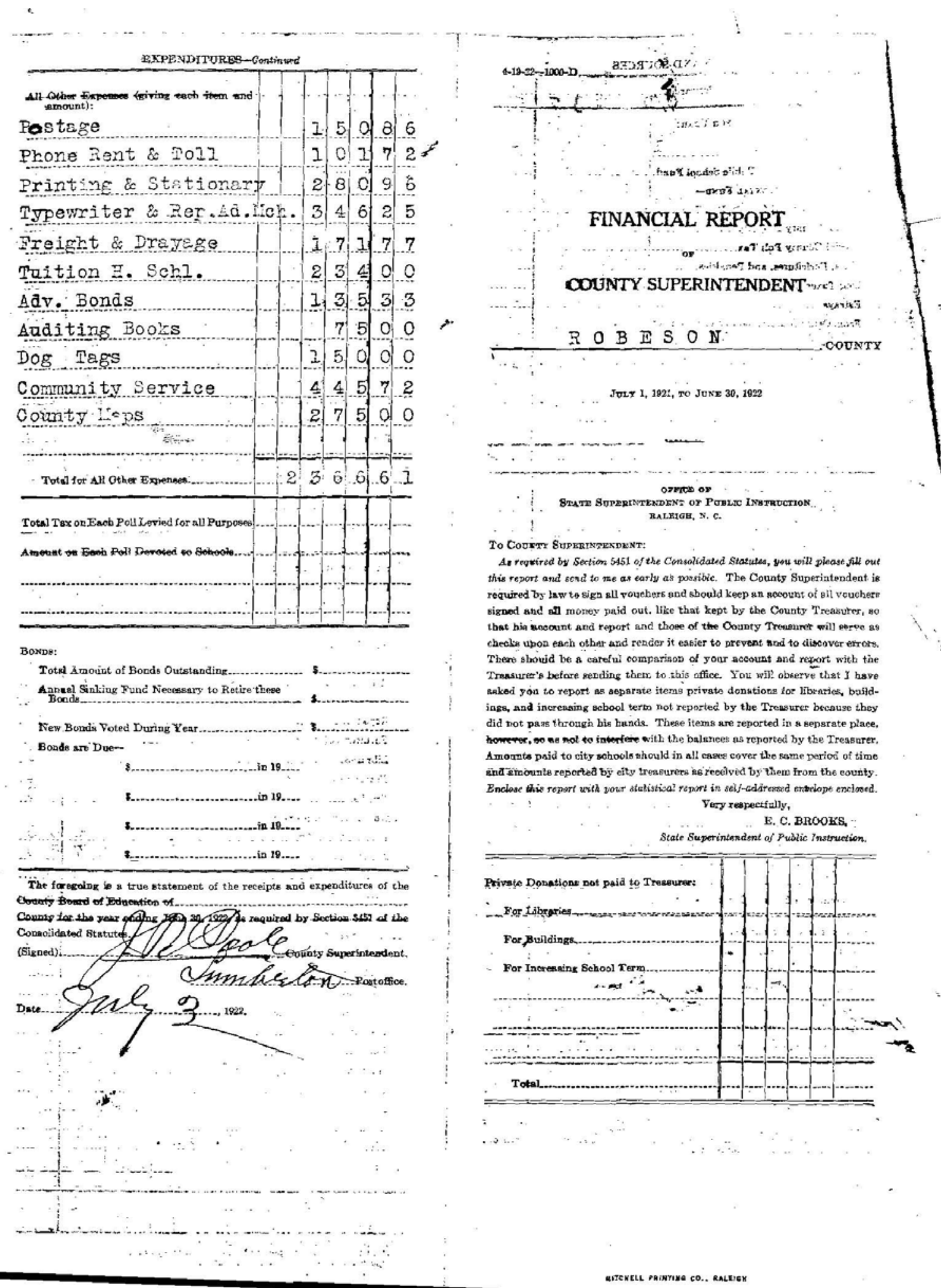




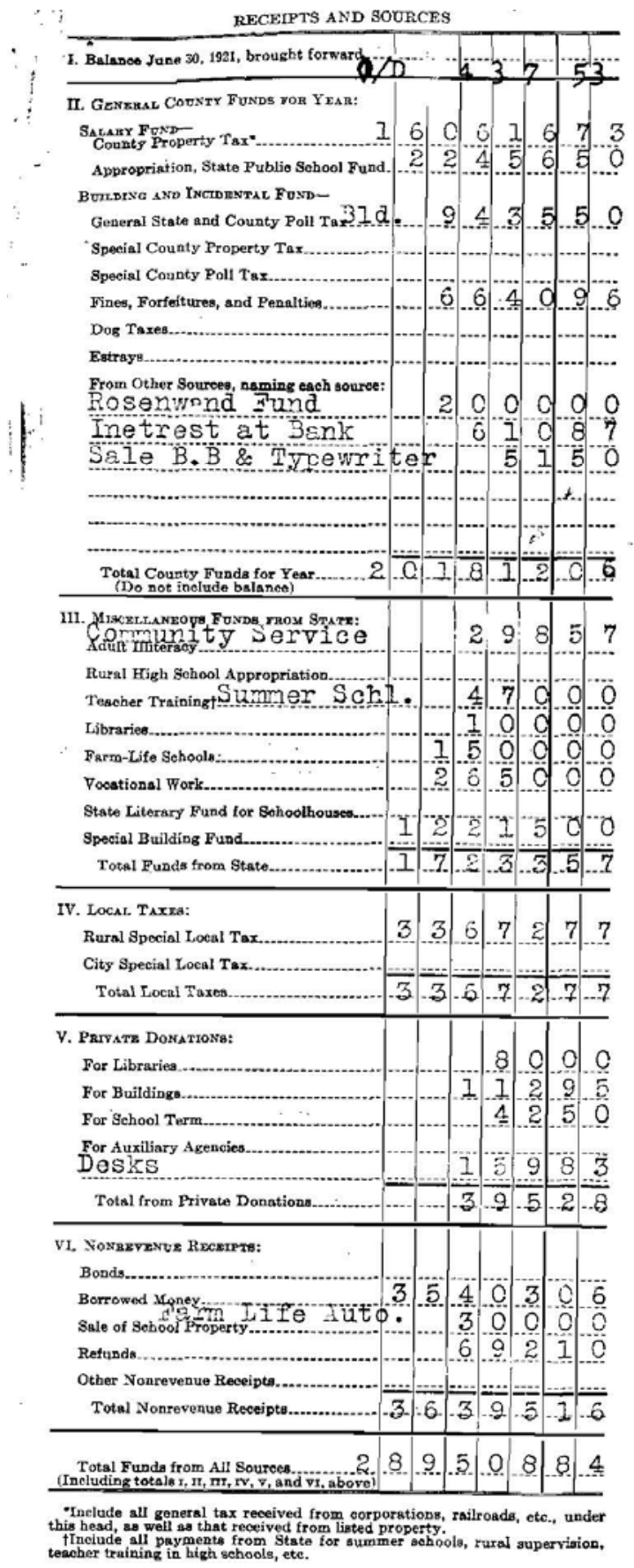

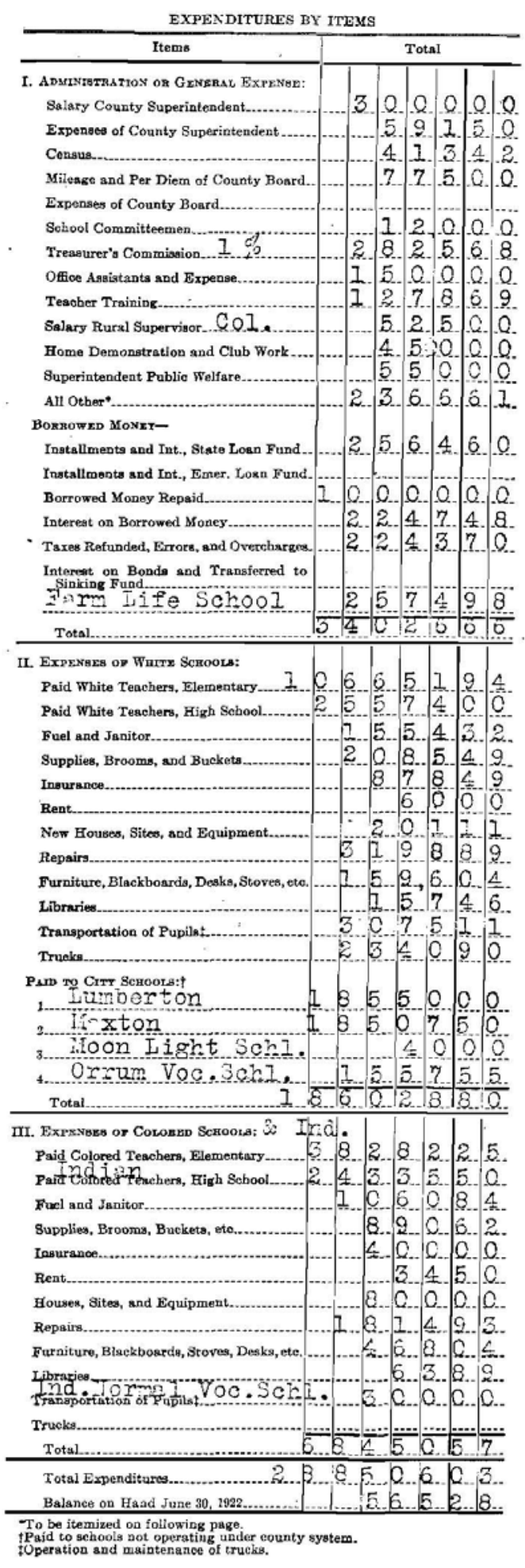

credit of said districts. 
GENERAL STATISTICS

=

(III. Draraters: WhiteInd colored Total

Namber of school distrito. \begin{tabular}{lll|l}
68 & 34 & 56 & 158
\end{tabular}

Namber of school districts........

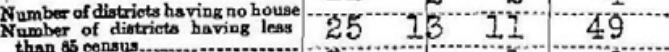

\section{Docreano in districts duriog yoar.} Number new diptriots formed $5 \quad-1-6$

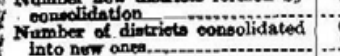

\section{Iv. Scroos:}

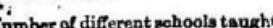
amber having one teacher. Number hay ying two tewhera.

19. Number having threo teachers-

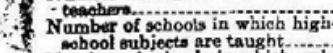
Number of sobools in which on
first forr grades are tsught.

toacher schoolo

7. Number of consolidaded sochoois

Number of nato trucks ued for tor

1. Number of pupils being transport

V. Trex:

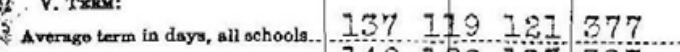
$\begin{array}{llllll}\text { Averago term in local-tax districta. } & 142 & 1 & 22 & 123 & 387\end{array}$

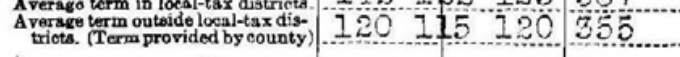

\section{a VI. Lomense:}

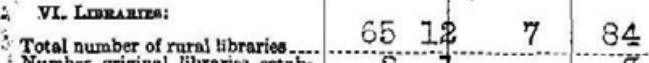
Number orivinal librariea eatsb: ……

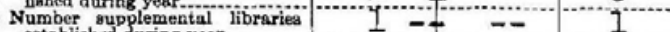
Total number of volumes in all $\quad 3198 \quad 348 \quad 211 \quad 3757$

Vin

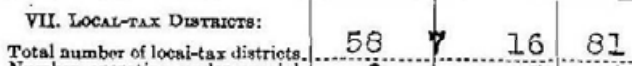

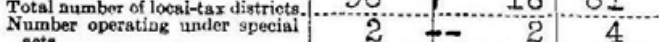
Number operating uader generai
law

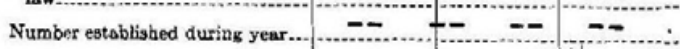
Number voted off during year..........--

Number of elections pending $---1---1-$

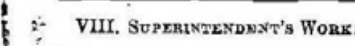

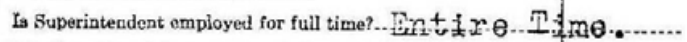
Totai number of days employed, if not for full time..........................
GENERAL BTATISTICS

\begin{tabular}{|c|c|c|c|c|c|c|c|c|c|c|}
\hline \multirow{2}{*}{ Yrasa } & \multicolumn{3}{|c|}{ Indian } & \multicolumn{3}{|c|}{ Writs } & \multicolumn{3}{|c|}{ COLORED } & \multirow{2}{*}{$\begin{array}{l}\text { Total } \\
\text { White } \\
\text { shd } \\
\text { colored }\end{array}$} \\
\hline & ele & $\mathrm{em}$. & Fotal & Male & Female & $\begin{array}{c}\text { Total } \\
\text { Mrale and } \\
\text { Female }\end{array}$ & Malo & Femsle & $\begin{array}{c}\text { Total } \\
\text { Yrale and } \\
\text { Fomale }\end{array}$ & \\
\hline Reral Scyoor Chasteg:" & 304 & 321 & 625 & 794 & $8 C 1$ & 1595 & 876 & 803 & 1679 & 3899 \\
\hline No. of children 6 years old... & $9 \div 8$ & $96 I$ & 1879 & 1910 & 1899 & 3809 & 1814 & 1871 & $\begin{array}{l}100 \\
3847\end{array}$ & 9095 \\
\hline 7 to 13 years old & ving & 369 & 521 & 890 & 831 & 1721 & 610 & 705 & 1527 & 3769 \\
\hline $\begin{array}{l}\text { No. of children } 14 \text { to } 17 \text { years old, inch } \\
\text { No. of obildren } 18 \text { to } 20 \text { years old, inel }\end{array}$ & lutive 109 & 105 & 212 & 247 & 214 & 461 & 186 & 152 & 38 & 1011 \\
\hline Total rural school ceneus, 6 to 21 & 1543 & 1694 & 3237 & 3797 & 3787 & 7586 & 3486 & 3531 & 7017 & 17840 \\
\hline
\end{tabular}

CrTy Scupol Cynsus: tumber

1. Mrixion

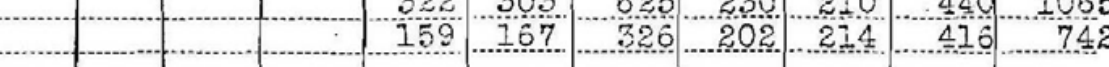

1
-

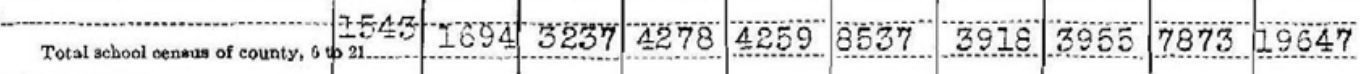

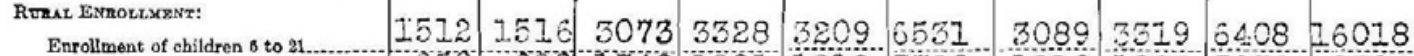

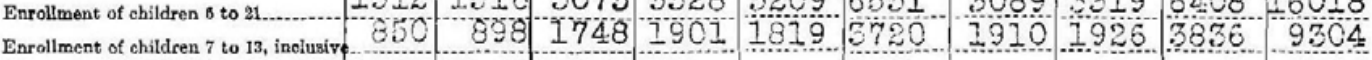

Enrollment of children 7

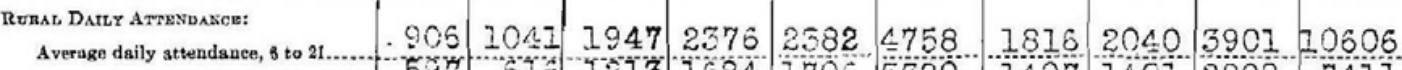

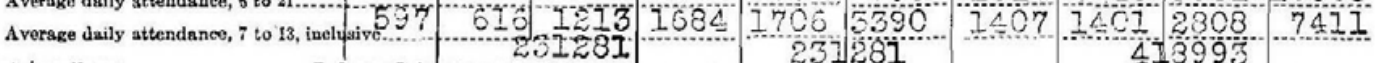

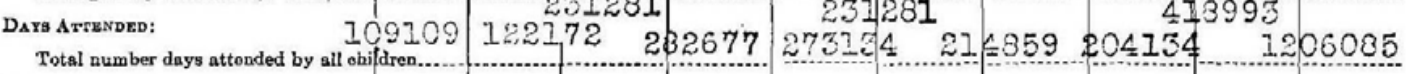

TrACHEN

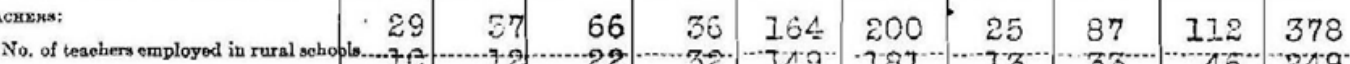

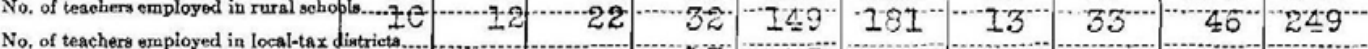

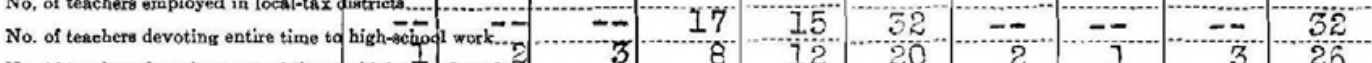

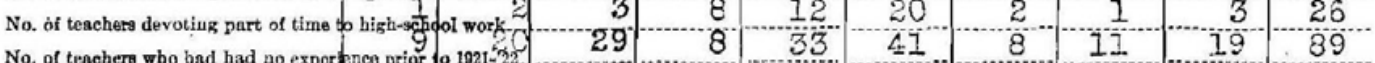

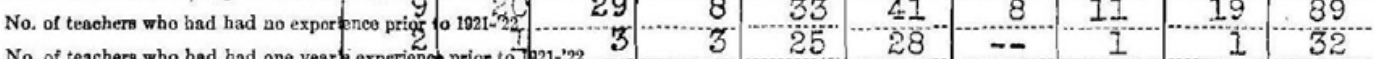

No. of teachers who had had one year s experiencp prior to

No. of tesobers who had had two

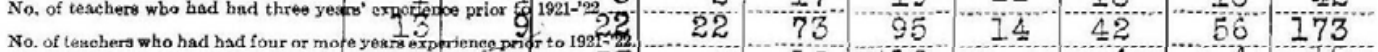

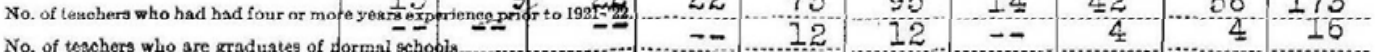

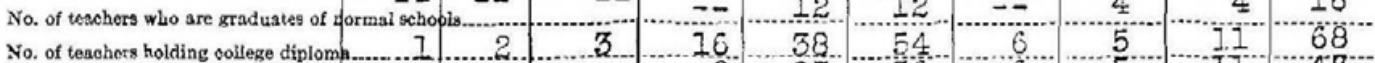

\begin{tabular}{ll|ll} 
&
\end{tabular}

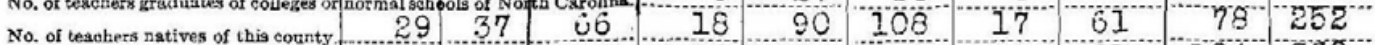

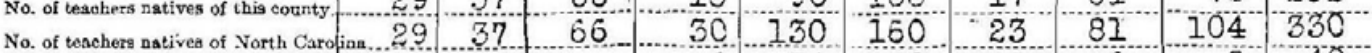

No. of teachers natives of ather Stated

ILLTTERATre:

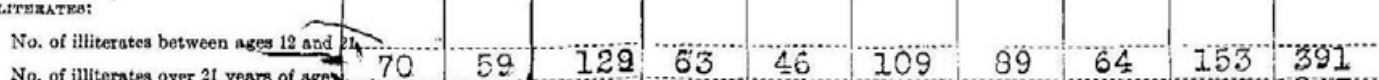

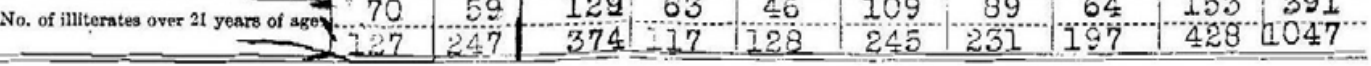

The age should be given as of September ist. 


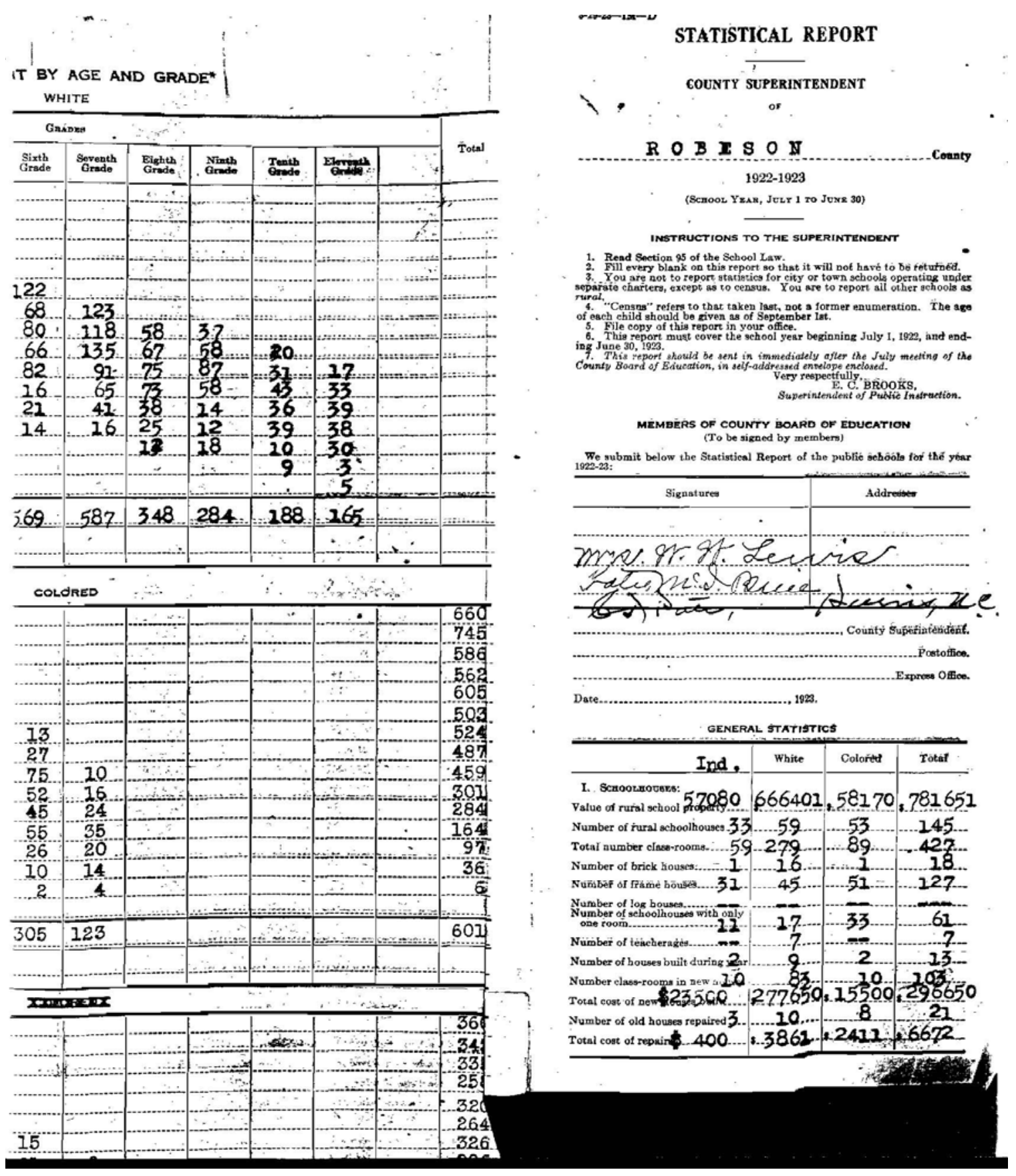




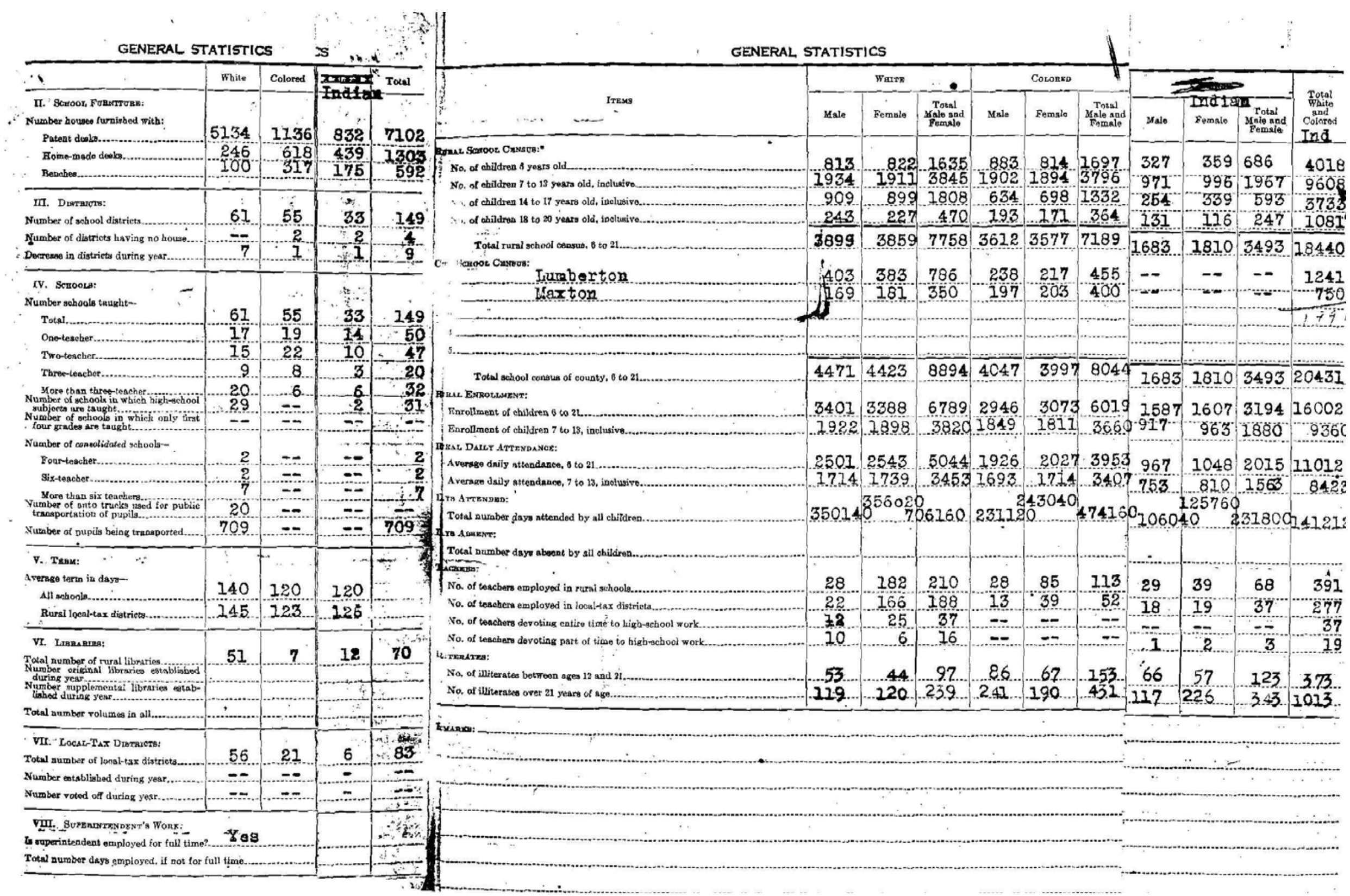


- enrollment by age and grade*

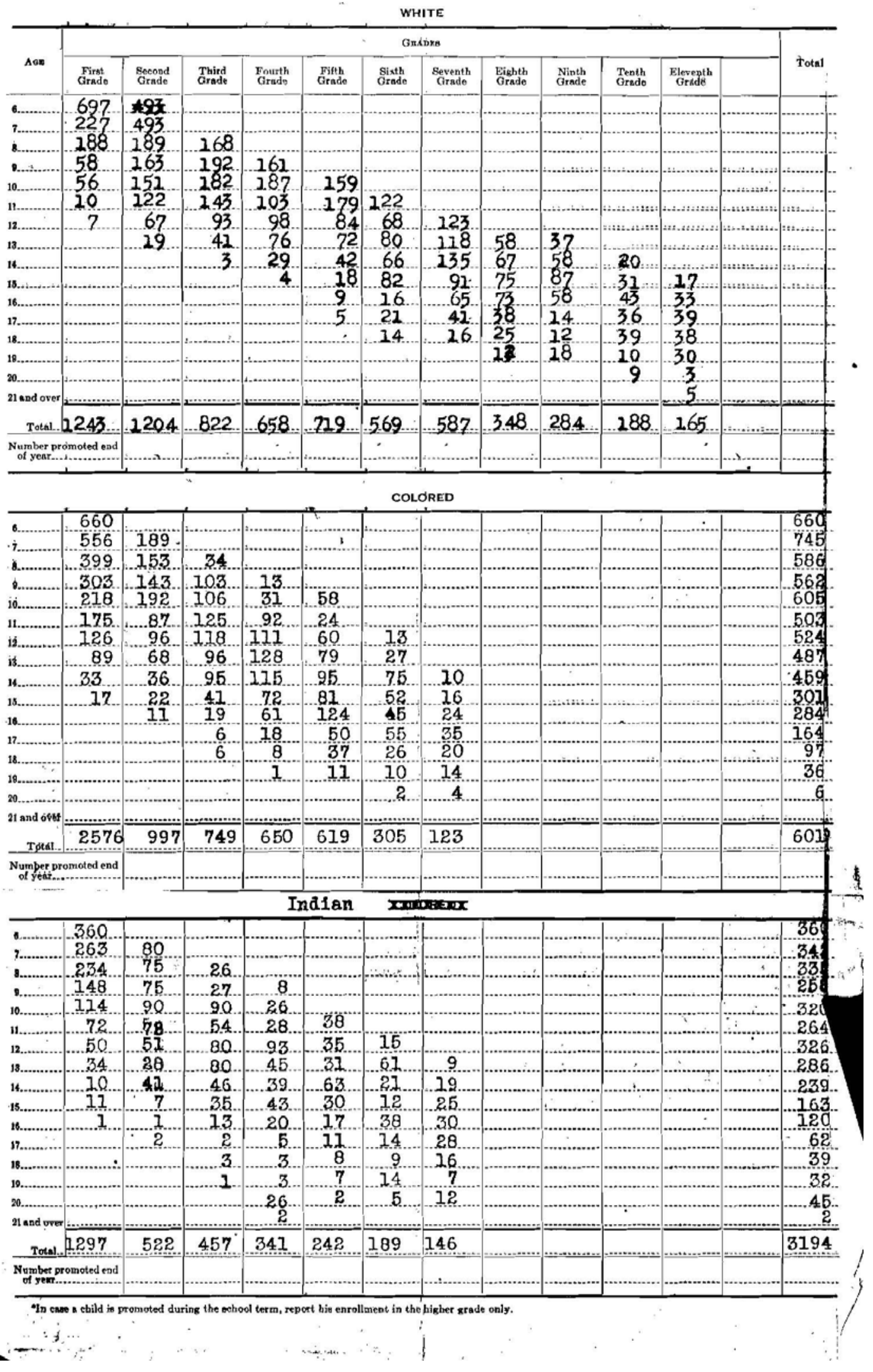


EXPENOITUAES-CONTINUED

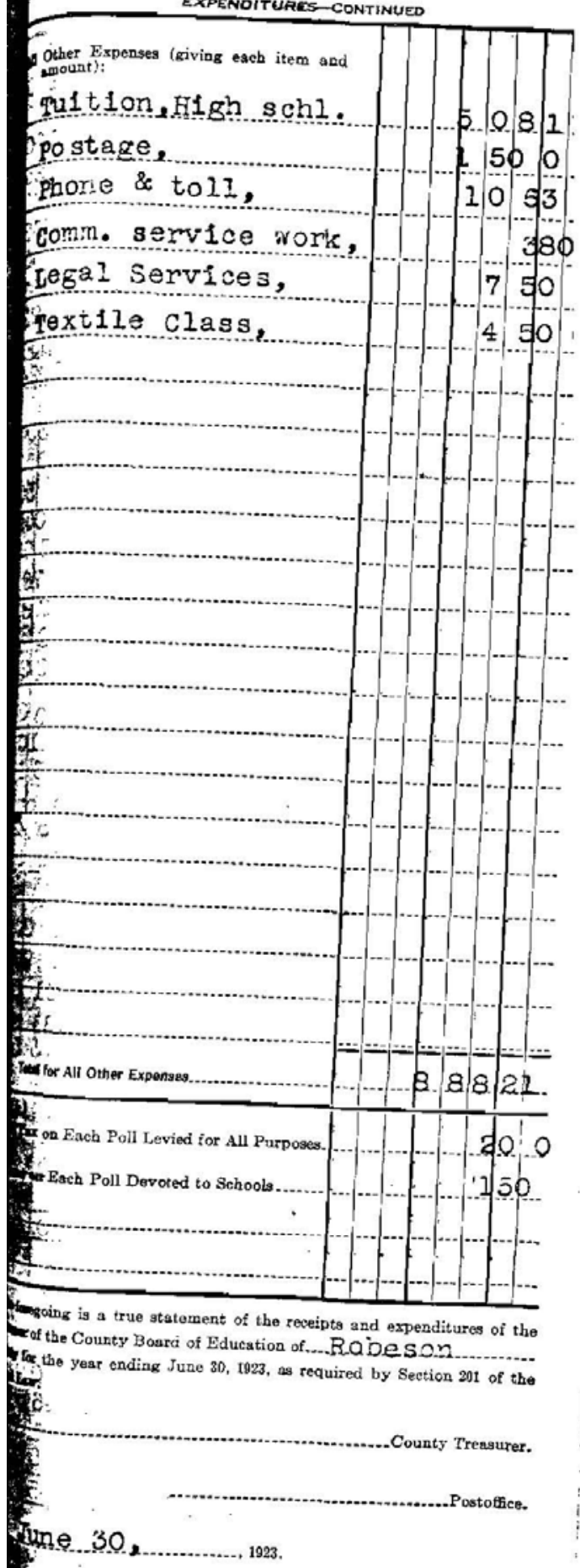

$3-29-23-131-D$

\section{COUNTY TREASURER'S REPORT}

or

\section{PUBLIC SCHOOL FUND}

R O B E S O N County

\section{2-1923}

\author{
(SCHOOL YRAB, JULT 1 TO JUNX 30)
}

INSTRUCTIONS TO THE TREASUREF

1. Itemize Property and Poll Tax as blank directs.

2. Be"carciul to report all local tarea which you handle in the form this blank direets.

3. Carefully itemize "all other expenses" in the proper place.

4.?Do"not inciude the Sherif's commiseions or allowances for ingolvents in your report. The Public School Fund is a net fund.

5. Your report is to include sil moneys received and paid out from July 1 , 1922, to June 30,1923, whether you have been Treasurer all that time or not.

6. Amounta paid to eity schools should in all cosses cover the same period of time and amounts reported by city ureasurers as received by them from the county.

7. This report muat be approsed by the County Bocrd of Education on first Monday in July and must bo sent to this office by firat Monday in A tuqust.

8. File s copy of this report for reference in making your next report. Send report to this office in sclf-addiressed envelope.

$$
\begin{aligned}
& \text { Very respectfully. } \\
& \text { E. C. BRoOKS, }
\end{aligned}
$$

Slafe Superintendent of Publtic Instruction.

This report was examined and approved by the County Board of Educa$\because$ tion on ........................... Juy of July, 1923.

(Bigned).

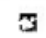

inst:

County Bosrd of Eduestion.

County 


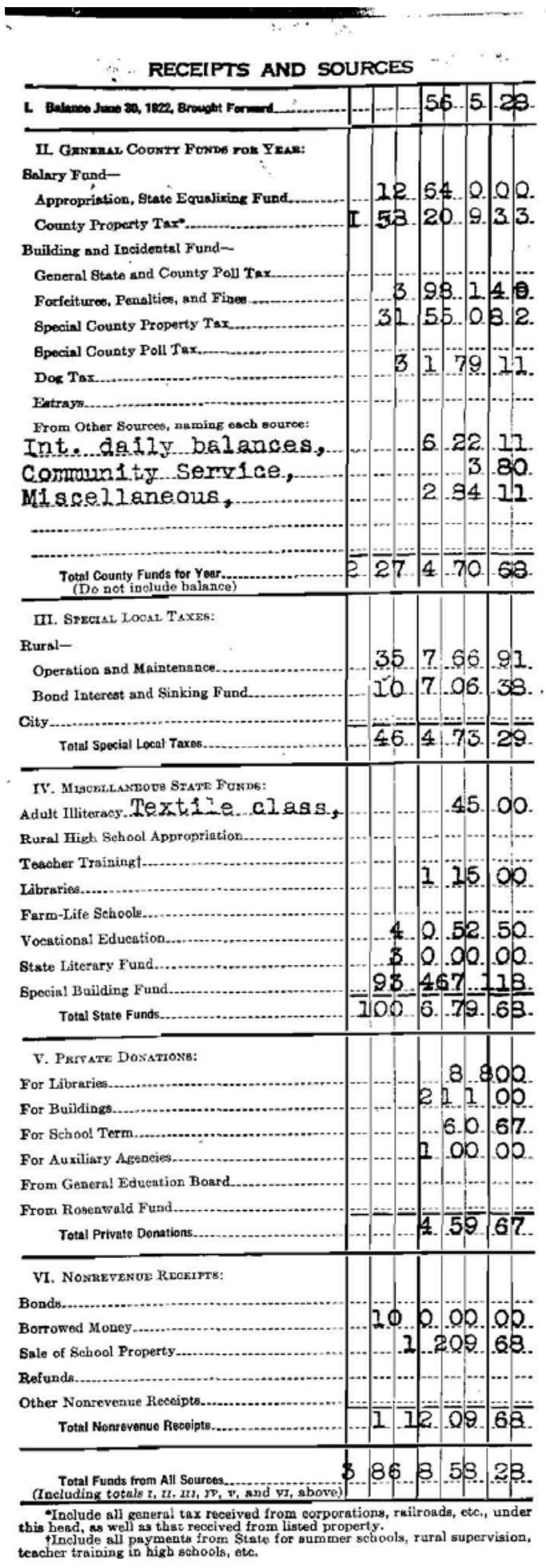

1
EXPENDITURES

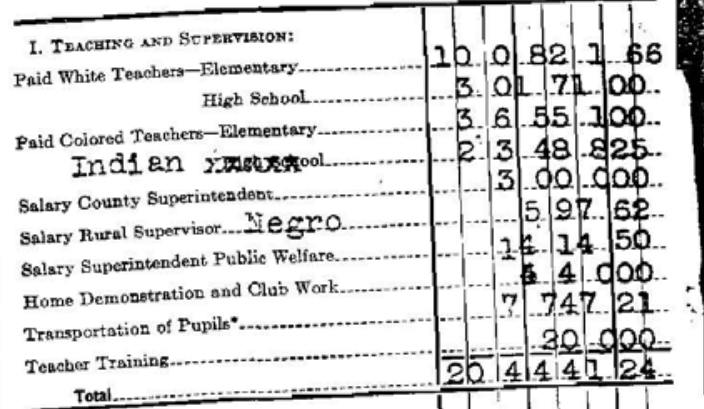

$A G x$

II. Admisistritiox:

Expenses of County Superintendont

Expenses of County Board....

Mileage and Per Diem of County Bostd............... 500

School Committeemen............................. 1777500

Offee Assirtant....................... 3. 9.3

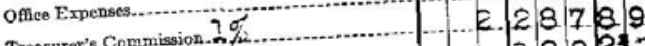

38 8 요.

All Othert.............................

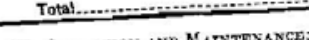

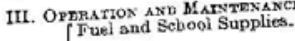

Rent and Insurance ............................

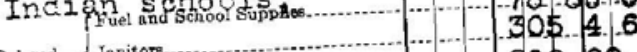

Colored- $\{$ Janitors.......................................

(Rebt and Insurance.......
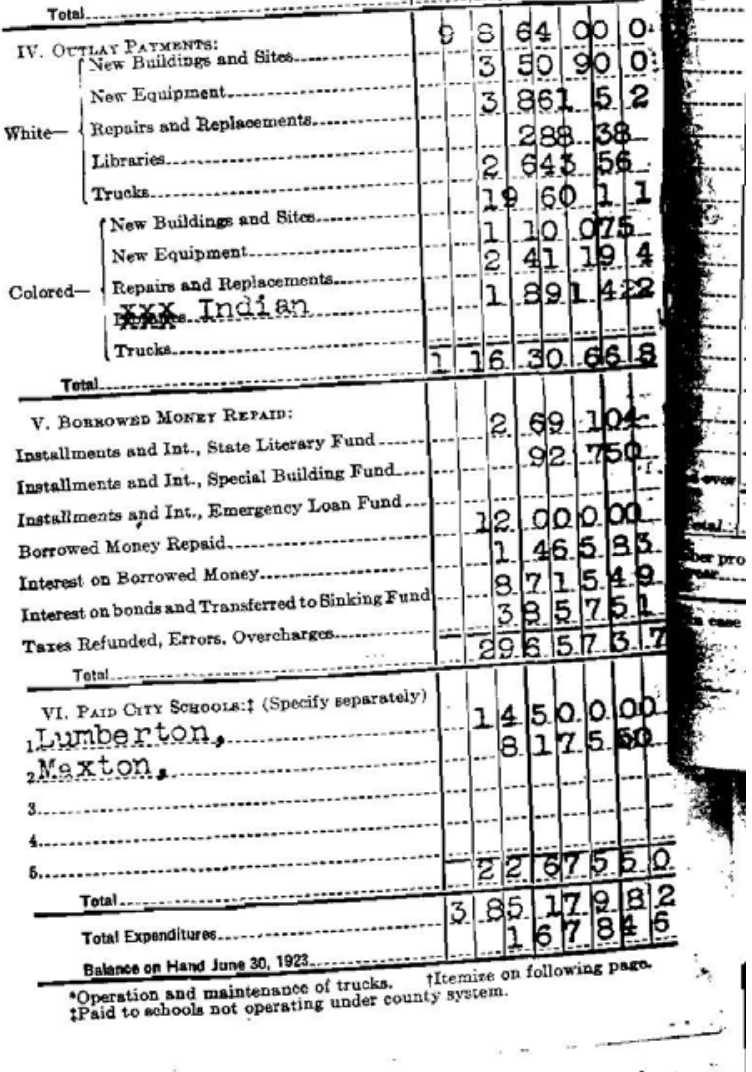
APPENDIX E: Letters from N.C. Newbold and A.T. Allen Concerning the Indian Schools

JuIy 23. 1923.

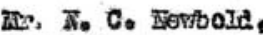

Stotis Deperstixe at A no=,

Raiei gha $\mathbb{H}_{0} \mathrm{C}_{0}$

thy dar, Hra Movbold:-

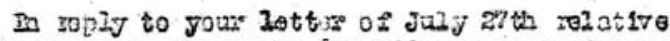
to the means of handiling the 35,000 approprlation for the parpose of bafleipg Indion schoolhouses in Roreson

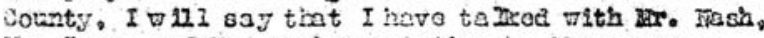
IIr. Inog, añ in: Durham reiutive to this matcer.

15-. Hash thinks that the money is under the cantrol of the state sumerint smient of Publ to Instruction, and If: Isoy is will lig, witen the maney bocmos avail-

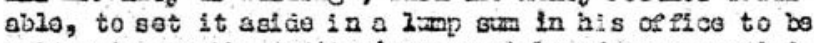
paid out upon the Aitditor's vasmant based on a raguisi-

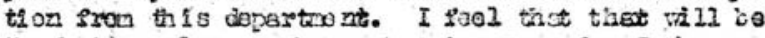

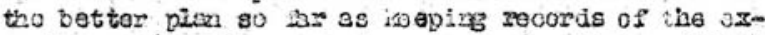
penditure o? this moneg is occeomndo. Fint would then give us a triplicste secord of evory gingle item

In arder to react for the paymont of this thond I thins wo should hevo a syeteo of ontracts lor evory item of tork that is to be cone, evon for the prarciose of Innd, made out in duplicate- one oopy of the o antsact to bo zillod in the of ico and ono in the offica of the County superingandent of Robescon County. This cont ract to uld becono valid aiter y ur daxartuont hod spproved it

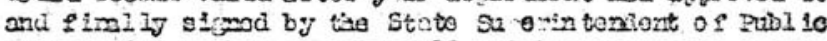

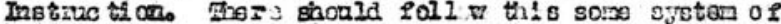
statenont that the vark hod been proparis dow, or in tho case of purcins so of land thet the peoplo giving the

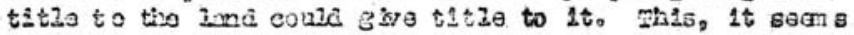
to $x$, should be done by tho attorney for tise county board of ourtention. Then sonobody ficald certify aftor the

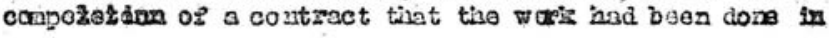




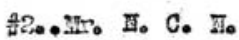

acourdance with the stiplatations of the contract, so that

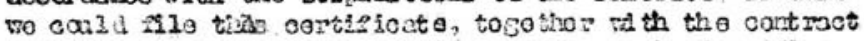

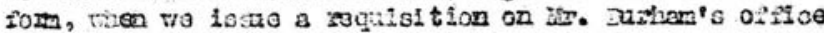
soi a varrat on tho rreasirem. I should bo glad 12 gou

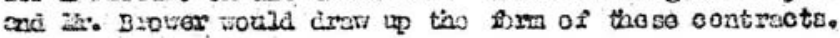

I should 11:0 to have in Roboson Count as our agents on the reveris Sanator Varsers and Ifro pools to 0 . K. the controcts. It gouns to also tiat is any con tracts shoula bo let uin the coat plas basis, there should be an undarstanding with tho contratars to cary the poy-roll sar at lo ast a month 20 it vonial not be necessary to $r$ th is dorar mot to fesw so meny requisit ioris.

\section{Tours very atroereis,}

A. T. $A$ ition

St to Supariatindezt Pablic Instruction. 
DIVISION OF NEGRÓ EDUCATION

N. C. NEWBOLD, OInECTON

MISS ANNABEL PRATT, SECAETAAY

G. H. FERGUSON, ASSIgTANT DIALCTON

W. A. ROBINSON, SURERVISOR OO

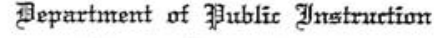
State of స̂̃orth Caralina

\section{Ŗaleigh}

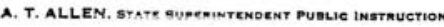

W, F, CREDLE, SUPERVISOR O

MISS LILLIAN AaY, STENOSENWLLO FUNO

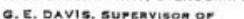

MRS. ANNIE W HOLOSENWALD DULLOINGE

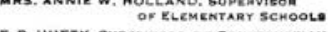

F. R. HUFTY, SURERVISOR OP CONGTRUCTION

July 27, 1923.

Superintendent A. T. Allen,

Raleigh, II. C.

Dear Mr. Allen:-

Fnclosed is a letter from

Senator Varser, although as you notice he did not sign it.

When I was in Robeson some days ago, it was suggested that the state appropriation for building several Indian Schools in Forth orolina be turned over to some Bank or individual in Robeson coun- pahesen $C_{0}$ ty who might act as Treasurer and through whom the details of paying out this money can be handled to the satisfaction of the State Board of Education. It would be possible also to have this handled on a voucher basis, the voucherg being made by the County superintendent and Mr. Varser and approved by this Division and then have a check drawn direct through the state Treasurer's office.

Please advise me which way you prefer handling this, so that the work of building the storechools may begin as soon as possible.

Very sincerely yours,

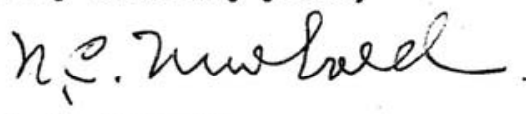

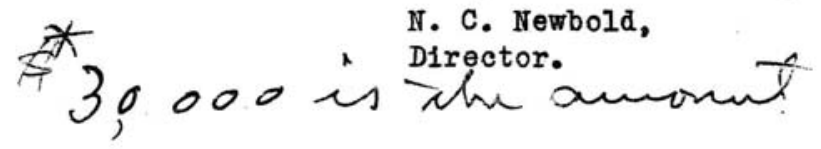




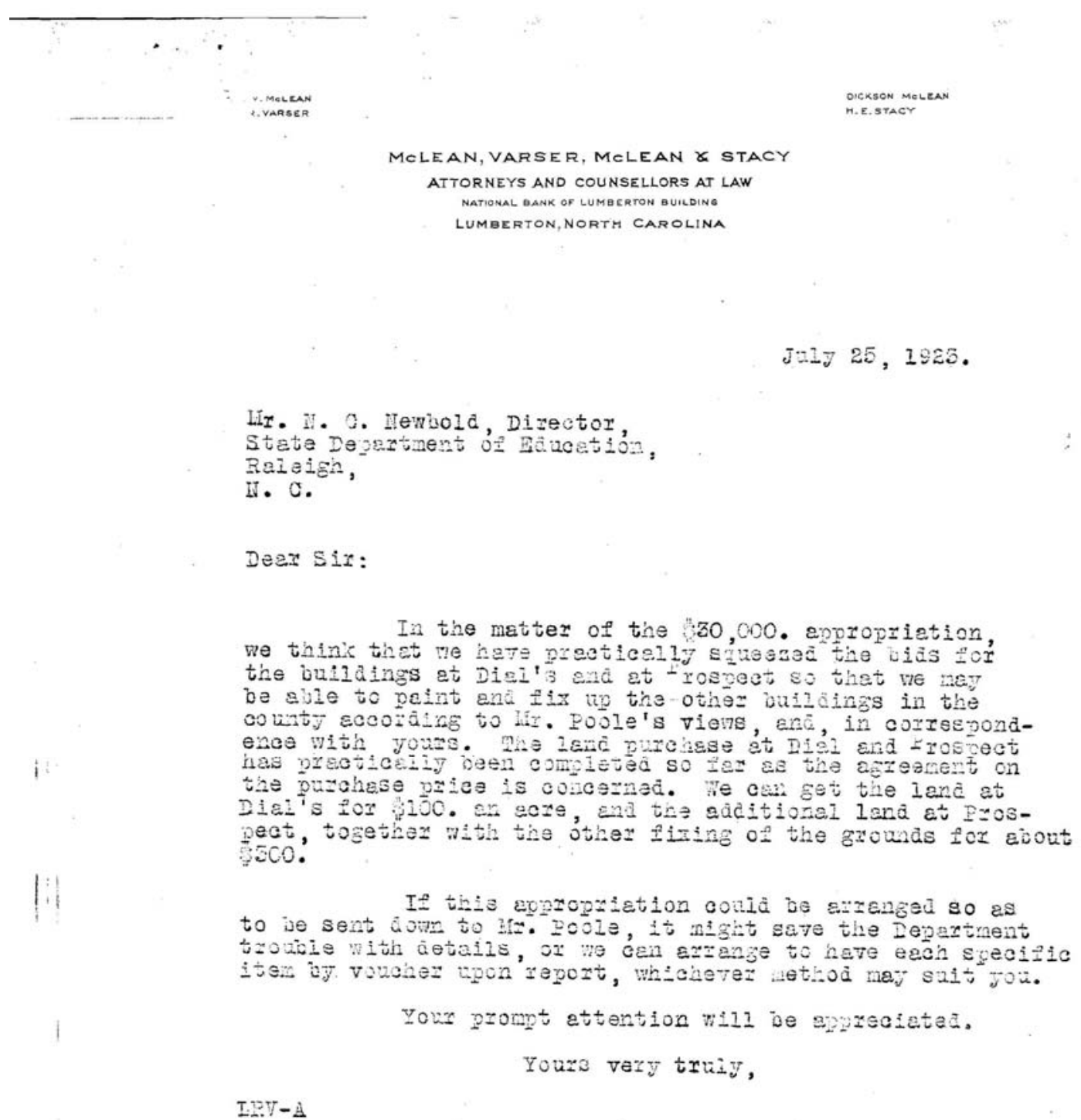

IIVT-A 


\section{ENDNOTES}

1 The terms Indian, Native American, and American Indian are used interchangeably throughout this document. This choice is not a matter of political correctness or of controlling what terminology is considered more socially acceptable than another. Rather, each of these terms used to identify the cultural population of indigenous peoples of the North American continent has a political context within the history of the dominant populations who labeled this population through political, economic, and social power. The decision to use which term-Indian, Native American, or American Indian-is a matter of respect of this cultural population. Respect means that one will learn and inquire from the individuals of this cultural population what terms they would prefer in self reference. Most Native Americans prefer reference by their tribal affiliation. There are more than 562 tribes in the United States.

Members of the Lumbee tribe use the terms "Indian," "Native American," and "American Indian" interchangeably when referring to their cultural population. In communication with fellow Native Americans, Lumbee Indians use the terms "Lumbee" or "Indian" to refer to themselves. The term Indian comes from Columbus' erroneous geographical assumption that the indigenous peoples he encountered on the North American continent were inhabitants of India. Native American is a term first used by the Bureau of Indian Affairs (BIA) in the 1960's to refer to American Indians, Alaska Native tribes, Native Hawaiians, and Pacific Islanders that the Bureau served. American Indian is a term that is preferred over the term Native American by indigenous peoples to refer to the legal language of documents and treaties that refer to them as 
Indians and not Native Americans. See also (See, Facts on; Fogelson, 1998; Yellow Bird, 1999).

2 The term black will be used to identify the cultural population of African Americans, and Black Americans throughout this document. In some historical references, this cultural population has been referred to as Negro or Colored. These references will be used within the historical context as necessary in this paper.

3 The term white will be used to identify the cultural population of European Americans, who represent the dominant cultural, political, and economic population in the United States.

4 The term non-reservation refers to the fact that the Lumbee have never lived on reservations, but rather owned their own land or shared common land.

Reservations were established as humanitarian alternatives to militaristic efforts to squelch the conflicts between Indians and white settlers in the western United States. This Indian policy was to promote peace by removing Indians from their home lands to the reservation. No matter the humanitarian intent, the reservations were places where the Indians were forced to live; Indians were not allowed to leave. Often military force was used to restrict their movement. Various writers contend that reservations were established as part of the United States' paternalistic effort to control and civilize Indians by removing them from their homelands and forcing them to live in concentrated areas of unusable and undesirable land (Bordewich, 1996; Cobb, 2000; Dial \& Eliades, 1975; Marshall, 2002; Spring, 2001).

This paternalistic and colonistic context is subdued in present definitions of "reservations" depicted in dictionaries and glossaries as well as in the language of the 
Bureau of Indian Affairs. Those sources refer to reservations as merely lands that have been reserved for the tribes' use due to treaties and legislation wherein the tribe ceded land to the United States to end hostilities under the agreement of protection by the federal government and support in the form of goods, services, and education.

5 Lost Colony refers to the colony established by Sir Walter Raleigh's charter to claim land in North America. Sir Walter Raleigh established a colony on the coast of what is today Roanoke Island, North Carolina. Before the settlers arrived, only the Hatteras Indians had lived on Roanoke Island. The English colonists arrived on Roanoke Island, too late in the year to plant crops. The colonists were unprepared for the winter. The leader of the colony, John White, returned to England to seek supplies from Sir Walter Raleigh for the colonists. When John White returned to the settlement, he found no trace of the colonists. John White found the carved letters of CROATOAN written on the fence post of the settlement's stockade. This led White to believe that the colonists went to the Hatteras Indians' island which was named Croatan. In his journal, White recorded that he was not overly concerned with finding the settlers before he left for England, he had discussed with the colonists the possibility of moving inland for approximately 50 miles. If the colonists did make a move, they agreed to signify this with a marking. The CROATOAN served as a marking to John White that the colonists had gone to the island of Croatan to live with the Indians there. John White tried to find the settlers on the island of Croatan. The weather conditions and the captain of the ship all served to prevent him from searching further. Sir Walter Raleigh and other Englishmen also tried to find the Lost Colonists; their efforts did not yield useful information (Dial \& Eliades, 1975). The Lost Colonists were theorized to have joined 
and intermarried with the Hatteras Indians. This is one of the theories of the probable origins of the Lumbee Indians. See also (Dial \& Eliades, 1975; McMillan, 1888).

$6 \quad$ Cherokee Indians of Robeson County refers to the belief of several scholars that in the early $18^{\text {th }}$ Century some Cherokee warriors who were part of the forces of Colonel John Barnwell decided to stay and join in with the Lumbee in the area of present day Robeson County on their return home from trying to calm a Tuscarora Indians uprising in 1711. See (Dial \& Eliades, 1975).

7 Indian Removal refers to the time period of 1814-1858 when the government policy inspired by Andrew Jackson, was to segregate Indians from Whites. The government forced military relocation of Indians from their home lands in the east to lands set aside west of the Mississippi River. The assumption was that this removal and relocation was of benefit to the tribes because they were only 'exchanging' lands in the east for lands in the west. Furthermore, the United States government would serve in a peace keeping role by preserving peace among the tribes and through securing the frontier, meaning military segregation of the Indians from Non-Indians (Spring, 2001).

8 These tribes may have found the area of Robeson County appealing because of (1) the geographic isolation, (2) fruitfulness of the land, (3) the disputed border, and (4) the presence of other Native Tribes in that area that they may have known through the trade route there on the Lumbee River. The Native American tribes may have sought to settle into this area because they were (1) seeking a haven from European diseases like smallpox, (2) were displaced by European settlers' encroachment upon their land, and (3) were avoiding the Tuscarora War of 1711 (Blu, 2001). This "peoplehood" of Natives and 
Non-natives may have used English as a common language which replaced their Native languages (Blu, 2001; Wolfram, Dannenburg, Knick, \& Oxendine, 2002).

9 Maroons were fugitive slaves that set up their own societies. They worked against slavery by attacking white settlements and through liberating slaves (Willis, 1963).

10 Blood quantum refers to the degree of Indian blood an individual possesses. It ranges from having no Indian blood to being a full-blooded Indian. This calculation of Indian blood was created by the government as an administrative measure of Indian identity in determining which Indians were eligible for benefits and services (Fogelson, 1998; Sokolow, 2000).

11 In fact, this 'myth of blood' was re-established in the calculation of blood quantum as an administrative measure of Indian identity (Fogelson, 1998). The Bureau of Indian Affairs (BIA), an agency of the dominant culture and the federal government, defines Indianness through blood quantum. An Indian, according to the BIA, is considered a person whose blood quantum is at least one quarter Indian (Bureau of Indian Affairs, 2004). However, another federal agency, the Census Bureau, relies on selfidentification (Facts on; Ogunwole , 2002). The focus on blood quantum served to assist the BIA and other agencies in their allocation of funds for programs for Native Americans and other issues such as "child custody, receipt of health benefits and scholarships, artistic license to authenticate one's work as Indian art, political and criminal jurisdiction, eligibility for health care, settlements of land claims, mining and other resource royalties, and local and federal taxation" (Fogelson, 1998, p. 47). Now the 
responsibility for blood quantum falls on the individual tribal governments and can vary greatly from tribe to tribe.

12 See the works of (Blu, 2001; Dial, 1993; Maynor, 1995, 2002; Perdue, 1985) for more views on the Lumbee resistance to black racial classification.

13 See Sider's (1993) discussion of single-shot voting on pages 93-97 of the text. In some elections voters were presented with a slate of candidates for whom to vote. Single-shot voting was a technique where minority voters who preferred one candidate over another chose to cast only one vote for their preferred Indian or Black candidate. When the minority voters withheld their votes for competing white candidates, the result was a concentration of their voting power as minorities. Sider explained that since the White population held the dominant political power, a concentrated voting power of minorities was a threat. Therefore, single-shot voting was outlawed. The result of outlawing single-shot voting resulted in diluting the minority voting power. By outlawing single-shot voting, minority voters were forced to vote for candidates that they did not want to win. Thus, the outlawing of single-shot voting thus prevented the election of candidates of color in Robeson County.

14 See Thompson's (1973) explanation on pages 79-80 of how doubling voting at the city and county level allowed Whites to dominate the boards of education. In Robeson County the dominant white population who lived in the city districts were able to cast votes for their city school board as well as for the county school board. The result gave the white population double votes which strengthened their voting power and their influence over the schools. In addition, Indians and Blacks outside the city districts were only able to vote for county school board members in Robeson County. The double vote 
of the white population also diluted the voting power of the non-White population in Robeson County. See also (Sider, 1993, p. 31, 43, 93-99).

15 See Dial p. 102-103 for his discussion of Julian Pierce which led to the appointment of Dexter Brooks. Judges are elected in North Carolina, but Dexter Brooks was appointed by the governor. Dexter Brooks was appointed in response to the outcries of the Lumbee and Black communities over the election of Joe Freeman Britt as Superior Court Judge in Robeson County. In 1988 there were two candidates running for Superior Court Julian Pierce (the Lumbee candidate) and Joe Freeman Britt (the white candidate). Julian Pierce died during the election, but was posthumously elected. Britt won the position by default because Pierce could not be replaced on the ballot. This upset the Lumbee and black communities in Robeson County resulting in a request to Governor James G. Martin for assistance. Consequently, Governor Martin created another judicial post and appointed Dexter Brooks to this position.

16 Freedman's Bureau also known as the Bureau of Refugees, Freedmen and Abandoned Lands was created by an act of Congress in 1865. The purpose of this Bureau was to facilitate the relief and education of former slaves in their transition into free society. Significantly the Freedman's Bureau helped to establish an educational system for Blacks (Anderson, 1988).

17 'Kill the Indian to save the man' is a motto used to justify the use of boarding schools and education to facilitate the deculturalization of American Indians. This motto is attributed to Captain Richard Henry Pratt the founder of the Carlisle Indian Industrial School who stated, 
A great general has said that the only good Indian is a dead one, and that high sanction of his destruction has been an enormous factor in promoting Indian massacres. In a sense, I agree with the sentiment, but only in this: that all the Indian there is in the race should be dead. Kill the Indian in him, and save the man (Pratt, 1892, pp. 260-261).

This quote is from a paper, The advantages of mingling Indians with Whites, written by Pratt expressing his extreme views on Indian Education to a $19^{\text {th }}$ Annual Conference of Charities and Correction in Denver, Colorado, in 1892 and this is reprinted in Prucha (1973).

18 Termination refers to the period of federal Indian policy in the 1940s to the early 1960s (Sokolow, 2000). The termination Indian policy of the federal government was enacted after World War II. The purpose of this policy was to reduce federal spending in light of the government's involvement in two major world wars. The goal of termination was for Indians to become more self-sufficient and to assist in their assimilation. Passage of House Concurrent Resolution 108 enabled the government to sever governmental trust responsibilities and services to tribes (Fuchs \& Havinghurst, 1973; Sokolow, 2000). This policy affected 109 tribes. The impact was damaging to the tribes because it was a revocation of federal recognition and the dispossession of tribal land trust status (Deloria, 1985; Fuchs \& Havinghurst, 1973; Sokolow, 2000). Thus, during the termination period, the tribes were treated as non-Indians; they were no longer treated as governmental entities. Tribal sovereignty for these tribes was negated. As a result, the state government assumed the federal responsibility over the former tribal lands in matters of education and in civil and criminal jurisdiction (Sokolow, 2000; Szasz, 1999). The 
tribes' former tribal lands could be treated as any private land appraised and sold to the highest bidder (Sokolow, 2000). State and local taxes applied to the Indian's land as well (Sokolow, 2000). See Sokolow (2000) and Deloria (1985) for more information on termination. See Szasz (1999) for the impact of termination on education.

19 Allotment refers to an assimilation policy wherein the tribal lands of the reservation were surveyed and divided. Each individual member of the tribe was given a share of the land to farm. Allotment was in opposition to the tribes' manner of holding lands in common. The Indian view of holding land in common was counter to that of the white culture's view of individual ownership of land. Once the individual tribal members had their own share of the land to farm, the remaining land was then sold to white settlers. This policy succeeded in breaking up the tribe's land and was also an effort to assimilate the Indians into white culture. See also (Bordewich, 1996).

20 The University of North Carolina at Pembroke began in 1887. Pembroke was an Indian Normal School for the training of teachers for the Lumbee community. The Lumbee Indians had to build the school on their own; the state did not allocate any funding for construction of the school. The school was first known as the Croatan Normal School, and eventually, the Indian Normal School of Robeson County. Thereafter, the school was known as the Cherokee Indian Normal School. In 1940 the school became recognized as an institution of higher learning and became Pembroke State College for Indians (Dial, 1993).

$21 \quad$ Plessy v. Ferguson case affirmed segregation of facilities under the condition of separate but equal. 

Ferguson decision of separate but equal and extended it to include education. Also, in this case the Supreme Court refused to interfere in the state of Georgia's decision to provide a high school education for white students and discontinue a high school for black students. This decision enabled the states to define separate but equal with regard to educational facilities. Additionally, this case showed the lack of federal protection of the educational rights of African American citizens.

23 Brown v. Board provided the hallmark supreme court decision against segregation by law in public schooling. The ruling found that separate was not equal.

24 General Education Board Fund refers to the philanthropic General Education Board (GEB) comprised of northern businessmen who wished to fund southern educational reform and impact the education of Blacks in the south. (See Anderson, 1988). It has also been argued that the GEB had their own desire to control the education of Blacks through funding educational programs under white leadership and denying funding to educational programs under black leadership. See Thuesen (2003).

25 Rosenwald Fund refers to the philanthropic efforts of Julius Rosenwald who advanced the education of Blacks in the South. Julius Rosenwald provided grants for school construction. The recipients of these grants had to provide matching funds in the form of cash or in-kind contributions of resources and labor (Anderson, 1988).

26 Jeanes Fund refers to the Anna T. Jeanes Foundation which influenced the education of Blacks in the South through funding industrial education and providing industrial teachers. The Jeanes Teachers taught practical industrial subjects (e.g., canning 
and sewing) and helped promote school improvement and raise funds for school construction throughout the rural South (Anderson, 1988).

27 Slater Fund refers to the John F. Slater Fund that affected the education for Blacks in the South through funding only industrial education programs. This helped the development of county training schools (Anderson, 1988).

28 Jim Crow refers to legal statutes passed during slavery, The Civil War, and the Reconstruction Period. Jim Crow Laws (1) segregated Whites from Non-Whites, (2) restricted the freedom of Non-Whites, (3) perpetuated the dominance of Whites and (4) perpetuated the subordinance of Non-Whites (Woodward, 1974).

29 Specifically these studies have shown that there are variations in cultures such as collectivist interdependent cultures which highly value group harmony, common goals, and shared identity differ within individualistic cultures (Leichtman, Wang, \& Pillemer, 2003). Collectivist societies are found in Africa, East Asia, Latin America, and southern Europe (Leichtman, Wang, \& Pillemer, 2003). Individualistic cultures place higher values on the individual over the collective group. These individualistic cultures promote individuality, autonomy, and self-actualization (Leichtman, Wang, \& Pillemer, 2003). Individualistic societies can be found in Australia, western Europe, and North America (Leichtman, Wang, \& Pillemer, 2003). In individualistic cultures, personal memory confirms the uniqueness of the individual and is the foundation for solidifying relationships (Leichtman, Wang, \& Pillemer, 2003). Specifically, research has shown that adults in individualistic Western cultures recount more detailed early memories than adults reared in collectivist cultures (Leichtman, Wang, \& Pillemer, 2003). Individualistic North Americans' memories are more self-focused than collectivist East 
Asians' memories. Memory in interdependent Eastern cultures focuses less on the self and these cultures use other means of valuing the individual (Leichtman, Wang, \& Pillemer, 2003). Interdependent cultures prefer nonverbal empathetic means of social bonding based on implicit understanding and shared points of view (Leichtman, Wang, \& Pillemer, 2003).

30 Victory Garden refers to the vegetable and fruit gardens that were grown by citizens during World War I and II to provide food for themselves. The government encouraged citizens to have victory gardens. During the war, large amounts of canned foods were sent to feed the troops (A History, 2005).

31 See also (Title VII) for the statement on the government's policy on Indian education that is described in Title VII programs.

32 LRDA refers to the Lumbee Regional Development Association, Inc. an Indian corporation. This corporation was established in 1968 to provide services and promote the development of the Lumbee Indian tribe, see (LRDA, 2005). Please note that LRDA is neither a part of the Lumbee tribe government nor is it an official representative of the Lumbee tribe. There are many issues of conflict within the tribe concerning LRDA and the tribal government.

${ }^{33}$ When I refer to "the Lumbee" and am reporting the results based on my six informants" oral histories. 